\title{
ANDRÉ BERTI SASSI
}

\section{Projeto de uma ULA de inteiros e de baixo consumo em tecnologia CMOS}

Dissertação apresentada à Escola de Engenharia de São Carlos da Universidade de São Paulo como parte dos requisitos para obtenção do título de Mestre em Ciências, Programa de Engenharia Elétrica.

Área de concentração: Telecomunicações

Orientador: Prof. Dr. João Navarro Soares Júnior

\section{São Carlos}

2013 
AUTORIZO A REPRODUÇÃO TOTAL OU PARCIAL DESTE TRABALHO, POR QUALQUER MEIO CONVENCIONAL OU ELETRÔNICO, PARA FINS DE ESTUDO E PESQUISA, DESDE QUE CITADA A FONTE.

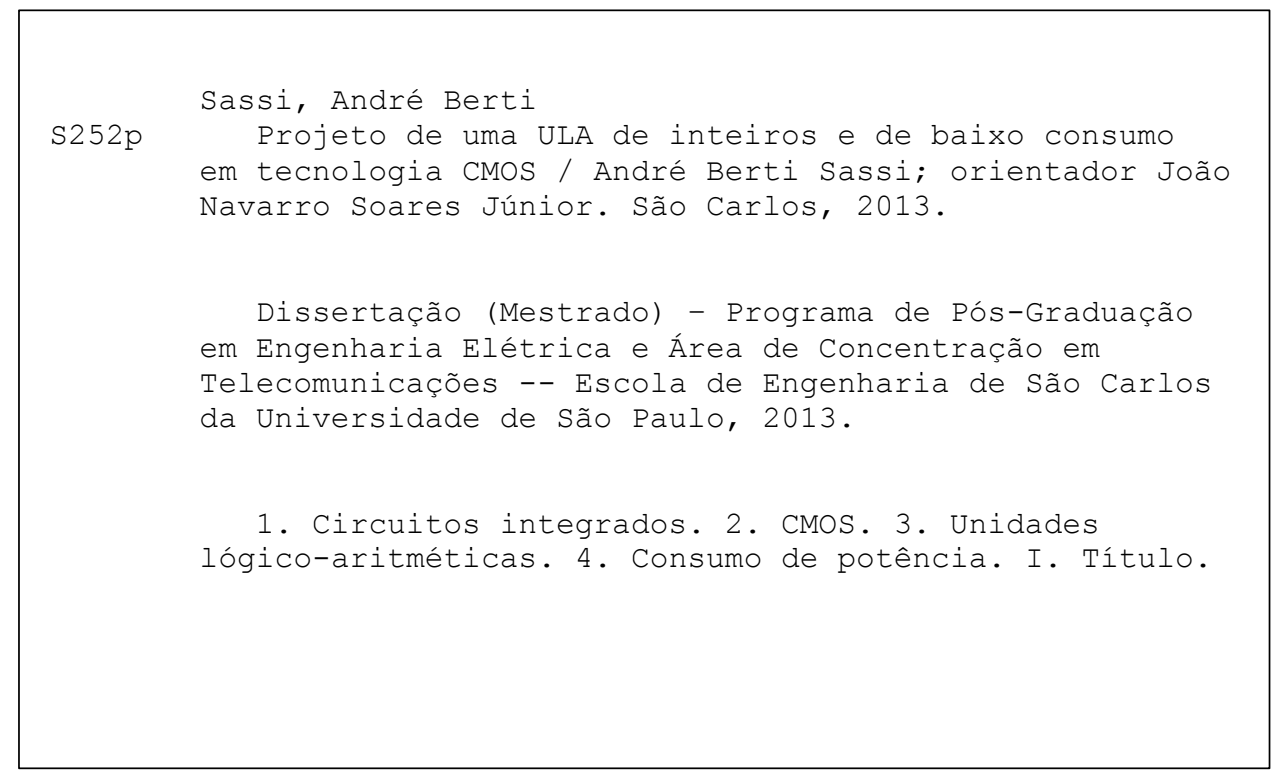




\section{FOLHA DE JULGAMENTO}

Candidato: Engenheiro ANDRÉ BERTI SASSI.

Título da dissertação: "Projeto de uma ULA de inteiros e de baixo consumo em tecnologia CMOS".

Data da defesa: 20/06/2013

\section{Comissão Julgadora:}

Prof. Dr. João Navarro Soares Júnior (Orientador)

(Escola de Engenharia de São Carlos/EESC)

Prof. Associado Evandro Luis Linhari Rodrigues

(Escola de Engenharia de São Carlos/EESC)

Dr. Marcelo Arturo Jara Perez

(Centro de Pesquisa e Desenvolvimento em Telelcomunicações/CPqD)

\section{Resultado:}
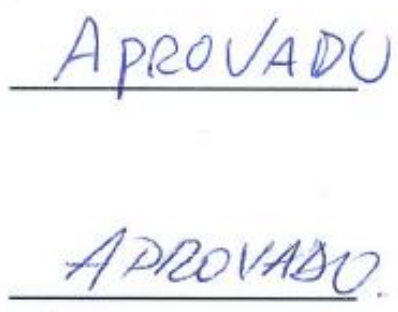

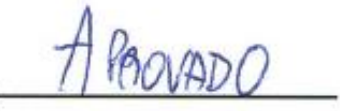

Coordenador do Programa de Pós-Graduação em Engenharia Elétrica e Presidente da Comissão de Pós-Graduação:

Prof. Titular Denis Vinicius Coury 

À minha esposa 



\section{Agradecimentos}

A Deus pela oportunidade de realizar este trabalho.

À minha família por sempre me incentivarem a estudar.

Ao meu orientador pela sua dedicação e seu apoio. 



\section{Resumo}

SASSI, A. B. Projeto de uma ULA de inteiros e de baixo consumo em tecnologia CMOS. 2013. 146 p. Dissertação (Mestrado em Engenharia Elétrica) - Escola de Engenharia de São Carlos, Universidade de São Paulo, São Carlos, 2013.

A redução no consumo de potência em circuitos eletrônicos tem se tornado um dos requisitos mais importantes em projetos, especialmente com o recente aumento no número e na variedade de dispositivos móveis ou operados à bateria. Em tais dispositivos, o gerenciamento eficiente de energia é, muitas vezes, considerado mais importante que sua capacidade de processamento. Unidades lógico-aritméticas (ULAs) são componentes fundamentais em processadores, sendo responsáveis por executar as instruções que envolvem processamento numérico ou lógico. Normalmente, a ULA é o componente de maior consumo em um processador, o que a torna alvo de diversos estudos sobre técnicas para redução de consumo. Este trabalho apresenta um resumo sobre consumo de potência em circuitos digitais CMOS e as principais técnicas para sua redução, assim como os fundamentos para o projeto de ULAs, incluindo um estudo sobre algumas topologias para construção de somadores, deslocadores e multiplicadores e uma visão geral sobre a implementação de operações com números de ponto-flutuante e sobre a organização interna da ULA. É realizado o projeto de uma ULA de números inteiros de 16 bits em uma tecnologia CMOS de 0,35 $\mu \mathrm{m}$ com aplicação de algumas das técnicas de redução de consumo apresentadas, que opera a uma frequência máxima de $212 \mathrm{MHz}$ em tensão de alimentação de 3,3 V, consumindo, em média, $57 \mu \mathrm{W}$ e ocupando uma área de $0,121 \mathrm{~mm}^{2}$. Este projeto é, ainda, comparado a uma ULA de referência, projetada na mesma tecnologia e com mesmas características funcionais, mas sem a utilização de quaisquer técnicas de redução de consumo.

Palavras-chave: circuitos integrados, CMOS, unidades lógico-aritméticas, consumo de potência. 



\section{Abstract}

SASSI, A. B. Design of a low-power integer ALU on CMOS technology. 2013. 146 p. Master's thesis (Electrical Engineering) - Escola de Engenharia de São Carlos, Universidade de São Paulo, São Carlos, 2013.

The power consumption reduction in electronic circuits has turned one of the most important design requirements, especially with the recent increase of the number and variety of mobile or battery operated devices. In such devices, the efficient energy management is, many times, considered more important than its processing capability. Logic and arithmetic units (ALUs) are fundamental components in processors, being responsible for executing the instructions involving logic and numeric processing. Usually, the ALU is the most power consuming component in a processor, which makes it the target of several studies about power reduction techniques. This work presents a brief about power consumption in CMOS digital circuits and the major techniques for its reduction as well the fundamentals of ALU design, including a study about some topologies for adders, shifters and multipliers and a general view about floating-point number operations and about ALU's internal organization. It is realized the design of a 16-bit integer ALU in a $0,35 \mu \mathrm{m}$ CMOS technology with the application of some presented power reduction techniques that operates on a maximum frequency of $212 \mathrm{MHz}$ on $3,3 \mathrm{~V}$ supply voltage, consuming, on average, $57 \mu \mathrm{W}$ and occupying an area of $0,121 \mathrm{~mm}^{2}$. This design is also compared to a reference ALU, designed on the same technology and with same functional characteristics, but without using any power reduction techniques.

Keywords: integrated circuits, CMOS, arithmetic and logic units, power consumption. 



\section{Lista de Figuras}

Figura 2.1: Corrente de drain em função da tensão gate-source na região de subthreshold. .28

Figura 2.2: Técnica de polarização auto-reversa. (a) Transistor PMOS entre a linha de alimentação e o restante do circuito. (b) Gráfico da tensão nos nós e e $V D D^{\prime}$ em função do tempo.

Figura 2.3: (a) Estrutura não balanceada em relação aos atrasos das entradas das portas lógicas. (b) Estrutura equivalente balanceada...........................................

Figura 2.4: Circuito para conversão entre domínios de tensão de alimentação........34

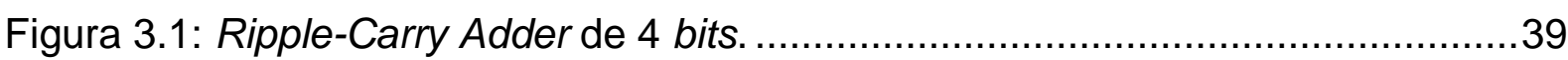

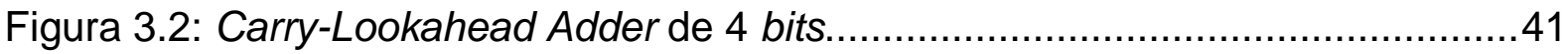

Figura 3.3: Carry-Lookahead Adder de 16 bits....................................................... 43

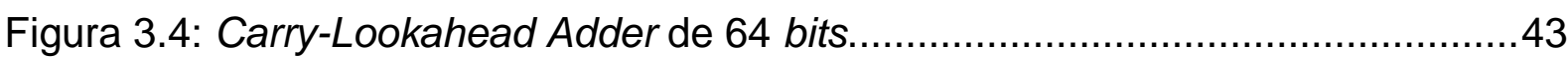

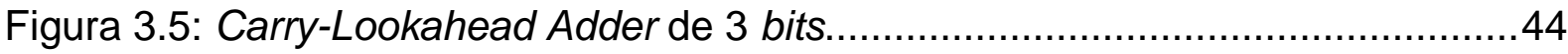

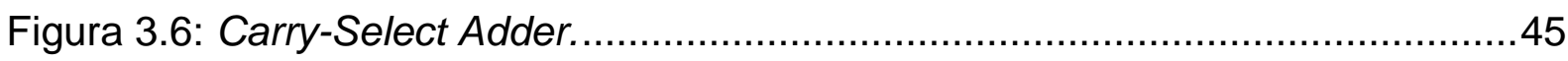

Figura 3.7: Carry-Select Adder com circuito de incremento....................................47

Figura 3.8: Carry-Select Adder com compartilhamento.......................................4 4

Figura 3.9: Soma e subtração de 4 bits em complemento de dois usando um

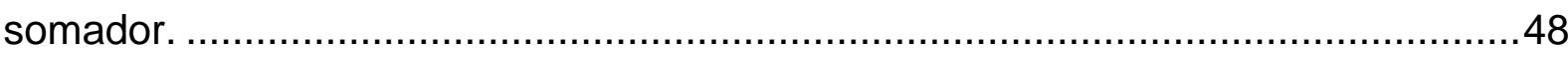

Figura 3.10: Operações de deslocamento e rotação.............................................50

Figura 3.11: Diagrama de blocos de um barrel shifter..........................................51

Figura 3.12: Diagrama de blocos de um funnel shifter...........................................53

Figura 3.13: Multiplicação de dois números de 4 bits............................................55

Figura 3.14: Multiplicador de Braun................................................................56

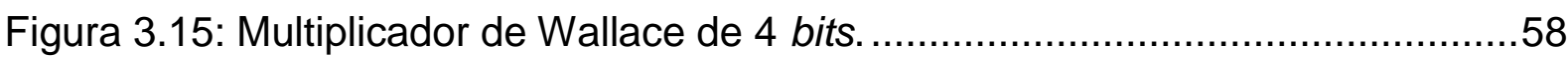

Figura 3.16: Diagrama de blocos de uma UPF do tipo FMA convencional. ...............64

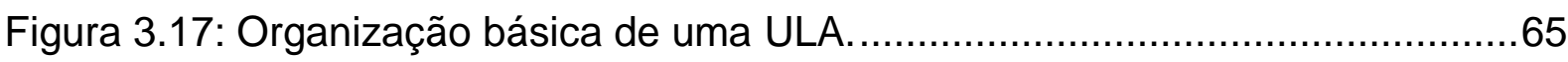

Figura 3.18: ULA com multiplexadores em árvore. ...............................................66

Figura 3.19: ULA com multiplexadores em cadeia..............................................66

Figura 3.20: ULA com extensores lógicos e aritméticos precedendo um somador. ..67

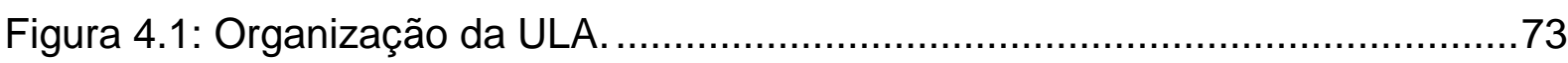

Figura 4.2: Circuito que realiza uma das oito possíveis operações lógicas bit-a-bit..74 
Figura 4.3: Mascarador sintetizado a partir de descrição em VHDL

Figura 4.4: Latch utilizado na ULA com indicação da largura dos transistores. Todos os transistores possuem comprimento de canal $(L)$ mínimo da tecnologia............... 79

Figura 4.5: Diagrama de blocos simplificado da ULA projetada. .............................. 81

Figura 4.6: Layout da ULA, com dimensões aproximadas de $490 \mu \mathrm{m} \times 350 \mu \mathrm{m} . \ldots . . .83$

Figura 4.7: Layout da ULA de referência, com dimensões aproximadas de $640 \mu \mathrm{m} \times 600 \mu \mathrm{m}$.

Figura 4.8: Produto energia-atraso da ULA em função da tensão de alimentação para os modelos WS, TM e WP.

Figura 4.9: Visão geral da ULA com indicação dos trechos entre os quais a ULA poderia ser dividida em diferentes estágios de pipeline.

Figura 4.10: Atraso de propagação na execução de diferentes tipos de operação na ULA

Figura 4.11: Estimativa do atraso de propagação na execução de diferentes tipos de operação na ULA após a criação de um pipeline de dois estágios. 97 


\section{Lista de Tabelas}

Tabela 3.1: Mascaramento no barrel shifter. .52

Tabela 3.2: Expansão do operando no funnel shifter. .53

Tabela 3.3: Estágios de multiplexação do funnel shifter de 32 bits. .54

Tabela 3.4: Casos resultantes da multiplicação de números negativos em multiplicadores que não consideram o sinal dos números. 60

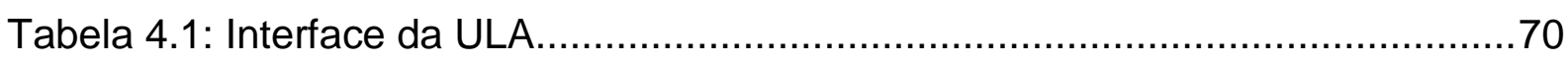

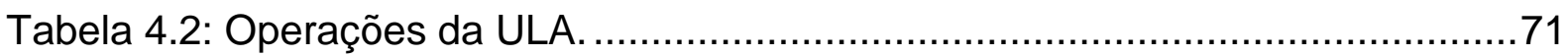

Tabela 4.3: Resultados para somas considerando variações no operando $B$ e no carry-in.

Tabela 4.4: Características do layout de somadores de 16 bits. 88

Tabela 4.5: Resultados de simulação de layouts de somadores de 16 bits. .89

Tabela 4.6: Características do layout da ULA projetada e da ULA de referência......90

Tabela 4.7: Resultados de simulação do layout da ULA projetada e da ULA de referência.

Tabela 4.8: Resultados de simulação do layout da ULA para tensão de alimentação de $3,3 \mathrm{~V}$ e de $1,5 \mathrm{~V}$.

Tabela 4.9: Resultados da simulação do esquemático das ULAs com e sem latches, com $V D D=3,3 \mathrm{~V}$ e modelo TM. .92

Tabela 4.10: Comparação dos resultados de simulação da ULA projetada com as ULAs de Sun e Jiang (2010). 



\section{Sumário}

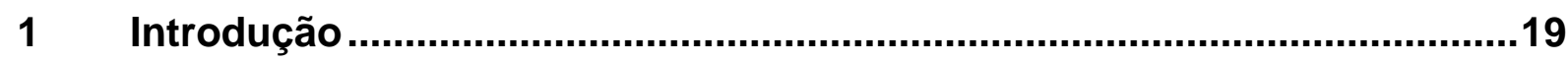

1.1 Objetivos

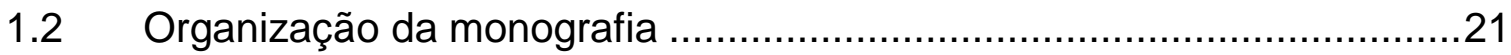

2 Consumo de potência em circuitos digitais..............................................23

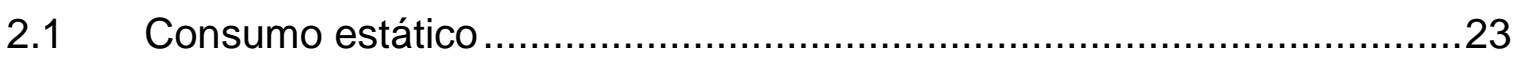

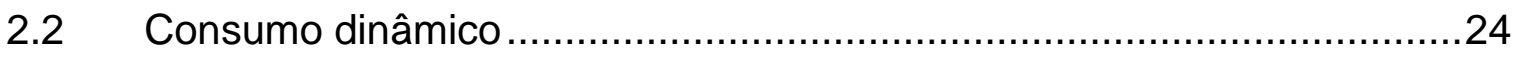

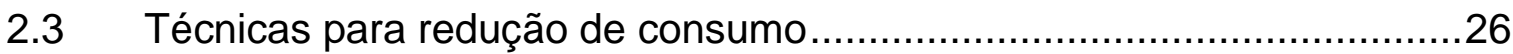

2.3.1 Dimensionamento de transistores e portas lógicas ..........................27

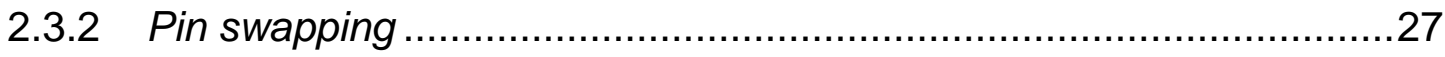

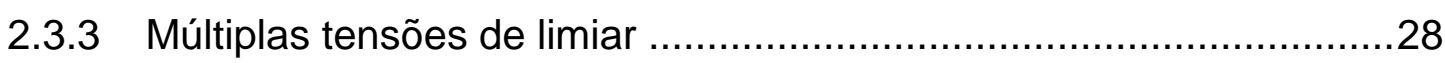

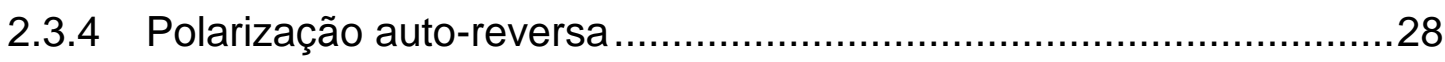

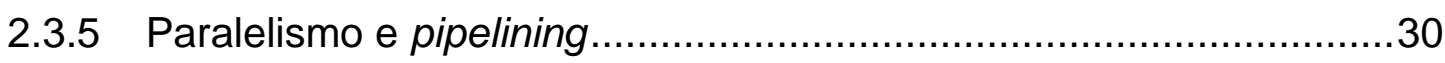

2.3.6 Balanceamento de atrasos de propagação ......................................31

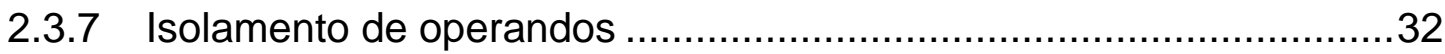

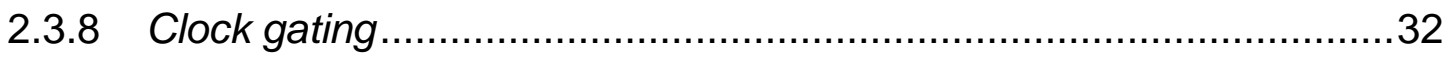

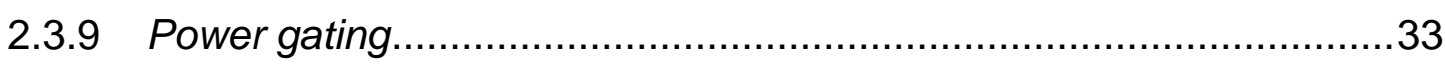

2.3.10 Múltiplas tensões de alimentação...................................................34

2.3.11 Escala dinâmica de tensão e frequência .........................................35

3 Unidades lógico-aritméticas.........................................................................37

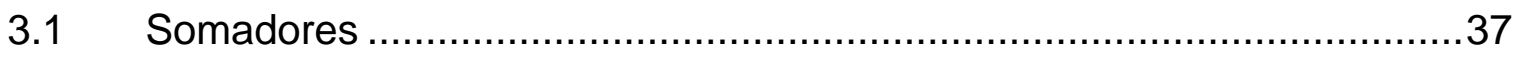

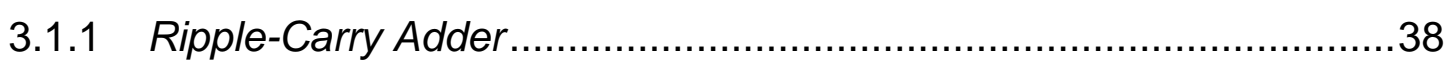

3.1.2 Carry-Lookahead Adder ............................................................

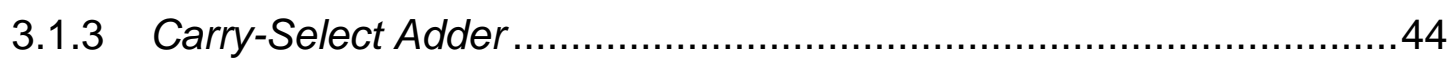

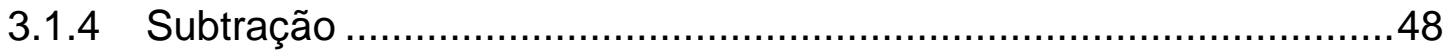

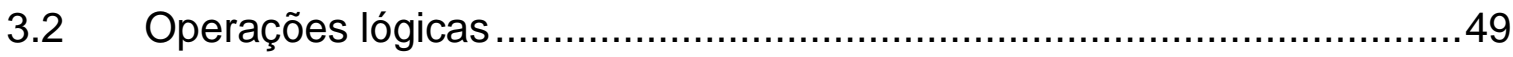

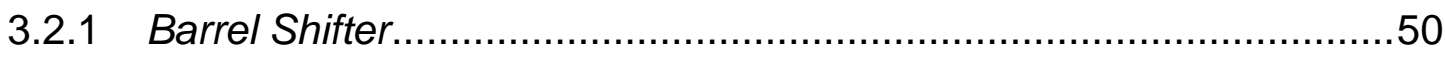

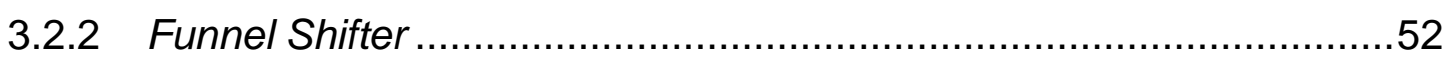

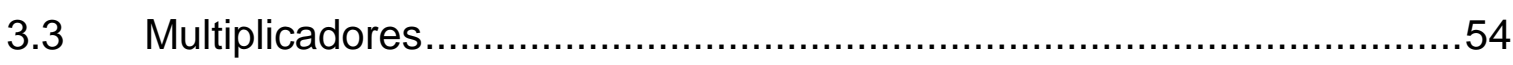

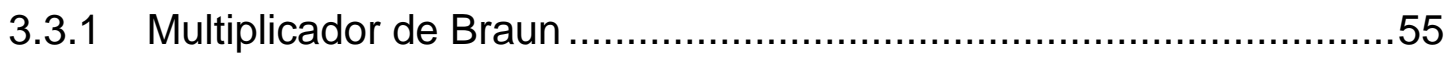

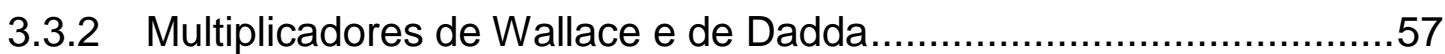

3.3.3 Multiplicação de números com sinal ....................................................60 


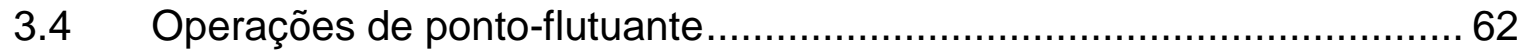

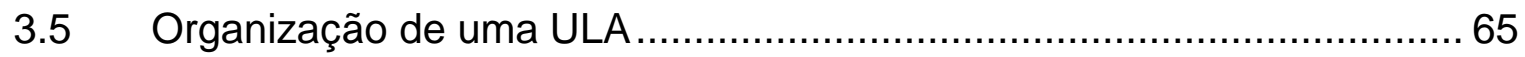

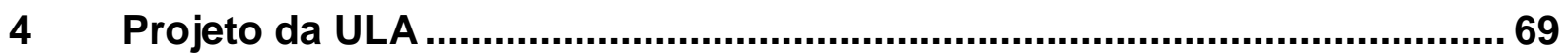

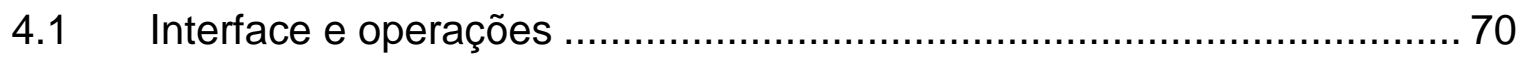

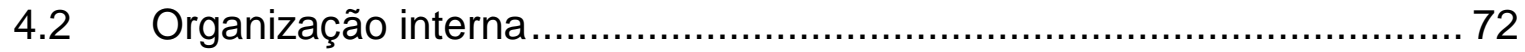

4.3 Operações lógicas bit-a-bit ............................................................. 74

4.4 Operações de deslocamento e rotação …………………………....... 75

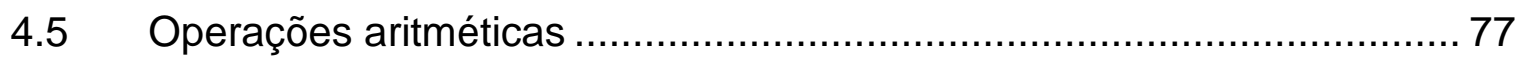

4.6 Consumo de potência ................................................................... 78

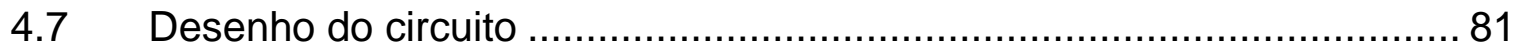

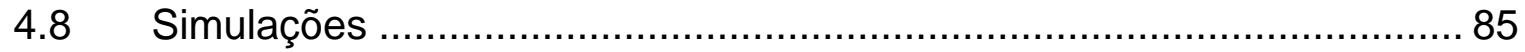

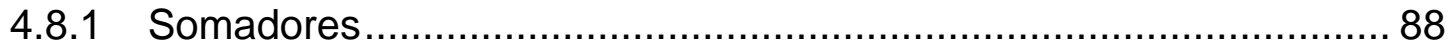

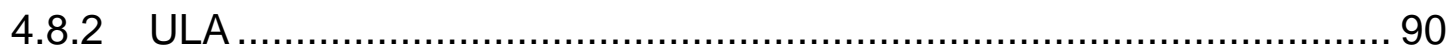

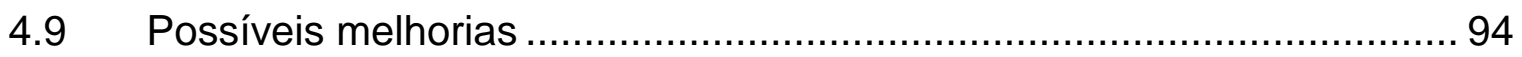

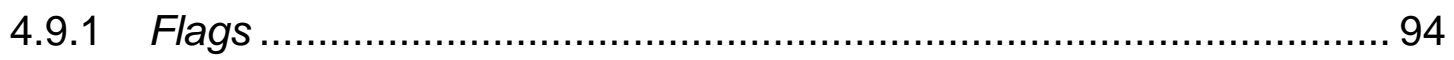

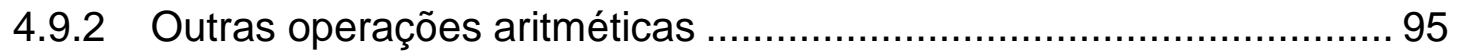

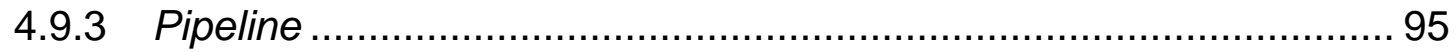

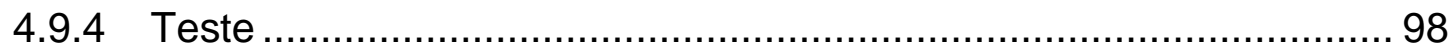

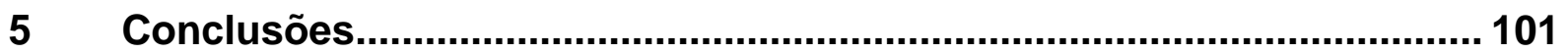

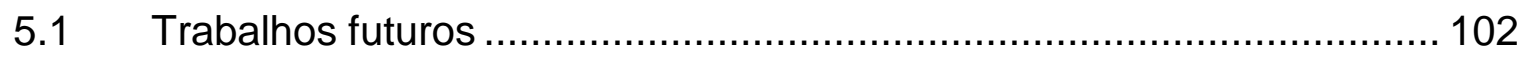

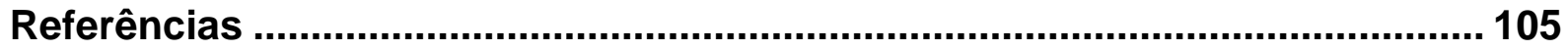

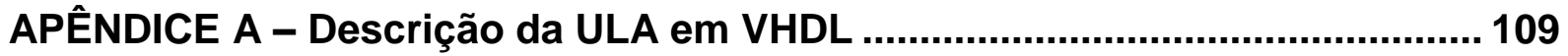

APÊNDICE B - Descrição do mascarador do barrel shifter..............................113

APÊNDICE C - Esquemáticos da ULA projetada ...........................................115

APÊNDICE D - Layouts da ULA projetada ..................................................... 127

APÊNDICE E - Programa para gerar vetores de entrada ................................... 137

APÊNDICE F - Programa para calcular atraso máximo ................................... 143 


\section{Introdução}

Recentemente, o consumo de potência tem sido uma das principais preocupações no projeto de circuitos integrados, pois o calor gerado pelos sistemas é cada vez maior devido ao aumento da complexidade e densidade dos circuitos. Em dispositivos portáteis, como telefones celulares ou notebooks, a potência dissipada determina o tempo máximo de operação do sistema entre recargas da bateria (KALYANARAMAN et al., 2005), (SUN; JIANG, 2010). Além disso, o tamanho e o peso da bateria são características importantes para estes dispositivos.

A redução do consumo de potência de um sistema pode ser realizada em vários níveis hierárquicos (ZHOU; GUO, 2008). Por exemplo, em nível sistêmico, é comum a utilização da técnica de escala dinâmica de tensão (dynamic voltage scaling, DVS). Por outro lado, redimensionamento de transistores e escalamento da tensão de limiar (threshold voltage scaling) são técnicas comuns aplicadas em nível de transistores. Em nível de transferência de registradores, pode-se utilizar técnicas de isolamento de operandos. A otimização do consumo do sistema também pode ser realizada em seus vários componentes (ZHOU; GUO, 2008), (SUN; JIANG, 2010).

Dentre os principais blocos funcionais que compõe um processador, encontrase a unidade lógico-aritmética (ULA), responsável pela execução das instruções lógicas e aritméticas. Tipicamente, a ULA é um circuito lógico capaz de realizar operações unárias, como identidade, negação, inverso e complemento, e operações binárias, como adição, subtração, multiplicação, divisão, e, ou, ou-exclusivo, deslocamento e rotação.

Ela também é um dos componentes de maior consumo de potência e o local onde se encontram as maiores temperaturas em um processador (MATHEW et al., 2005). A ULA, portanto, é um dos principais componentes a ser otimizado em relação à potência dissipada. O projeto de ULAs energeticamente eficientes é ainda mais importante quando considerados processadores modernos que possuem múltiplos núcleos. Além disso, é fundamental que o tempo de execução de suas operações seja suficientemente pequeno, evitando que este componente se torne um fator limitante na frequência de operação e execução de instruções de um processador. 
Neste trabalho, é apresentado o projeto de uma ULA de baixo consumo de números inteiros de 16 bits que implementa soma, subtração, deslocamento, rotação e as principais operações lógicas bit-a-bit. Imagina-se que esta ULA possa ser utilizada na implementação de um microcontrolador de 16 bits de baixo consumo.

Por não implementar operações mais complexas, como multiplicação, divisão, operações com números de ponto-flutuante e por trabalhar com operandos com número relativamente pequeno de bits, quando comparado ao número de bits suportados pelas ULAs de processadores mais recentes, esta ULA não é adequada na implementação de processadores de última geração. Entretanto, a metodologia utilizada no projeto desta ULA também se aplica ao projeto de uma ULA de 32 ou 64 bits, por exemplo, e que suporte mais operações.

\subsection{Objetivos}

Os objetivos deste trabalho são o estudo de ULAs de alto desempenho, isto é, com baixo atraso na execução das operações e consumo reduzido de potência, e o emprego deste estudo para o projeto de uma ULA capaz de executar as principais operações lógicas e aritméticas. Neste projeto, será utilizada a tecnologia CMOS de $0,35 \mu \mathrm{m}$ da Austria Micro Systems (AMS) (2013), devido ao seu custo relativamente baixo de fabricação.

É desejado que a ULA projetada apresente um consumo de potência menor e velocidade semelhante quando comparada a ULAs com mesmas características funcionais, ou seja, que realiza as mesmas operações, e projetada na mesma tecnologia, mas sem aplicação de quaisquer técnicas de redução de consumo.

Devido ao grande número de variações possíveis no projeto de uma ULA, principalmente com relação às operações que são realizadas por ela, comparações dos resultados da ULA projetada com outros trabalhos similares devem levar em conta essas diferenças. Também é possível realizar comparações dos ganhos obtidos ao se aplicar cada uma das técnicas de redução de consumo, observadas possíveis diferenças tecnológicas. 


\subsection{Organização da monografia}

No Capítulo 2, são abordadas as principais causas de dissipação de potência em circuitos integrados e algumas técnicas para redução de consumo. No Capítulo 0, são apresentados os conceitos gerais sobre ULAs, alguns dos seus principais blocos funcionais e as diversas formas para sua implementação. O projeto da ULA realizado durante a execução deste trabalho está detalhado no Capítulo 1. Por fim, no Capítulo 1, estão as conclusões desta monografia. 



\section{Consumo de potência em circuitos digitais}

As diversas causas do consumo de potência de um circuito eletrônico digital são geralmente classificadas em dinâmicas, isto é, que ocorrem durante transições nos sinais lógicos, e estáticas, que ocorrem independentemente dessas transições.

As subseções a seguir descrevem estes dois tipos de consumo.

\subsection{Consumo estático}

Em circuitos CMOS, o consumo de potência estático corresponde, principalmente, à potência dissipada através de correntes que passam pelos transistores quando estes estão em corte, devido à condução de subthreshold, de correntes de fuga pelo gate e de correntes de fuga pelas junções formadas no drain e no source. A condução de subthreshold ocorre quando os transistores estão na sua região de corte (tensão entre gate e source menor, em módulo, que o módulo da tensão de limiar do transistor).

O consumo estático, por não depender das transições lógicas do circuito, não depende, também, da frequência de operação. Dessa forma, técnicas de redução de consumo que utilizam redução da frequência ou desativam o sinal de clock de uma parte do circuito não tem efeito sobre a parcela estática do consumo.

Historicamente, o consumo estático não era considerado, pois as correntes que atravessavam o circuito durante transições lógicas eram muito maiores. Há três principais motivos para que este consumo passe a ser considerado nos projetos de circuitos integrados recentes.

O aumento da complexidade dos circuitos, refletido diretamente no número de transistores integrados em um único chip, é um desses motivos, pois o consumo estático é proporcional ao número de transistores (YAN; CHEN, 2010).

Com a redução da tensão de alimentação dos circuitos lógicos para reduzir o consumo dinâmico do circuito, a tensão de limiar dos transistores MOS teve que ser reduzida para que as portas lógicas operassem normalmente. Como consequência, as correntes de subthreshold tornaram-se maiores (RAZAVI, 2001). 
Além disso, com a utilização de processos mais avançados de fabricação de transistores, a espessura do material isolante que separa o gate do transistor de seu canal foi reduzida consideravelmente, melhorando o desempenho do transistor. Por outro lado, a corrente de fuga através do gate aumentou consideravelmente.

\subsection{Consumo dinâmico}

A principal fonte de consumo de potência dinâmico é a carga e descarga das capacitâncias conectadas às saídas das portas lógicas durante a transição do sinal de saída (RABAEY; CHANDRAKASAN; BORIVOJE, 2003). Nos circuitos digitais, as capacitâncias de carga mais comuns são as capacitâncias dos gates dos transistores conectados à saída da porta lógica, as capacitâncias de interconexão e as capacitâncias dos drains/sources dos transistores da própria porta lógica.

De forma simplificada, o consumo dinâmico $\left(P_{d}\right)$ de um circuito, devido à carga e descarga de capacitâncias, pode ser equacionado como em (2.1).

$$
P_{d}=\sum_{i} \alpha_{i} f C_{i} V_{D D}^{2}
$$

Em que:

- $\quad i$ indexa cada nó do circuito;

- $\alpha_{i}$ é o fator de atividade do nó do circuito, isto é, número médio de transições que ocorrem no nó por ciclo de clock;

- $f$ é a frequência do clock;

- $C_{i}$ é a capacitância do nó;

- $V_{D D}$ é a tensão de alimentação do circuito.

Por esta equação, pode-se derivar quatro principais abordagens para redução do consumo: redução da tensão de alimentação, redução das capacitâncias de carga, redução da frequência de operação e redução da atividade do circuito.

A tensão de alimentação e a frequência de operação são relacionadas pelo atraso das portas lógicas. $O$ atraso aumenta conforme se reduz a tensão de alimentação, como mostra a equação (2.2) para o caso de um inversor: 


$$
t_{p} \approx \frac{C_{L} V_{D D}}{2 I_{D}} \propto \frac{C_{L}}{V_{D D}}
$$

Nessa equação, $I_{D}$ é a corrente de drain do transistor conduzindo e $C_{L}$ é a capacitância de carga do inversor. Como o tempo de propagação é considerado somente até o instante em que metade da capacitância de carga seja carregada ou descarregada, assume-se que os transistores, quando conduzindo, estão na região de saturação e, por isso, $I_{D}$ é proporcional à $V_{D D}{ }^{2}$.

Dessa forma, a frequência é proporcional à tensão de alimentação, uma vez que o atraso é inversamente proporcional à tensão de alimentação. Considerando a relação entre frequência, tensão de alimentação e potência da equação (2.1), tem-se que a potência será reduzida cubicamente com a redução da tensão de alimentação. Por outro lado, o tempo total para conclusão de uma determinada operação aumentará linearmente, o que faz com que o ganho, em termos de redução de energia, seja somente quadrático (ZHAl et al., 2004).

Todos os capacitores formados entre os terminais dos transistores MOS dependem do processo usado para fabricação do circuito, que determina, principalmente, a espessura do óxido do gate, influenciando as capacitâncias entre o gate e os outros três terminais do transistor, e a dopagem do drain e do source, que influencia nas capacitâncias de junção formadas entre essas regiões e o substrato. O tamanho dos transistores também influencia diretamente na área desses capacitores.

Outra capacitância que aparece, e de grande importância, é a de interconexão (DEDIC, 2012). Todos os componentes do fluxo de dados de um processador, incluindo a ULA, são interconectados através de barramentos paralelos. Cada linha do barramento possui capacitâncias de acoplamento com as linhas vizinhas e com as camadas superior e inferior à camada do barramento. Todas estas capacitâncias são proporcionais ao comprimento do barramento, que muitas vezes tem centenas de micrômetros. Megalingam et al. (2009) apresentam a viabilidade e as vantagens de transformar barramentos de dados paralelos de um processador em barramentos seriais.

Uma das técnicas mais simples para redução da atividade do circuito é inserir, nas entradas do circuito, latches para manter as entradas constantes quando o circuito não for utilizado. Por exemplo, em ULAs convencionais, todas as operações 
são sempre executadas, mas somente o resultado da operação desejada é selecionado. Os blocos responsáveis pelas operações não desejadas poderiam ter seus sinais de entrada fixos para reduzir a atividade e, portanto, o consumo.

A equação (2.1), entretanto, não modela de forma satisfatória o consumo de potência dinâmica de uma porta lógica quando as transições em suas entradas são muito lentas. Nessa situação, a corrente de curto-circuito que ocorre quando tanto os transistores NMOS como os PMOS conduzem tem valor significativo. A equação da potência dinâmica, nesse caso, é acrescida de um termo proporcional ao valor médio desta corrente de curto-circuito, $I_{S C}$, como mostra (2.3).

$$
P_{d}=\sum_{i} \alpha_{i} f\left(C_{i} V_{D D}^{2}+I_{S C} V_{D D}\right)
$$

Rabaey, Chandrakasan e Borivoje (2003) estimam o valor de $I_{S C}$ considerando que a corrente de curto-circuito cresce linearmente até o um valor máximo, $I_{\text {peak }}$, na metade da transição e, então, descresce linearmente. $O$ valor médio dessa corrente é, portanto dado pela equação (2.4).

$$
I_{S C}=\frac{I_{p e a k} t_{s c}}{2}
$$

onde $t_{s c}$ é o tempo no qual há condução simultânea em ambos os transistores. Para uma transição linear na entrada, esse tempo é aproximadamente:

$$
t_{s c} \approx \frac{V_{D D}-2 V_{t h}}{0,8 V_{D D}} t_{t}
$$

onde $V_{t h}$ é a tensão de limiar, em módulo, média dos transistores e $t_{t}$ é o tempo total da transição na saída.

Um estudo detalhado sobre o comportamento desta corrente é encontrado em Bisdounis, Koufopavlou e Nikolaidis (1996).

\subsection{Técnicas para redução de consumo}

Algumas das principais técnicas para redução do consumo de potência são explicadas a seguir. 


\subsubsection{Dimensionamento de transistores e portas lógicas}

Portas lógicas com transistores maiores são capazes de carregar ou descarregar capacitâncias de carga mais rapidamente, reduzindo o tempo de transição e, por consequência, o consumo de potência dinâmica (CADENCE DESIGN SYSTEMS, 2008). Entretanto, transistores maiores implicam em capacitâncias de carga maiores para os sinais de entrada da porta lógica. Se os transistores das portas conectadas a essas entradas não forem suficientemente grandes, essas capacitâncias serão carregadas ou descarregadas de forma lenta, ocasionando a passagem de correntes de curto-circuito.

Por outro lado, transistores menores consomem menos potência estática. Por isso, para que o dimensionamento seja efetivo, otimizando os consumos dinâmicos e estáticos, deve-se levar em consideração, principalmente, a relação entre o tamanho do transistor, as capacitâncias de carga e o fator de atividade.

Em alguns casos, nos quais o aumento dos transistores de uma porta lógica é necessário, mas inviável, podem ser utilizados buffers na saída da porta lógica, que, se bem projetados, possuem capacitância de entrada pequena, mas capacidade de fornecer corrente suficiente para carregar e descarregar grandes capacitâncias, com o objetivo de reduzir o tempo de transição e, consequentemente, o consumo de potência. Considerando que o uso adequado de buffers evita o aumento demasiado das dimensões dos transistores e acelera as transições, a inserção de buffers pode, também, reduzir atrasos e área de circuitos (CADENCE DESIGN SYSTEMS, 2008).

\subsubsection{Pin swapping}

As portas lógicas, mesmo que possuam entradas simétricas, podem apresentar valores diferentes de capacitância em suas entradas. O consumo de potência pode ser reduzido conectando-se, quando possível, os sinais de entrada que alternam com maior probabilidade em entradas que ofereçam menor capacitância de carga (CADENCE DESIGN SYSTEMS, 2008). 


\subsubsection{Múltiplas tensões de limiar}

Em algumas tecnologias, é possível utilizar transistores com diferentes valores de tensão de limiar $\left(V_{t h}\right)$, o que permite otimizar o circuito com relação ao seu consumo estático e à sua velocidade. Isto porque uma porta lógica com transistores com alto $V_{t h}$ apresenta menores correntes de fuga, mas opera mais lentamente em comparação à mesma porta com transistores com menor $V_{t h}$ (HEMANTHA; DHAWAN; KAR, 2008).

O gráfico da Figura 2.1 mostra, de forma simplificada, a relação da corrente de drain de um transistor, $I_{D}$, em função da tensão entre gate e source, $V_{G S}$. $O$ valor de $I_{D}$ quando $V_{G S}=0$ corresponde ao valor da corrente de fuga.

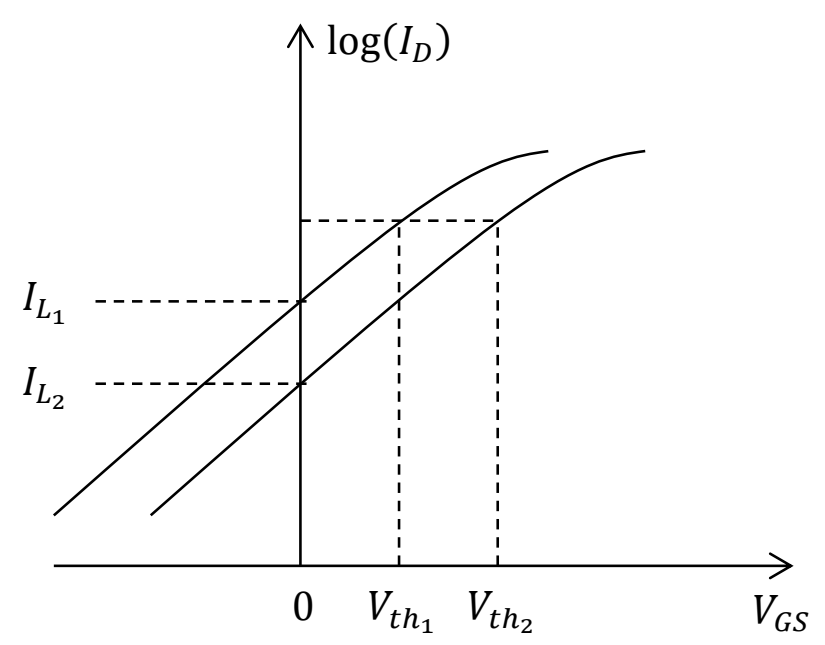

Figura 2.1: Corrente de drain em função da tensão gate-source na região de subthreshold.

Por este gráfico, é possível perceber que a redução na tensão de limiar dos transistores aumenta a corrente de fuga e, por consequência, o consumo estático do circuito.

\subsubsection{Polarização auto-reversa}

A técnica de polarização auto-reversa (KAWAHARA et al., 1993) visa a redução do consumo de potência estática de circuitos onde somente uma parte do circuito está ativa por vez, sendo sua principal aplicação em memórias estáticas. 
Nessas memórias, há uma grande quantidade de células, sendo que somente um pequeno conjunto delas, correspondente a uma palavra, é acessado por vez. As demais permanecem inativas. As células são, geralmente, formadas por transistores grandes com função de drivers para linhas muito longas, que conduzem os sinais armazenados ao barramento de dados. Dessa forma, a corrente estática que atravessa esses transistores é comparativamente grande em relação à de portas lógicas comuns.

A técnica, conforme ilustrada na Figura 2.2a, consiste em inserir, entre a linha de alimentação e os drivers de várias de células, um transistor. Apesar de este transistor estar conectado a muitos drivers, como somente um deles opera por vez, então o tamanho deste transistor pode ser pouco maior que o transistor do driver. Quando nenhuma das células está operando, este transistor é cortado $(\bar{e}=1)$ e o consumo estático do circuito é limitado pela corrente de subthreshold deste transistor.

Quando o transistor está cortado, o nó comum entre o transistor e os drivers $\left(V_{D D}{ }^{\prime}\right)$ descarrega lentamente em função das correntes de fuga dos drivers, como no exemplo do gráfico da Figura 2.2b. Conforme este nó descarrega, os transistores PMOS dos drivers com entrada em nível lógico "1" ficam reversamente polarizados (tensão no source menor que a tensão no gate), reduzindo ainda mais o consumo.

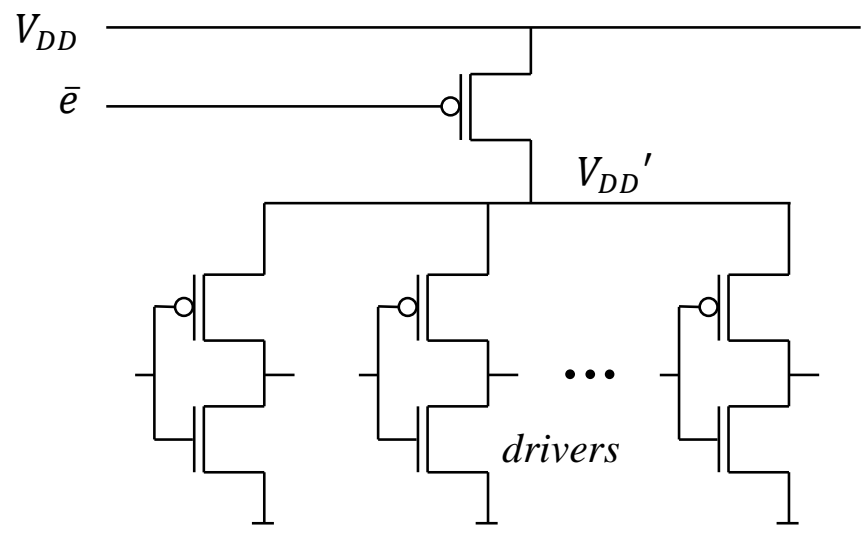

(a)

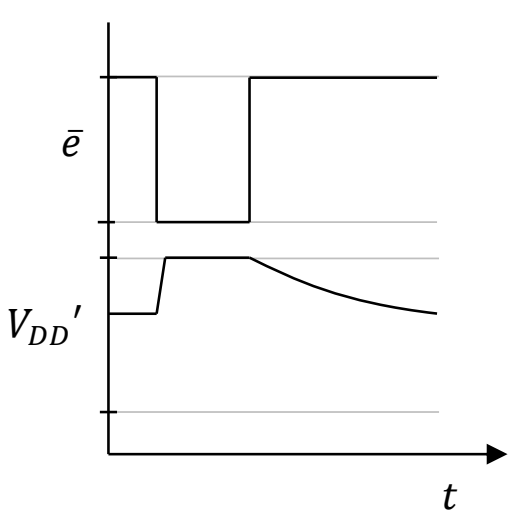

(b)

Figura 2.2: Técnica de polarização auto-reversa. (a) Transistor PMOS entre a linha de alimentação e o restante do circuito. (b) Gráfico da tensão nos nós $\bar{e}$ e $V_{D D}{ }^{\prime}$ em função do tempo. 


\subsubsection{Paralelismo e pipelining}

A redução na tensão de alimentação reduz o consumo de potência de um circuito, mas aumenta seu atraso. Em alguns casos, esse aumento no atraso pode não atender aos requisitos do projeto. Duas técnicas, paralelismo e pipelining, podem ser empregadas para executar operações em paralelo com o objetivo de aumentar o número de operações concluídas por unidade de tempo (BELLAOUAR; ELMASRY, 1995). A execução em paralelo é possível desde que não haja interdependência entre as operações ou que esta interdependência possa ser contornada, por exemplo, não executando uma operação antes da conclusão de todas as operações das quais ela depende.

Tanto na técnica de paralelismo quanto na de pipeline, a frequência do clock pode ser aumentada e continua sendo disponibilizado a cada ciclo de clock uma nova saída (visto a seguir). Entretanto, para que haja redução de consumo, a tensão de alimentação e o clock podem ser reduzidos de tal forma que o número de operações concluídas por unidade de tempo seja igual ao obtido antes da aplicação das técnicas mencionadas.

O paralelismo consiste em replicar o circuito para que múltiplas execuções da mesma operação sejam executadas em paralelo, porém defasadas no tempo. Isto é, cada réplica inicia sua operação em um ciclo de clock diferente. Seus resultados são, então, multiplexados. A grande desvantagem desta técnica é o grande aumento da área ocupada, que corresponderá à área do circuito original multiplicada pelo número de réplicas mais a área do multiplexador e de uma lógica de controle.

O pipelining consiste em dividir o circuito em uma sequência de estágios que executam partes da operação, operando em paralelo, cada um com um conjunto de dados correspondente a uma entrada diferente. Os dados são transferidos de um estágio ao próximo através de flip-flops ou latches.

A técnica de pipelining é mais complexa de ser implementada, pois necessita de um circuito que possuir um ou mais pontos, com um número razoável de sinais intermediários que serão armazenados para transferência, onde serão realizadas as divisões em estágios e estes pontos devem estar espaçados, em termos de atraso, de forma mais ou menos homogênea. Se o número de sinais intermediários for muito grande, o consumo extra de potência para armazena-los entre os estágios 
pode ser maior que a economia obtida com a redução da frequência permitida pelo aumento do desempenho devido ao pipeline. Os estágios devem ter, também, atrasos mais ou menos iguais, pois a frequência do clock será definida pelo atraso do estágio mais lento.

\subsubsection{Balanceamento de atrasos de propagação}

Como as portas lógicas apresentam diferentes atrasos de propagação entre os sinais de entrada e os de saída, as entradas de uma determinada porta podem mudar de valor em instantes de tempo diferentes (BELLAOUAR; ELMASRY, 1995). Assim, essa porta poderá alterar o nível lógico de sua saída diversas vezes, até que suas entradas se estabilizem. A cada transição, a capacitância de carga na saída dessa porta é carrega ou descarregada, ocasionando um consumo de potência desnecessário. Somadores que realizam propagação do carry são um exemplo típico onde ocorre este problema.

Uma das formas de resolver este problema é alterar, quando possível, a estrutura do circuito para que atrasos sejam balanceados, a fim de que as entradas das portas lógicas sejam geradas aproximadamente ao mesmo tempo para que os sinais de saída realizem uma única transição. Por exemplo, considerando que as entradas $a, b, c$ e $d$ dos circuitos da Figura 2.3 são geradas simultaneamente, os sinais $x_{1}$ e $x_{2}$ estão atrasados em relação às entradas $c$ e $d$, respectivamente. Por outro lado, os sinais $y_{1}$ e $y_{2}$ são gerados aproximadamente ao mesmo tempo.

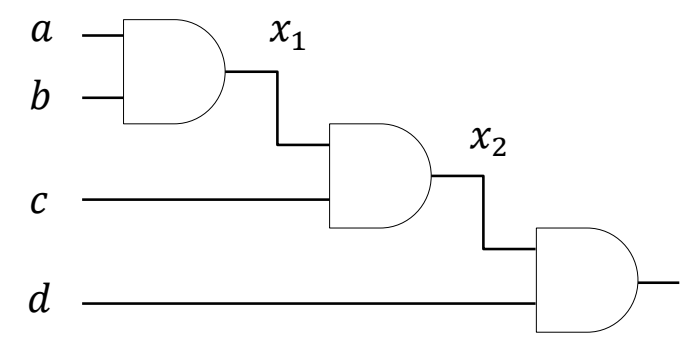

(a)

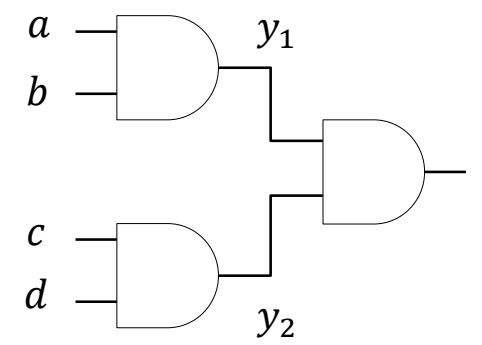

(b)

Figura 2.3: (a) Estrutura não balanceada em relação aos atrasos das entradas das portas lógicas. (b) Estrutura equivalente balanceada. 
Outra forma de balancear o atraso é inserir buffers ou reduzir o tamanho das portas no caminho mais rápido.

\subsubsection{Isolamento de operandos}

A técnica de isolamento de operandos (operand isolation) consiste em bloquear a propagação dos sinais de entrada de um circuito quando a saída deste circuito não será aproveitada. Quando os sinais de entrada são mantidos constantes, os demais sinais do circuito não realizam transições, não havendo consumo de potência dinâmica.

Normalmente, são usados latches para manter sinais no valor que estão no momento da desabilitação do circuito. Outra abordagem para a fixação dos sinais de entrada é através de portas lógicas AND ou OR. Por exemplo, Sun e Jiang (2010) utilizam portas lógicas AND para implementação desta técnica e a redução do consumo obtida por eles foi de $7 \%$. Nessa segunda abordagem, deve-se notar que 0 consumo aumenta, ao invés de diminuir, na situação que o circuito é desabilitado por um único ciclo.

Por outro lado, em tecnologias mais recentes, onde há grande redução do comprimento do canal, da espessura do óxido de gate e da tensão de limiar, as correntes de fuga possuem valor considerável, mas que depende das entradas aplicadas às portas lógicas (ZHANG et al., 2007). Por exemplo, em uma porta NAND, onde há dois transistores NMOS em série, normalmente a entrada "11" causa maior consumo de potência estática comparada à entrada "00". Dessa forma, pode ser mais interessante, nessas tecnologias, fixar, na entrada, valores que minimizam o consumo estático ao invés de manter os últimos valores aplicados, o que minimiza o consumo dinâmico.

\subsubsection{Clock gating}

Uma das maiores fontes de consumo dinâmico de um sistema é a árvore de distribuição do sinal de clock, pois esse sinal normalmente chaveia na frequência 
máxima do sistema e possui uma capacitância de carga muito grande (CADENCE DESIGN SYSTEMS, 2008).

Se há blocos síncronos no circuito que não precisam operar em todos os ciclos de clock, o sinal de clock que entra nesses blocos pode ser desativado, de forma a também evitar que eles operem. A granularidade na qual esta técnica é aplicada varia de sistema para sistema, sendo possível até o controle em nível de registrador.

Uma dos possíveis usos desta técnica é na desabilitação de estágios de pipeline que não estão executando uma operação útil, por exemplo, por ser necessário aguardar a conclusão de uma operação em andamento em outro estágio.

\subsubsection{Power gating}

De forma semelhante à técnica de clock gating, um bloco pode ser completamente desligado, desconectando-o de sua alimentação quando ele não for utilizado (CADENCE DESIGN SYSTEMS, 2008).

Para que um bloco possa ser desligado, é necessário que todos os sinais, principalmente os de saída, sejam conectados a portas lógicas que isolem condicionalmente estes sinais do restante do circuito. Podem-se usar portas lógicas comuns, como AND ou OR, para este fim. Caso o desligamento do circuito ocorra antes do isolamento de suas saídas, níveis lógicos indefinidos podem ser propagados pelo restante do sistema. Em alguns casos, além de portas para isolamento dos sinais, é necessário o uso de outros elementos para armazenar o estado do bloco e recuperar este estado após o religamento.

Para controlar quando um circuito está ligado ou desligado, são inseridos transistores entre a linha de alimentação e o circuito, de forma muito semelhante à técnica de polarização auto-reversa (Seção 2.3.4). Hemantha, Dhawan e Kar (2008) apresentam uma metodologia de projeto para inserção desses transistores de forma a minimizar o atraso do circuito e evitar, quando o circuito é religado, uma grande corrente devido à carga dos nós intermediários do circuito. 


\subsubsection{Múltiplas tensões de alimentação}

Quando as restrições de velocidade variam entre os blocos que compõe um sistema, é possível a operação dos blocos que podem ter maior atraso em uma tensão de alimentação menor, consumindo menor potência. Por outro lado, na interface entre blocos alimentados com tensões diferentes devem ser inseridos circuitos para conversão dos níveis lógicos. Um exemplo de circuito, chamado de contention mitigated level shifter (CMLS) (TRAN; KAWAGUCHI; SAKURAI, 2005) que realiza a conversão é mostrado na Figura 2.4.

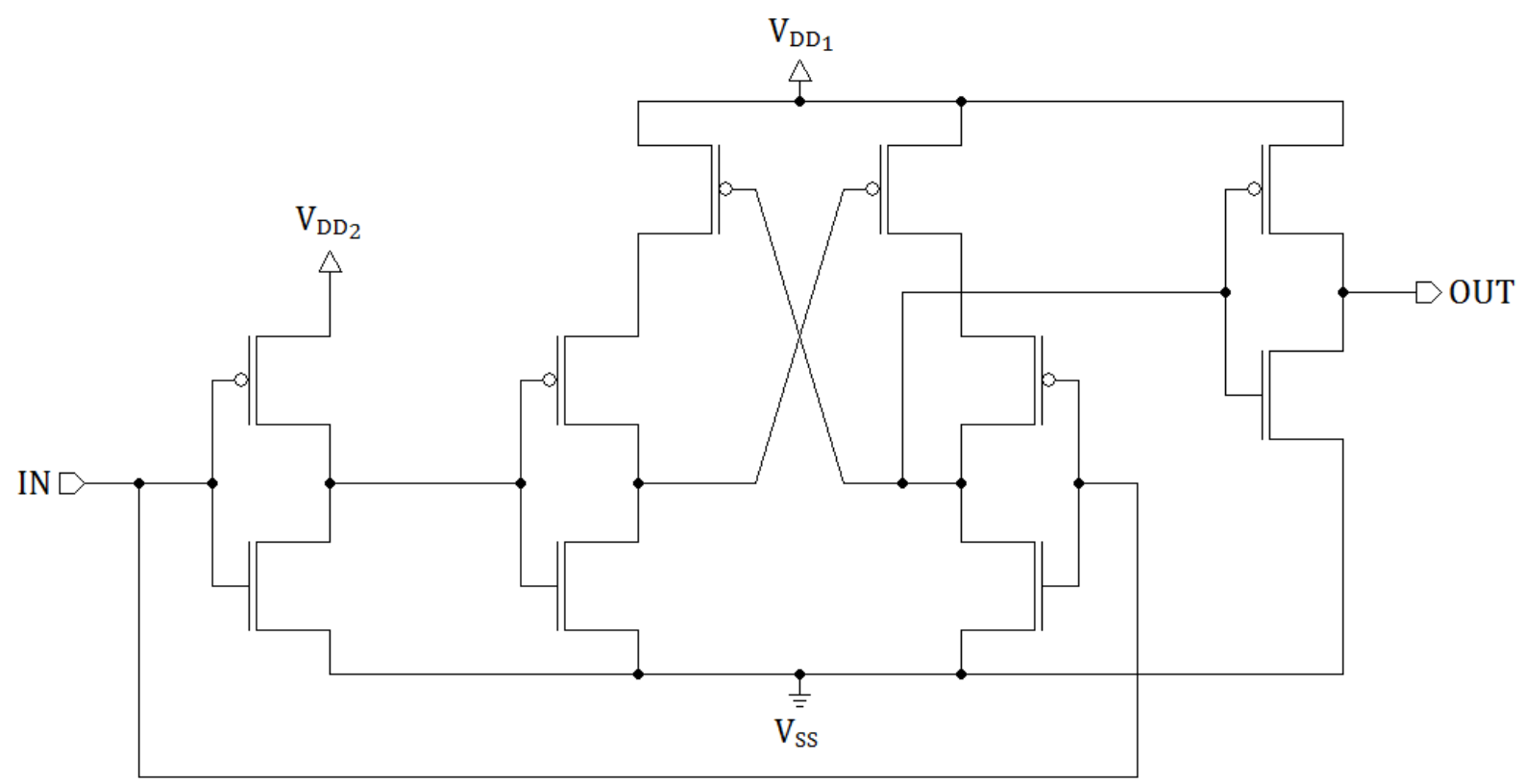

Figura 2.4: Circuito para conversão entre domínios de tensão de alimentação.

Nesse circuito, o sinal de entrada, $I N$, com nível lógico 1 igual a $V_{D D_{2}}$, é transportado para o sinal de saída, OUT, com nível lógico 1 igual a $V_{D D_{1}}$. Essa conversão é especialmente necessária quando o sinal está sendo convertido para uma tensão maior. Em tal situação, caso o sinal fosse ligado diretamente a um inversor, por exemplo, a tensão na gate do transistor PMOS seria inferior à tensão do source, podendo fazer com que o transistor PMOS conduzisse corrente quando devesse estar cortado.

Outros circuitos, similares a este, são apresentados e comparados por Kumar, Arya e Pandey (2010). 


\subsubsection{Escala dinâmica de tensão e frequência}

Considerando-se que o consumo de potência reduz e o atraso do circuito aumenta com a redução da tensão de alimentação, é possível, tendo informações sobre os requisitos instantâneos de velocidade e consumo, variar a tensão de alimentação e a frequência do circuito durante seu funcionamento, com o objetivo de minimizar o consumo de potência.

A variação da tensão de alimentação de um circuito e, consequentemente, da sua frequência durante a operação, é conhecida como dynamic voltage scaling (DVS) (HUERTA et al., 2006). É muito comum sua aplicação em processadores com carga de trabalho variável ao longo do tempo. O que geralmente ocorre neles é a necessidade de execução de tarefas intercaladas por intervalos de tempo ociosos. A ideia da técnica de DVS é executar as tarefas mais lentamente para minimizar o tempo ocioso e o consumo de potência.

$\mathrm{Na}$ técnica de DVS, é realizado o controle tensão-frequência em malha aberta, de forma que os valores de tensão e de frequência são previamente calculados durante o projeto do circuito. Uma vez que o desempenho do circuito também varia com fatores do processo de fabricação e ambientais, como a temperatura, são mantidas margens de segurança para que o circuito opere sempre corretamente. Há, também, técnicas mais avançadas que realizam o controle em malha fechada, permitindo o acerto entre tensão de alimentação e frequência em tempo real. Neste caso, se obtém um menor consumo de potência, uma vez que as margens de segurança podem ser mais estreitas. Por outro lado, o controle em malha fechada é mais complexo, geralmente requerendo o uso de circuitos analógicos de monitoração dos parâmetros de desempenho para retroalimentação (CADENCE DESIGN SYSTEMS, 2008). 



\section{Unidades lógico-aritméticas}

O projeto de uma ULA envolve, principalmente, a definição das operações que serão realizadas por ela e sua organização interna, isto é, como as operações ou seus resultados são selecionados e de que forma as operações relacionadas se interconectam.

A escolha das operações influencia diretamente na área do circuito e na taxa de utilização da ULA, pois se apenas operações mais simples forem implementadas em uma ULA, ela deverá ser acionada muitas vezes para realizar tarefas mais complexas.

A organização interna da ULA, por sua vez, influencia em sua área, em seu atraso e em seu consumo de potência.

Outra consideração importante durante o projeto de uma ULA é o formato de codificação dos números usado pelos operandos e pelo resultado. No caso de números binários inteiros, existem diversas formas de codificação de números negativos, como sinal-magnitude, complemento de um ou complemento de dois, sendo que esta última é a mais utilizada. A principal vantagem do complemento de dois é a facilidade de realizar a subtração de dois números. Os outros formatos, entretanto, também têm suas vantagens. Um somador em complemento de um, por exemplo, possui melhor desempenho no cálculo do checksum usado no protocolo de comunicação IPv4 (Internet Protocol version 4) (UNIVERSITY OF SOUTHERN CALIFORNIA, 1981).

A operação aritmética mais simples e na qual todas as outras operações aritméticas se baseiam é a adição, que, em uma ULA, é realizada por circuitos chamados somadores. Utilizando os somadores como base, várias outras operações aritméticas podem ser realizadas.

\subsection{Somadores}

Um somador é um circuito lógico que tem como entrada dois operandos $(A \mathrm{e}$ $B$ ) de $N$ bits cada, codificados em um determinado sistema numérico (através dos 
bits $a_{0}, a_{1}, a_{2}, \ldots, a_{N-1}$ e $\left.b_{0}, b_{1}, b_{2}, \ldots, b_{N-1}\right)$ e, opcionalmente, um sinal de carry-in $\left(c_{i n}\right)$. Este circuito tem como saída $(S)$, também de $N$ bits $\left(s_{0}, s_{1}, s_{2}, \ldots, s_{N-1}\right)$, a soma dos dois operandos mais o valor do carry-in, e um sinal de carry-out $\left(c_{\text {out }}\right)$.

Os somadores são construídos a partir de blocos funcionais mais simples. Um destes blocos é o meio somador, ou half adder ( $\mathrm{HA})$, que realiza a soma de apenas dois bits, produzindo a soma e o carry-out. Outro desses blocos é o somador completo, ou full adder (FA), que, por sua vez, realiza a soma de três bits (dois operandos e o carry-in), produzindo, também, a soma e o carry-out, conforme as Equações (3.1) e (3.2).

$$
\begin{gathered}
\mathrm{s}=a \oplus b \oplus \mathrm{c}_{\text {in }} \\
c_{\text {out }}=a \cdot b+a \cdot c_{\text {in }}+b \cdot c_{\text {in }}
\end{gathered}
$$

Há diversas formas de implementação de somadores propostas na literatura. As subseções seguintes abordam em maiores detalhes as principais dessas formas.

\subsubsection{Ripple-Carry Adder}

A topologia mais simples de somador de vários bits, conhecido como RippleCarry Adder (RCA), é um circuito formado por um conjunto de somadores completos associados em série, como mostra a Figura 3.1.

Apesar de sua simplicidade, o RCA tem um tempo de resposta muito elevado, pois o resultado da soma e o carry-out final estarão disponíveis somente após a propagação dos sinais de carry intermediários através de todos os blocos somadores completos. Neste tipo de somador, o tempo total da soma, a área do circuito e o seu consumo crescem linearmente em função do número de bits. 


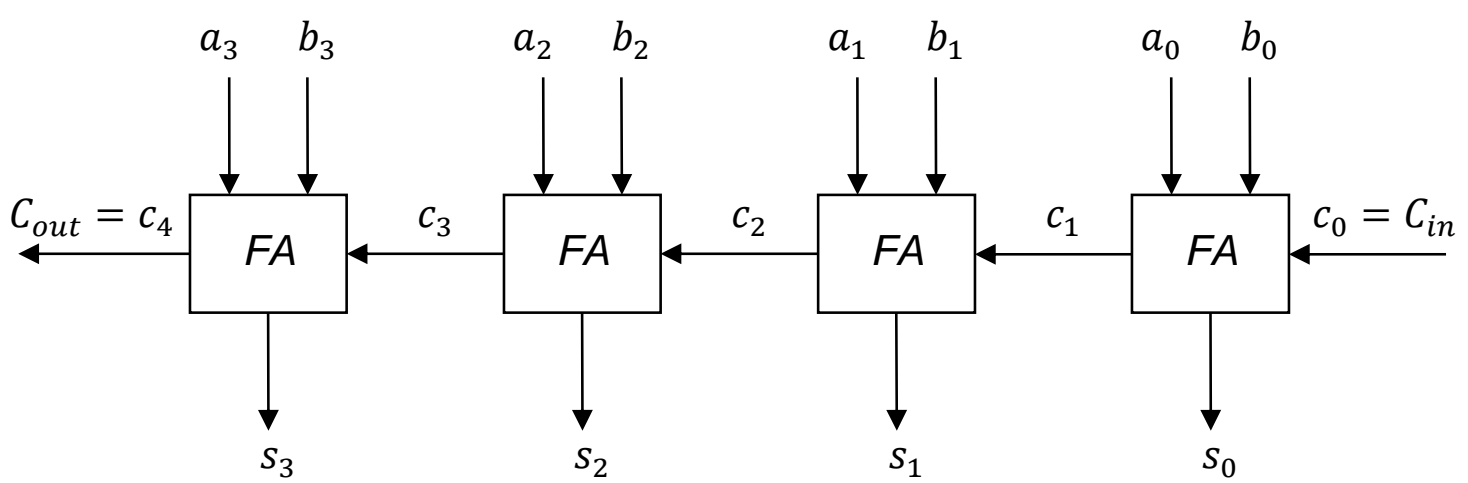

Figura 3.1: Ripple-Carry Adder de 4 bits.

\subsubsection{Carry-Lookahead Adder}

O somador com topologia Carry-Lookahead Adder (CLA) é conhecido por ter um dos melhores desempenhos dentre os somadores (ASHMILA; DLAY; HINTON, 2005). A ideia básica desse somador é calcular o valor do carry-in de cada bit a partir somente dos operandos e do carry-in do primeiro bit. Desta forma, não há necessidade de espera pela propagação do carry através do circuito.

O cálculo do carry-in de cada bit é realizado através das funções de geração e propagação de carry. A função de geração indica, para um determinado bit da soma, se esse bit irá gerar um carry, independente da presença de um carry-in. A função de propagação indica, para um determinado bit da soma, se este bit irá propagar o carry no caso da presença do carry-in. Pode-se escrever a função de geração $g$ e a função de propagação $p$ em função dos operandos $a$ e $b$ como nas Equações (3.3) e (3.4), respectivamente.

$$
\begin{gathered}
g(a, b)=a \cdot b \\
p(a, b)=a+b
\end{gathered}
$$

Outra definição válida para a função de propagação é apresentada na Equação (3.5), que considera propagação somente se não houver geração. A vantagem de usar essa outra definição é que se pode aproveitar o valor de $p$ para $o$ cálculo da soma, reduzindo a área do circuito.

$$
p(a, b)=a \oplus b
$$


A partir dessas funções, pode-se verificar que o carry-out $\left(c_{\text {out }}\right)$ de um bit, em função de $g$ e $p$ e do carry-in $c_{i n}$ é escrito como:

$$
c_{\text {out }}=g(a, b)+p(a, b) \cdot c_{\text {in }}
$$

Para o caso da soma de múltiplos bits e considerando:

- $\quad c_{i}$ o valor do carry-in do bit $i$;

- $g_{i}$ o valor da função de geração do bit $i$; e

- $p_{i}$ o valor da função de propagação do bit $i$, pode-se representar o carry-out $\left(c_{i+1}\right)$ como sendo:

$$
c_{i+1}=g_{i}+p_{i} c_{i}
$$

Expandindo esta equação recursivamente, obtêm-se as equações para o carry-out de cada bit a partir dos operandos e do carry-in do somador $\left(c_{0}\right)$.

$$
\begin{aligned}
& c_{1}=g_{0}+p_{0} c_{0} \\
& \begin{aligned}
c_{2} & =g_{1}+p_{1} c_{1}=g_{1}+p_{1}\left(g_{0}+p_{0} c_{0}\right)=g_{1}+p_{1} g_{0}+p_{1} p_{0} c_{0}
\end{aligned} \\
& \begin{aligned}
c_{3} & =g_{2}+p_{2} c_{2}=g_{2}+p_{2}\left(g_{1}+p_{1} g_{0}+p_{1} p_{0} c_{0}\right)= \\
& =g_{2}+p_{2} g_{1}+p_{2} p_{1} g_{0}+p_{2} p_{1} p_{0} c_{0}
\end{aligned} \\
& \begin{aligned}
c_{4} & =g_{3}+p_{3} c_{3}=g_{3}+p_{3}\left(g_{2}+p_{2} g_{1}+p_{2} p_{1} g_{0}+p_{2} p_{1} p_{0} c_{0}\right)= \\
& =g_{3}+p_{3} g_{2}+p_{3} p_{2} g_{1}+p_{3} p_{2} p_{1} g_{0}+p_{3} p_{2} p_{1} p_{0} c_{0}
\end{aligned}
\end{aligned}
$$

A parte do circuito que implementa estas equações, bem como o cálculo das funções de geração e propagação é chamada de carry-lookahead unit. A Figura 3.2 apresenta a arquitetura básica da topologia carry-lookahead adder. Nesta figura, os blocos que compõe o carry-lookahead unit implementam as equações indicadas para calcular de forma antecipada cada carry. Os sinais de geração e propagação são calculados a partir dos operandos, conforme Equações (3.3) e (3.4).

Deve-se observar, que, no caso do CLA, os blocos para o cálculo dos bits da soma não precisam calcular o carry-out, uma vez que esse é determinado por outra parte do circuito, não sendo necessário usar um somador completo. Apesar da vantagem do cálculo direto do carry-in de cada bit, o CLA torna-se demasiadamente complexo quando se aumenta o número de bits, como pode ser observado pelas equações acima. Dessa forma, esse tipo de somador é geralmente implementado para até 4 bits apenas. 


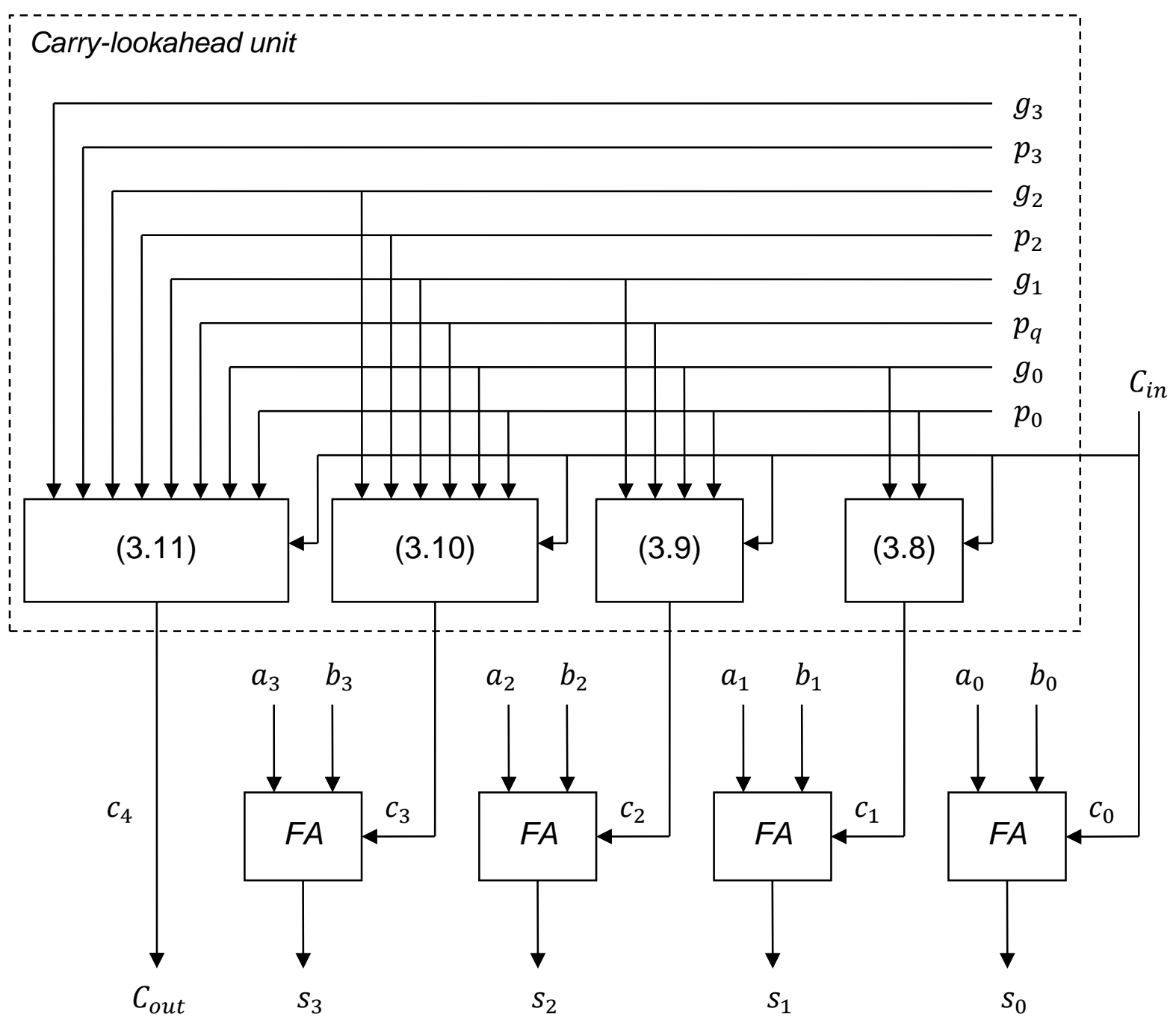

Figura 3.2: Carry-Lookahead Adder de 4 bits.

No caso de somadores com número maior de bits, os operandos são divididos em diversos grupos de 4 bits cada. Os bits de cada um dos grupos são somados por um somador CLA de 4 bits. Para evitar a propagação do carry entre os grupos, emprega-se a mesma ideia usada para evitar a propagação entre os bits, ou seja, constrói-se um somador de grupos do tipo CLA onde cada grupo realiza a soma de números de 4 bits.

Para o somador de grupos, as funções de geração e propagação de carry são definidas de forma ligeiramente diferente. Para o caso de grupos de 4 bits, as funções são determinadas a partir da Equação (3.11), que é equação expandida para o carry-out do último bit do grupo. A função de geração será a parte que não depende de $c_{0}$ (carry-in do grupo) e a função de propagação será a parte que 
depende de $c_{0}$. Portanto, para o caso de 4 bits, a função de geração do grupo $g_{G}$ e a função de propagação do grupo $p_{G}$ são definidas como sendo:

$$
\begin{gathered}
g_{G}=g_{3}+p_{3} g_{2}+p_{3} p_{2} g_{1}+p_{3} p_{2} p_{1} g_{0} \\
p_{G}=p_{1} p_{2} p_{3} p_{4}
\end{gathered}
$$

O carry-out do grupo, que será usado como carry-in do grupo seguinte, é definido de forma análoga à Equação (3.7):

$$
c_{G_{i+1}}=g_{G_{i}}+p_{G_{i}} c_{G_{i}}
$$

Essa equação deve ser expandida para encontrar o carry-in dos grupos seguintes.

O circuito torna-se, também, muito complexo para além de 4 grupos consecutivos, isto é, somadores de 16 bits. Novamente, para somadores de tamanho maior, aplica-se a mesma técnica de maneira recursiva: quatro somadores de 4 bits são agrupados em um somador CLA de 16 bits. Deve-se encontrar novamente as funções de geração e propagação do carry, partindo, nesse caso, da equação do carry-out do quarto somador de 4 bits. Assim, podem-se juntar vários somadores de 16 bits para compor somadores de tamanhos ainda maiores, como de 64 bits, 256 bits, 1024 bits e assim por diante. A Figura 3.3 mostra, de forma geral, como é construído um somador de 16 bits a partir de quatro somadores de 4 bits cada.

A Figura 3.4, representa, de forma mais simplificada, um somador de 64 bits usando agrupamentos de 4 bits e, depois, de 16 bits.

A Figura 3.5 mostra, em nível de portas lógicas, como seria um CLA de 3 bits, considerando as simplificações acima. Algumas adaptações ainda podem ser feitas para melhoria do circuito, dependendo da lógica usada para implementação das portas lógicas. Por exemplo, em lógica CMOS, portas NAND são mais rápidas e mais econômicas, em termos de área e potência, em comparação com portas AND e OR, devendo assim ser utilizadas. 


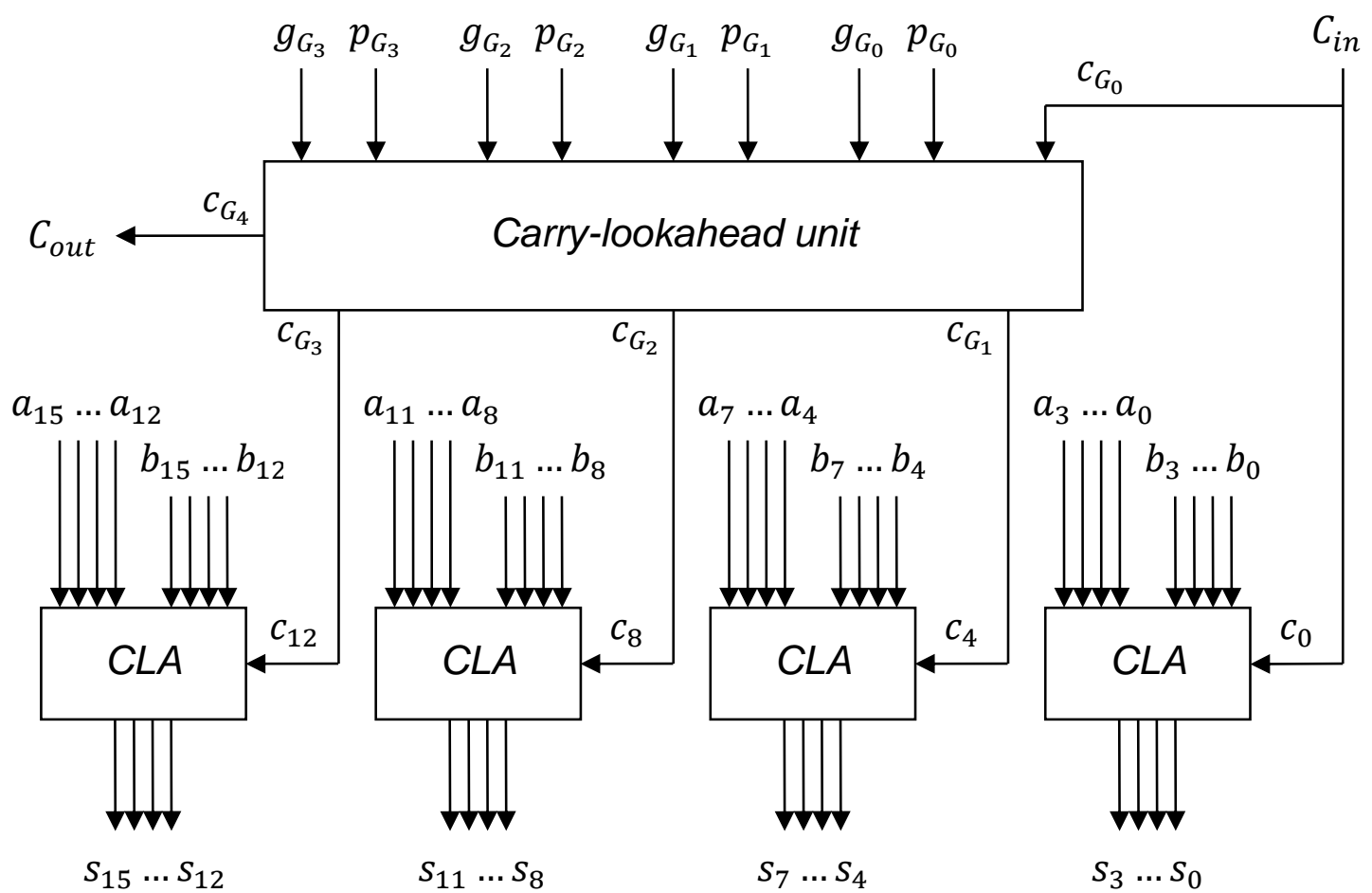

Figura 3.3: Carry-Lookahead Adder de 16 bits.

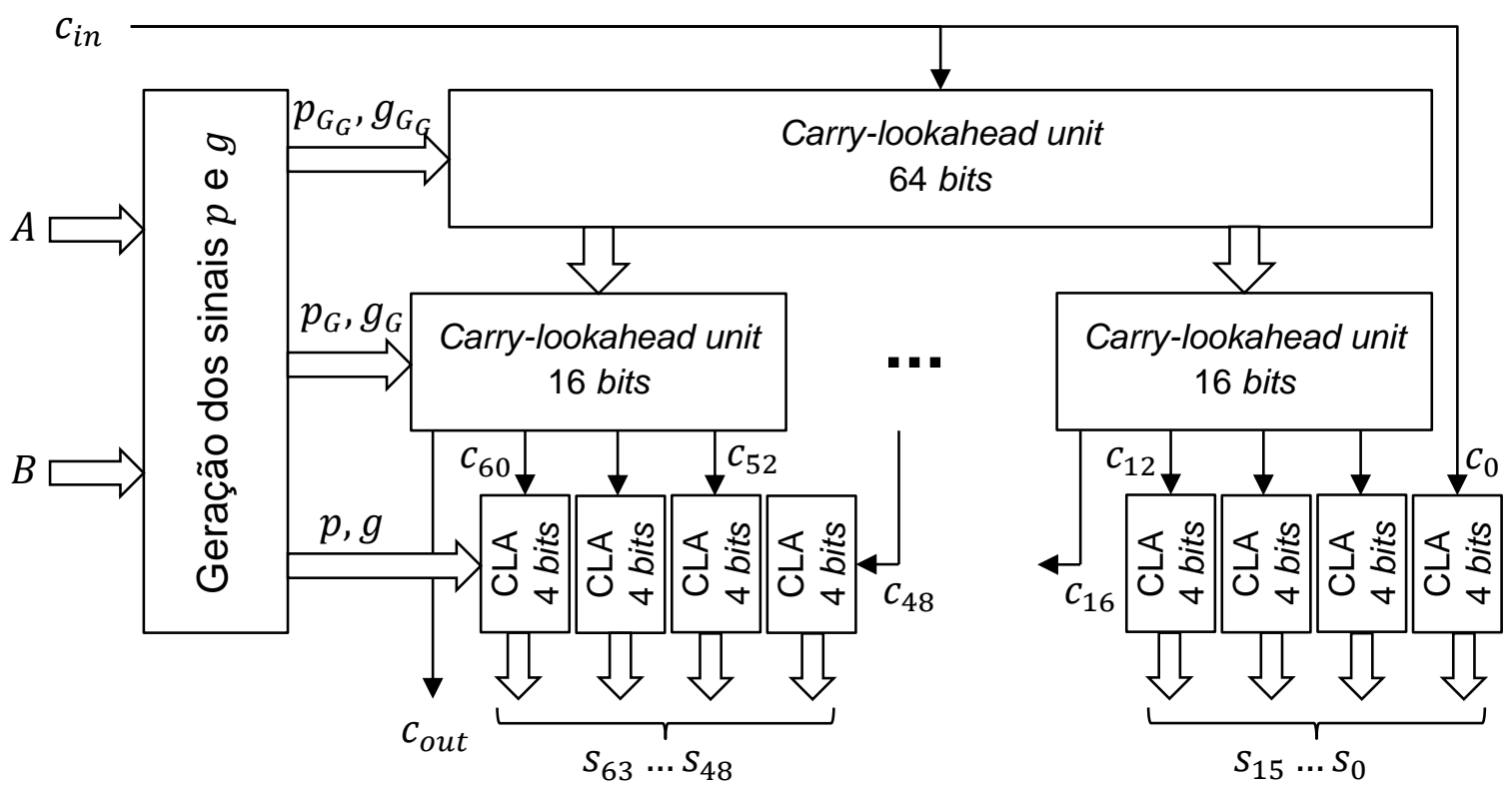

Figura 3.4: Carry-Lookahead Adder de 64 bits. 


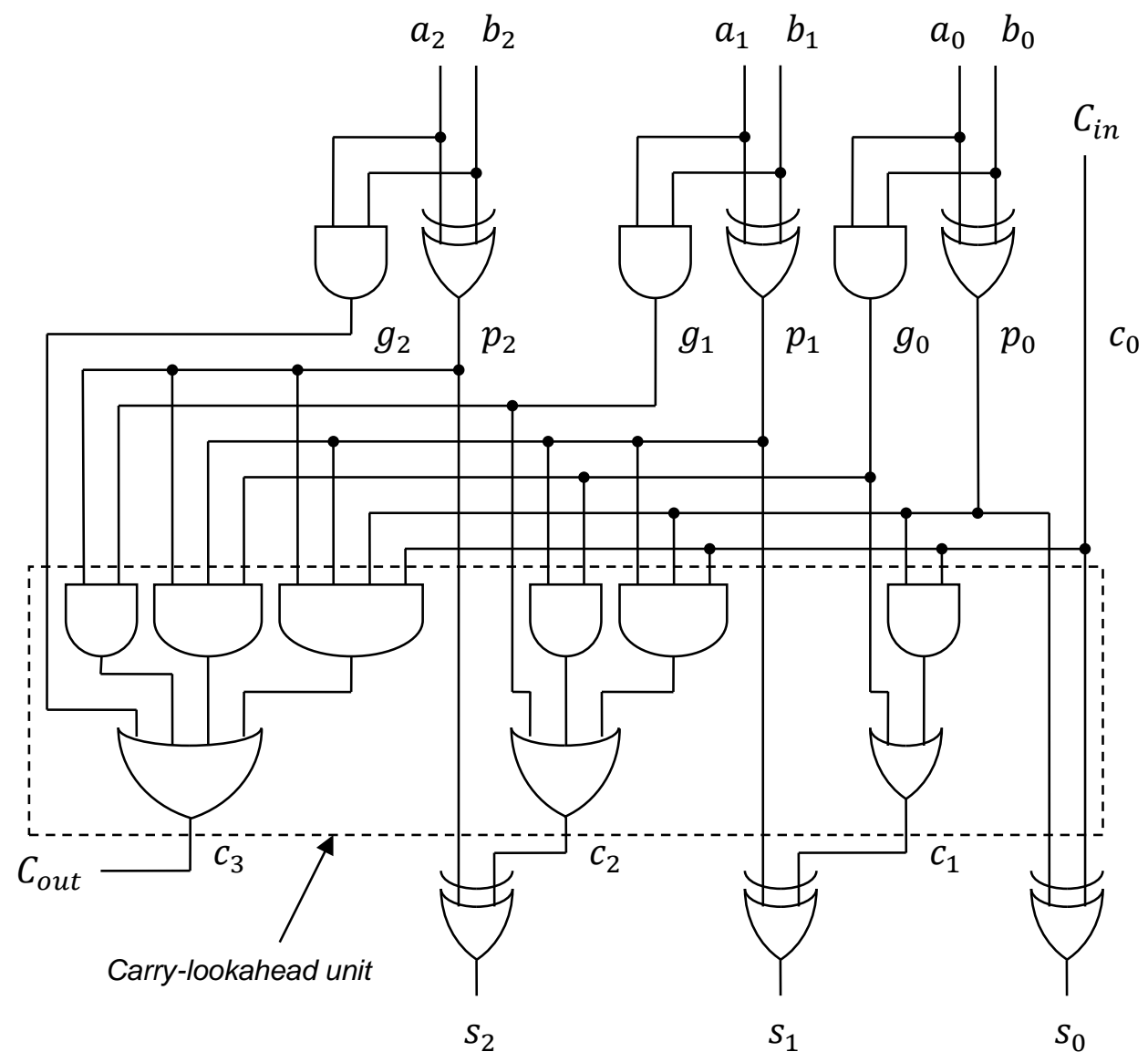

Figura 3.5: Carry-Lookahead Adder de 3 bits.

\subsubsection{Carry-Select Adder}

Outra forma de implementação de somadores é o Carry-Select Adder (CSA) (BEDRIJ, 1962), que, apesar de não ter melhor desempenho, tem área reduzida quando comparado ao Carry-Lookahead Adder (ASHMILA; DLAY; HINTON, 2005), (YOUNGJOON; LEE-SUP, 2001).

Nesse tipo de somador, as entradas são divididas em duas partes: uma com os bits mais significativos e a outra com os menos significativos. A parte menos significativa é calculada por um somador do tipo RCA. A parte mais significativa da soma é calculada, em paralelo, por dois RCAs, considerando-se as duas possibilidades de carry-in para esta parte (0 ou 1). Quando o valor real do carry-in torna-se disponível, isto é, após o cálculo do carry-out da parte menos significativa, o 
resultado final é selecionado, através de um multiplexador, dentre os dois resultados previamente calculados.

A Figura 3.6 apresenta a topologia básica desse somador. Nesta figura, a primeira parte, menos significativa, realiza a soma de $N_{0}$ bits e a segunda parte, mais significativa, de $N_{1}=N-N_{0}$ bits.

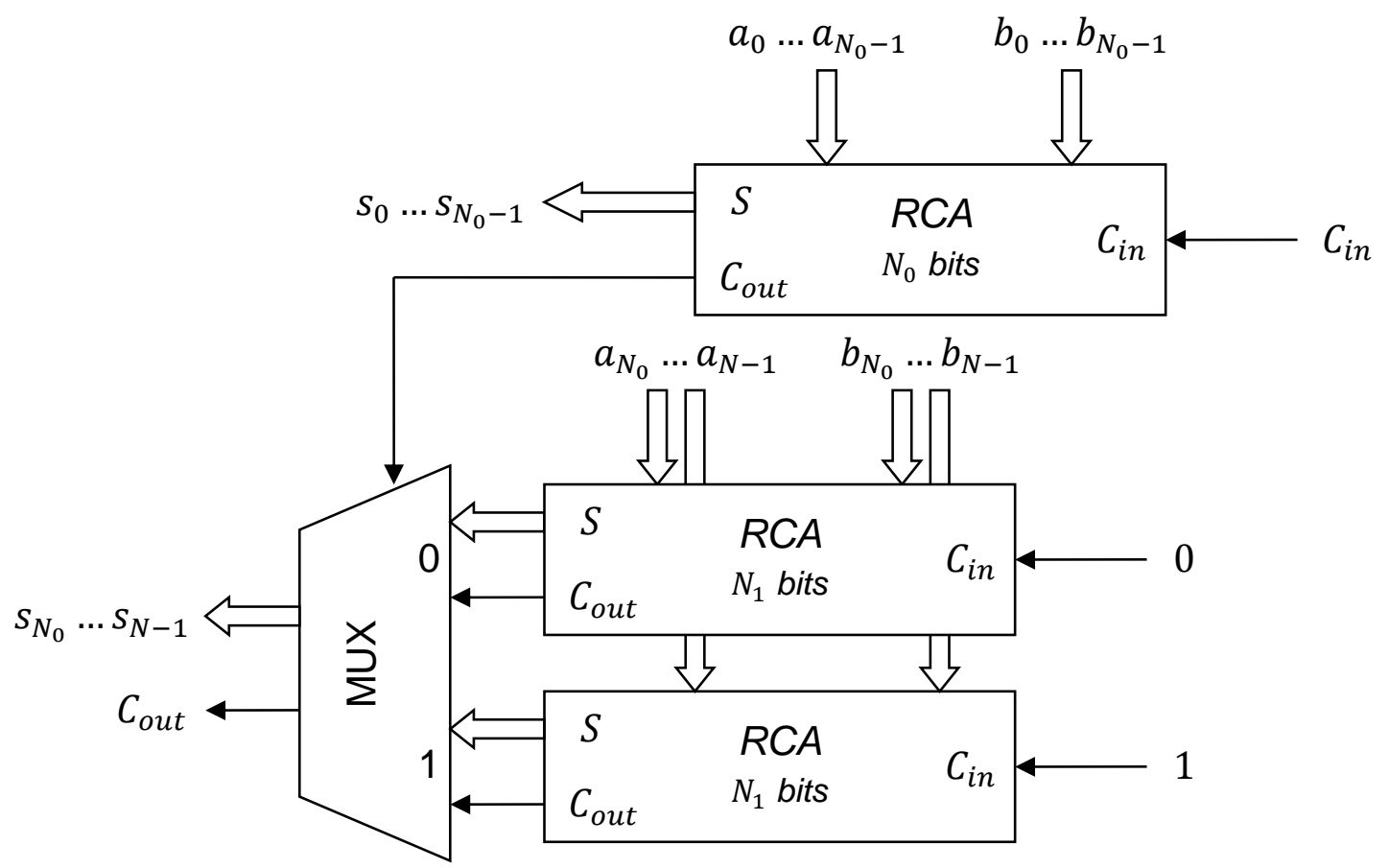

Figura 3.6: Carry-Select Adder.

Utilizando esta abordagem, pode-se reduzir o tempo da soma para aproximadamente metade do tempo de um RCA simples. Para redução ainda maior do tempo total da soma, pode-se dividir o somador em um número maior de partes até o limite em que todos os bits são multiplexados independentemente. Entretanto, neste último caso, o tempo total da soma não será mínimo, pois o carry terá que se propagar através de todos os multiplexadores para que o resultado final seja obtido. O número ideal de divisões e a quantidade de bits em cada parte podem ser obtidos conhecendo-se os atrasos de propagação dos sinais através dos somadores completos e dos multiplexadores.

Sendo $T_{R C A}(N)$ o atraso de um RCA de $N$ bits e $T_{M} 0$ atraso de um multiplexador $2 \times 1$ de $N$ bits, o atraso total do CSA, $T_{C S A}$, é dado pela Equação (3.15). 


$$
T_{C S A}(N)=T_{R C A}\left(N_{0}\right)+\sum_{i=1}^{P}\left(T_{R C A}\left(N_{i}\right)+T_{M}\right)
$$

em que $P$ é o número de partes do CSA e $N_{i}$ é o tamanho da $i$-ésima parte, de tal forma que:

$$
\sum_{i=0}^{P} N_{i}=N
$$

O número ideal de divisões e o tamanho de cada parte podem, portanto, ser obtidos minimizando $T_{C S A}$.

Diversas otimizações podem ser aplicadas a esse somador. Uma delas consiste na substituição dos RCAs utilizados para calcular a soma quando o carry-in é igual a um por um circuito de incremento associado ao somador utilizado para calcular a soma quando o carry-in é igual a zero (YOUNGJOON; LEE-SUP, 2001), (SUN; ZHANG; JIN, 2008). A principal vantagem nesta otimização é a redução significativa da área do circuito, uma vez que um circuito de incremento, quando utilizando lógica de transistor de passagem, pode ser construído em uma área significativamente menor. A Figura 3.7 mostra o CSA com circuito de incremento.

Outra otimização possível para esse somador é o compartilhamento de um único somador para a parte mais significativa e o uso de um latch para armazenar um dos resultados (AMELIFARD; FALLAH; PEDRAM, 2005). Um sinal de clock pode ser usado para controlar o compartilhamento do somador. A Figura 3.8 apresenta como é feita essa otimização.

No caso do somador da Figura 3.8, o somador dos bits mais significativos realiza a soma dos operandos considerando o sinal de clock como carry-in. Dessa forma, na primeira metade do período do clock, o somador realiza o cálculo para carry-in igual a um e o latch armazena o resultado. Na segunda metade do período do clock, o somador realiza a soma para carry-in igual a zero e o latch mantém-se com o resultado para carry-in igual a um. Ao final do período, a soma dos bits menos significativos completa-se e o carry-out dessa parte seleciona o resultado da parte mais significativa dentre o resultado do somador e o resultado armazenado no latch. 


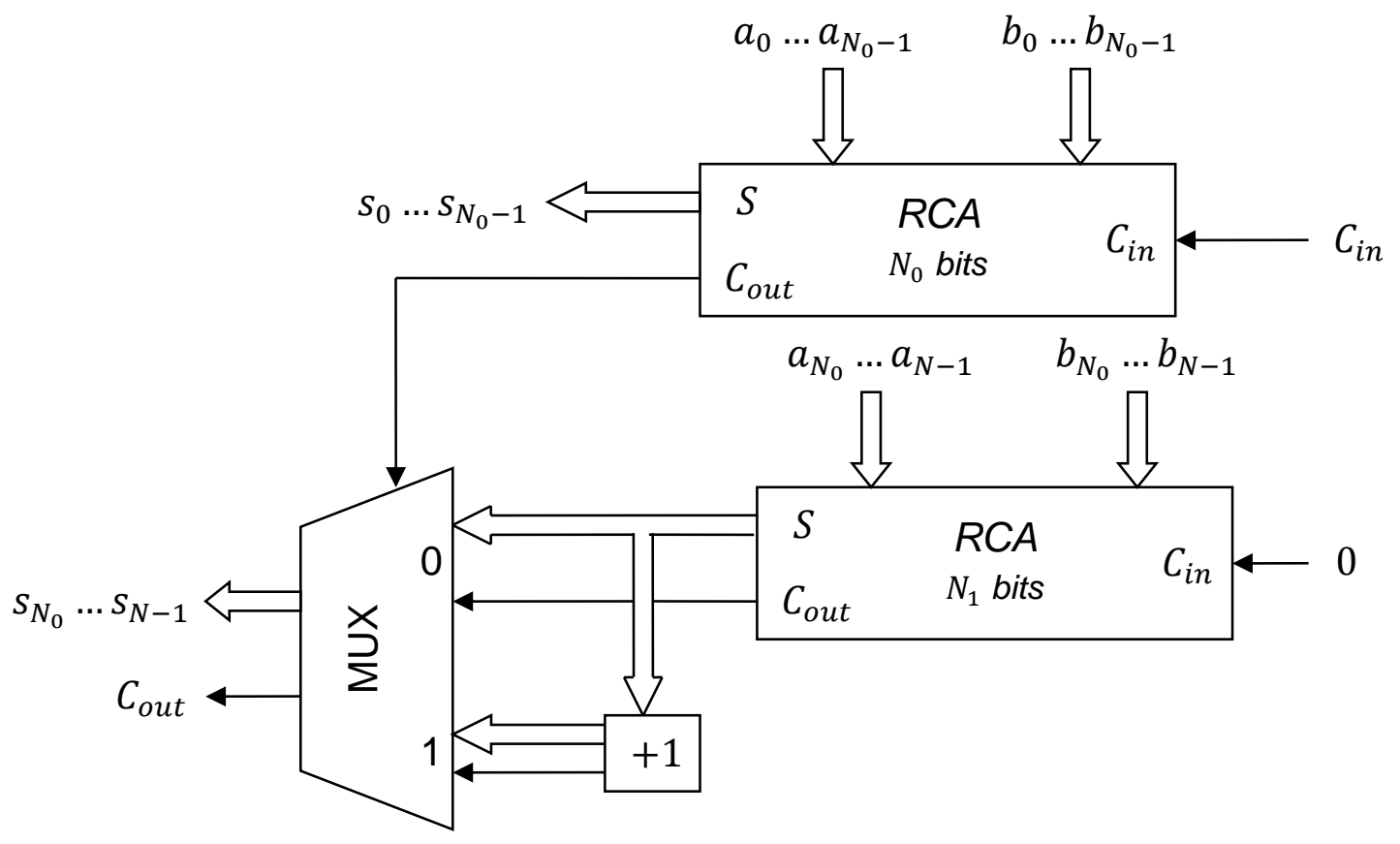

Figura 3.7: Carry-Select Adder com circuito de incremento.

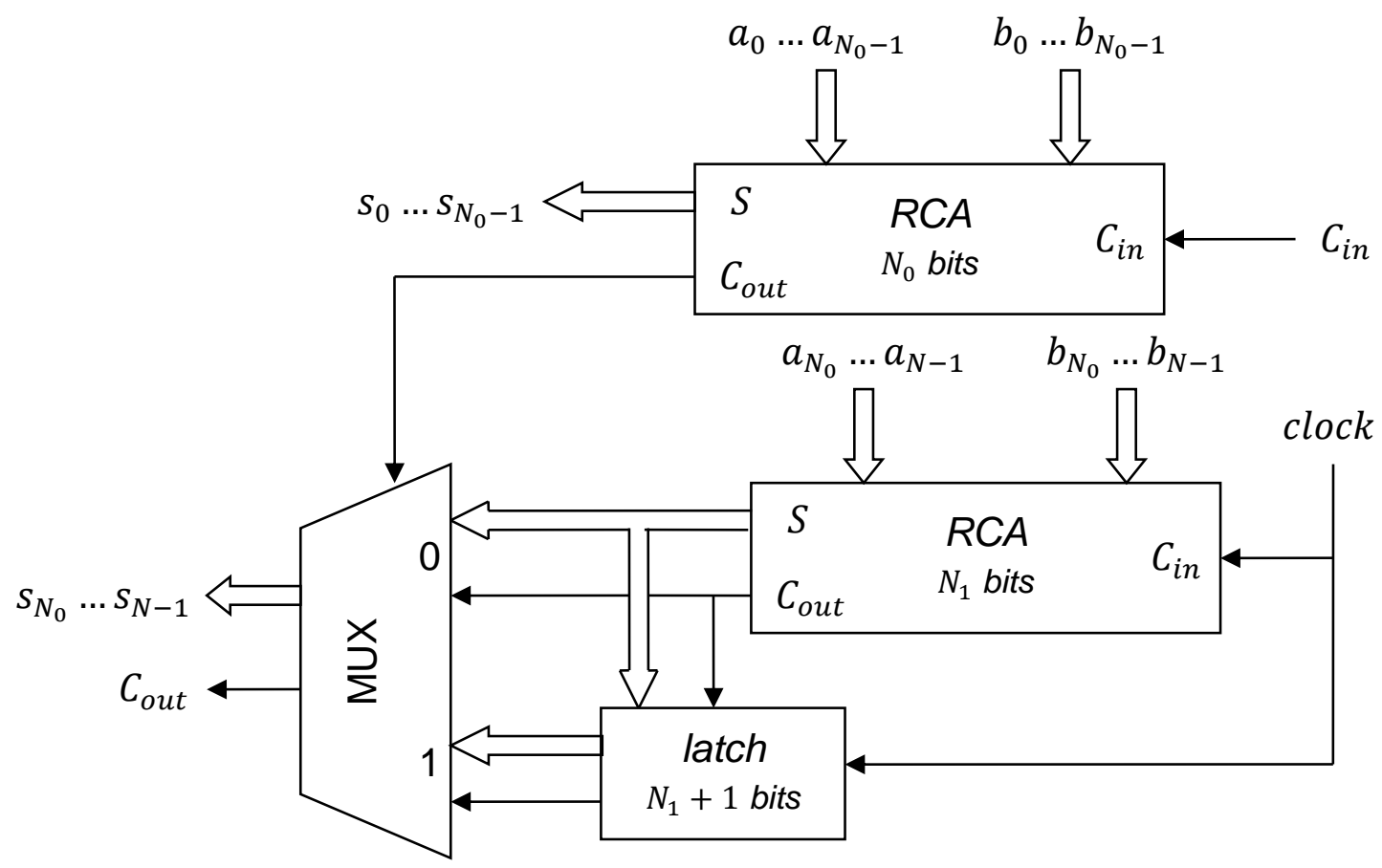

Figura 3.8: Carry-Select Adder com compartilhamento. 


\subsubsection{Subtração}

A subtração pode ser realizada diretamente através de um somador com alterações somente nas entradas e saídas do somador, dependendo da representação utilizada para os números negativos. Por exemplo, para a subtração usando complemento de dois, inverte-se todos os bits do segundo operando e soma-se um ao resultado (que pode ser feito através do carry-in). O número resultante da operação anterior é simplesmente somado ao primeiro operando para se obter a subtração, como mostrado no somador/subtrator da Figura 3.9.

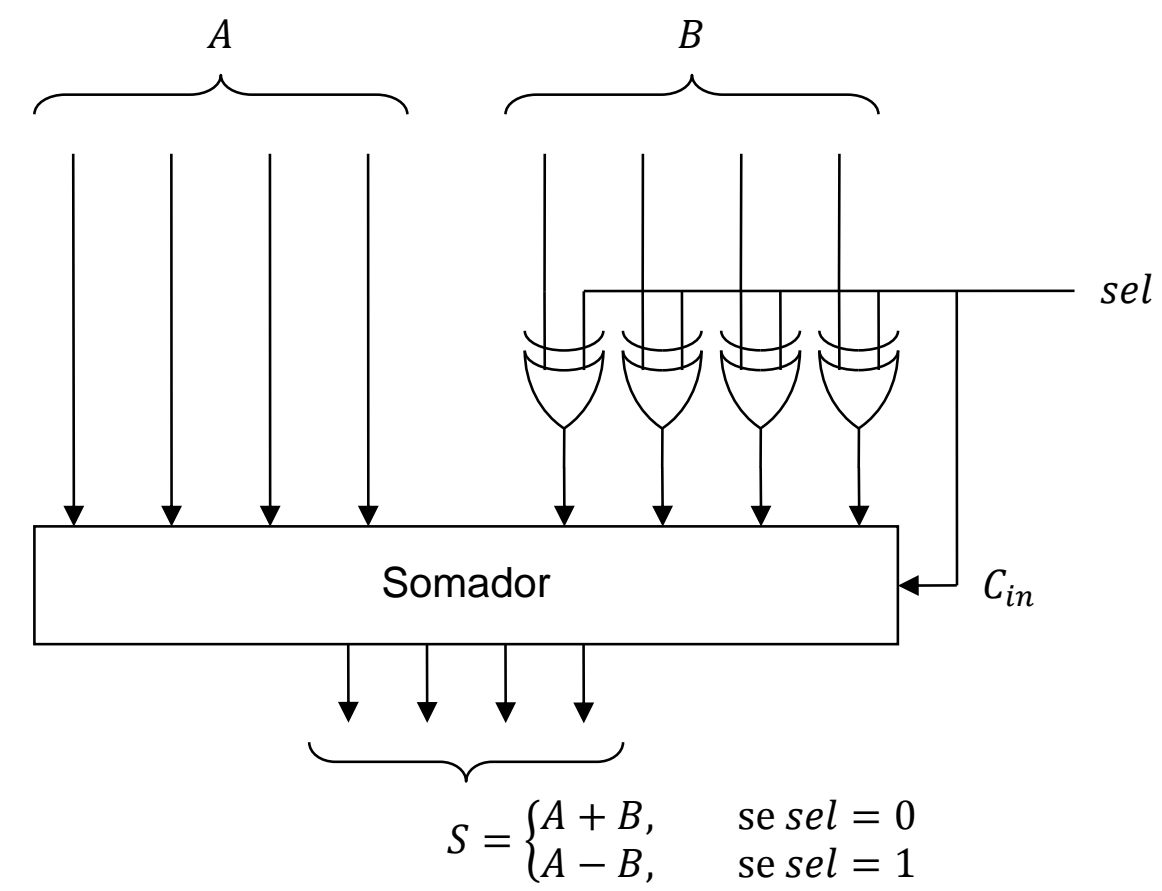

Figura 3.9: Soma e subtração de 4 bits em complemento de dois usando um somador.

Em uma subtração, o sinal de carry do somador corresponde à indicação de borrow (empresta-um), mas em lógica inversa, isto é, quando o carry é zero, ocorre o empréstimo. É comum a implementação de ULAs que invertem o carry-in e o carry-out durante uma subtração, para que o valor a ser utilizado fora da ULA não tenha lógica inversa. 


\subsection{Operações lógicas}

As ULAs geralmente implementam todas as operações lógicas típicas, como complemento, e, ou, ou-exclusivo, deslocamento e rotação. Com exceção das operações de deslocamento e rotação, todas as operações, classificadas como operações lógicas bit-a-bit, podem ser implementadas de forma paralela usando uma porta lógica para cada bit.

Tanto o deslocamento como a rotação modificam o operando deslocando todos os seus bits em uma determinada direção por um ou mais bits. Como os registradores que armazenam os operandos e o resultado têm tamanho fixo, alguns bits são deslocados para fora do resultado, enquanto outros bits são inseridos no resultado pelo outro lado.

Os deslocamentos são classificados em dois tipos: lógicos e aritméticos. Os deslocamentos lógicos simplesmente deslocam os bits de um operando para a esquerda ou para a direita, inserindo bits iguais a zero no lado oposto ao deslocamento. Os deslocamentos aritméticos, por outro lado, realizam o deslocamento dos bits preservando o sinal do número. Nos formatos típicos de representação de números com sinal, o sinal pode ser preservado inserindo bits iguais ao bit mais significativo quando o deslocamento é para a direita e, quando o deslocamento é para a esquerda, inserindo zeros para as representações em complemento de dois e sinal-magnitude ou bits iguais ao bit mais significativo para complemento de um. Nota-se que, em sinal-magnitude, não se deve deslocar o bit mais significativo, que representa o sinal, nas operações de deslocamento aritmético.

Os deslocamentos têm a característica de executar a multiplicação ou divisão por uma potência de dois. Isto é, o deslocamento de $N$ bits para a direita equivale à divisão por $2^{N}$ e o deslocamento de $N$ bits para a esquerda, à multiplicação por $2^{N}$.

No caso das rotações, os bits inseridos são iguais aos bits removidos, preservando todos os bits do operando. Além disso, as rotações podem ser realizadas com ou sem carry. O carry, nesse caso, participa da operação como sendo um bit extra no operando e no resultado.

A Figura 3.10 apresenta as operações de deslocamento lógico, deslocamento aritmético e rotação, para a esquerda e para a direita. 
Deslocamento lógico para a esquerda

Deslocamento lógico para a direita

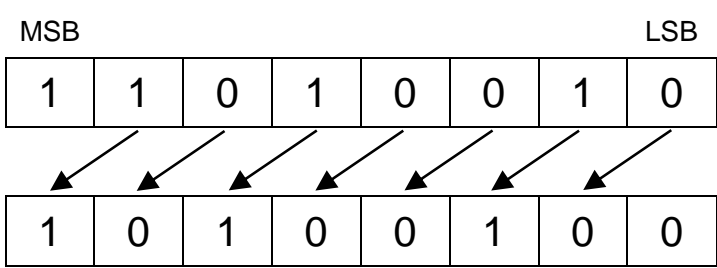

(a)

Deslocamento aritmético para a esquerda

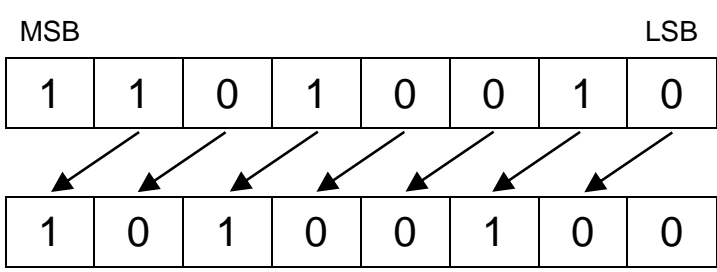

(c)

Rotação para a esquerda

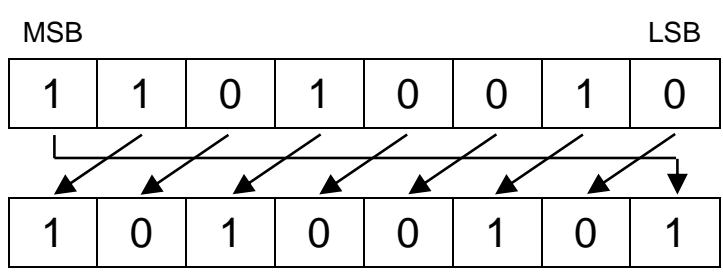

(e)

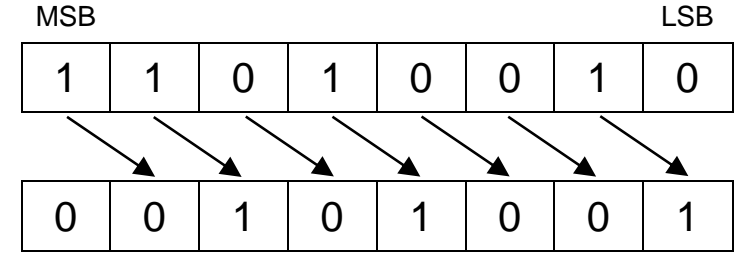

(b)

Deslocamento aritmético para a direita

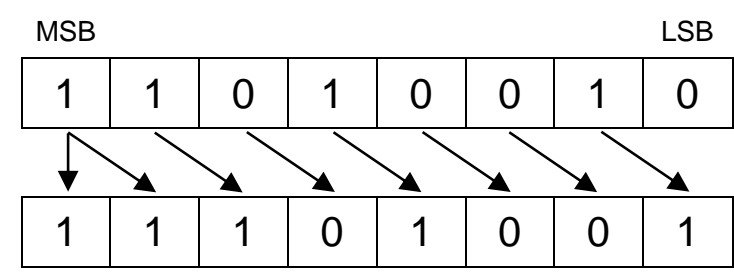

(d)

Rotação para a direita

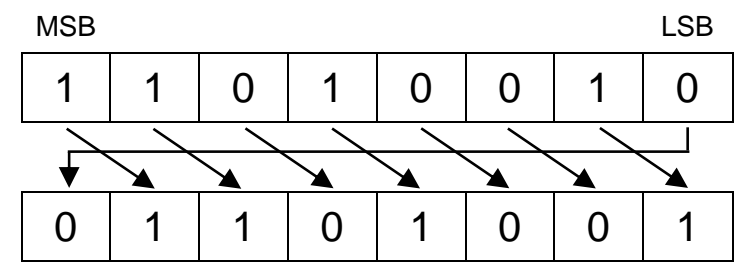

(f)

Figura 3.10: Operações de deslocamento e rotação.

O circuito mais comumente usado para implementação de todas essas operações de deslocamento e rotação é o barrel shifter. Outra topologia também usada é o funnel shifter. Ambas são descritas e comparadas nas subseções seguintes e, em mais detalhes, por Huntzicker (2008).

\subsubsection{Barrel Shifter}

O barrel shifter é, essencialmente, um rotacionador. No caso de deslocamentos, o resultado da rotação deverá ser mascarado, conforme o diagrama de blocos da Figura 3.11. 


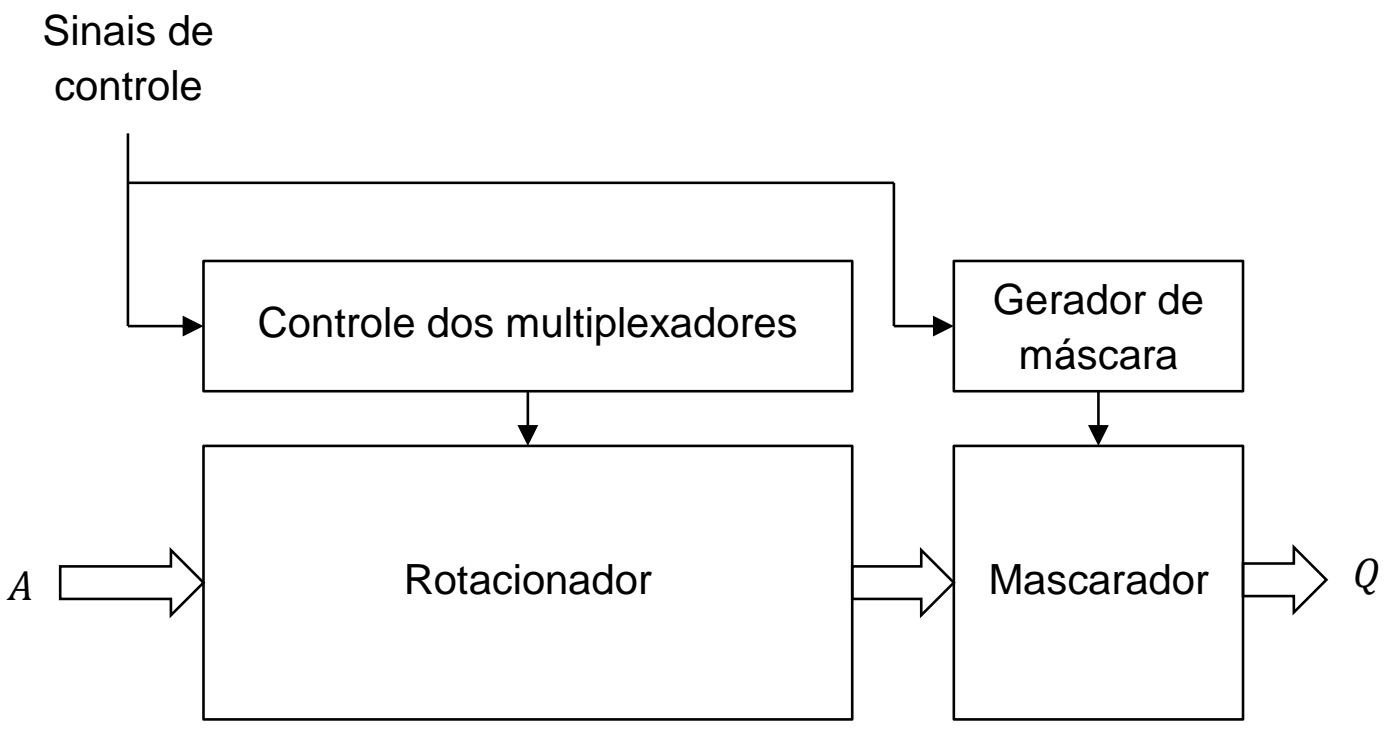

Figura 3.11: Diagrama de blocos de um barrel shifter.

O rotacionador realiza uma sequência de rotações para a direita de 1 bit, 2 bits, 4 bits e assim por diante até metade do número de bits do operando. Cada rotação é realizada por um conjunto de multiplexadores em paralelo, sendo um para cada bit. Cada multiplexador seleciona, a partir da entrada ou da saída do conjunto de multiplexadores anteriores, entre o bit na mesma posição (sem rotação) ou o bit $2^{i}$ posições seguintes (rotação de $2^{i}$ ).

Para realizar uma rotação para a direita de $k$ posições, o controle dos multiplexadores de cada conjunto corresponde, respectivamente, aos bits do número $k$. Isto é, os multiplexadores que realizam a rotação de 1 bit são controlados pelo bit menos significativo de $k$, os que realizam a rotação de 2 bits, pelo segundo bit menos significativo de $k$ e assim por diante.

Já a rotação para a esquerda de $k$ posições é equivalente à rotação para a direita de $N-k$ posições, onde $N$ é o número de bits do operando. $\mathrm{O}$ valor $(N-k)$ pode ser obtido calculando-se o seu complemento de dois $(\bar{k}+1)$. Para evitar o uso de um somador neste cálculo, pode ser adicionado mais uma rotação de um bit na série de rotações.

Para realizar um deslocamento de $k$ bits, realizam-se as rotações e, ao final destas, é feito o mascaramento dos resultados. Para a operação, constrói-se uma máscara, que é a uma sequência de $N$ bits, tal que os $k$ primeiros bits são iguais a zero e os demais, a um. Combina-se, então, essa máscara, representada pelos bits 
$m_{0}, m_{1}, \ldots, m_{N-1}$, com o resultado da rotação, representado pelos bits $b_{0}, b_{1}, \ldots, b_{N-1}$, conforme a Tabela 3.1.

Tabela 3.1: Mascaramento no barrel shifter.

\begin{tabular}{lc}
\hline \multicolumn{1}{c}{ Operação } & Resultado \\
\hline Deslocamento lógico para a direita & $b_{i} \cdot m_{N-1-i}$ \\
Deslocamento aritmético para a direita & $b_{i} \cdot m_{N-1-i}+s_{D} \cdot \bar{m}_{N-1-i}$ \\
Deslocamento lógico para a esquerda & $b_{i} \cdot m_{i}$ \\
Deslocamento aritmético para a esquerda & $b_{i} \cdot m_{i}+s_{E} \cdot \bar{m}_{i}$ \\
\hline
\end{tabular}

Nessa tabela, $s_{D}$ corresponde ao sinal do operando utilizado no deslocamento para a direita, normalmente o bit mais significativo do operando, e $s_{E}$ o sinal a ser utilizado no deslocamento para a esquerda (zero para representação em complemento de dois e o bit mais significativo do operando, para complemento de um).

\subsubsection{Funnel Shifter}

O funnel shifter, ao contrário do barrel shifter, não rotaciona o operando. Inicialmente, são calculados, a partir de um operando de $N$ bits, outros $(N-1)$ bits que, em conjunto, formam uma expansão do operando de $(2 N-1)$ bits, $A_{1}$, da qual $N$ bits contíguos serão selecionados para formar o resultado. $O$ diagrama de blocos da Figura 3.12 ilustra o funnel shifter.

A escolha da operação que será realizada define como é feita a expansão do operando. Os bits de $A_{1}$ podem ser separados em três partes, a saber: a parte mais significativa, com $N-1$ bits, a parte do meio, com um bit, e a parte menos significativa, com $N-1$ bits. Essas partes são formadas a partir dos bits $a_{0}, a_{1}, \ldots, a_{N-1}$ do operando $A$ conforme a Tabela 3.2. 


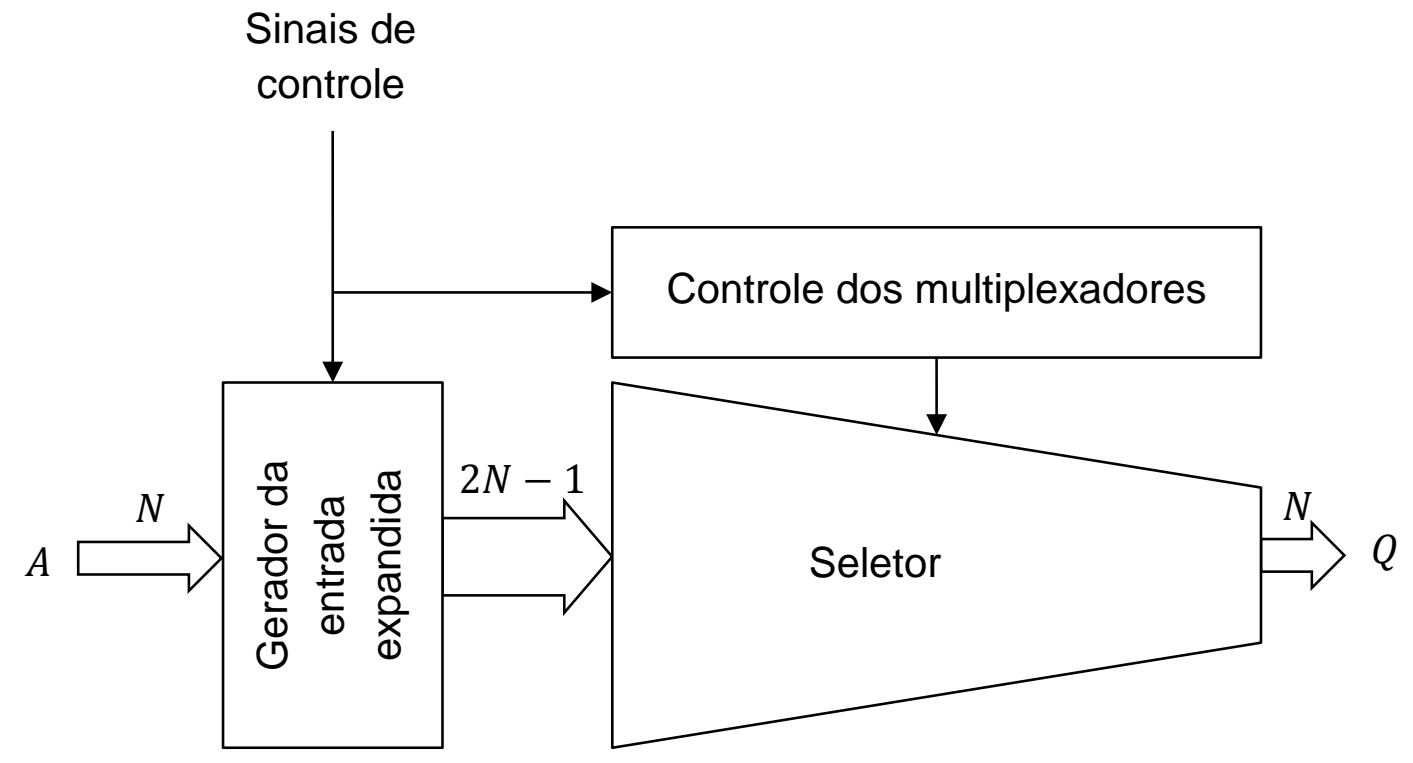

Figura 3.12: Diagrama de blocos de um funnel shifter.

Tabela 3.2: Expansão do operando no funnel shifter.

\begin{tabular}{lccc}
\hline \multicolumn{1}{c}{ Operação } & $\begin{array}{c}\text { Parte mais } \\
\text { significativa }\end{array}$ & $\begin{array}{c}\text { Parte do } \\
\text { meio }\end{array}$ & $\begin{array}{c}\text { Parte menos } \\
\text { significativa }\end{array}$ \\
\hline $\begin{array}{l}\text { Deslocamento lógico para a } \\
\text { direita }\end{array}$ & 0 & $a_{N-1}$ & $a_{N-2} \ldots a_{0}$ \\
$\begin{array}{l}\text { Deslocamento aritmético para a } \\
\text { direita }\end{array}$ & $a_{N-1}$ (sinal) & $a_{N-1}$ & $a_{N-2} \ldots a_{0}$ \\
$\begin{array}{l}\text { Deslocamento lógico para a } \\
\text { esquerda }\end{array}$ & $a_{N-1} \ldots a_{1}$ & $a_{0}$ & 0 \\
$\begin{array}{l}\text { Deslocamento aritmético para a } \\
\text { esquerda }\end{array}$ & $a_{N-1} \ldots a_{1}$ & $a_{0}$ & 0 ou $a_{N-1}(\operatorname{sinal})^{*}$ \\
Rotação para a direita & $a_{N-2} \ldots a_{0}$ & $a_{N-1}$ & $a_{N-2} \ldots a_{0}$ \\
Rotação para a esquerda & $a_{N-1} \ldots a_{1}$ & $a_{0}$ & $a_{N-1} \ldots a_{1}$
\end{tabular}

* Deve ser usado zero para representação em complemento de dois e $a_{N-1}$ para complemento de um.

A seleção dos $N$ bits é feita usando-se estágios sequenciais formados por conjuntos de multiplexadores em paralelo, que deslocam para a direita $N / 2, N / 4, \ldots$, 8, 4, 2 e 1 posição. A cada estágio, o número de bits é reduzido de um número igual ao que se está deslocando, até que se obtenha exatamente $N$ bits, que é o resultado desejado. Por exemplo, para um operando de 32 bits, são necessários 5 estágios, como mostra a Tabela 3.3. Nessa tabela, a entrada $A_{1}$ corresponde à expansão do operando $A$ em $(2 N-1)$ bits e o resultado final é $A_{6}$, que possui 32 bits. 
Tabela 3.3: Estágios de multiplexação do funnel shifter de 32 bits.

\begin{tabular}{|c|c|c|c|c|}
\hline Estágio & $\begin{array}{l}\text { Número de bits } \\
\text { de entrada }\end{array}$ & Entrada & $\begin{array}{c}\text { Deslocamento } \\
\text { para a direita (bits) }\end{array}$ & Saída \\
\hline 1 & 63 & $A_{1}[62 \ldots 0]$ & 0 ou 16 & $A_{2}=\left\{\begin{array}{c}A_{1}\left[\begin{array}{lll}46 & \ldots & 0\end{array}\right] \\
A_{1}\left[\begin{array}{lll}62 & \ldots & 16\end{array}\right]\end{array}\right.$ \\
\hline 2 & 47 & $A_{2}[46 \ldots 0]$ & 0 ou 8 & $A_{3}=\left\{\begin{array}{l}A_{2}[38 \ldots 0 \\
A_{2}\left[\begin{array}{lll}46 & \ldots & 8\end{array}\right]\end{array}\right.$ \\
\hline 3 & 39 & $A_{3}[38 \ldots 0]$ & 0 ou 4 & $A_{4}=\left\{\begin{array}{l}A_{3}[34 \ldots 0 \\
A_{3}[38 \ldots\end{array}\right]$ \\
\hline 4 & 35 & $A_{4}[34 \ldots 0]$ & 0 ou 2 & $A_{5}=\left\{\begin{array}{l}A_{4}\left[\begin{array}{lll}32 & \ldots & 0\end{array}\right] \\
A_{4}\left[\begin{array}{lll}34 & \ldots & 2\end{array}\right]\end{array}\right.$ \\
\hline 5 & 33 & $A_{5}[32 \ldots 0]$ & 0 ou 1 & $A_{6}=\left\{\begin{array}{l}A_{5}[31 \ldots 0 \\
A_{5}[32 \ldots 1\end{array}\right.$ \\
\hline
\end{tabular}

Para realizar um deslocamento para a direita de $k$ bits, o controle dos multiplexadores de cada estágio corresponde, respectivamente, aos bits do número $k$. Já o deslocamento para a esquerda de $k$ bits, é equivalente ao deslocamento para a direita de $(N-1-k)=\bar{k}$ bits.

\subsection{Multiplicadores}

Multiplicação é uma operação complexa que pode ser realizada de duas principais formas: através de circuitos lógicos dedicados, chamados de multiplicadores, ou por uma sequência de instruções de soma e deslocamento.

Para efetuar multiplicações com alto desempenho, os multiplicadores executam as operações de soma e deslocamento de forma paralela. Estes multiplicadores são chamados de multiplicadores paralelos. Para multiplicações de menor velocidade, os multiplicadores executam as operações de soma e deslocamento de forma serial. Estes são chamados de multiplicadores de vários passos.

A multiplicação é fundamental em aplicações de processamento digital de sinais, justificando-se a implementação de multiplicadores de altíssimo desempenho em ULAs de DSPs (digital signal processors). Projetistas de processadores de 
propósito geral, por outro lado, podem optar por implementar ULAs sem multiplicadores por diversas razões, entre elas a redução de área e potência.

Algumas implementações possíveis de multiplicadores são discutidas adiante.

\subsubsection{Multiplicador de Braun}

Um dos multiplicadores paralelos mais utilizados é o multiplicador de Braun, também chamado de array multiplier. Sua estrutura é bastante regular, tornando-o prático para implementação em VLSI (DAS; RAHAMAN, 2010).

Considerando os operandos $A$ e $B$, formados respectivamente pelos bits $a_{0}, a_{1}, \ldots, a_{N-1}$ e $b_{0}, b_{1}, \ldots, b_{N-1}$, e 0 produto $P$, formado por $p_{0}, p_{1}, \ldots, p_{2 N-1}$, a multiplicação $P=A B$, para operandos inteiros e sem sinal, é realizada da mesma forma como se faria com lápis e papel. Na Figura 3.13, é ilustrado um caso para $N=4$. O produto $P$ é obtido a partir da soma dos produtos parciais, que são gerados pela multiplicação de cada bit $b_{i}$ do multiplicador pelo multiplicando, $A$.

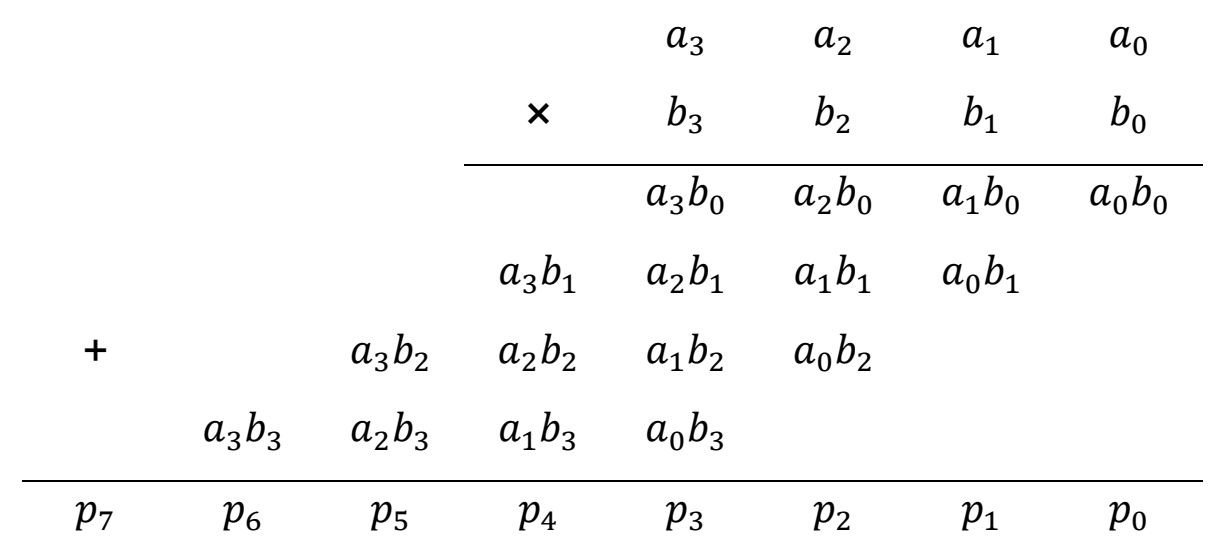

Figura 3.13: Multiplicação de dois números de 4 bits.

Os produtos entre dois bits são realizados através de portas lógicas AND. A soma destes produtos, no caso do multiplicador de Braun, é realizada através de um conjunto de $(N-1) \times N$ somadores completos arranjados de forma matricial, na qual as linhas, exceto a última, formam uma estrutura de somador chamada de Carry Save Adder. 
Nesta estrutura os carries gerados não são propagados para os bits mais significativos da mesma linha, mas sim para os bits dos somadores da linha seguinte. Dessa forma, todas as somas de uma mesma linha são realizadas simultaneamente. O multiplicador de Braun de 4 bits pode ser visto na Figura 3.14.

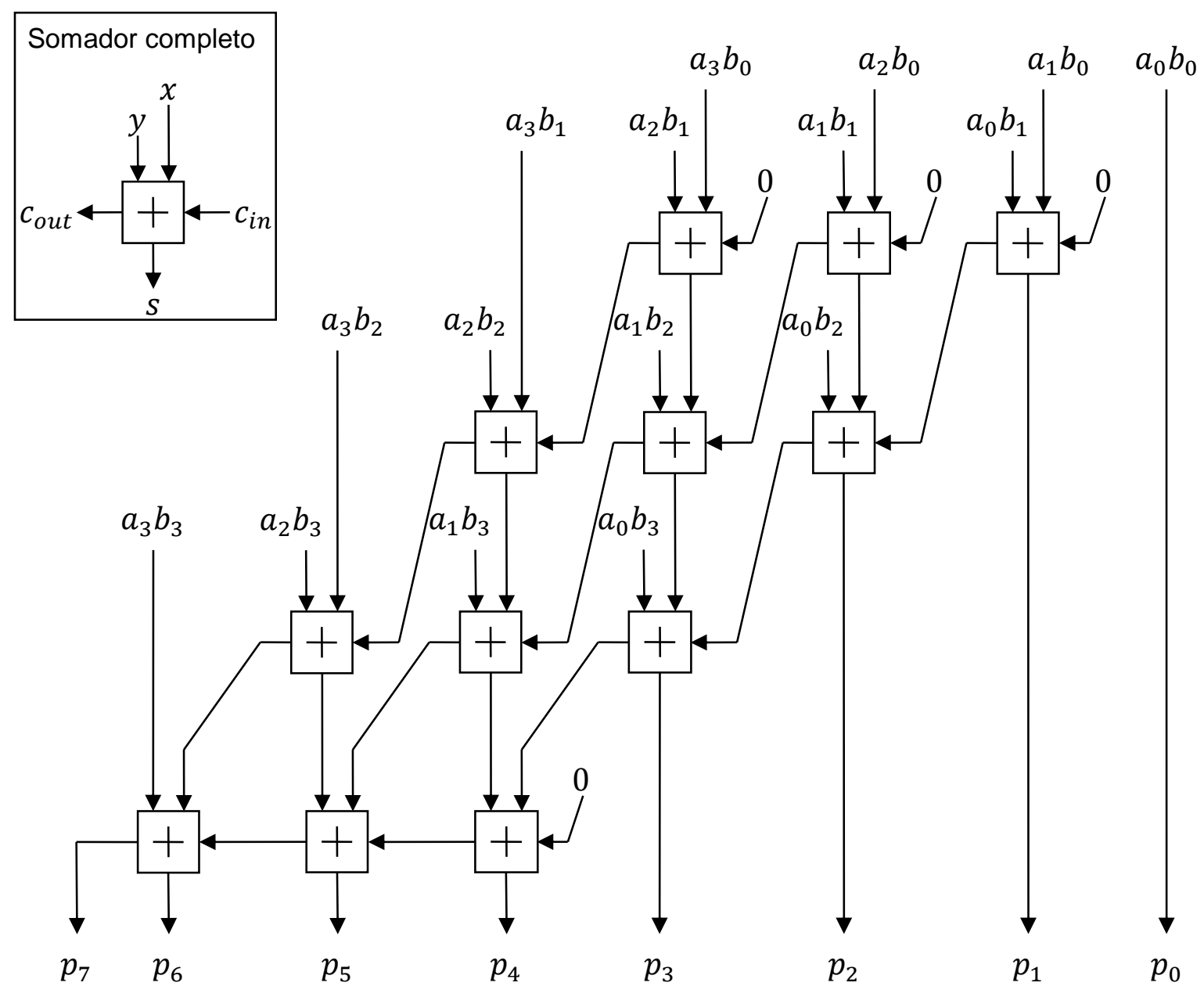

Figura 3.14: Multiplicador de Braun.

No caso da primeira linha, os somadores completos podem ser substituídos por meio somadores, uma vez que não há uma linha anterior para propagar carries. No caso da última linha, os somadores estão arranjados na forma de um RippleCarry Adder, porém outros tipos de somadores podem ser empregados, como 0 Carry-Lookahead Adder.

No caso da multiplicação de números binários, o produto parcial da linha $j$, que é o produto do multiplicando pelo bit $b_{j}$ do multiplicador, é igual a zero quando $b_{j}=0$ e igual ao multiplicando quando $b_{j}=1$. 
Uma das possíveis otimizações do multiplicador de Braun, chamada de row bypassing (OHBAN; MOSHNYAGA; INOUE, 2002), consiste em não efetuar as somas de uma linha $j$ quando o produto parcial for zero $\left(b_{j}=0\right)$. Isto pode ser feito inserindo multiplexadores ao final de cada linha, selecionando o resultado dos somadores ou o resultado da linha anterior, em função de $b_{j}$. Os somadores também podem ser temporariamente desabilitados para reduzir a potência dissipada pelo multiplicador.

Uma otimização análoga, chamada de column bypassing (WEN; WANG; LIN, 2005), pode ser realizada não efetuando as somas da coluna $i$ quando $a_{i}=0$. Ambas as otimizações podem ser usadas simultaneamente, reduzindo a potência dissipada pelo circuito e até mesmo o número de transistores, através de simplificações do circuito em nível de portas lógicas (YAN; CHEN, 2009), (YAN; CHEN, 2010).

O multiplicador apresentado somente opera com números sem sinal. Para executar multiplicações de números com sinal, algumas modificações precisam ser introduzidas, como, por exemplo, as descritas na Seção 3.3.3.

\subsubsection{Multiplicadores de Wallace e de Dadda}

O atraso total do multiplicador paralelo de Braun é limitado, principalmente, pelo tempo da soma de todos os produtos parciais. Nesse multiplicador, as somas são realizadas de forma sequencial e, portanto, o atraso cresce linearmente em função do número de bits dos operandos.

Em 1964, Wallace (1964) propôs um método para acelerar a soma dos produtos parciais somando-os de três em três e de forma paralela. No ano seguinte, Dadda (1965) apresentou outros arranjos para soma paralela de todos os produtos parciais usando um número menor de componentes.

A ideia de ambos é, ao invés de somar todos os produtos parciais, utilizar um circuito que reduza o número de produtos parciais a apenas dois, que, então, seriam somados por um somador comum. A redução do número de produtos parciais é realizada em vários estágios, nos quais os bits atravessam blocos redutores que efetuam a soma de $n$ bits resultando em um número binário de $m$ bits $\left(n<2^{m}\right)$. 
No caso do multiplicador proposto por Wallace, os blocos usados eram somadores completos, que somam três entradas independentes $(n=3)$ produzindo um número de 2 bits $(m=2)$, e meio somadores que somam duas entradas e produzem, também, números de 2 bits $(n=2, m=2)$.

A regra geral para redução do número de produtos parciais em um estágio é somar os bits de uma determinada coluna de três em três, ou de dois, se houver apenas dois números restantes. Os bits mais significativos dos resultados das somas são transferidos para o próximo estágio na coluna seguinte. Os bits menos significativos, bem como qualquer bit não somado, são transferidos para o próximo estágio na mesma coluna. A regra é ilustrada na Figura 3.15 para um multiplicador de 4 bits.

$$
\begin{aligned}
& a_{3} b_{0} \quad a_{2} b_{0} \quad a_{1} b_{0} \quad a_{0} b_{0} \\
& a_{3} b_{1} \quad a_{2} b_{1} \quad a_{1} b_{1} \quad a_{0} b_{1} \\
& a_{3} b_{2} \quad a_{2} b_{2} \quad a_{1} b_{2} \quad a_{0} b_{2} \\
& a_{3} b_{3} \quad a_{2} b_{3} \quad a_{1} b_{3} \quad a_{0} b_{3}
\end{aligned}
$$
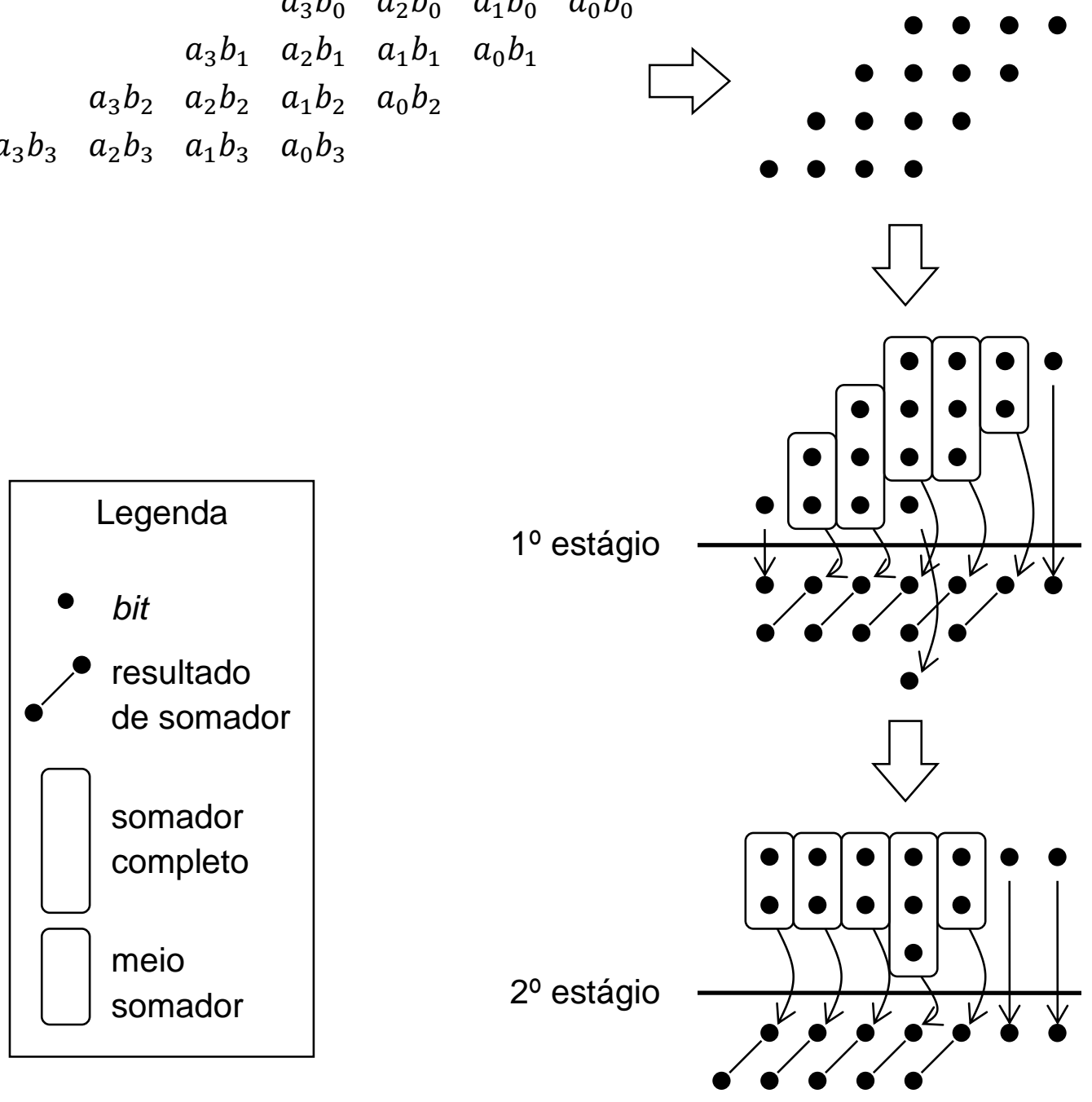

Figura 3.15: Multiplicador de Wallace de 4 bits. 
Dadda usa uma regra semelhante, mas que busca minimizar o número de componentes usados pelo circuito. Além disso, a regra que ele desenvolveu se aplica a quaisquer valores de $n$ e $m$ dos blocos redutores, não somente a somadores completos ou meio somadores.

$\mathrm{Na}$ regra de Dadda, as colunas são reduzidas parcialmente, até que se alcance o número ideal de linhas para o próximo estágio, diferentemente da abordagem anterior, em que cada coluna é reduzida ao máximo.

O número ideal de linhas pode ser obtido partindo do último estágio, onde se sabe que deve haver duas linhas, e aplicando a transformação inversa dos blocos redutores para encontrar o número de linhas dos estágios anteriores. Para isso, precisam-se escolher inicialmente quais blocos serão usados para redução das linhas.

Abaixo estão as sequências de números ideais de linhas (do último estágio para o primeiro) considerando alguns tipos de blocos redutores de $n$ bits para $m$ bits, representados na forma $(n \rightarrow m)$ :

- Blocos $(3 \rightarrow 2)$ e $(2 \rightarrow 2)$ :

$2,3,6,9,13,19,28,42,63, \ldots$

- Blocos $(7 \rightarrow 3),(3 \rightarrow 2)$ e $(2 \rightarrow 2)$ :

$2,3,7,15,35,79, \ldots$

- Blocos $(15 \rightarrow 4),(7 \rightarrow 3),(3 \rightarrow 2)$ e $(2 \rightarrow 2)$ :

$2,3,7,21,61,226, \ldots$

Portanto, para um somador de 48 bits usando a regra de Dadda para redução dos produtos parciais, seriam necessários 8 estágios caso fossem usados somente somadores completos e meio somadores, isto é, blocos $(3 \rightarrow 2)$ e $(2 \rightarrow 2)$. No primeiro estágio, é feita a redução de 48 para 42 linhas. Os sete estágios seguintes reduzem as linhas, de 42 até 2 , conforme a sequência apresentada acima. Caso fossem usados, também, blocos $(7 \rightarrow 3)$, seriam necessários 5 estágios. E caso fossem usados blocos $(15 \rightarrow 4)$, seriam somente 4 estágios. 


\subsubsection{Multiplicação de números com sinal}

No caso de números codificados na forma sinal-magnitude, a multiplicação é bastante simples, uma vez que o sinal pode ser tratado de forma independente e um circuito multiplicador comum pode ser usado para multiplicação da magnitude dos números.

Nos números em complemento de dois, entretanto, o sinal está embutido no valor do número e não pode ser tratado separadamente. Para resolver o problema da multiplicação de números com sinal nesse caso, há duas abordagens comuns:

- Adicionar circuitos antes e/ou depois de um circuito de multiplicação de números sem sinal para alterar/corrigir operandos e produto;

- Alterar o circuito de multiplicação para considerar o sinal dos números.

Um dos trabalhos pioneiros sobre esse problema é o de Booth (1951), no qual foram apresentadas duas formas de realizar a multiplicação com sinal para operandos codificados em complemento de dois.

Na primeira forma, foi usada a primeira abordagem, corrigindo o produto após a multiplicação sem sinal. Quando um número negativo é aplicado a um multiplicador que não considera o sinal dos números, este é expandido para $2 \mathrm{~N}$ bits, sendo que os bits adicionais são incorretamente considerados como zero. Desta forma, um número negativo $x$ de $N$ bits será transformado em $2^{N}-|x|$, com $2 N$ bits.

Assim, a multiplicação de dois números com sinal pode resultar em quatro casos diferentes, como indicado na Tabela 3.4. Nela, $A$ e $B$ representam o valor dos operandos, codificados em complemento de dois com $N$ bits. $O$ produto é formado por $2 N$ bits.

Tabela 3.4: Casos resultantes da multiplicação de números negativos em multiplicadores que não consideram o sinal dos números.

\begin{tabular}{cccc}
\hline Caso & Condição & Resultado de $A \times B$ em multiplicador sem sinal & Desejado \\
\hline 1 & $A>0$ & $A B$ & $+A B$ \\
& $B>0$ & & $-|A| B$ \\
2 & $A<0$ & $\left(2^{N}-|A|\right) B=2^{N} B-|A| B$ & $-A|B|$ \\
& $B>0$ & & \\
3 & $A>0$ & $A\left(2^{N}-|B|\right)=2^{N} A-A|B|$ & \\
& $B<0$ & & \\
4 & $B<0$ & $\left(2^{N}-|A|\right)\left(2^{N}-|B|\right)=2^{2 N}-2^{N}|A|-2^{N}|B|+|A||B|$ & $+|A||B|$ \\
\hline
\end{tabular}


Observa-se que nem todos os resultados são como desejados, mas é possível corrigi-los. Além disso, deve-se lembrar de que, em complemento de dois, o resultado de subtrações é sempre correto, mesmo quando for negativo.

O caso 1 já está correto. Os casos 2, 3 e 4 podem ser corrigidos segundo as seguintes regras:

- Se o primeiro operando, $A$, é negativo, subtrai-se $2^{N} B$ do produto obtido.

- Se o segundo operando, $B$, é negativo, subtrai-se $2^{N} A$ do produto obtido.

Pode-se verificar facilmente pela Tabela 3.4 que os casos 2 e 3 são corrigidos aplicando-se as regras acima. $O$ caso 4 também é corrigido, pois $A$ e $B$ negativos, quando multiplicados por $2^{N}$, geram termos que, com a subtração, cancelarão $-2^{N}|A|$ e $-2^{N}|B|$ e o termo $2^{2 N}$ não aparecerá no produto final, que tem somente $2 N$ bits.

Os produtos $2^{N} A$ e $2^{N} B$ são obtidos pelo deslocamento aritmético de $A$ e $B$ para a esquerda de $N$ bits.

$\mathrm{Na}$ segunda forma, Booth usa a abordagem que altera o circuito multiplicador. $\mathrm{O}$ algoritmo desenvolvido por ele executa os seguintes passos, considerando os operandos $A$ e $B$ com $N$ bits cada e $b_{-1}=0$ :

1. $P \leftarrow 0$;

2. Para $i$ de 0 a $N-1$, faça:

a. Se $b_{i}=0$ e $b_{i-1}=1$, some $2^{N} A$ ao produto $\left(P \leftarrow P+2^{N} A\right)$;

b. Se $b_{i}=1$ e $b_{i-1}=0$, subtraia $2^{N} A$ do produto $\left(P \leftarrow P-2^{N} A\right)$;

c. Desloque o produto um bit à direita $(P \leftarrow P \gg 1)$;

Para o correto funcionamento do algoritmo, o produto deve ser implementado com $2 N+1$ bits, isto é, com um bit extra à esquerda, que deve ser descartado ao final da multiplicação.

Há variações desse algoritmo, no qual são consultados mais bits por iteração. Essas variações permitem a implementação de multiplicadores que executam a multiplicação com menor número de somas ou subtrações de produtos parciais. Por exemplo, na chamada codificação de Booth em base 4, são observados três bits por iteração e o número de somas parciais é reduzido à metade. 
Este algoritmo, apesar de ter sido apresentado desta forma sequencial, é também utilizado na implementação de multiplicadores paralelos.

Baugh e Wooley (1973) propuseram modificações na estrutura do multiplicador paralelo de Braun, para que ele realize a multiplicação de números em complemento de dois. Uma solução mais eficiente, baseada nesse trabalho, é apresentada por Das e Rahaman (2010).

\subsection{Operações de ponto-flutuante}

A representação de números em ponto-flutuante permite codificar um subconjunto finito dos números reais. Uma ULA que somente realiza operações com números em ponto flutuante ou a parte de uma ULA dedicada a essas operações é comumente chamada de unidade de ponto-flutuante (UPF).

Há diferentes representações possíveis para ponto-flutuante. O padrão IEEE 754 (INSTITUTE OF ELECTRICAL AND ELECTRONICS ENGINEERS, 2008) define várias codificações para números em ponto-flutuante e é amplamente empregado pelas UPFs.

Neste padrão, são definidos 5 formatos básicos:

- Três formatos binários, com tamanhos de 32, 64 e 128 bits;

- Dois formatos decimais, com tamanhos de 64 e 128 bits.

Um determinado formato de ponto-flutuante é especificado pelos seguintes parâmetros:

- $\quad b$ : base (2 ou 10$)$;

- $\quad p$ : precisão (número de digitos da magnitude);

- $e_{\max }$ : máximo expoente;

- $e_{\min }$ : mínimo expoente $\left(e_{\min }=1-e_{\max }\right)$;

As classes de números em ponto-flutuante são:

- Zero com sinal e números diferentes de zero, representados na forma $(-1)^{s} \times m \times b^{e}$, em que:

- $s$ é 0 (sinal positivo) ou 1 (sinal negativo);

○ e é um inteiro (expoente); 
- $m$ é um número (magnitude) no intervalo $0 \leq m<b$ representado em ponto fixo pelos dígitos $d_{0} . d_{1} d_{2} \ldots d_{p-1}$.

- Infinitos com sinal $(+\infty$ e $-\infty)$;

- Dois NaN (not-a-number): qNaN (quiet $\mathrm{NaN}$ ) e sNaN (signaling $\mathrm{NaN}$ ).

O padrão também especifica como esses números são codificados, para permitir a troca de dados entre diferentes implementações, e quais são as operações obrigatórias que uma UPF deve suportar.

As operações aritméticas de ponto-flutuante são implementadas usando os mesmos blocos básicos de uma ULA de números inteiros, como somadores e multiplicadores.

Por exemplo, a multiplicação de dois números de ponto flutuante envolve a multiplicação sem sinal da magnitude de ambos operandos, a soma de seus expoentes e uma operação lógica de ou-exclusivo entre os sinais. O resultado da multiplicação deve ainda ser deslocado para ajustar-se à melhor representação em ponto-flutuante do número.

Dentre as diversas arquiteturas de unidades de ponto-flutuante, destaca-se uma conhecida como Fused Multiply-Add (FMA), que realiza a operação $A \times B+C$. Além dessa operação, as operações básicas de ponto-flutuante, soma e multiplicação, podem ser obtidas no FMA, respectivamente, usando-se $B=1 \mathrm{e}$ $C=0$. A Figura 3.16 apresenta um diagrama de blocos para um FMA convencional (QUINNELL, 2007).

As magnitudes dos operandos $A$ e $B$ são multiplicadas para se obter um resultado no formato carry-save, isto é, não é realizada a soma final do multiplicador e o produto é representado por um número com dois bits para cada dígito. $\mathrm{O}$ operando $C$ é deslocado, em paralelo, é deslocado para ser alinhado ao resultado da multiplicação e, se necessário, tem seus bits invertidos. Esse operando, já alinhado, é parcialmente somado ao produto, em um somador do tipo carry-save adder 3:2, que produz como resultado uma soma intermediária no mesmo formato do produto.

Essa soma intermediária é finalizada através de um somador típico, que realiza a propagação do carry, e, caso o resultado seja negativo, a soma é invertida e o sinal é ajustado. O resultado da soma intermediária é aplicado como entrada de um bloco LZA (leading-zero antecipator), que calcula a posição onde ficará o bit mais significativo do resultado. A saída do LZA é utilizada para normalização da 
soma e, após a normalização, é feito um ajuste no expoente, para refletir essa normalização. Por fim, o resultado é arredondado e, caso seja necessário, é novamente normalizado.

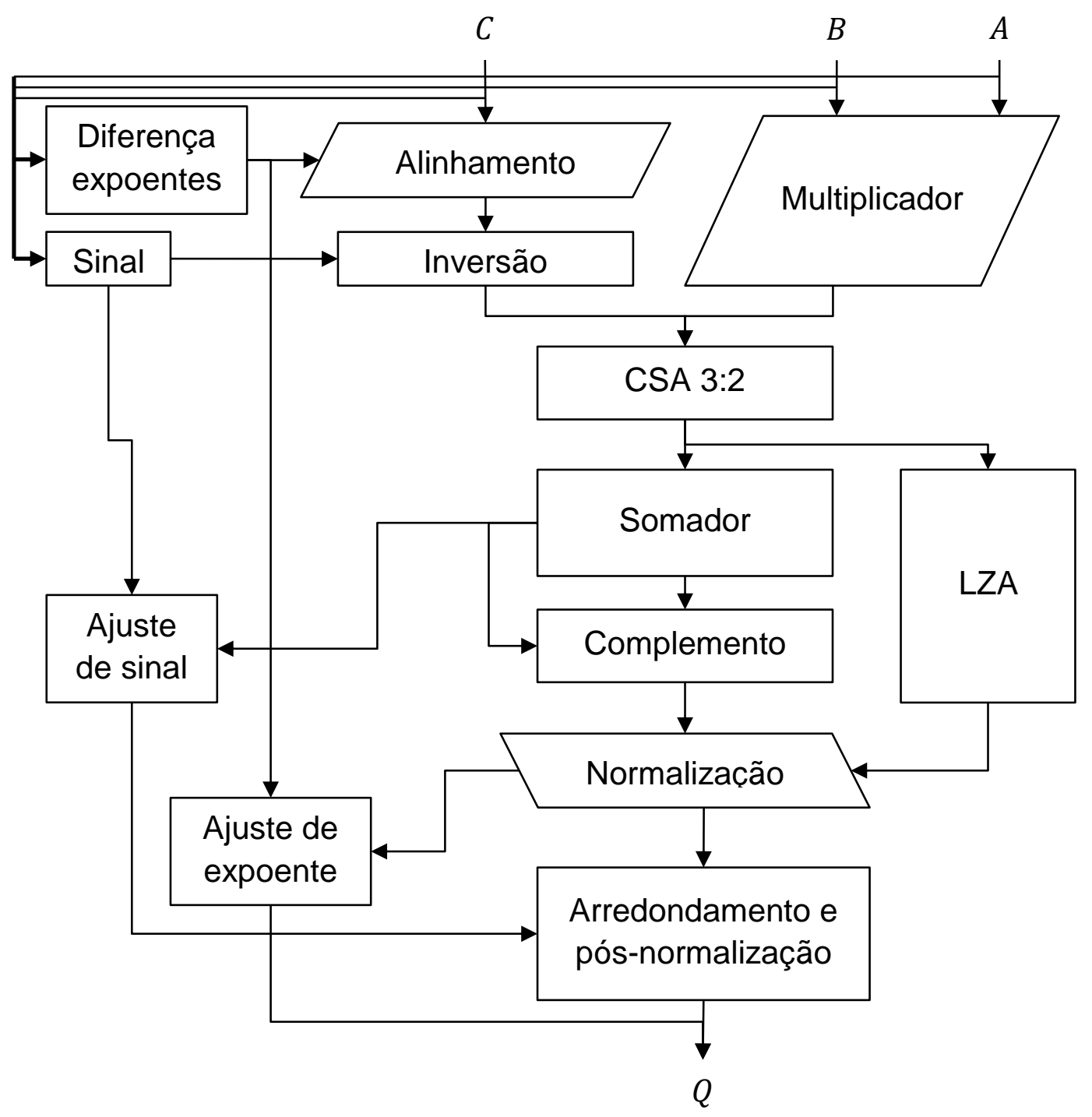

Figura 3.16: Diagrama de blocos de uma UPF do tipo FMA convencional.

Esta arquitetura, apesar de ocupar uma área relativamente pequena, possui um atraso grande (LANG; BRUGUERA, 2004). Há várias arquiteturas na literatura baseadas no FMA, mas com menores atraso e consumo. Dentre elas, pode-se citar a arquitetura apresentada por Qi et al. (2010), na qual são construídos dois caminhos paralelos, um dedicado a operações com operandos próximos e outro para operandos distantes. Todos os somadores e deslocadores e o multiplicador são projetados em duas partes independentes, de modo que se pode realizar uma única operação de precisão dupla ou duas operações de precisão simples em paralelo. 


\subsection{Organização de uma ULA}

A forma como os blocos funcionais de uma ULA são organizados e como a operação é selecionada afetam diretamente o desempenho e o consumo da unidade. A organização mais simples de uma ULA é a distribuição dos operandos através de todas as operações e a seleção do resultado desejado por um ou mais multiplexadores, como representado na Figura 3.17.

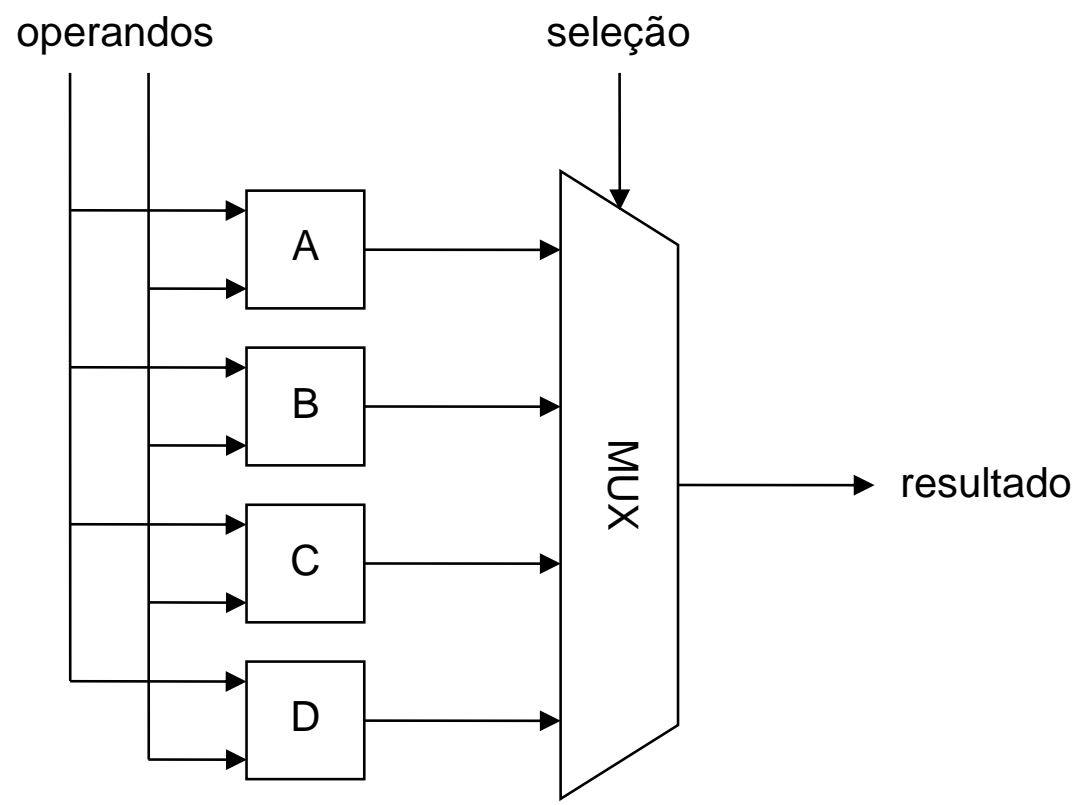

Figura 3.17: Organização básica de uma ULA.

Na Figura 3.17, os blocos A, B, C e D representam as diferentes operações que essa ULA executa.

O bloco MUX multiplexa o resultado de cada operação. Este bloco pode ser implementado através de um único multiplexador com uma entrada para cada operação da ULA ou através de um arranjo de vários multiplexadores mais simples. Os arranjos típicos, nesse caso, são em árvore (Figura 3.18) ou em cadeia (Figura 3.19). 


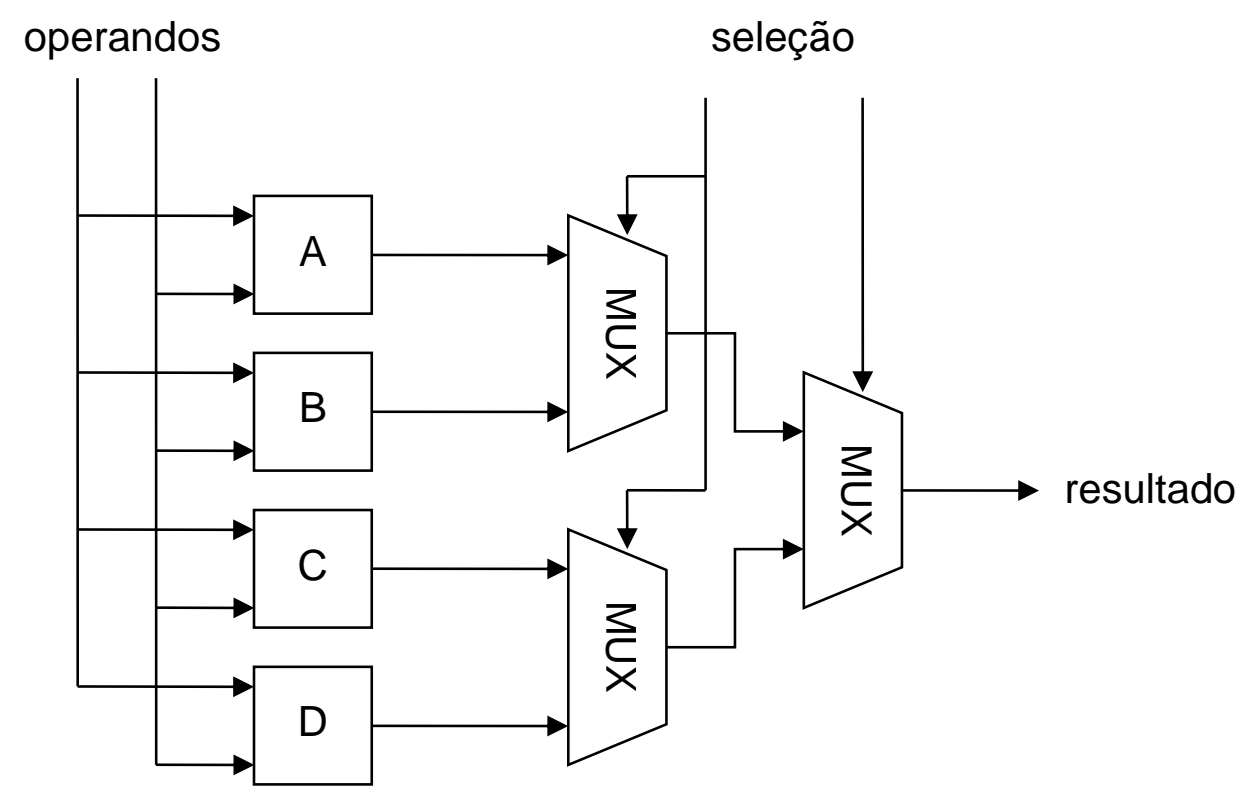

Figura 3.18: ULA com multiplexadores em árvore.

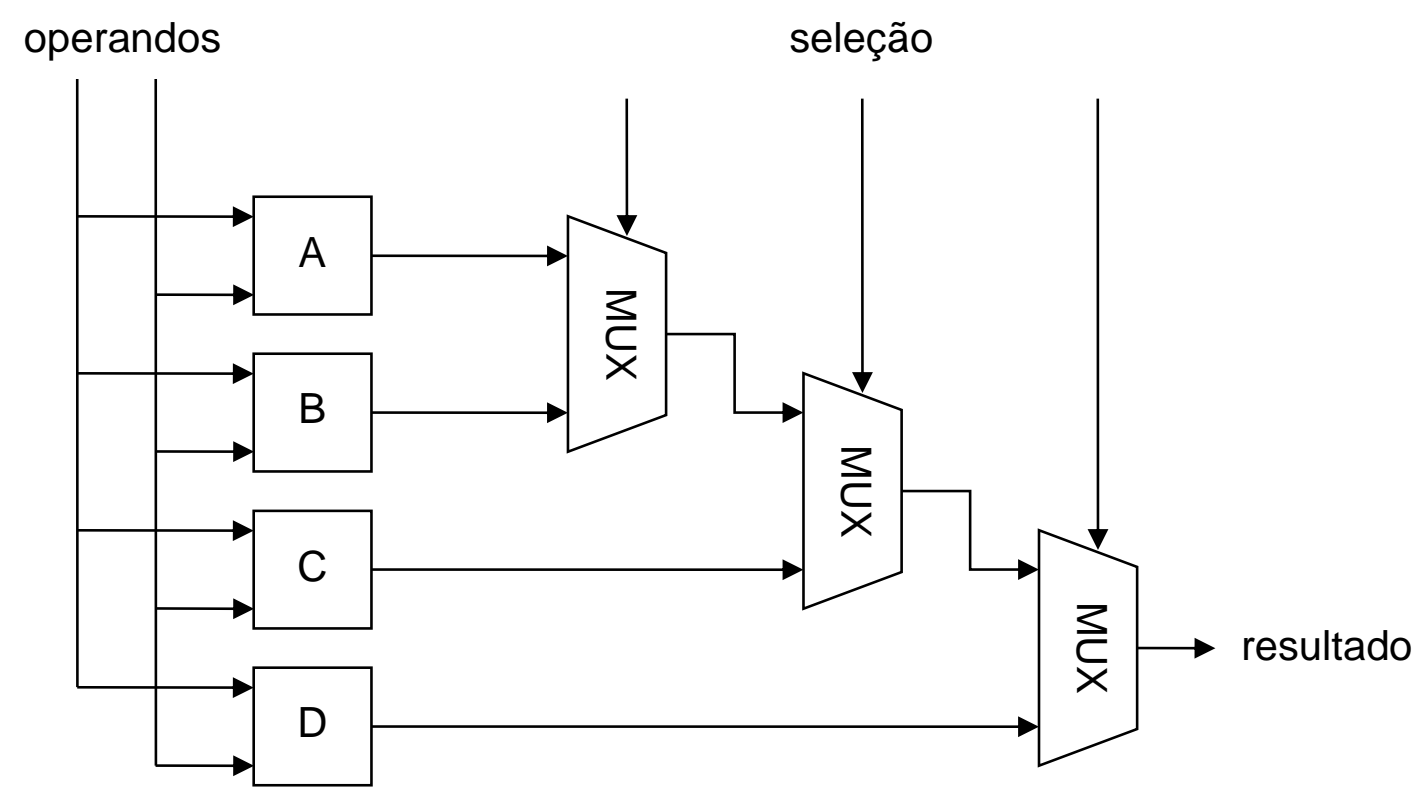

Figura 3.19: ULA com multiplexadores em cadeia.

Em processadores modernos, em que as instruções estão divididas em vários estágios de um pipeline, a ULA geralmente não é o estágio de maior atraso, como é o caso do processador projetado por Zhou e Guo (2008). Assim, nestes processadores, é vantajosa a utilização de multiplexadores menores para economia de área. Além disso, estes autores mostram que a estrutura em cadeia, apesar de ter maior atraso, pode ser usada para redução de consumo de potência em 
processadores de aplicação específica através da ordenação das operações colocadas na cadeia de multiplexadores.

Outra abordagem de organização de ULA é o uso de extensores lógicos (EL) e extensores aritméticos (EA) precedendo um único somador, como na Figura 3.20. Dessa forma, não há necessidade de multiplexação do resultado, pois os extensores transformam os operandos de modo que a soma seja o resultado desejado.

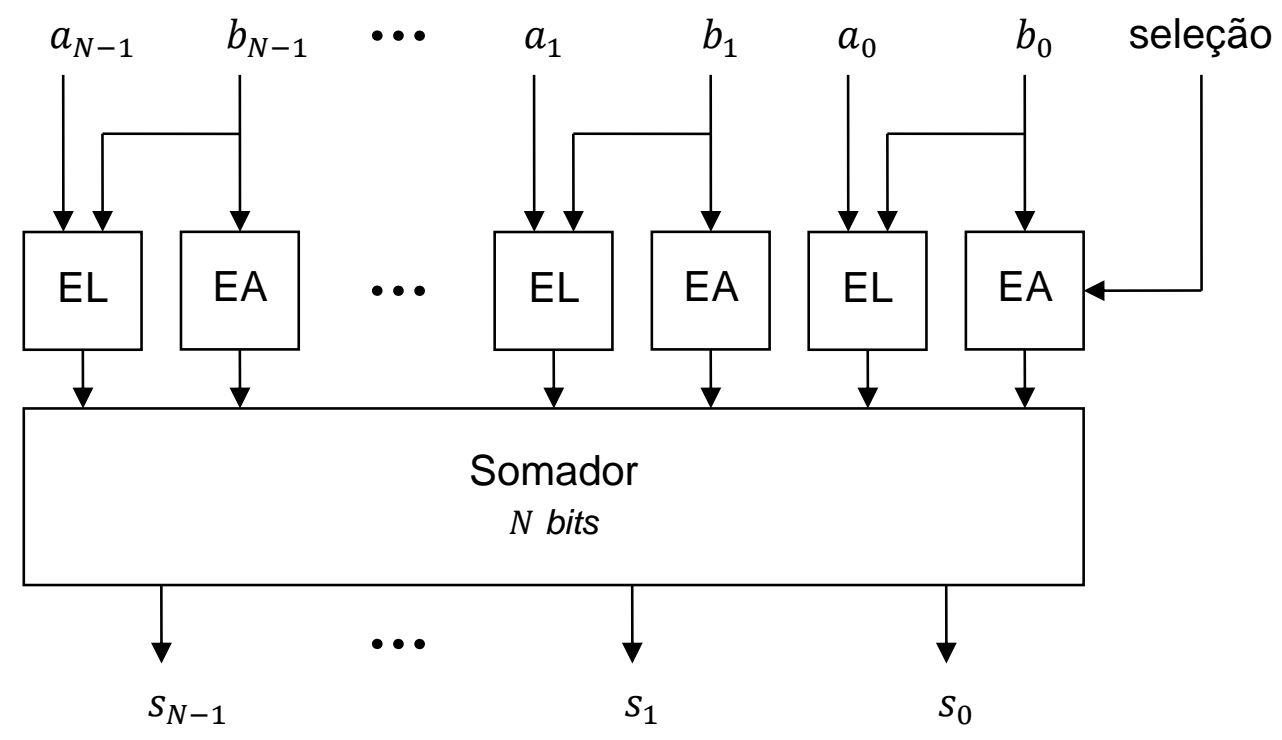

Figura 3.20: ULA com extensores lógicos e aritméticos precedendo um somador.

As portas lógicas XOR do somador/subtrator da Figura 3.9 são um exemplo de EA simples para que as operações de subtração possam ser executadas através de um somador.

Essa abordagem, entretanto, não é muito adequada para a realização de operações lógicas bit-a-bit. O EL geralmente é projetado para que, nestas operações, um dos operandos seja o valor final da operação lógica e o outro operando seja zero. Assim, há atividade desnecessária no somador, aumentando o consumo da ULA. Uma abordagem híbrida mais adequada é separar as operações lógicas das aritméticas por multiplexação.

A organização de uma ULA pode se tornar consideravelmente complexa conforme as operações que ela é capaz de executar. Por exemplo, em ULAs que executam multiplicação, pode ser desejável que a saída do multiplicador seja direcionada para a entrada do somador, ao invés de diretamente para os resultados, para permitir a execução de instruções multiplicar-e-acumular em um único passo. 
De forma semelhante, em uma ULA que não possua multiplicador, as operações de deslocamento e soma podem ser organizadas em série, para melhorar o desempenho da multiplicação quando implementada em microcódigo ou software.

Outra consideração importante sobre a organização da ULA é o uso de uma arquitetura baseada em pipeline. Um pipeline, como já dito, divide o fluxo de dados em diversos estágios de processamento a fim de executar as operações nestes estágios em paralelo. No caso de ULAs mais complexas, em que o tempo de execução de uma operação é consideravelmente superior ao tempo de acesso aos registradores, por exemplo, o uso de pipeline seria adequado para permitir que múltiplas instruções sejam executadas simultaneamente em diferentes estágios da ULA. 


\section{Projeto da ULA}

Durante o desenvolvimento deste trabalho, uma ULA de números inteiros de 16 bits em complemento de dois foi projetada na tecnologia CMOS de sinal misto de $0,35 \mu \mathrm{m}$ com quatro camadas de metal da AMS, denominada C35B4C3 (AUSTRIAMICROSYSTEMS, 2013).

O projeto da ULA foi realizado, em sua maior parte, com células padrão e lógica CMOS estática. Dentre as poucas exceções, nas quais foi feito um desenho full custom, está o multiplexador de saída. Há, também, casos em que foi utilizada outra lógica, como os latches, que utilizam portas de passagem para aumentar o desempenho do circuito. O projeto do circuito foi feito diretamente no nível de portas lógicas ou, no caso das células full custom, em nível de transistores, ambos na forma de esquemáticos. Seguiu-se uma abordagem bottom-up, na qual são projetados inicialmente os blocos mais simples e básicos e, então, os blocos maiores que eles compõem.

Os tipos de operações que a ULA realiza, bem como o tamanho dos operandos, foram definidos de forma que se pudessem exercitar algumas das principais técnicas de redução de consumo em um circuito digital suficientemente complexo, mas que ainda pudesse ser realizado de forma viável em nível de portas lógicas com as ferramentas disponíveis.

Outro projeto de ULA, com mesmas interfaces e operações, foi especificado de forma comportamental em VHDL (APÊNDICE A) e sintetizado de forma automática, seguindo um processo típico de projeto de ASICs, no qual o sistema é inicialmente projetado em uma linguagem em alto nível, verificado através de simulações lógicas, mapeado automaticamente em uma biblioteca de células, e, então, estas células são posicionadas e roteadas para formar o layout do circuito. Este outro projeto serve como referência para comparação de parâmetros de desempenho (potência, velocidade e área) entre o circuito projetado e outro circuito equivalente, porém projetado sem utilizar quaisquer técnicas de redução de consumo.

Deve-se notar que esta comparação não indica qual a melhor forma de projeto de circuitos de baixo consumo, uma vez que é possível a aplicação de diversas otimizações em um projeto especificado em alto nível, inclusive otimizações 
em nível de transistores, se estas estiverem incorporadas à biblioteca de células utilizada pelo sintetizador. O projeto diretamente na forma de esquemáticos, entretanto, permite um maior entendimento de como as técnicas de redução de consumo são aplicadas a um circuito lógico e de que forma elas influenciam o circuito completo. Por isso, ela foi escolhida para o desenvolvimento deste projeto.

\subsection{Interface e operações}

A interface da ULA projetada consiste dos sinais de entrada de seleção da operação, de operandos, de carry-in e de clock, e dos sinais de saída de resultado e de carry-out, conforme a Tabela 4.1.

Tabela 4.1: Interface da ULA.

\begin{tabular}{ccll}
\hline Sinal & Tamanho & Direção & \multicolumn{1}{c}{ Descrição } \\
\hline$S$ & 5 & Entrada & Seleção da operação \\
$c l k$ & 1 & Entrada & Clock \\
$A$ & 16 & Entrada & Primeiro operando \\
$B$ & 16 & Entrada & Segundo operando \\
$c_{\text {in }}$ & 1 & Entrada & Carry-in \\
$Q$ & 16 & Saída & Resultado \\
$c_{\text {out }}$ & 1 & Saída & Carry-out \\
\hline
\end{tabular}

As operações realizadas pela ULA estão classificadas, por similaridade, em três grupos: operações lógicas bit-a-bit, operações de deslocamento e rotação e operações aritméticas. Dos cinco bits de seleção de operação, os dois mais significativos determinam o grupo de operações e os três restantes, a operação dentro do grupo.

As operações estão listadas na Tabela 4.2. 
Tabela 4.2: Operações da ULA.

\begin{tabular}{|c|c|c|c|c|}
\hline Tipo & Operação & $Q$ & $C_{\text {out }}$ & $S_{4 . .0}$ \\
\hline \multirow{8}{*}{ 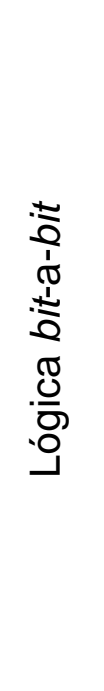 } & Identidade & $A$ & * & 00000 \\
\hline & Complemento & $\bar{A}$ & * & 00001 \\
\hline & Não-e & $\overline{A \cdot B}$ & * & 00010 \\
\hline & $E$ & $A \cdot B$ & * & 00011 \\
\hline & Não-ou & $\overline{A+B}$ & * & 00100 \\
\hline & $\mathrm{Ou}$ & $A+B$ & * & 00101 \\
\hline & Ou-exclusivo & $A \oplus B$ & * & 00110 \\
\hline & Não-ou-exclusivo & $\overline{A \oplus B}$ & * & 00111 \\
\hline \multirow{5}{*}{ 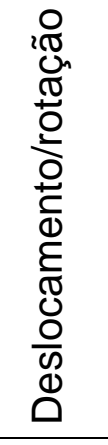 } & Deslocamento lógico para a direita & $* *$ & * & 01000 \\
\hline & Deslocamento aritmético para a direita & ** & * & 01001 \\
\hline & Rotação para a direita & ** & * & $0101 X$ \\
\hline & Rotação para a esquerda & ** & * & $0110 x$ \\
\hline & Deslocamento para a esquerda & ** & * & $0111 X$ \\
\hline \multirow{9}{*}{ 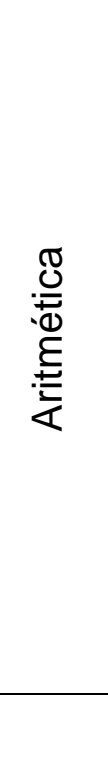 } & Incremento & $A+1$ & carry & 10000 \\
\hline & Decremento & $A-1$ & $\overline{\text { borrow }}$ & 10001 \\
\hline & Adição do carry & $A+c_{i n}$ & carry & 10010 \\
\hline & Subtração do borrow & $A-\overline{C_{l n}}$ & $\overline{\text { borrow }}$ & 10011 \\
\hline & Adição & $A+B$ & carry & 10100 \\
\hline & Subtração & $A-B$ & $\overline{\text { borrow }}$ & 10101 \\
\hline & Adição com carry & $A+B+c_{i n}$ & carry & 10110 \\
\hline & Subtração com borrow & $A-B-\overline{C_{l n}}$ & $\overline{\text { borrow }}$ & 10111 \\
\hline & Nenhuma operação & * & * & $11 X X X$ \\
\hline
\end{tabular}


Os operandos, para o caso das operações aritméticas que envolvem subtração e operações de deslocamento aritmético, devem estar representados em complemento de dois.

A indicação de $\overline{\text { borrow }}$ como carry-out das subtrações significa que a saída da ULA é o próprio carry-out do somador, não sendo invertido para a subtração. Por esse motivo, nas operações de subtração com borrow, o valor subtraído é o complementar do carry-in, permitindo a propagação do borrow entre subtrações se o valor do carry-out da primeira subtração é diretamente utilizado como carry-in na segunda.

Estas operações permitem também realizar a comparação de números. Por exemplo, para verificar se $A=0$, realiza-se uma operação de decremento e verifica se o carry-out, que será igual a zero se, e somente se, a igualdade for verdadeira. Para verificar se $A$ é positivo ou negativo, no caso da codificação em complemento de dois, verifica-se o bit mais significativo de $A$. Associando-se esses dois testes, pode-se obter qualquer tipo de comparação de $A$ com zero. Para comparar $A \operatorname{com} B$, basta realizar, antes, $A-B$ e realizar a comparação desejada sobre o resultado.

Operações mais complexas, como multiplicação, divisão e raiz quadrada, podem ser realizadas, de forma sequencial, pela ULA combinando-se as operações lógicas e aritméticas disponíveis. Lembremos que as operações de deslocamento equivalem a multiplicar ou dividir $A$ por $2^{B}$.

\subsection{Organização interna}

Cada grupo de operações da ULA é implementado em um bloco funcional dedicado a estas operações e o resultado delas é multiplexado no barramento de saída.

Para reduzir o consumo de potência, no máximo um bloco está ativo por operação. Este controle é realizado através de latches aplicados a cada sinal de entrada destes blocos. O papel dos latches é manter, nas entradas dos blocos, os sinais de entrada da última operação realizada pelo bloco, evitando o consumo de potência dinâmica quando o bloco não está em operação. 
A multiplexação dos resultados de cada bloco é realizada por dois multiplexadores 2:1 em cadeia. O primeiro multiplexador unifica os resultados dos dois blocos mais rápidos, o de lógica bit-a-bit e o de deslocamento e rotação. 0 segundo unifica o resultado do primeiro multiplexador com o resultado do bloco mais lento, o aritmético.

Esta organização está representada na Figura 4.1.

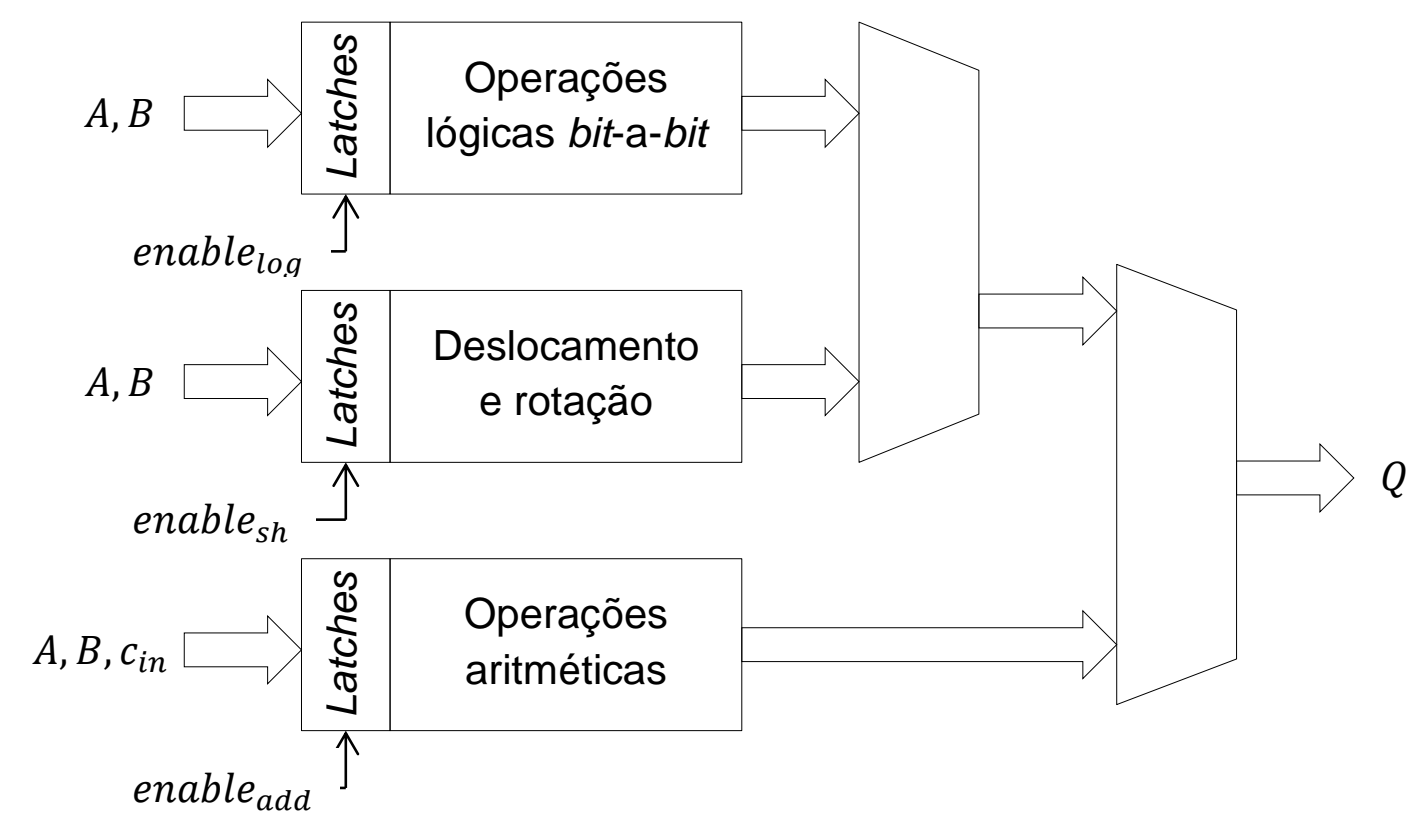

Figura 4.1: Organização da ULA.

Os sinais de controle da ULA são responsáveis por selecionar, através dos latches, o bloco de operações que irá operar e por controlar os multiplexadores para encaminhar o resultado deste bloco à saída da ULA. Para isso, são usados os dois bits mais significativos de $S$ e o sinal de clock.

O clock, no caso desta ULA tem uma função ligeiramente diferente da convencional, uma vez que a ULA é, desconsiderando os latches para economia de potência, um circuito combinacional. Idealmente, o sinal de clock não é necessário, pois a habilitação dos latches é realizada pela seleção da operação. Entretanto, durante a transição entre uma operação em um bloco e a operação em outro bloco, os dois blocos estão parcialmente habilitados, causando a execução da operação em ambos. Combinando o sinal de habilitação de cada bloco com o sinal de clock, tem-se uma solução simples para este problema. 


\subsection{Operações lógicas bit-a-bit}

O bloco de operações lógicas bit-a-bit consiste uma parte comum de controle e um conjunto de 16 blocos de operações lógicas, um para cada bit, que realizam as oito operações lógicas disponíveis.

As oito operações são, na verdade, quatro operações (identidade, não-e, nãoou e ou-exclusivo) e seus complementos (complemento, e, ou, não-ou-exclusivo). Assim, há duas opções para implementação dessas operações:

- Com oito portas lógicas em paralelo multiplexadas.

- Com quatro portas lógicas em paralelo multiplexadas e a saída do multiplexador podendo ser invertida, se necessário.

Para a implementação da primeira opção de forma eficiente, é necessário um multiplexador de 8:1 ou combinação de multiplexadores menores. Além disso, para se obter as funções lógicas E ou OU em CMOS, é necessário inverter a saída ou as entradas de uma porta lógica.

Como não há disponível na biblioteca de células padrão da tecnologia utilizada um multiplexador 8:1 e a topologia de latch utilizada não possui saída complementar, a segunda opção é mais simples de implementar e proporciona um circuito menor e com velocidade equivalente. Por esta razão, ela foi escolhida neste projeto.

Dentro do bloco, o circuito da Figura 4.2, que realiza uma das oito operações lógicas definidas para um bit, é replicado para cada um dos 16 bits.

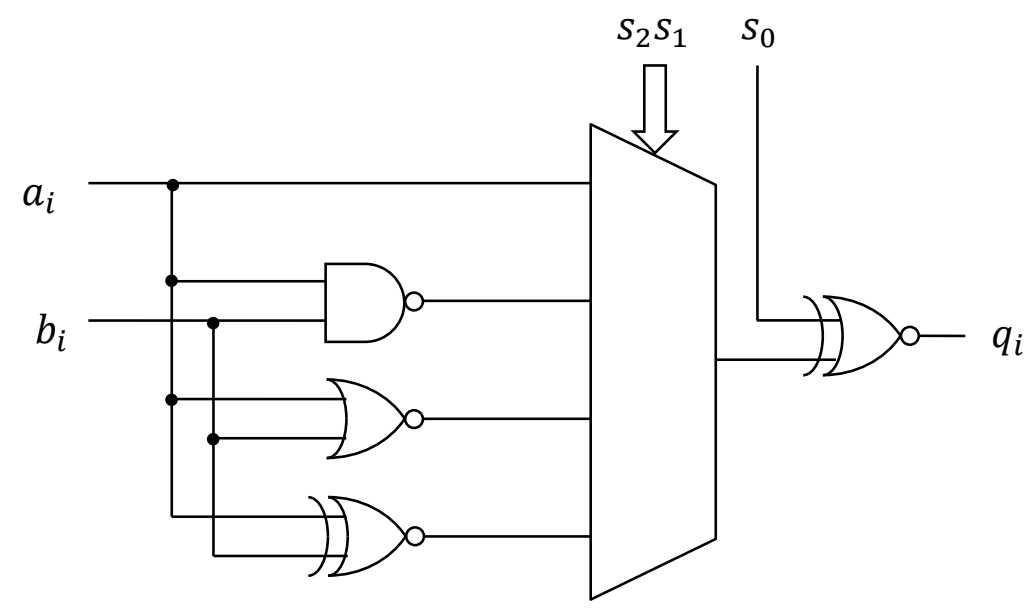

Figura 4.2: Circuito que realiza uma das oito possíveis operações lógicas bit-a-bit. 


\subsection{Operações de deslocamento e rotação}

As operações de deslocamento e rotação foram implementadas através de um barrel shifter, uma vez que o seu atraso é menor que o atraso do funnel shifter e o consumo de potência é similar (HUNTZICKER et al., 2008). Além disso, o barrel shifter é menor e possui uma estrutura mais regular, contribuindo para manter a área do circuito e o comprimento das interconexões entre os blocos da ULA reduzidos.

A escolha entre o barrel ou o funnel shifter depende também das operações que serão realizadas. Caso sejam realizadas somente rotações, o barrel shifter sem mascarador é a melhor escolha. Caso sejam realizados somente deslocamentos, o funnel shifter é a melhor escolha, pois o gerador de entrada expandida do funnel shifter pode ser bastante simplificado. No entanto, neste projeto são realizados os dois tipos de operação, o que descarta esse critério na escolha da topologia mais adequada.

As operações são sempre realizadas sobre o operando $A$, que é deslocado ou rotacionado $B$ bits. Somente os 4 bits menos significativos do operando $B$ são considerados para determinar o número de deslocamentos ou rotações. No caso da rotação, os demais bits, sendo ignorados ou não, produziriam o mesmo resultado. Para o deslocamento, se algum desses bits mais significativos fosse diferente de zero, o resultado correto seria um deslocamento completo de $A$, mas este comportamento não foi implementado.

Os multiplexadores utilizados no barrel shifter têm como saída o complemento de uma das entradas, simplificando sua implementação em lógica CMOS, o que reduz o atraso, o consumo e a área. Por outro lado, como cada bit atravessa cinco multiplexadores, a saída do rotacionado é invertida. Isto, no entanto, não é um problema, pois é compensado pela lógica do mascarador.

O gerador da máscara foi construído com portas lógicas NAND diretamente a partir das equações lógicas de cada bit da máscara, escritas na forma de soma de produtos.

A equação lógica do mascarador (4.1), derivada da Tabela 3.1 e idêntica para todos os bits, é muito complexa para ser implementada da mesma forma.

$$
q_{i}=b_{i} \cdot r+\bar{r}\left(b_{i} \cdot l \cdot \bar{m}_{i}+\bar{l}\left(b_{i} \cdot \bar{m}_{N-i-1}+s \cdot a \cdot m_{N-i-1}\right)\right)
$$


Onde todas as variáveis da equação assumem valor zero ou um e:

- $q_{i}$ é a saída do mascarador;

- $b_{i}$ é o bit do operando já rotacionado;

- $r=1$ indica que a operação é de rotação;

- $l=1$ indica que a operação é para a esquerda;

- $a=1$ indica que a operação é aritmética (considera o sinal do operando);

- $m$ é a máscara;

- $s$ é o sinal do operando;

A abordagem escolhida para construir o mascarador foi descrevê-lo em VHDL (APÊNDICE A) e então sintetizá-lo otimizando o atraso do caminho entre a entrada do bit proveniente do rotacionador $\left(\bar{b}_{i}\right)$ e a saída $\left(q_{i}\right)$. O circuito gerado, como pode ser visto na Figura 4.3, possui somente uma porta lógica nesse caminho. Para a síntese, foi utilizado o programa Leonardo Spectrum da Mentor Graphics (MENTOR GRAPHICS, 2013).

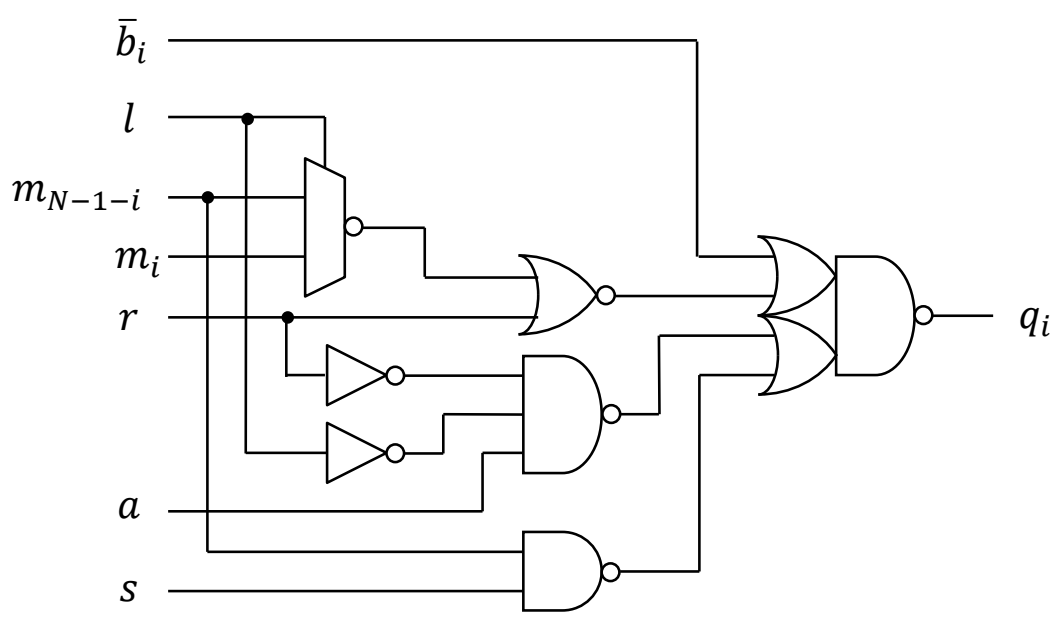

Figura 4.3: Mascarador sintetizado a partir de descrição em VHDL.

O sinal do operando $(s)$ utilizado como entrada para o mascarador foi o bit mais significativo do operando, antes da rotação. Isto é correto para todas as principais representações numéricas de números negativos. Este sinal é necessário para a implementação de deslocamentos aritméticos. 


\subsection{Operações aritméticas}

Inicialmente, foram projetados e simulados três somadores de 16 bits: um RCA (ripple-carry adder), um CLA (carry-lookahead adder) e um CSA (carry-select adder). O full adder (FA) utilizado para a implementação dos somadores RCA e CSA foi o disponível na biblioteca de células padrão. O CLA não utiliza o carry-out e, portanto, foi construído utilizando somente portas XOR ao invés de FAs.

No projeto do CLA, foram utilizados grupos de 4 bits cada e todas as simplificações citadas na Seção 3.1.2. No projeto do CSA, foi considerado a divisão do somador em blocos RCA iguais de 1, 2, 4 ou 8 bits e estimado o atraso total do somador a partir de valores de atraso das células fornecidos na documentação das células. Para o FA, o atraso usado na estimativa foi de $330 \mathrm{~ns}$ e, para o multiplexador, de $380 \mathrm{~ns}$. Nestas condições, o menor atraso estimado é igual a 2,46 $\mu$ s para CSA com blocos de 4 bits.

$\mathrm{Na}$ ULA, com operações aritméticas projetadas de soma e subtração, foi utilizado um único somador CLA.

Para a construção das operações aritméticas com um único somador, é necessário, para alguns casos, modificar os operandos que serão somados. Um exemplo disso foi apresentado na Seção 3.1.4, onde o somador/subtrator (Figura 3.9) modifica o operando $B$ através de portas lógicas $X O R$.

$\mathrm{Na}$ ULA projetada, outras variações de soma e subtração são possíveis: soma e subtração do operando $A$ com carry, soma e subtração de ambos operandos com carry, incremento e decremento. Para a realização dessas operações, utilizam-se as seguintes quatro possibilidades para as entradas $B$ e $c_{i n}$.

- Todos os bits iguais a um;

- Todos os bits iguais a zero;

- A própria entrada;

- O complemento da entrada.

Para se entender o que resulta da soma quando aplicada cada uma dessas possibilidades, deve-se lembrar de que em um somador comum, como é o caso do CLA, as somas em complemento de dois são executadas diretamente, sem necessidade de qualquer ajuste no somador ou na soma. 
Adicionalmente, na representação em complemento de dois, para um dado número $X$, seu oposto é definido como seu complemento mais um, ou seja, $-X=$ $\bar{X}+1$. Disso resulta que o complemento de $X$ é $\bar{X}=-X-1$.

Já para o caso de todos os bits iguais a um, isto é, o complemento de zero, o valor desse número é $\overline{0}=-0-1=-1$. Quando se trata de um único bit, como é o caso do carry-in, a definição de complemento é: $\bar{x}=1-x$.

A partir do dito acima, a Tabela 4.3 pode ser construída. Nela, são avaliadas as operações possíveis de soma entre $A$, cada possibilidade de $B$ (cada linha) e cada possibilidade de $c_{\text {in }}$ (cada coluna).

Tabela 4.3: Resultados para somas considerando variações no operando $B$ e no carry-in.

\begin{tabular}{c|cccc}
\hline & 0 & 1 & $c_{\text {in }}$ & $\bar{c}_{\text {in }}=1-c_{\text {in }}$ \\
\hline 0 & $A$ & $A+1$ & $A+c_{\text {in }}$ & $A-c_{\text {in }}+1$ \\
-1 & $A-1$ & $A$ & $A+c_{\text {in }}-1$ & $A-c_{\text {in }}$ \\
$B$ & $A+B$ & $A+B+1$ & $A+B+c_{\text {in }}$ & $A+B-c_{\text {in }}+1$ \\
$\bar{B}=-B-1$ & $A-B-1$ & $A-B$ & $A-B+c_{\text {in }}-1$ & $A-B-c_{\text {in }}$ \\
\hline
\end{tabular}

Como não são consideradas outras possibilidades para a entrada $A$, a ULA realiza somente subtrações do tipo $(A-x)$, mas não do tipo $(B-x)$.

\subsection{Consumo de potência}

Das técnicas de redução de consumo de potência apresentadas anteriormente, na Seção 2.3, a que mais se adequa à ULA projetada é a de isolamento de operandos, pois os dados na ULA seguem por três caminhos paralelos, mas somente o resultado de um deles será aproveitado. Dessa forma, os dois caminhos cujos resultados serão descartados podem ser isolados a fim de evitar a propagação das entradas por eles. $\mathrm{O}$ isolamento de operandos neste projeto foi realizado através de latches.

Como houve necessidade de inserir latches no caminho crítico de todas as operações da ULA, tomou-se um cuidado especial no projeto destes latches para 
que os atrasos introduzidos por eles não prejudicassem o desempenho do circuito. Optou-se por uma topologia de latch que possui somente uma porta de passagem entre a entrada e a saída, como mostra a Figura 4.4.

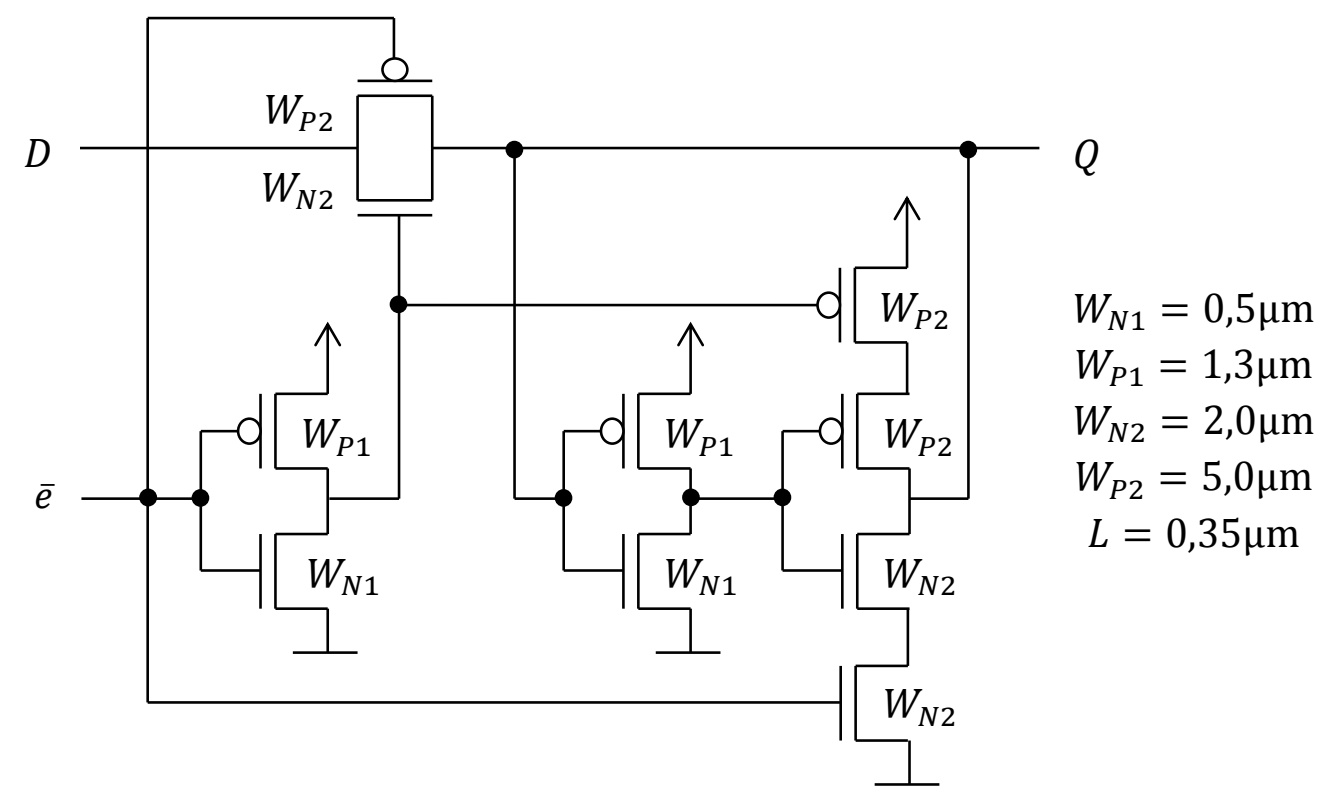

Figura 4.4: Latch utilizado na ULA com indicação da largura dos transistores. Todos os transistores possuem comprimento de canal $(L)$ mínimo da tecnologia.

Essa é a principal técnica de redução de consumo aplicada à ULA, sendo responsável por uma redução no consumo médio de aproximadamente 63\%.

No bloco de operações lógicas bit-a-bit, foram comparadas duas possibilidades de posicionamento dos latches dos operandos: na entrada do bloco ou na entrada imediata de cada porta lógica que executa a operação. No primeiro caso, o mesmo sinal que habilita os latches dos sinais de controle é usado para habilitar os latches dos operandos, enquanto que no segundo caso, há a necessidade de decodificar os sinais de seleção de operação para permitir a passagem do sinal somente através dos latches conectados às portas lógicas que efetuarão a operação selecionada.

Para o caso da ULA projetada, latches posicionados na entrada do bloco causam um aumento de consumo de cerca de $3 \%$. A área do circuito, neste caso, é consideravelmente menor do que no caso de colocação de latches antes de cada porta lógica, pois são necessários, quatro latches por bit além do decodificador (contra um latch por bit). Dessa forma os latches foram posicionados na entrada do bloco. 
Neste projeto, pela utilização de células padrão, não é possível realizar dimensionamento dos transistores diretamente, mas a biblioteca utilizada disponibiliza células da mesma porta lógica com dimensionamento diferente para operar com diferentes cargas de saída. Células mais complexas, no entanto, normalmente não possuem versões com transistores grandes. Nestas células, quando necessário, foram adicionados buffers de inversores à saída.

Pôde-se verificar, durante simulações realizadas na elaboração do projeto, que a inserção dos buffers, além de reduzir o consumo de potência, também reduziu significativamente 0 atraso, principalmente nos casos onde a capacitância de carga é grande. Os casos mais comuns de grandes capacitâncias de carga na ULA são aqueles em que os sinais de controle são conectados a portas lógicas replicadas para cada bit. Por exemplo, no bloco de operações lógicas bit-a-bit, os sinais de seleção de operação são conectados aos 16 multiplexadores e às portas lógicas XOR; no bloco de operações aritméticas, dois dos sinais de seleção são conectados às portas lógicas AND e XOR que modificam cada bit do operando $B$; e no bloco de operações de deslocamento e rotação, os sinais de controle do mascarador são conectados às portas lógicas dos 16 mascaradores.

No bloco de operações aritméticas, o operando $A$ não é modificado, mas 0 operando $B$ atravessa duas fileiras de portas lógicas, que o modificam o operando, permitindo a execução das diferentes operações aritméticas (Seção 4.5). A diferença entre os atrasos dos operandos era suficientemente grande para que o somador acabasse por realizar duas somas ao invés de uma: a primeira quando o operando $A$ se tornava disponível (operação não desejada), e a segunda após a propagação de $B$ por essas duas fileiras de portas lógicas (operação desejada). Para reduzir a diferença de atrasos de propagação entre ambos operandos, de forma que somente uma operação de soma passasse a ser realizada, foram inseridos quatro inversores no caminho do operando $A$. Com isto houve uma redução no consumo médio de cerca de $3 \%$.

Foram realizados experimentos para testar o uso de múltiplas tensões de alimentação na ULA, particularmente o uso de tensões reduzidas no bloco de operações lógicas bit-a-bit, que, comparado aos outros dois blocos de operação, possui um atraso menor. Para isso, a ULA projetada foi modificada, inserindo um conjunto de células conversoras de nível lógico entre o bloco operações lógicas bita-bit operando com tensão reduzida, e o primeiro multiplexador de saída. 
Adicionalmente, foi alterado o conjunto de latches utilizados nesse bloco, pois os circuitos na topologia da Figura 4.4 conduzem correntes estáticas quando a tensão na entrada é maior que sua tensão de alimentação. Porém, o atraso adicional causado pelas células conversoras e pelos novos latches foi maior que a margem de tempo disponível, mesmo quando não se reduz a tensão de alimentação do bloco.

\subsection{Desenho do circuito}

O diagrama de blocos da Figura 4.5 apresenta a ULA projetada, incluindo os principais blocos internos que compõe os blocos de execução de operações.

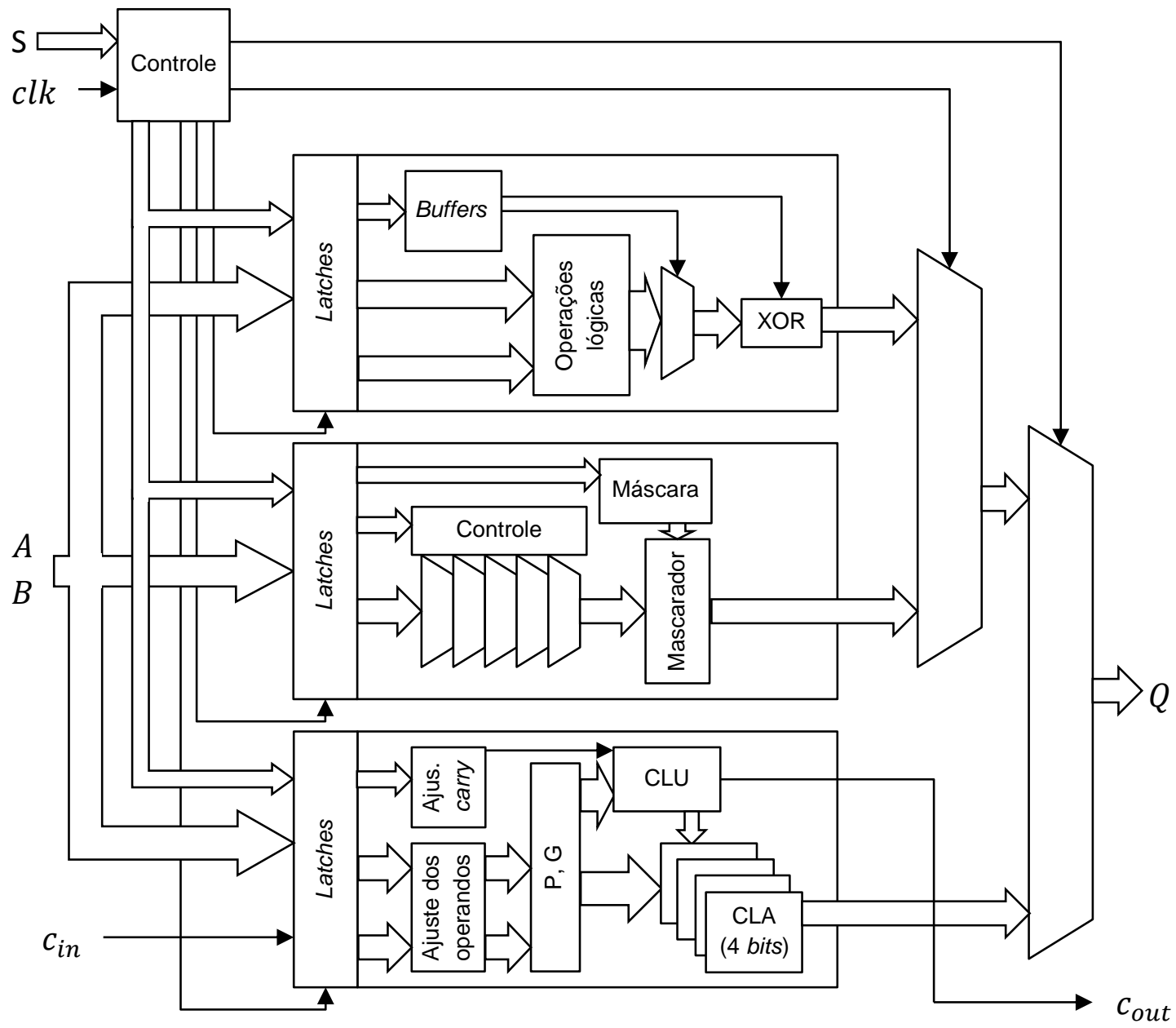

Figura 4.5: Diagrama de blocos simplificado da ULA projetada. 
A ULA projetada efetua operações lógicas e aritméticas com números inteiros de 16 bits representados em complemento de dois $e$ tem as seguintes características:

- os sinais de controle da ULA são enviados para um bloco de controle, responsável por gerar os sinais de controle para os demais blocos da ULA;

- as operações lógicas foram implementadas em dois blocos: um para as operações lógicas bit-a-bit e outro para as operações de deslocamento e rotação;

- o bloco de operações lógicas bit-a-bit efetua quatro operações lógicas entre bits dos operandos $A$ e $B$ e resultado de uma delas é selecionado e, se necessário, invertido;

- o bloco de operações de deslocamento e rotação utiliza a topologia barrel shifter, composta, principalmente, de um rotacionador de cinco estágios e um mascarador;

- as operações aritméticas foram implementadas em um bloco a parte, no qual o operando $B$ e o carry-in são modificados e ambos, junto com o operando $A$, são entradas de um somador do tipo CLA de 16 bits;

- o somador CLA foi implementado através dos blocos de geração dos sinais de propagação e geração do carry, carry-lookahead unit e somadores CLA de 4 bits;

- cada um dos três blocos que executam as operações possui latches para todas as suas entradas, devido à utilização da técnica de isolamento de operandos;

- as saídas dos primeiros dois blocos (operações lógicas bit-a-bit e operações de deslocamento e rotação) são multiplexadas e este resultado é multiplexado com a saída do terceiro bloco (operações aritméticas);

- o carry-out, por ser gerado somente pelo bloco de operações artiméticas, não é multiplexado.

O desenho final da ULA (layout) pode ser visualizado na Figura 4.6. Nele, estão demarcados os principais blocos que compõe a ULA e a localização das portas de entrada e de saída. 


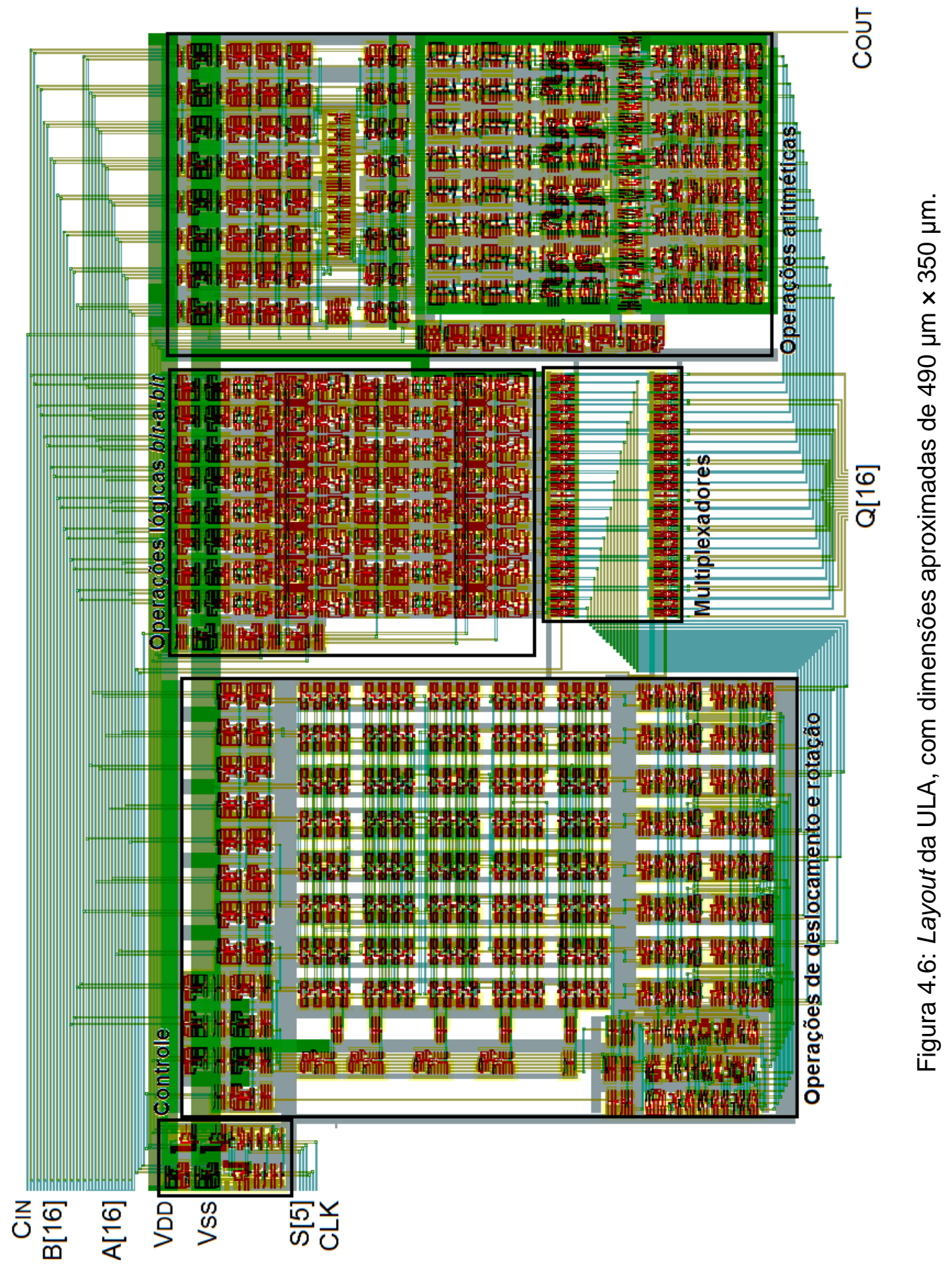


Neste layout, é possível observar uma característica típica de projetos bottomup: o interior dos blocos é mais compacto e otimizado, em termos de área, enquanto que a ULA como um todo possui algumas regiões não ocupadas por transistores, pois os blocos foram projetados de forma independente e não se encaixam perfeitamente.

O barramento com os sinais de entrada está posicionado na parte superior do layout. Logo abaixo dele, encontram-se as linhas de alimentação e terra, que se ramificam em uma estrutura de árvore, de forma que todo o circuito seja alcançado por estes sinais.

Os esquemáticos da ULA e de seus principais blocos e seus respectivos layouts podem ser visualizados no APÊNDICE A e no APÊNDICE A. O circuito foi desenhado utilizando as ferramentas da Mentor Graphics: IC Studio, Leonardo Spectrum (síntese lógica), Design Architect IC (esquemático), IC Station (layout) e Calibre (verificação).

Na Figura 4.7, é apresentado o layout da ULA de referência, projetada partindo-se de uma descrição em VHDL. O código em VHDL desta ULA, como mencionado anteriormente, está disponível no APÊNDICE A.

Neste layout, as células estão alinhadas em linhas horizontais espaçadas regularmente entre si. O espaço entre cada linha de células equivale, aproximadamente, ao dobro da altura de uma célula e foi definido desta forma para que o roteamento fosse realizável. As entradas e saídas encontram-se em dois barramentos verticais posicionados, respectivamente, dos lados esquerdo e direito da célula. As linhas de alimentação e de terra são posicionadas ao longo da parte superior e inferior das linhas de células. Além disso, elas são interconectadas por duas linhas verticais de maior largura.

Para comparação dos dois layouts, podem ser utilizados os critérios de área e de taxa de ocupação. A área apresentada é o produto da largura pela altura do layout, isto é, a área do menor retângulo que envolve todas as estruturas desenhadas, enquanto que a taxa de ocupação é a razão entre a área efetivamente ocupada por alguma estrutura do circuito e a área total do circuito.

O layout da ULA projetada possui área de $0,170 \mathrm{~mm}^{2}$ e o layout da ULA de referência, $0,388 \mathrm{~mm}^{2}$. Ambos possuem taxa de ocupação de $86 \%$. 


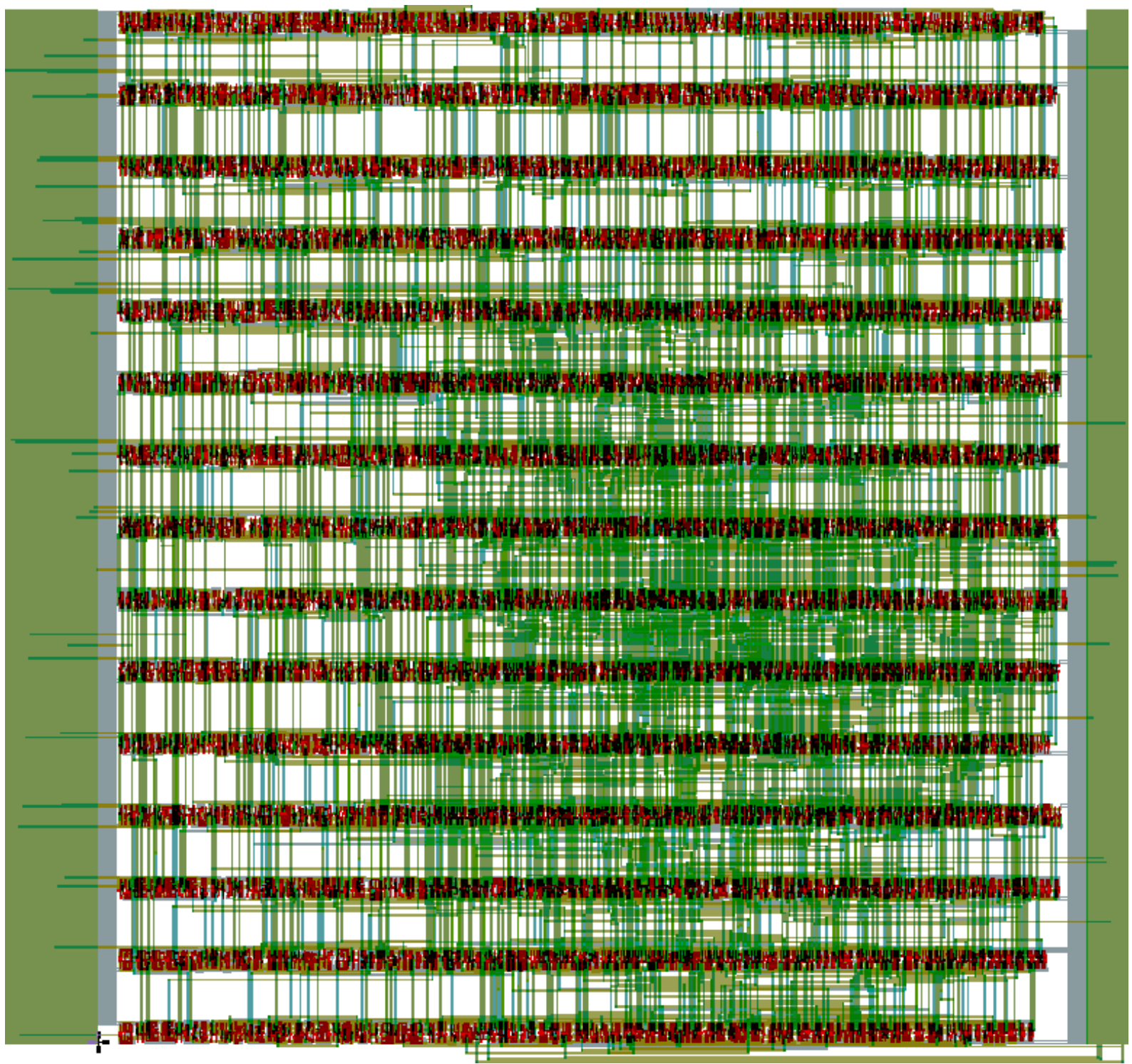

Figura 4.7: Layout da ULA de referência, com dimensões aproximadas de $640 \mu \mathrm{m} \times 600 \mu \mathrm{m}$.

\subsection{Simulações}

A ULA e seus principais blocos foram simulados, tanto para verificar o funcionamento como para medir os parâmetros de desempenho, em duas fases do projeto: após a elaboração dos esquemáticos e após o desenho do layout do circuito. Além dos resultados de simulação, esta seção apresenta também a quantidade de transistores e a área ocupada pelo circuito.

Todas as simulações foram executadas no Eldo, um simulador elétrico semelhante ao SPICE, com modelos BSIM3v3 (Berkeley Short-channel IGFET 
Model 3, version 3). A descrição do circuito no formato SPICE foi gerada através de extração a partir do layout utilizando a ferramenta Calibre PEX, considerando todas as capacitâncias parasitas suportadas por ela. Além dessas capacitâncias, foi adicionada uma capacitância de carga de $10 \mathrm{fF}$ para cada sinal de saída da ULA com o objetivo de simular as capacitâncias de entrada de portas lógicas conectadas à saída da ULA.

Os resultados das simulações foram validados pelo próprio simulador, sendo fornecido a ele o resultado esperado para cada vetor de entrada. Os arquivos com as definições dos vetores de entrada e dos vetores de resultados esperados foram gerados por um programa desenvolvido para isso, cujo código-fonte está disponível no APÊNDICE A.

As simulações foram realizadas com três modelos de transistores, a fim de se verificar o comportamento da ULA em relação a variações no processo de fabricação. Esses modelos representam o caso típico (typical mean), o pior caso de velocidade (worst speed) e o pior caso de consumo (worst power). Os resultados para cada um desses modelos estão distribuídos, respectivamente, nas colunas "TM", "WS" e "WP" das tabelas desta seção.

Através da simulação de um conjunto de $M$ entradas aleatórias com probabilidade uniforme, tanto para dados como para sinais de controle, são realizadas as seguintes medidas:

- Atraso máximo $\left(D_{\max }\right)$ : o máximo tempo decorrido entre uma transição de subida do sinal de clock e a última transição em qualquer um dos sinais de saída.

- Frequência máxima $\left(F_{\max }\right)$ : a máxima frequência de clock na qual o circuito é capaz operar corretamente. Esta medida é calculada como na Equação (4.2).

$$
F_{\max }=\frac{1}{D_{\max }}
$$

- Potência estática $\left(P_{S}\right)$ : a potência consumida pelo circuito com entradas fixas. Esta medida é calculada como na Equação (4.3), onde $V_{D D}$ é a tensão de alimentação e $I_{V_{D D}}(t)$ é a corrente que atravessa a fonte de alimentação no instante de tempo $t$. No caso desta medida, é observada a corrente em $t=0$. 


$$
P_{S}=V_{D D} I_{V_{D D}}(0)
$$

- Potência média normalizada $\left(P_{N}\right)$ : a potência média consumida pelo circuito durante a simulação de todos os vetores de entrada normalizada para frequência de clock de $1 \mathrm{MHz}$. Esta medida é calculada como na Equação (4.5), onde $T$ é o período do clock e $P_{m}$ é a potência média, dada por (4.4).

$$
\begin{gathered}
P_{m}=\frac{V_{D D}}{M T} \int_{0}^{M T} I_{V_{D D}}(t) d t \\
P_{N}=P_{m} T 10^{6}=\frac{V_{D D} 10^{6}}{M} \int_{0}^{M T} I_{V_{D D}}(t) d t
\end{gathered}
$$

- Potência média no pior caso $\left(P_{w c}\right)$ : a potência média consumida pelo circuito com as entradas se alternando entre os dois vetores de entrada que causam o maior número de transições no circuito, no modelo de pior caso de consumo e com clock na frequência máxima de operação. A frequência máxima utilizada é a obtida no modelo de pior caso de velocidade, pois esta frequência é aquela na qual o circuito funcionará corretamente independente de variações no processo de fabricação.

- Produto energia-atraso (EDP) (GONZALES; HOROWITZ, 1996): o produto da energia por operação, isto é, a energia média consumida pelo circuito por ciclo de clock, pelo atraso máximo do circuito. Esta medida é calculada como na Equação (4.6).

$$
E D P=P_{m} T D_{\max }=\frac{V_{D D} D_{\max }}{M} \int_{0}^{M T} I_{V_{D D}}(t) d t
$$

As medidas de potência estática foram calculadas através de análises DC do circuito com um vetor de entrada aleatório. Portanto, os valores de potência estática apresentados, inclusive os de mínimo e máximo, são aproximados, pois não consideram todas possíveis entradas do circuito.

As demais medidas de potência e energia foram calculadas a partir da corrente média na fonte de alimentação durante a simulação. O número de entradas 
apresentadas ao circuito, $M$, é suficientemente grande, de forma que os valores de potência apresentados não sofrem variações significativas caso sejam simulados mais vetores de entrada.

As medidas de atraso máximo foram obtidas através de um programa, que realiza o pós-processamento das formas de onda geradas pelo simulador. $O$ programa determina o maior atraso em relação ao clock apresentado por um conjunto de sinais. O código-fonte desse programa está disponível no APÊNDICE A.

$O$ produto da potência pelo atraso é uma métrica que indica a energia média consumida pelo circuito para cada ciclo. Entretanto, esta métrica não é muito utilizada para otimizar o consumo de circuitos, pois conforme a tensão de alimentação é reduzida, a energia consumida é, também, reduzida. O produto energia-atraso, por outro lado, relaciona a energia consumida por ciclo com o atraso do circuito, o que permite encontrar a menor tensão de alimentação na qual a redução no consumo compensa o aumento atraso (RABAEY; CHANDRAKASAN; BORIVOJE, 2003). O valor ideal do EDP para um dado circuito, no entanto, pode não ser o mínimo, especialmente se houver restrições de velocidade mínima na qual o circuito deve funcionar.

\subsubsection{Somadores}

Foram projetados e simulados os três somadores discutidos anteriormente (RCA, CLA e CSA) e um quarto somador, sintetizado a partir de uma descrição em VHDL. A Tabela 4.4 apresenta as características do layout desses somadores e a

Tabela 4.5, os resultados de simulação pós-layout, utilizando tensão de alimentação de $3,3 \mathrm{~V}$ e frequência de clock de $100 \mathrm{MHz}$. Todos os somadores foram projetados para operandos de 16 bits.

Tabela 4.4: Características do layout de somadores de 16 bits.

\begin{tabular}{lcccc}
\hline & RCA & CLA & CSA & VHDL \\
\hline Número de transistores NMOS & $\mathbf{2 2 4}$ & 453 & 482 & 660 \\
Número de transistores PMOS & $\mathbf{2 2 4}$ & 453 & 482 & 660 \\
Largura $(\mu \mathrm{m})$ & $\mathbf{3 3 6 , 0}$ & 152,7 & 193,5 & 185,2 \\
\hline
\end{tabular}




\begin{tabular}{lcccc}
\hline & RCA & CLA & CSA & VHDL \\
\hline Altura $(\mu \mathrm{m})$ & $\mathbf{1 3 , 0}$ & 118,4 & 75,1 & 167,1 \\
Área $\left(\mu \mathrm{m}^{2}\right)$ & $\mathbf{4 3 6 8}$ & 18074 & 14532 & 30938 \\
Densidade (transistores $\left./ \mathrm{mm}^{2}\right)$ & $\mathbf{1 0 2 5 6 4}$ & 50128 & 66337 & 42666 \\
\hline
\end{tabular}

Tabela 4.5: Resultados de simulação de layouts de somadores de 16 bits.

\begin{tabular}{lcccccc}
\hline & \multicolumn{3}{c}{$\mathrm{RCA}$} & & \multicolumn{3}{c}{ CLA } \\
\cline { 2 - 7 }$D_{\text {max }}(\mathrm{ns})$ & $\mathrm{WS}$ & $\mathrm{TM}$ & $\mathrm{WP}$ & $\mathrm{WS}$ & $\mathrm{TM}$ & WP \\
$F_{\text {max }}(\mathrm{MHz})$ & 3,34 & 2,38 & 1,60 & $\mathbf{2 , 0 7}$ & $\mathbf{1 , 4 9}$ & $\mathbf{1 , 0 3}$ \\
$P_{S}(\mathrm{nW})$ & 299,7 & 419,5 & 623,8 & $\mathbf{4 8 2 , 6}$ & $\mathbf{6 7 2 , 0}$ & $\mathbf{9 6 7 , 1}$ \\
$P_{N}(\mu \mathrm{W} / \mathrm{MHz})$ & 1,5 & $\mathbf{1 , 6}$ & $\mathbf{1 1 , 2}$ & $\mathbf{1 , 4}$ & 4,8 & 32,0 \\
$P_{w c}(\mu \mathrm{W})$ & $\mathbf{6 , 2}$ & $\mathbf{6 , 5}$ & $\mathbf{7 , 4}$ & 19,2 & 19,1 & 26,2 \\
$E D P(\mathrm{pJ} \mathrm{ns})$ & & & $\mathbf{3 , 1 2}$ & & & 17,30 \\
\hline & $\mathbf{2 0 , 8}$ & $\mathbf{1 5 , 5}$ & $\mathbf{1 1 , 9}$ & 39,8 & 28,5 & 27,1 \\
\hline & & $\mathrm{CSA}$ & & Sintetizado a partir de VHDL \\
\hline$D_{\text {max }}(\mathrm{ns})$ & $\mathbf{W S}$ & $\mathrm{TM}$ & $\mathrm{WP}$ & $\mathrm{WS}$ & $\mathrm{TM}$ & $\mathrm{WP}$ \\
$F_{\text {max }}(\mathrm{MHz})$ & 291,7 & 403,9 & 591,4 & 445,0 & 620,7 & 893,7 \\
$P_{S}(\mathrm{nW})$ & 3,6 & 3,7 & 25,1 & 1107,0 & 5,7 & 55,5 \\
$P_{N}(\mu \mathrm{W} / \mathrm{MHz})$ & 12,3 & 12,9 & 14,3 & 34,9 & 36,6 & 51,4 \\
$P_{w c}(\mu \mathrm{W})$ & & & 5,89 & & & 39,89 \\
$E D P(\mathrm{pJ} \mathrm{ns})$ & 42,2 & 31,8 & 24,2 & 78,5 & 59,0 & 57,6 \\
\hline
\end{tabular}

Por esses resultados, observa-se que o RCA possui o melhor desempenho em termos de produto energia-atraso nessa tecnologia, enquanto que o CSA possui atraso similar, mas consumo de potência e área muito maiores. Portanto, para somadores de 16 bits nesta tecnologia, o CSA não apresenta resultados vantajosos sobre o RCA. O atraso do CLA, por outro lado, é consideravelmente menor, apesar 
de seu consumo médio ser mais de três vezes maior que o do RCA. O somador sintetizado a partir da descrição em VHDL apresenta o pior valor de EDP e, apesar de ser quase tão rápido quanto o CLA, o seu consumo é aproximadamente o dobro.

$\mathrm{Na}$ implementação desta ULA, o CLA foi escolhido por estar no caminho crítico e a utilização de um somador mais lento impactaria na máxima frequência de operação da ULA. Caso houvesse outra operação, como, por exemplo, multiplicação, que possuísse atraso maior ou igual ao atraso do RCA ou, ainda, o sistema que utilizasse a ULA possuísse outro bloco restringindo suficientemente a frequência máxima de operação, este tipo de somador seria a melhor escolha.

\subsubsection{ULA}

Diferentemente dos circuitos anteriores, as simulações da ULA foram executadas com frequência de clock igual a $10 \mathrm{MHz}$, pois, em alguns casos, especialmente nos quais a tensão de alimentação foi reduzida, a frequência máxima não alcançou $100 \mathrm{MHz}$.

Além da ULA projetada, foi testada a ULA sintetizada a partir da descrição em VHDL, chamada ULA de referência.

A Tabela 4.6 apresenta as características do layout das duas ULAs projetadas e a Tabela 4.7, os resultados de simulação.

Tabela 4.6: Características do layout da ULA projetada e da ULA de referência.

\begin{tabular}{lcc}
\hline & ULA projetada & ULA de referência \\
\hline Número de transistores NMOS & $\mathbf{2 3 9 9}$ & 4233 \\
Número de transistores PMOS & $\mathbf{2 3 8 3}$ & 4233 \\
Largura $(\mu \mathrm{m})$ & $\mathbf{4 8 8 , 7}$ & 642,2 \\
Altura $(\mu \mathrm{m})$ & $\mathbf{3 4 8 , 8}$ & 604,6 \\
Área $\left(\mu \mathrm{m}^{2}\right)$ & $\mathbf{1 7 0 ~ 4 5 9}$ & 388274 \\
Densidade $\left(\right.$ transistores $\left./ \mathrm{mm}^{2}\right)$ & $\mathbf{2 7 9 9 5}$ & 21804 \\
\hline
\end{tabular}


Tabela 4.7: Resultados de simulação do layout da ULA projetada e da ULA de referência.

\begin{tabular}{lcccccc}
\hline & \multicolumn{3}{c}{ ULA projetada } & \multicolumn{3}{c}{ ULA de referência } \\
\cline { 2 - 7 } & WS & TM & WP & WS & TM & WP \\
\hline$D_{\max }(\mathrm{ns})$ & $\mathbf{6 , 8 1}$ & $\mathbf{4 , 7 1}$ & $\mathbf{3 , 0 5}$ & 10,54 & 7,57 & 5,14 \\
$F_{\text {max }}(\mathrm{MHz})$ & $\mathbf{1 4 6 , 9}$ & $\mathbf{2 1 2 , 5}$ & $\mathbf{3 2 8 , 1}$ & 94,9 & 132,0 & 194,4 \\
$P_{S}(\mathrm{nW})$ & $\mathbf{3 1 , 2}$ & $\mathbf{3 2 , 2}$ & $\mathbf{6 0 , 9}$ & 38,3 & 39,8 & 316,8 \\
$P_{N}(\mu \mathrm{W} / \mathrm{MHz})$ & $\mathbf{5 6 , 3}$ & $\mathbf{5 6 , 9}$ & $\mathbf{6 0 , 2}$ & 236,7 & 251,1 & 299,3 \\
$P_{w c}(\mu \mathrm{W})$ & & & $\mathbf{1 0} \mathbf{4 8 9}$ & & & 43080 \\
$E D P(\mathrm{pJ} \mathrm{ns})$ & $\mathbf{3 8 3 , 1}$ & $\mathbf{2 6 7 , 8}$ & $\mathbf{1 8 3 , 6}$ & 2494,6 & 1901,8 & 1539,4 \\
\hline
\end{tabular}

É possível verificar que a ULA projetada apresentou, quando comparada à ULA de referência, menor número de transistores, menor área ocupada e, para todos os modelos simulados, melhores resultados de atraso e consumo de potência.

O gráfico da Figura 4.8 apresenta o produto energia-atraso da ULA projetada em função da tensão de alimentação para os modelos WS, TM e WP.

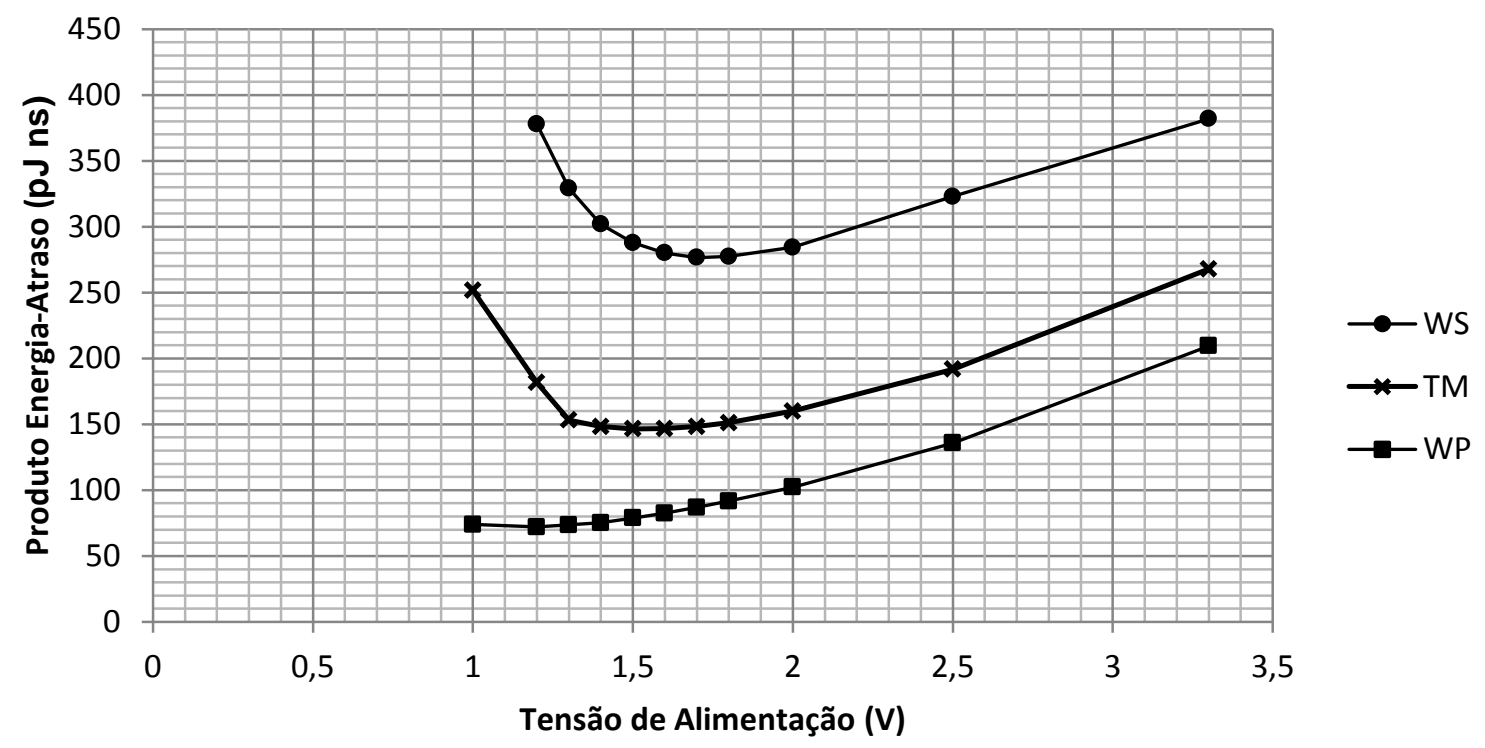

Figura 4.8: Produto energia-atraso da ULA em função da tensão de alimentação para os modelos WS, TM e WP.

Nesse gráfico, é possível verificar que, reduzindo a tensão de alimentação até, aproximadamente, $1,5 \mathrm{~V}$, há redução no produto energia-atraso para o caso 
típico (TM). Isso significa que a redução no consumo é proporcionalmente maior que o aumento no atraso. Considerando as variações no processo, o valor de tensão de alimentação onde o produto energia-atraso é mínimo varia entre 1,2 e 1,7 V.

A Tabela 4.8 apresenta os resultados da ULA projetada para tensões de alimentação de $3,3 \mathrm{~V}$ e de $1,5 \mathrm{~V}$.

Tabela 4.8: Resultados de simulação do layout da ULA para tensão de alimentação de 3,3 V e de $1,5 \mathrm{~V}$.

\begin{tabular}{lcccccc}
\hline & \multicolumn{3}{c}{$V_{D D}=3,3 \mathrm{~V}$} & \multicolumn{3}{c}{$V_{D D}=1,5 \mathrm{~V}$} \\
\cline { 2 - 7 } & $\mathrm{WS}$ & $\mathrm{TM}$ & $\mathrm{WP}$ & $\mathrm{WS}$ & $\mathrm{TM}$ & WP \\
\hline$D_{\max }(\mathrm{ns})$ & $\mathbf{6 , 8 1}$ & $\mathbf{4 , 7 1}$ & $\mathbf{3 , 0 5}$ & 27,46 & 11,40 & 7,34 \\
$F_{\text {max }}(\mathrm{MHz})$ & $\mathbf{1 4 6 , 9}$ & $\mathbf{2 1 2 , 5}$ & $\mathbf{3 2 8 , 1}$ & 36,4 & 87,7 & 136,2 \\
$P_{S}(\mathrm{nW})$ & 31,2 & 32,2 & 60,9 & $\mathbf{6 , 2}$ & $\mathbf{6 , 5}$ & $\mathbf{5 0 , 9}$ \\
$P_{N}(\mu \mathrm{W} / \mathrm{MHz})$ & 56,3 & 56,9 & 60,2 & $\mathbf{1 1 , 5}$ & $\mathbf{1 1 , 3}$ & $\mathbf{1 1 , 3}$ \\
$P_{w c}(\mu \mathrm{W})$ & & & 10489 & & & $\mathbf{3 0 9}$ \\
$E D P(\mathrm{pJ} \mathrm{ns})$ & 383,1 & 267,8 & 183,6 & $\mathbf{3 1 5 , 8}$ & $\mathbf{1 2 8 , 8}$ & $\mathbf{8 2 , 8}$ \\
\hline
\end{tabular}

A fim de se verificar o ganho na utilização da técnica de isolamento de operandos, foram feitas simulações da ULA projetada, onde são utilizados latches, e de uma variante, onde eles não são utilizados. Estas simulações foram realizadas apenas a partir do esquemático dos circuitos, com tensão de alimentação de $3,3 \mathrm{~V} e$ modelo TM. Os resultados estão apresentados na Tabela 4.9.

Tabela 4.9: Resultados da simulação do esquemático das ULAs com e sem latches, com $V_{D D}=3,3 \mathrm{~V}$ e modelo $\mathrm{TM}$.

\begin{tabular}{lcc}
\hline & Sem latches & Com latches \\
\hline$D_{\max }(\mathrm{ns})$ & $\mathbf{2 , 7 9}$ & 3,25 \\
$F_{\max }(\mathrm{MHz})$ & $\mathbf{3 5 8 , 2}$ & 307,7 \\
$P_{S}(\mathrm{nW})$ & $\mathbf{1 9 , 2}$ & 24,5 \\
$P_{N}(\mu \mathrm{W} / \mathrm{MHz})$ & 110,7 & $\mathbf{4 1 , 1}$ \\
$E D P(\mathrm{pJ} \mathrm{ns})$ & 308,9 & $\mathbf{1 3 3 , 6}$ \\
\hline
\end{tabular}


Observa-se, nesses resultados, que a utilização da técnica de isolamento de operandos proporcionou uma redução no consumo de potência médio de 62,9\%, com aumento no atraso de somente 14,1\%. Dessa forma, o produto energia-atraso reduziu em 56,8\%, o que evidencia a importância da utilização da técnica de isolamento de operandos em ULAs de baixo consumo.

Sun e Jiang (2010) comparam três arquiteturas de ULA. Na primeira, todas as operações são executadas por uma única estrutura complexa, baseada em um somador do tipo CLA. Nas outras duas, as diferentes operações aritméticas são geradas modificando os operandos de um somador e as operações lógicas são realizadas separadamente. Em uma delas, há uma única cadeia de multiplexadores para todas as operações lógicas e a saída do somador, enquanto que na outra, as operações lógicas são combinadas e, então, multiplexadas com a saída do somador. Os resultados de simulação foram obtidos pelos autores após implementação em uma tecnologia CMOS de 0,18 $\mu \mathrm{m}$.

A ULA apresentada neste trabalho implementa mais operações quando comparada às ULAs de Sun e Jiang, incluindo, sobretudo, as operações de deslocamento e rotação. Mesmo com mais operações e projetada em uma tecnologia mais antiga, a ULA deste trabalho possui atraso e área equivalentes e consumo de potência menor. Os resultados de área, atraso e consumo de potência de ambos os trabalhos são apresentados na Tabela 4.10.

Tabela 4.10: Comparação dos resultados de simulação da ULA projetada com as ULAs de Sun e Jiang (2010).

\begin{tabular}{lcc}
\hline & Sun e Jiang (2010) & Este trabalho \\
\hline Tecnologia & CMOS 0,18 $\mu \mathrm{m}$ & CMOS 0,35 $\mu \mathrm{m}$ \\
Área $\left(\mathrm{mm}^{2}\right)$ & 0,043 a 0,067 & $0,045^{*}$ \\
Atraso em 1,8 V (ns) & 4 a 5 & 10 \\
Potência em $100 \mathrm{MHz}$ e 1,8 V (mW) & 2 a 2,75 & 1,5 \\
\hline
\end{tabular}

${ }^{*}$ Após escala linear para $0,18 \mu \mathrm{m}$. 


\subsection{Possíveis melhorias}

O projeto realizado pode ser melhorado em diversos aspectos. As subseções seguintes indicam possíveis melhorias ao projeto.

\subsubsection{Flags}

Uma funcionalidade simples que poderia ser acrescida ao projeto desta ULA é a geração de flags para sinalizar algumas características importantes do resultado de uma operação. Dentre as flags usualmente disponíveis em ULAs, destacam-se a flag de zero, que indica se o resultado é nulo e a de overflow, que indica se o resultado da operação não pôde ser representado porque eram necessários mais bits.

A flag de zero é simples de ser obtida, pois basta aplicar a função lógica OU entre todos os bits do resultado. Como não é viável a construção de uma porta lógica OR com 16 entradas em lógica CMOS, pois haveria muitos transistores PMOS em série, pode-se realizar esta função lógica através da associação de portas lógicas menores. $\mathrm{O}$ atraso e o consumo de potência variam dependendo de como elas são associadas. $O$ atraso depende geralmente do número de portas lógicas em série e o consumo de potência, do produto do fator de atividade pelas capacitâncias de carga dos nós internos.

A flag de overflow, para ser determinada, precisa de uma informação adicional sobre os operandos: se eles são números com ou sem sinal, o que não é entrada da ULA projetada. Para o caso de operações de soma entre operandos sem sinal, a flag de overflow é igual ao carry-out. No caso de subtrações entre operandos sem sinal, a flag é igual ao complemento do carry-out. Já para o caso de operações entre números com sinal, há overflow se os sinais das entradas do somador forem iguais entre si, mas diferentes do resultado. Uma regra equivalente é verificar se o carry-in do bit mais significativo é diferente do seu carry-out.

No caso de operações de deslocamento, a flag de overflow pode ser obtida verificando-se se algum bit "1" foi descartado durante o mascaramento. Pode-se, também, diferenciar os casos de overflow dos de underflow. O overflow indicaria 
quando um bit "1" foi descartado em uma operação de deslocamento para a esquerda e o underflow, para a direita. Os deslocamentos aritméticos, neste caso, correspondem às operações com números com sinal e os deslocamentos lógicos, a números sem sinal.

No caso de rotações ou operações lógicas bit-a-bit, a flag de overflow não faz sentido e, neste caso, a flag pode repetir o último valor gerado ou ser zerada.

\subsubsection{Outras operações aritméticas}

Neste projeto, foram implementadas somente as operações aritméticas de adição e subtração, com algumas pequenas variações, por exemplo: com ou sem carry, incremento e decremento. Outras operações aritméticas de inteiros comuns são multiplicação e divisão. Algumas topologias de multiplicadores foram apresentadas na Seção 3.3. Há também, na literatura, algumas topologias para divisão de números inteiros, como as de Alverson (2005) e de Khoo (2005). Esta operação pode ser implementada, assim como a multiplicação, através de um circuito dedicado a estas operações ou através da execução de uma sequência de operações mais simples.

\subsubsection{Pipeline}

As técnicas de pipelining ou de paralelismo poderiam ser implementadas na ULA, com o objetivo de reduzir ainda mais o consumo de potência sem reduzir a frequência de operação da ULA. A desvantagem seria que a ULA utilizaria mais de um ciclo de clock por operação.

A Figura 4.9 ilustra possíveis partições do caminho de dados da ULA para formação de estágios de pipeline. Nestas partições apontadas, o número de sinais intermediários é mantido pequeno. 


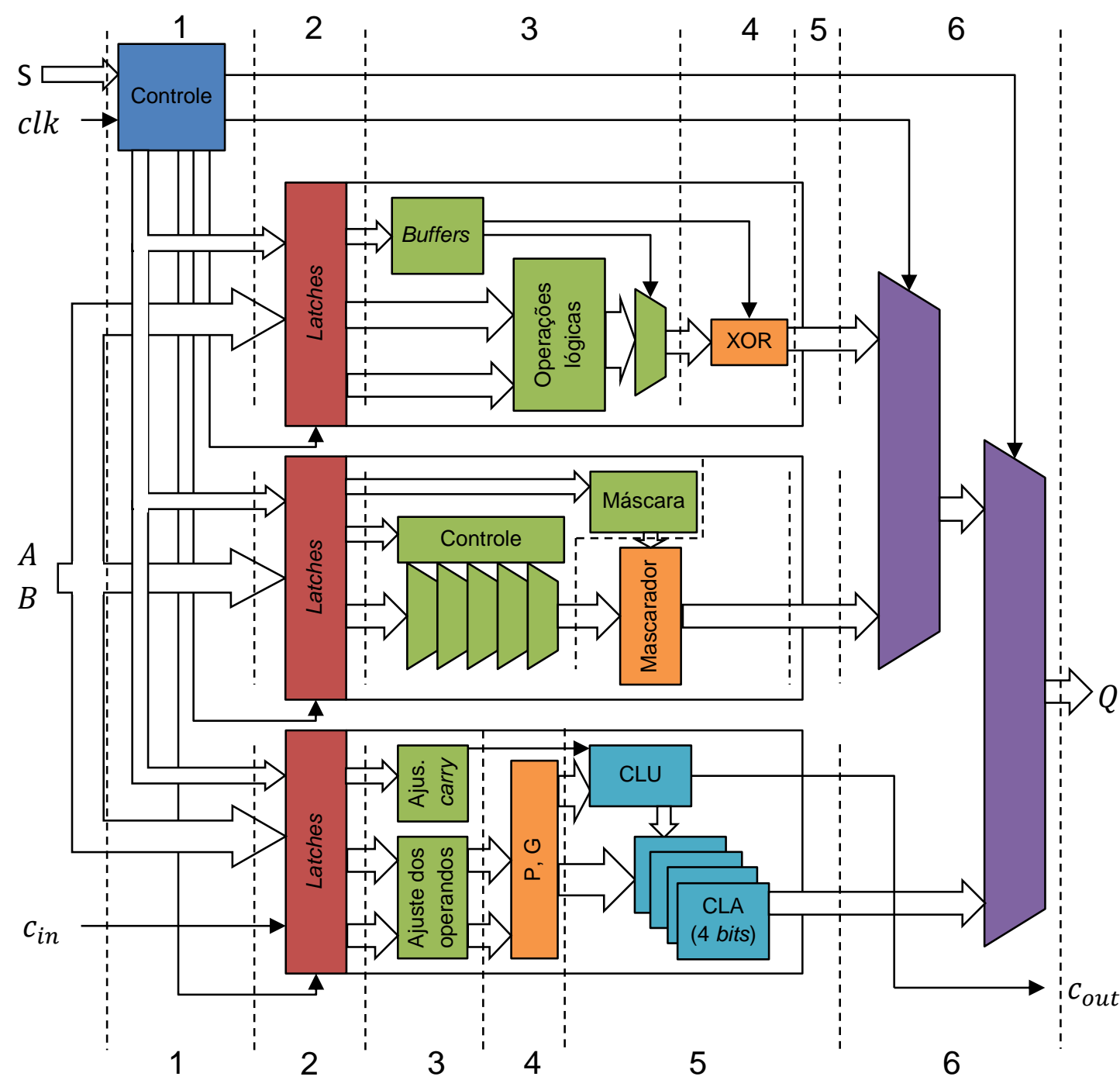

Figura 4.9: Visão geral da ULA com indicação dos trechos entre os quais a ULA poderia ser dividida em diferentes estágios de pipeline.

O diagrama da Figura 4.10 mostra, o atraso de propagação em cada um dos possíveis estágios para cada grupo de operação. As medidas foram realizadas através de simulação SPICE a partir do esquemático da ULA. A escala de tempo foi normalizada para o tempo de execução da operação mais lenta.

A partir deste diagrama, verifica-se que há partições mais adequadas para serem realizadas, de forma que o atraso máximo em cada estágio possa ser aproximadamente igual. Para o caso de dois estágios, a partição ideal seria na posição com atraso igual a $50 \%$ do atraso máximo. A alternativa mais próxima e que causaria menor impacto no atraso total seria em $52 \%$, de forma que, no primeiro estágio do pipeline, seriam executados os trechos 1, 2 e 3 das operações aritméticas e de deslocamento e rotação e 1 e 2 das operações lógicas bit-a-bit. 


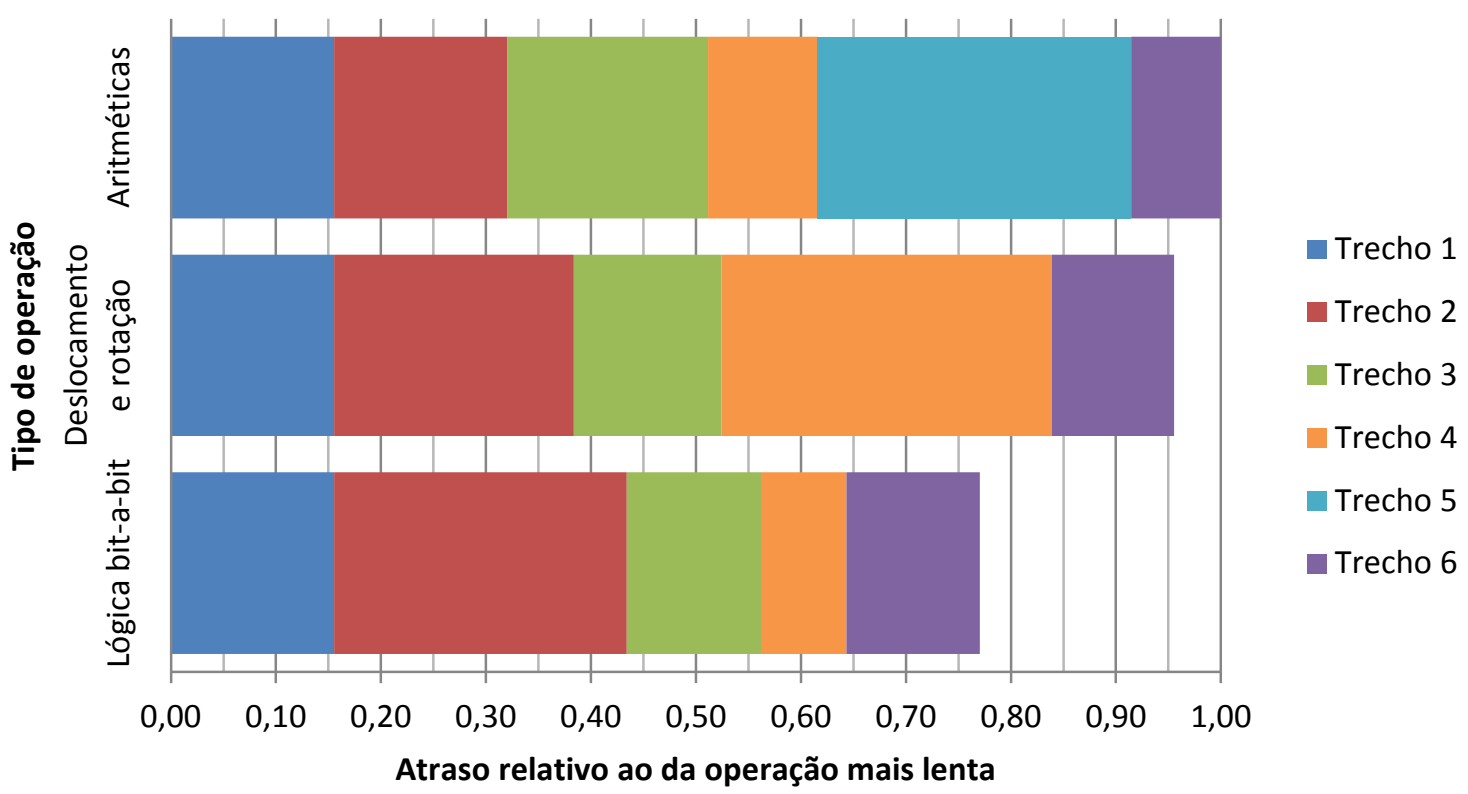

Figura 4.10: Atraso de propagação na execução de diferentes tipos de operação na ULA

A Figura 4.11 mostra o mesmo diagrama, alterado para indicar o resultado teórico da criação do pipeline da forma como foi proposto.

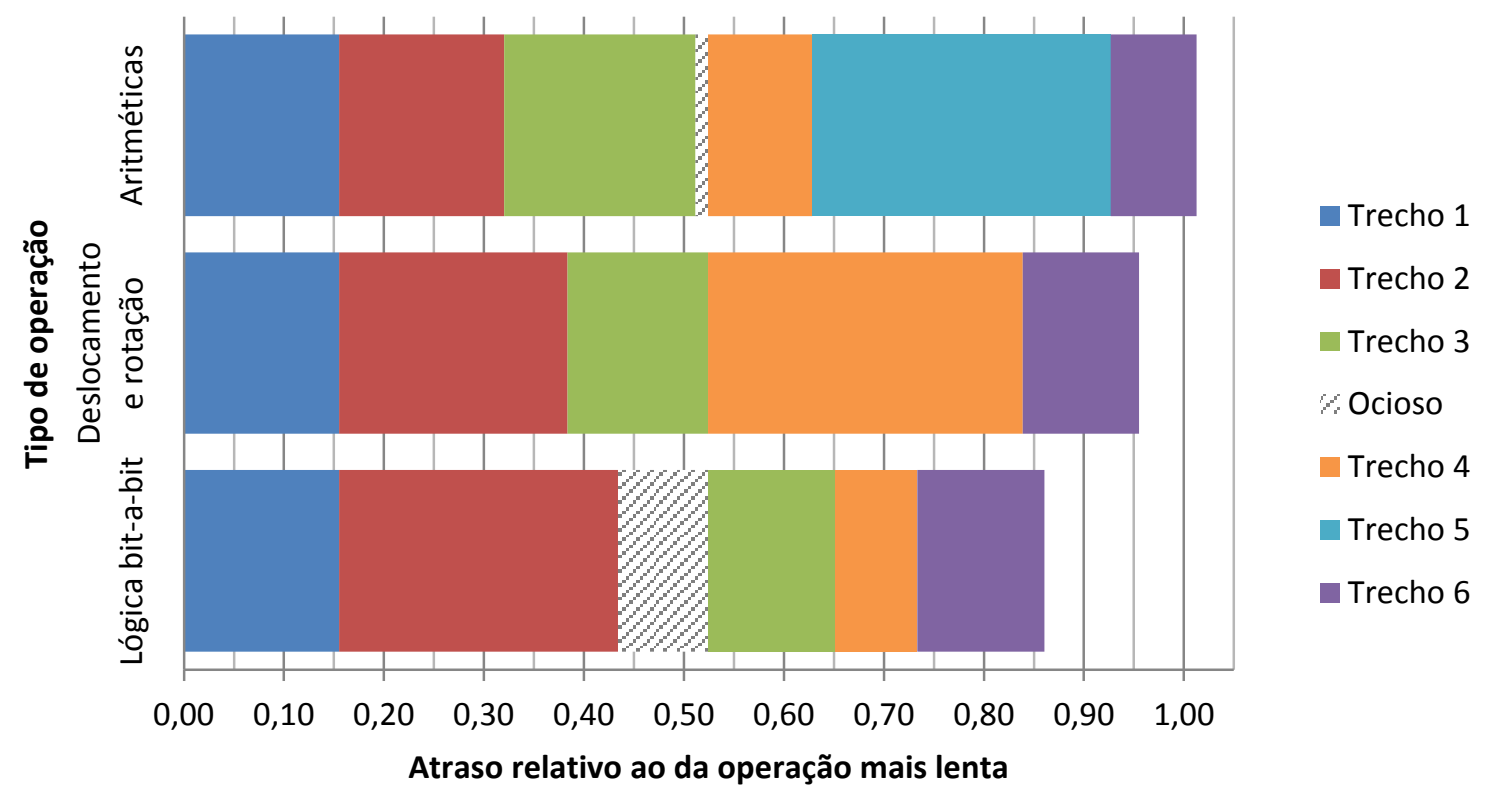

Figura 4.11: Estimativa do atraso de propagação na execução de diferentes tipos de operação na ULA após a criação de um pipeline de dois estágios. 
O registrador entre os dois estágios do pipeline teria, neste caso, 35 bits para as operações lógicas bit-a-bit, 35 bits para as de deslocamento e rotação, 33 bits para as aritméticas e 2 bits para o controle dos multiplexadores, totalizando 105 bits.

O atraso e o consumo do registrador entre os estágios de pipeline, no entanto, deve ser considerado ao estimar o ganho que seria obtido pela implementação do pipeline.

Foram executadas simulações preliminares a fim de se verificar a viabilidade desta melhoria, a partir de uma modificação do esquemático da ULA para inclusão dos registradores. Os registradores foram construídos utilizando-se células de flipflops tipo $\mathrm{D}$, disponíveis na biblioteca. Com o pipeline, o atraso máximo da ULA reduziu $16 \%$ e o seu consumo aumentou 46\%. De acordo com esses resultados, o uso desse registrador para construção do pipeline não traz melhorias à ULA, pois o impacto no consumo de potência é grande, de forma que mesmo reduzindo a tensão de alimentação, o consumo ainda seria maior em comparação à ULA sem pipeline. A viabilidade do uso de pipeline, portanto, depende do projeto de um registrador com menor atraso e, principalmente, menor consumo de potência.

\subsubsection{Teste}

Quando a ULA fosse fabricada, haveria necessidade de verificar se o chip não possui defeito de fabricação e qual seu desempenho.

Considerando que a ULA possui 38 entradas e 17 saídas, além das tensões de alimentação $V_{D D}$ e $V_{S S}$, haveria necessidade de uma quantidade muito grande de pads para que todos essas entradas e saídas fossem acessíveis externamente. $A$ área ocupada por todos os pads seria muito superior à área da ULA. Por esse motivo, seria interessante que a ULA pudesse ser completamente testada utilizandose poucos sinais de entrada e saída.

Uma das formas de se reduzir o número de entradas e saídas, é serializando a interface da ULA. Assim, os bits das entradas poderiam ser enviados, em sequência, para uma registrador e, quando todas as entradas estivessem armazenadas, elas seriam apresentadas à ULA. Similarmente, a saída da ULA seria 
armazenada em um registrador e os bits armazenados seriam transmitidos em sequência.

Outra forma é com a construção de estruturas de teste junto à ULA que, por exemplo, gerassem vetores de entrada para a ULA e comparassem os vetores de saída com os resultados esperados.

No caso do somador projetado por Ocheretny (2010), as células básicas do somador são modificadas para gerar a soma e seu complemento através de portas lógicas independentes e é calculado, a partir da paridade dos operandos, a paridade esperada da saída. Esse somador calcula a cada soma, se o resultado e o seu complemento são realmente complementares e se a paridade da saída é igual à paridade esperada.

Além do funcionamento correto, as características de atraso e consumo da ULA precisam ser testadas. A ULA projetada por Chatterjee e Sachdev (2005) possui estruturas para verificar o atraso do circuito, sendo capazes de detectar falhas com maior precisão quando comparadas a um equipamento de teste automático. 



\section{Conclusões}

A redução no tamanho dos dispositivos eletrônicos, além de viabilizar a construção de sistemas maiores e mais complexos, traz novos e grandes desafios para o projeto de circuitos integrados. O consumo de energia e a dissipação do calor gerado pela atividade de milhões de transistores em um único chip são um dos mais importantes desses novos desafios.

A unidade lógico-aritmética é um componente fundamental em processadores, sejam eles de propósito geral ou específicos para uma aplicação. A otimização do consumo de uma ULA é, portanto, crítica para o projeto de processadores de baixo consumo. Idealmente, essa otimização deve reduzir o consumo sem aumentar significativamente o tempo para execução das operações para que a ULA não se torne um fator limitante na frequência máxima do processador.

Neste trabalho, foi apresentado o projeto de uma ULA de números inteiros de 16 bits, no qual foram aplicadas algumas técnicas de redução de consumo. Durante o projeto, foram definidas quais operações seriam realizadas pela ULA e como a ULA seria organizada internamente.

A ULA é capaz de executar operações lógicas bit-a-bit, deslocamento lógico, deslocamento aritmético, rotação, adição e subtração. Essas operações foram implementadas em três blocos distintos: um para as operações lógicas bit-a-bit, um para as operações de deslocamento e rotação e um para as operações aritméticas. Para as operações de deslocamento e rotação, foi utilizado um barrel shifter e, para as operações aritméticas, um CLA. As saídas desses três blocos são multiplexadas para gerar a saída da ULA. Devido ao uso da técnica de isolamento de operandos, somente um dos três blocos opera por ciclo de clock, evitando consumo de potência dinâmica nos outros dois blocos.

A ULA, implementada em uma tecnologia de 0,35 $\mu \mathrm{m}$ utilizando, em sua maioria, células padrão, opera a uma frequência máxima de $212 \mathrm{MHz}$ em $3,3 \mathrm{~V}$ ou $36 \mathrm{MHz}$ em 1,5 V e, nessa frequência, onde o consumo de energia por operação é mínimo, o consumo máximo e médio são de $309 \mu \mathrm{W}$ e $11 \mu \mathrm{W}$ respectivamente, para o modelo típico (TM). 
Quando comparada a ULA projetada com outra ULA de referência, onde não foram aplicadas otimizações em relação ao consumo de potência, projetada em uma linguagem de descrição de hardware e implementada com ajuda de ferramentas de síntese automática, os resultados de velocidade, consumo e área são bem superiores: atraso máximo 35\% menor, consumo médio $77 \%$ menor e área $56 \%$ menor. Entretanto, o tempo de projeto utilizando ferramentas automáticas de síntese é muito menor. A diferença entre os resultados, não se deve somente à aplicação das técnicas de redução de consumo, mas também ao método de implementação.

Dentre as técnicas de redução de consumo apresentadas, foram utilizadas as de isolamento de operandos, dimensionamento de portas lógicas e balanceamento de atrasos de propagação. A técnica de múltiplas tensões de alimentação foi testada, mas não produziu resultados melhores. Das demais técnicas que poderiam ser aplicadas a esta ULA, pipelining poderia trazer benefícios ao desempenho da ULA, conforme apresentado na Seção 4.9.

No caso da tecnologia utilizada, o consumo estático é muito menor que o consumo dinâmico, como pode ser observado nos resultados de simulação da Seção 4.8. Assim, a aplicação das técnicas de redução de consumo estático não trariam vantagens significativas à ULA e, por isso, não foram consideradas no projeto.

Este trabalho apresenta, além das principais técnicas de redução de consumo em circuitos digitais CMOS e das principais estruturas utilizadas na construção de ULAs, todas as etapas do projeto de uma ULA, tornando-se uma referência para o projeto de outras ULAs de baixo consumo.

\subsection{Trabalhos futuros}

Nesta seção, são apresentados alguns trabalhos futuros, incluindo as melhorias apontadas na Seção 4.9. Especificamente, os trabalhos identificados são:

- implementação da geração de flags para indicar características do resultado, como, por exemplo, as flags de zero e de overflow;

- implementação de outras operações na ULA, como multiplicação e divisão; 
- projeto de um registrador de baixo consumo e utilização deste registrador para implementação de um pipeline com o objetivo de reduzir o consumo de potência;

- aumento da testabilidade do circuito, considerando o projeto de estruturas para teste do circuito ou aplicação de alguma outra técnica que permita a verificação do correto funcionamento da ULA;

- fabricação da ULA projetada para verificar seu desempenho real;

- alteração do projeto da ULA para suportar operandos maiores, como, por exemplo, de 32 ou de 64 bits;

- alteração do projeto da ULA para uma tecnologia com transistores menores para comparação dos resultados da aplicação de técnicas de redução de consumo.

No caso da alteração do projeto da ULA para implementação de outras operações, para suportar operandos maiores ou para utilização de outra tecnologia, deve-se verificar novamente a viabilidade de algumas técnicas de redução de consumo de potência como, por exemplo, a de múltiplas tensões de alimentação. A realização destas alterações é interessante para comparar os resultados obtidos e verificar, por exemplo, como os parâmetros de desempenho da ULA variam em função do número de bits dos operandos ou da tecnologia utilizada.

Além disso, para validar a interface e a utilidade das operações da ULA projetada, seria interessante emprega-la no projeto de um microprocessador ou outro circuito similar. No caso do emprego da ULA para uma aplicação específica, algumas alterações podem ser necessárias para adaptar os parâmetros de desempenho da ULA, principalmente atraso e consumo, e as operações que ela realiza, aos requisitos dessa aplicação. 



\section{Referências}

ALVERSON, R. Integer division using reciprocals. In: IEEE SYMPOSIUM ON COMPUTER ARITHMETIC, 2005, Grenoble. Proceedings... Los Alamitos: IEEE Computer Society, 2005. p. 186-190.

AMELIFARD, B.; FALLAH, F.; PEDRAM, M. Closing the Gap between Carry Select Adder and Ripple Carry Adder: A New Class of Low-power High-performance Adders. In: INTERNATIONAL SYMPOSIUM ON QUALITY OF ELECTRONIC DESIGN, 6, 2005, San Jose. Proceedings... Los Alamitos: IEEE Computer Society, 2005. p. $148-152$.

ASHMILA, E. M.; DLAY, S. S.; HINTON, O. R. Adder methodology and design using probabilistic multiple carry estimates. IEE Proceedings: Computers and Digital Techniques, Stevenage, UK, v. 152, n. 6, p. 697-703, November 2005.

AUSTRIAMICROSYSTEMS. 0.35 $\mathrm{\mu}$ CMOS Technology Selection Guide, 2013. Disponivel em: <http://www.austriamicrosystems.com/eng/Products/Full-ServiceFoundry/Process-Technology/CMOS/0.35-m-CMOS-Technology-Selection-Guide>. Acesso em: 3 fev. 2013.

BAUGH, C. R.; WOOLEY, B. A. A Two's Complement Parallel Array Multiplication Algorithm. IEEE Transactions on Computers, Los Alamitos, v. C-22, n. 12, p. 10451047, December 1973.

BEDRIJ, O. J. Carry-Select Adder. IRE Transactions on Electronic Computers, New York, v. EC-11, n. 3, p. 340-346, junho 1962.

BELLAOUAR, A.; ELMASRY, M. Low-Power Digital VLSI Design. Norwell: Kluwer Academic, 1995. ISBN 0792395875.

BISDOUNIS, L.; KOUFOPAVLOU, O.; NIKOLAIDIS, S. Accurate Evaluation of CMOS Short-Circuit Power Dissipation for Short-Channel Devices. In:

INTERNATIONAL SYMPOSIUM ON LOW POWER ELECTRONICS AND DESIGN, 1996, Monterey. Proceedings... Piscataway: IEEE, 1996. p. 189-192.

BOOTH, A. D. A Signed Binary Multiplication Technique. The Quarterly Journal of Mechanics and Applied Mathematics, Oxford, v. 4, n. 2, p. 236-240, junho 1951.

CADENCE DESIGN SYSTEMS. A Practical Guide to Low-Power Design. Si2. Austin. 2008.

CHATTERJEE, B.; SACHDEV, M. Design of a 1.7-GHz Low-Power Delay-FaultTestable 32-b ALU in 180-nm CMOS Technology. IEEE Transactions on Very Large Scale Integration (VLSI) Systems, Piscataway, v. 13, n. 11, p. 1296-1304, nov. 2005.

DADDA, L. Some schemes for parallel multipliers. Alta Frequenza, n. 34, p. 349356, 1965. 
DAS, D.; RAHAMAN, H. A Novel Signed Array Multiplier. In: INTERNATIONAL CONFERENCE ON ADVANCES IN COMPUTER ENGINEERING, 2010, Bangalore. Proceedings... Los Alamitos: CPS, 2010. p. 19-23.

DEDIC, I. Advances in Semiconductor Technology Towards Low Power. In: TOWARDS TERABIT PER SECOND OPTICAL NETWORKS: INTERNATIONAL WORKSHOP ON TRENDS IN OPTICAL TECHNOLOGIES, 2012, Campinas. Proceedings..., 2012.

GONZALES, R.; HOROWITZ, M. Energy dissipation in General Purpose Microprocessors. IEEE Journal of Solid-State Circuits, Piscataway, v. 31, n. 9 , 1996.

HEMANTHA, S.; DHAWAN, A.; KAR, H. Multi-Threshold CMOS Design for Low Power Digital Circuits. In: IEEE REGION 10 CONFERENCE, 2008, Hyderabad. Proceedings... Piscataway: IEEE, 2008. p. 1-5.

HUERTA, S. C. et al. Review of DVS techniques to reduce power consumption of digital circuits. In: INTERNATIONAL CONFERENCE ON INTEGRATED POWER SYSTEMS, 2006, Naples. Proceedings... Frankfurt: VDE Conferences, 2006. p. 1-6.

HUNTZICKER, S. et al. Energy-Delay Tradeoffs in 32-bit Static Shifter Designs. In: IEEE INTERNATIONAL CONFERENCE ON COMPUTER DESIGN, 2008, Lake Tahoe, CA. Proceedings... Los Alamitos: IEEE Computer Society, 2008. p. 626632.

INSTITUTE OF ELECTRICAL AND ELECTRONICS ENGINEERS. IEEE Standard for Floating-Point Arithmetic. IEEE Computer Society. New York. 2008. (IEEE Std 754-2008).

KALYANARAMAN, V. et al. A Power Dissipation Comparison of ALU-Architectures for ASIPs. In: EUROPEAN CONFERENCE ON CIRCUIT THEORY AND DESIGN, 2005, Cork. Proceedings... Piscataway: IEEE, 2005. p. 217-220.

KAWAHARA, T. et al. Subthreshold current reduction for decoded-driver by selfreverse biasing. IEEE Journal of Solid-State Circuits, Piscataway, v. 28, n. 11, p. 1136-1144, 1993.

KHOO, K.-Y. Efficient VLSI implementation of N/N integer division. In: IEEE INTERNATIONAL SYMPOSIUM ON CIRCUITS AND SYSTEMS, 2005, Kobe. Proceedings... Piscataway: IEEE, 2005. p. 672-675.

KUMAR, M.; ARYA, S.; PANDEY, S. Level Shifter Design for Low Power Applications. International Journal of Computer Science \& Information Technology, Hong-Kong, v. 2, n. 5, p. 124-132, 2010.

LANG, T.; BRUGUERA, J. D. Floating-point Fused Multiply-Add with Reduced Latency. IEEE Transactions on Computers, Los Alamitos, v. 53, n. 8, p. 988-1003, 2004. 
MATHEW, S. K. et al. A 4-GHz 300-mW 64-bit Integer Execution ALU With Dual Supply Voltages in 90-nm CMOS. IEEE Journal of Solid-State Circuits, Piscataway, v. 40, n. 1, 2005.

MEGALINGAM, R. K. et al. Gating and Serializing the Data Path of CPU for Low Power Consumption. In: INTERNATIONAL CONFERENCE ON PARALLEL PROCESSING WORKSHOPS, 2009, Vienna. Proceedings... Los Alamitos: IEEE Computer Society, 2009. p. 550-557.

MENTOR GRAPHICS. Software for IC Design and Circuit Design Verification, 2013. Disponivel em: <http://www.mentor.com/products/ic_nanometer_design/>. Acesso em: 17 fev. 2013.

OCHERETNY, V. Self-Checking Arithmetic Logic Unit with Duplicated Outputs. In: IEEE INTERNATIONAL ON-LINE TESTING SYMPOSIUM, 2010, Piraeus. Proceedings... Los Alamitos: IEEE Computer Society, 2010. p. 202-203.

OHBAN, J.; MOSHNYAGA, V. G.; INOUE, K. Multiplier energy reduction through bypassing of partial products. In: IEEE ASIA-PACIFIC CONFERENCE ON CIRCUITS AND SYSTEMS, 2002, Kaohsiung. Proceedings... [S.I.]: IEEE Circuits and Systems Society, 2002. p. 13-17.

QI, Z. et al. Design of Low-Cost High-performance Floating-point Fused Multiply-Add with Reduced Power. In: INTERNATIONAL CONFERENCE ON VLSI DESIGN, 2010, Bangalore. Proceedings... Los Alamitos: CPS, 2010.

QUINNELL, E. C. Floating-Point Fused Multiply-Add Architectures. 2007. Ph. D. Dissertation - Faculty of the Graduate School, The University of Texas at Austin. 2007.

RABAEY, J. M.; CHANDRAKASAN, A.; BORIVOJE, N. Digital Integrated Circuits. 2. ed. Upper Saddle River: Prentice Hall, 2003.

RAZAVI, B. Design of Analog CMOS Integrated Circuits. 1. ed. New York: McGraw-Hill, 2001.

SUN, J.; JIANG, A. The Power Dissipation Comparison of Different ALU Architectures. In: INTERNATIONAL CONFERENCE ON MECHANICAL AND ELECTRICAL TECHNOLOGY, 2010, Singapore. Proceedings... Chengdu: IEEE, 2010. p. 430-433.

SUN, Y.; ZHANG, X.; JIN, X. Low-power Carry Select Adder Using Fast All-one Finding Logic. In: IEEE INTERNATIONAL CONFERENCE ON SYSTEM OF SYSTEMS ENGINEERING, 2008, Monterey. Proceedings... Piscataway: IEEE, 2008. p. 1-5.

TRAN, C. Q.; KAWAGUCHI, H.; SAKURAI, T. Low-power High-speed Level Shifter Design for Block-level Dynamic Voltage Scaling Environment. In: IEEE INTERNATIONAL CONFERENCE ON INTEGRATED CIRCUIT AND TECHNOLOGY, 2005, Austin. Proceedings... Piscataway: IEEE, 2005. 
UNIVERSITY OF SOUTHERN CALIFORNIA. Internet Protocol. IETF. [S.I.]. 1981. (RFC 791).

WALLACE, C. S. A Suggestion for a Fast Multiplier. IEEE Transactions on Electronic Computers, New York, v. EC-13, n. 1, p. 14-17, fev. 1964.

WEN, M.-C.; WANG, S.-J.; LIN, Y.-N. Low-power parallel multiplier with column bypassing. Electronics Letters, London, v. 41, n. 10, p. 581-583, May 2005.

YAN, J.-T.; CHEN, Z.-W. Low-Power Multiplier Design with Row and Column Bypassing. In: IEEE INTERNATIONAL SOC CONFERENCE, 2009, Belfast.

Proceedings... Belfast: Queen's University, 2009. p. 227-230.

YAN, J.-T.; CHEN, Z.-W. Low-Cost Low-Power Bypassing-Based Multiplier Design. In: IEEE INTERNATIONAL SYMPOSIUM ON CIRCUITS AND SYSTEMS, 2010, Paris. Proceedings... Piscataway: IEEE, 2010. p. 2338-2341.

YOUNGJOON, K.; LEE-SUP, K. A low power carry select adder with reduced area. In: IEEE INTERNATIONAL SYMPOSIUM ON CIRCUITS AND SYSTEMS, 2001, Sydney. Proceedings... Piscataway: IEEE, 2001. p. 218-221.

ZHAI, B. et al. Theoretical and Practical Limits of Dynamic Voltage Scaling. In: DESIGN AUTOMATION CONFERENCE, 2004, San Diego. Proceedings... New York: ACM, 2004. p. 868-873.

ZHANG, G. et al. Low Power Techniques on a High Speed Floating-point Adder Design. In: IEEE INTERNATIONAL CONFERENCE ON INTEGRATION TECHNOLOGY, 2007, Shenzhen. Proceedings... , 2007. p. 241-244.

ZHOU, Y.; GUO, H. Application Specific Low Power ALU Design. In: IEEE/IFIP INTERNATIONAL CONFERENCE ON EMBEDDED AND UBIQUITOUS COMPUTING, 2008, Sydney. Proceedings... Los Alamitos: IEEE Computer Society, 2008. p. 214-220. 


\section{APÊNDICE A - Descrição da ULA em VHDL}

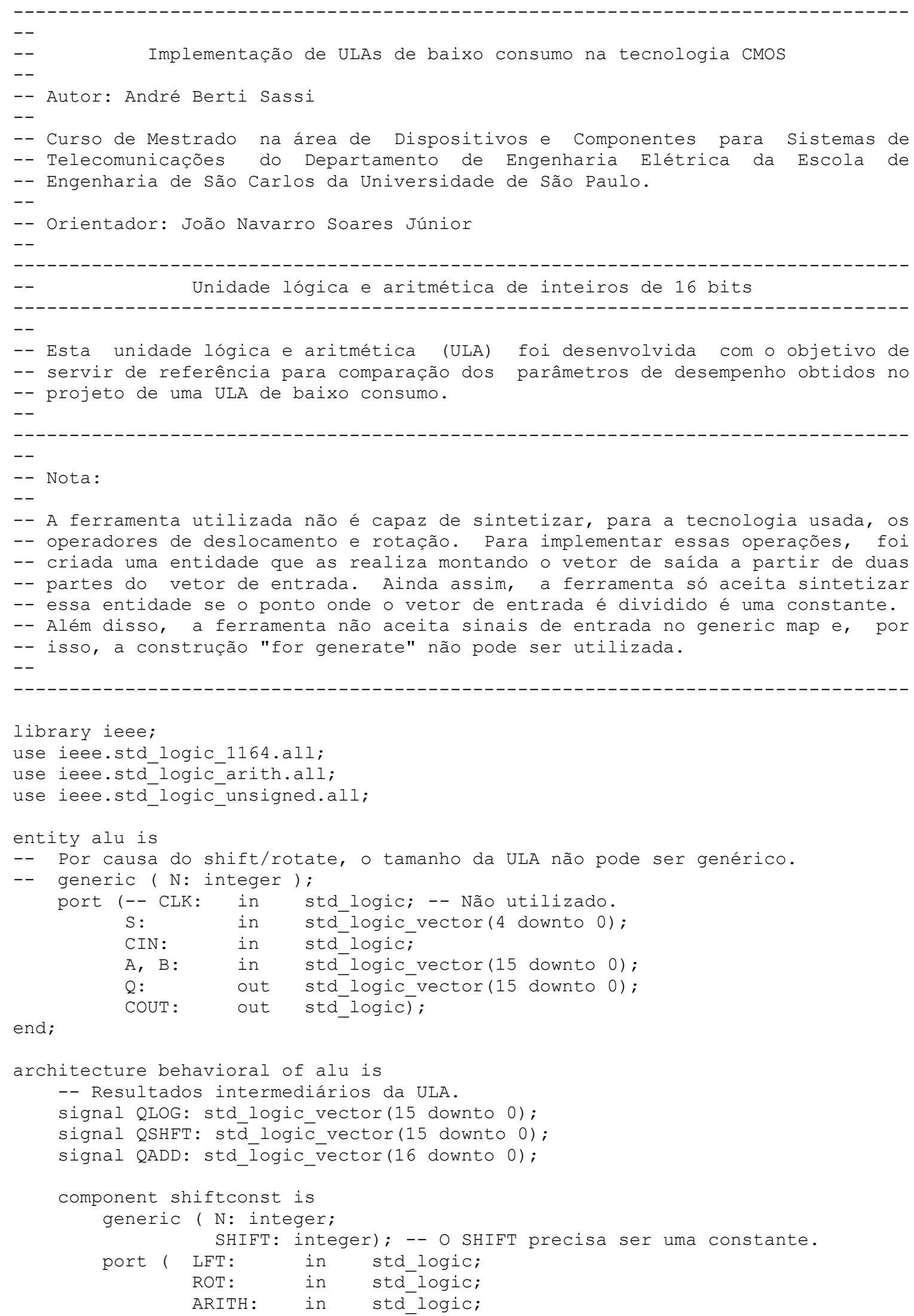




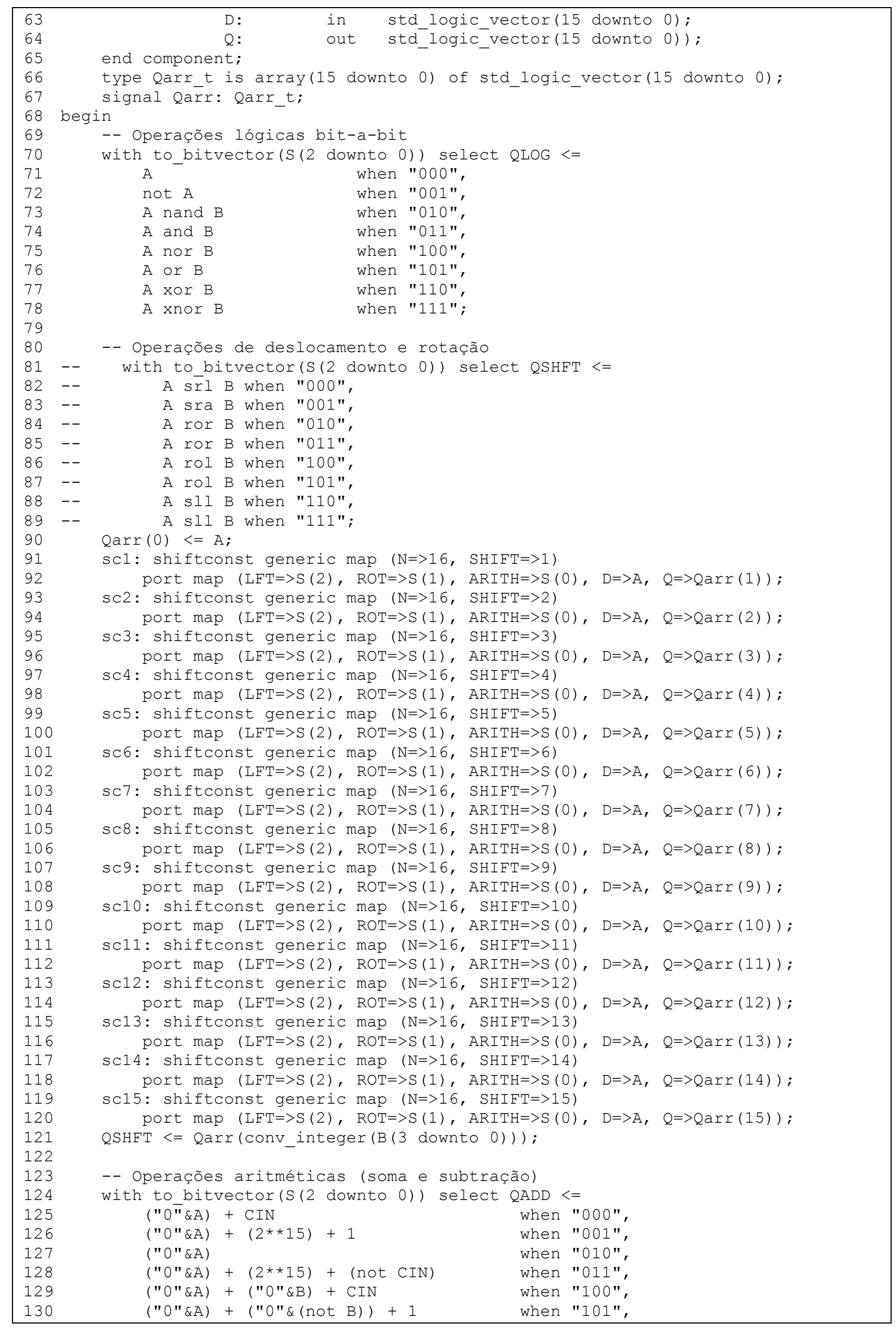




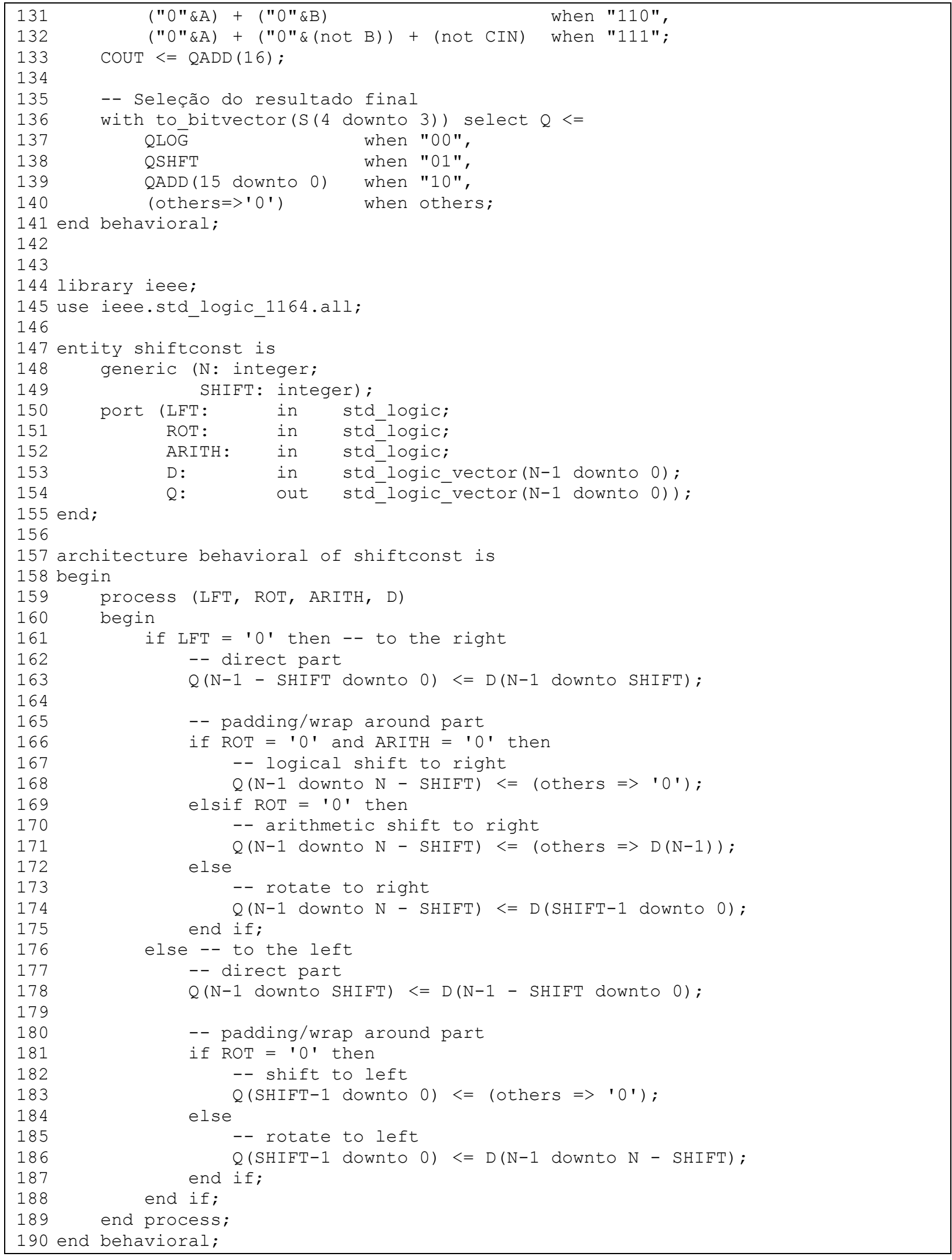





\section{APÊNDICE B - Descrição do mascarador do barrel shifter}

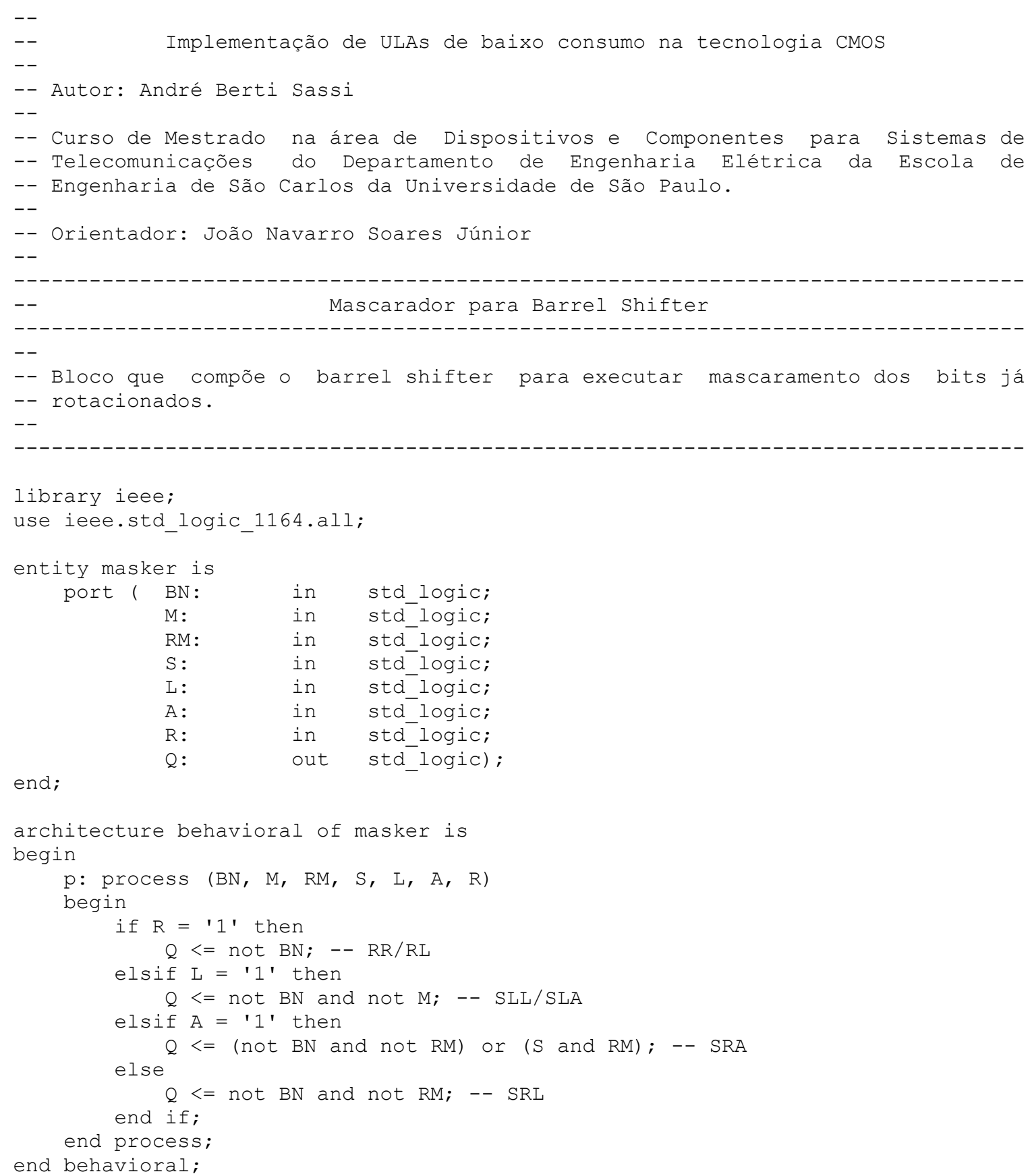





\section{APÊNDICE C - Esquemáticos da ULA projetada}

Abaixo, estão os esquemáticos de todos os blocos que compõe a ULA, conforme desenhados na ferramenta utilizada. Não estão apresentados os esquemáticos das células-padrão da biblioteca fornecida pela AMS.

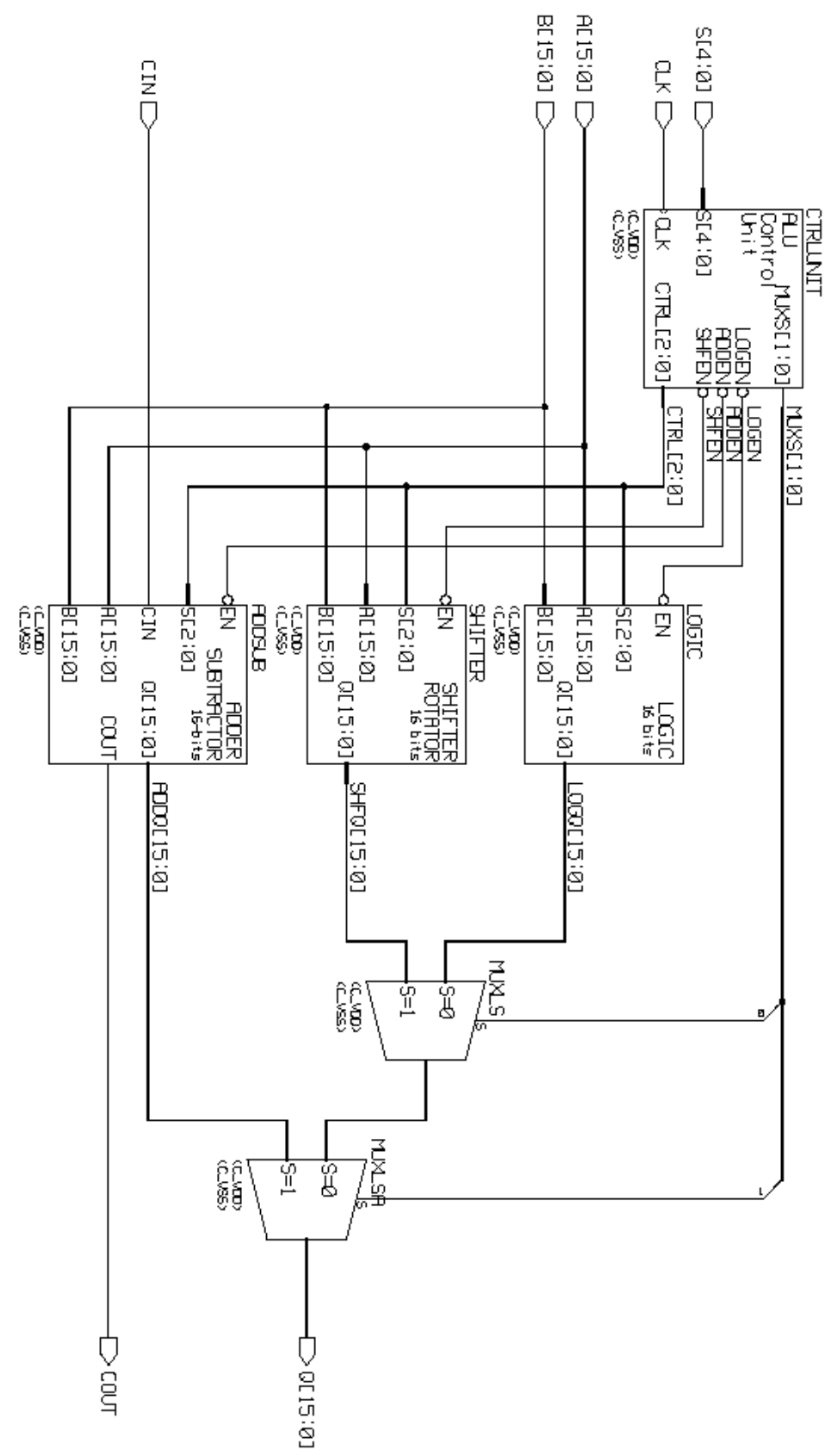

Figura C.1: Esquemático da célula alu16: a ULA. 


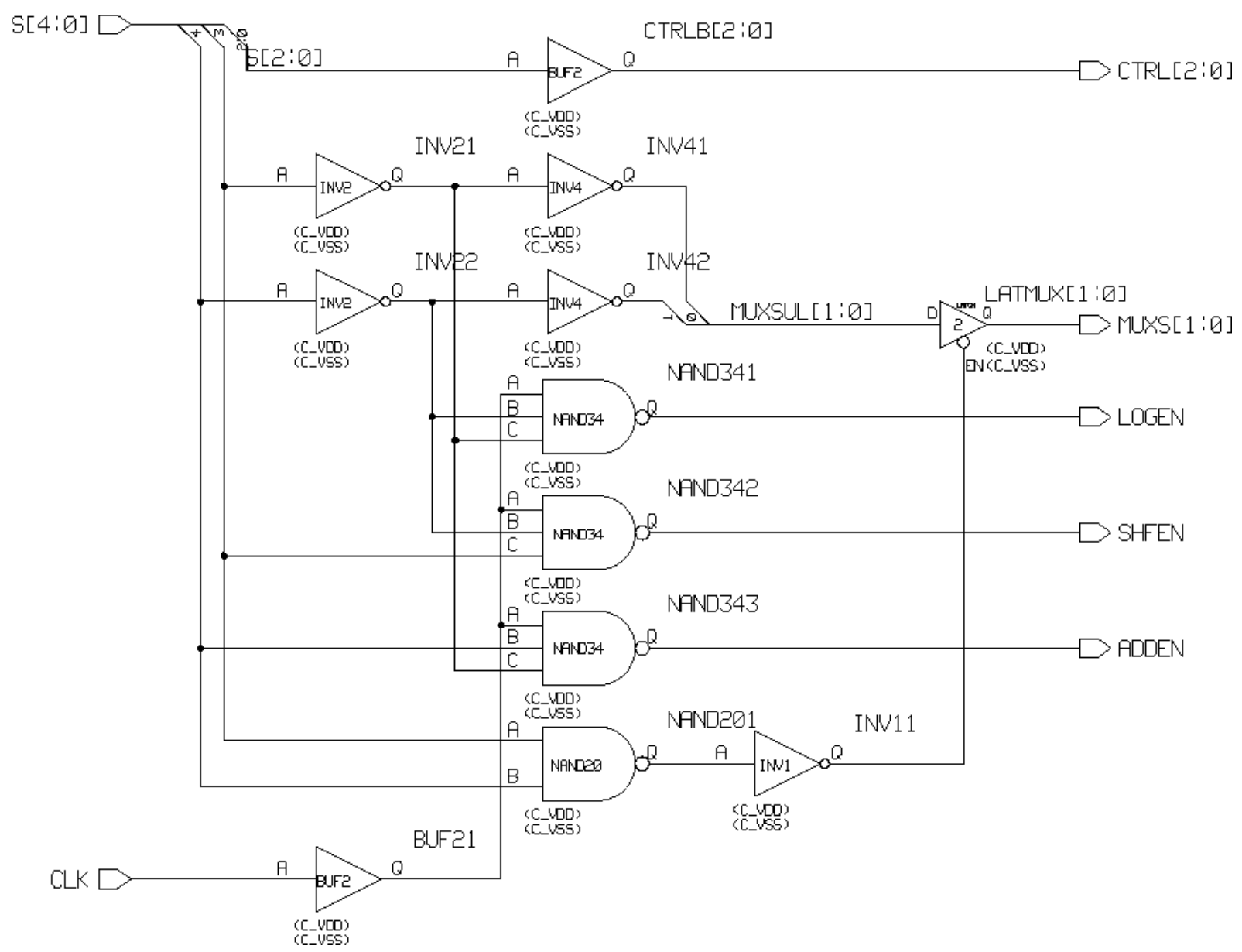

Figura C.2: Esquemático da célula control: unidade de controle da ULA.

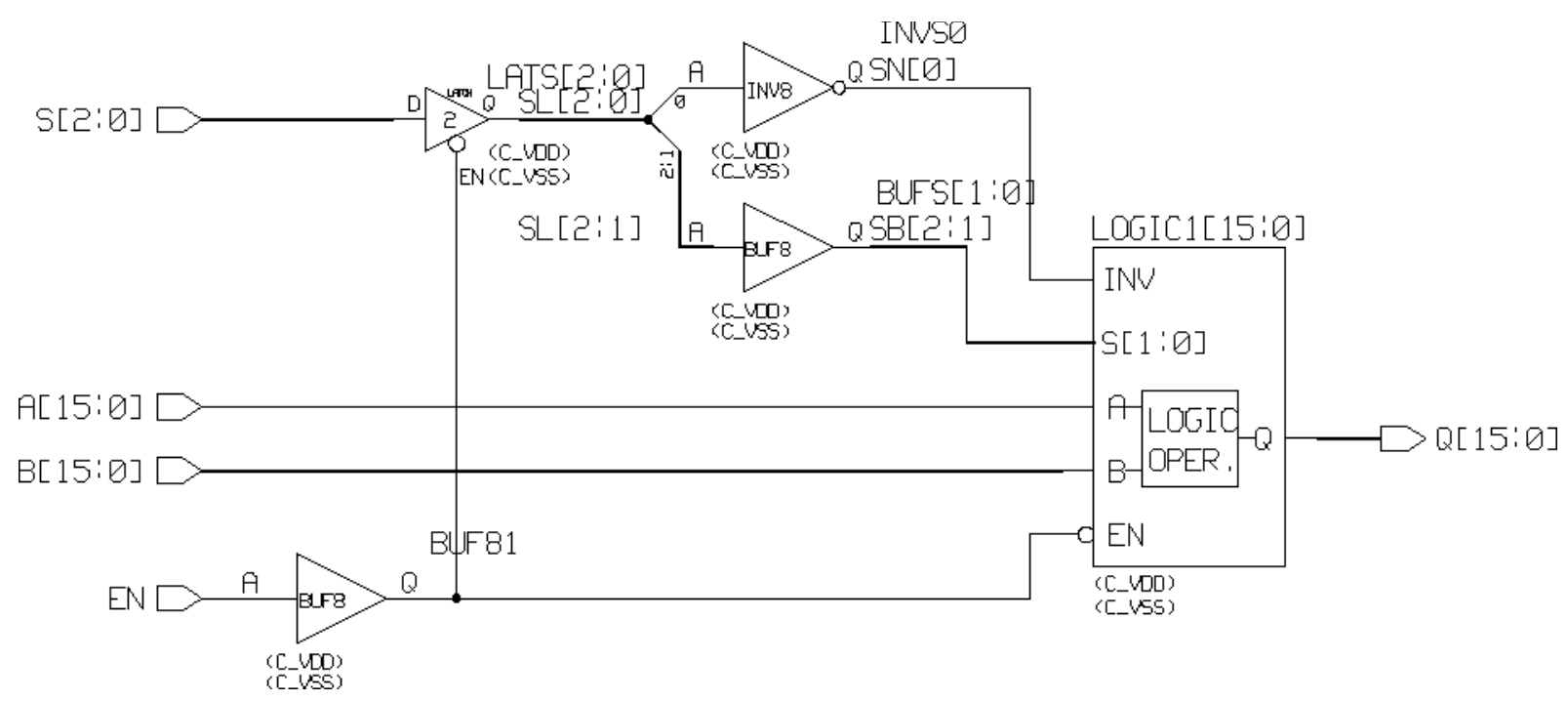

Figura C.3: Esquemático da célula logic16: bloco de operações lógicas bit-a-bit. 


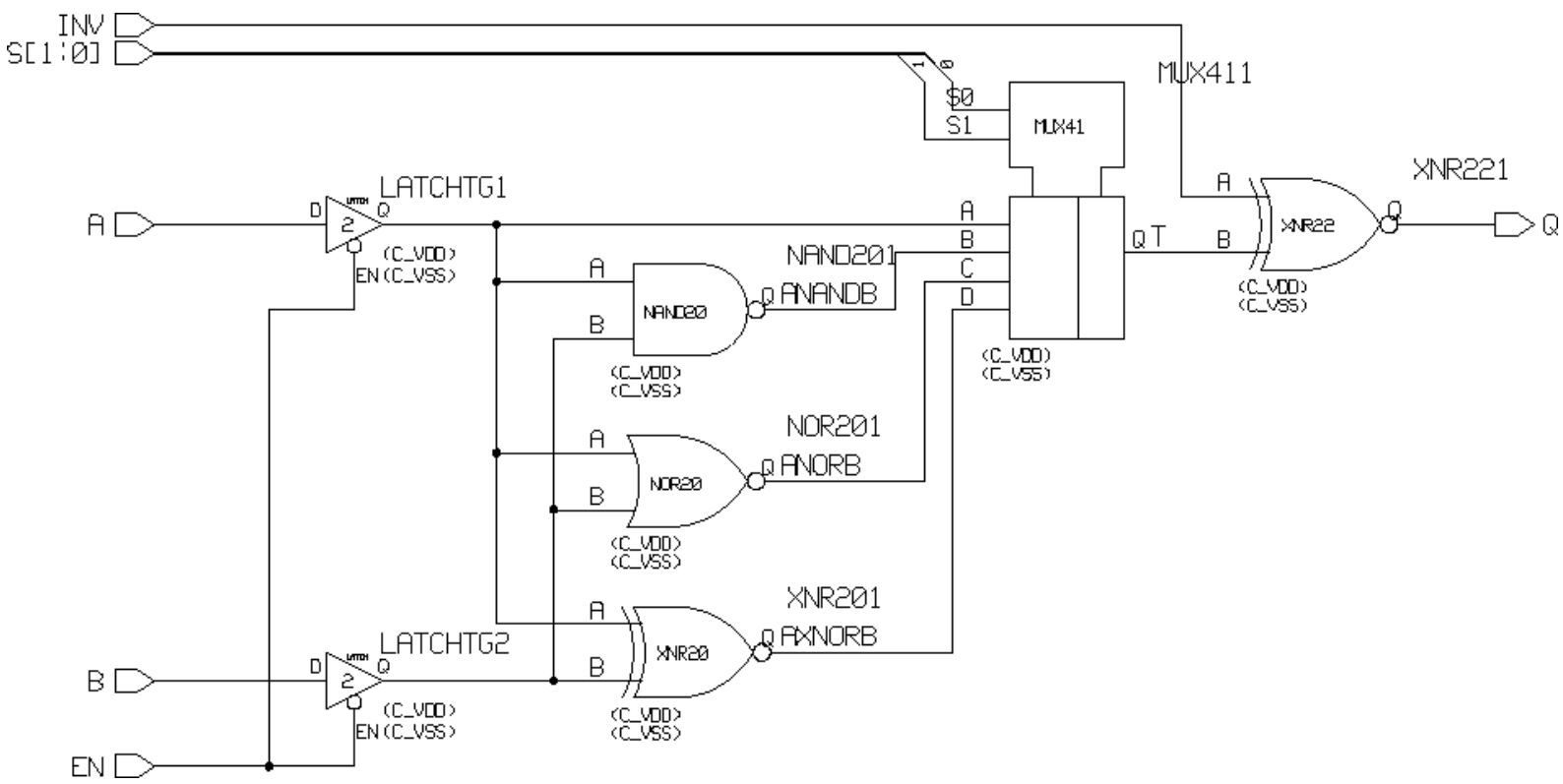

Figura C.4: Esquemático da célula logic1: operação lógica de um bit.

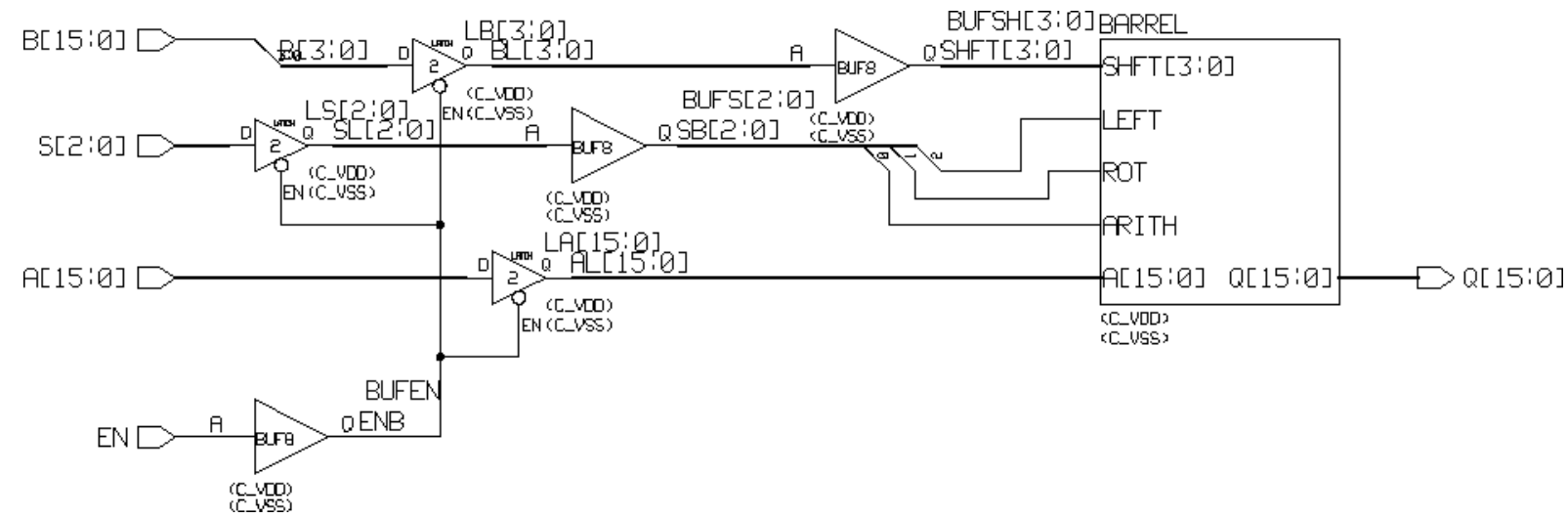

Figura C.5: Esquemático da célula shifter16: bloco de operações de deslocamento e rotação.

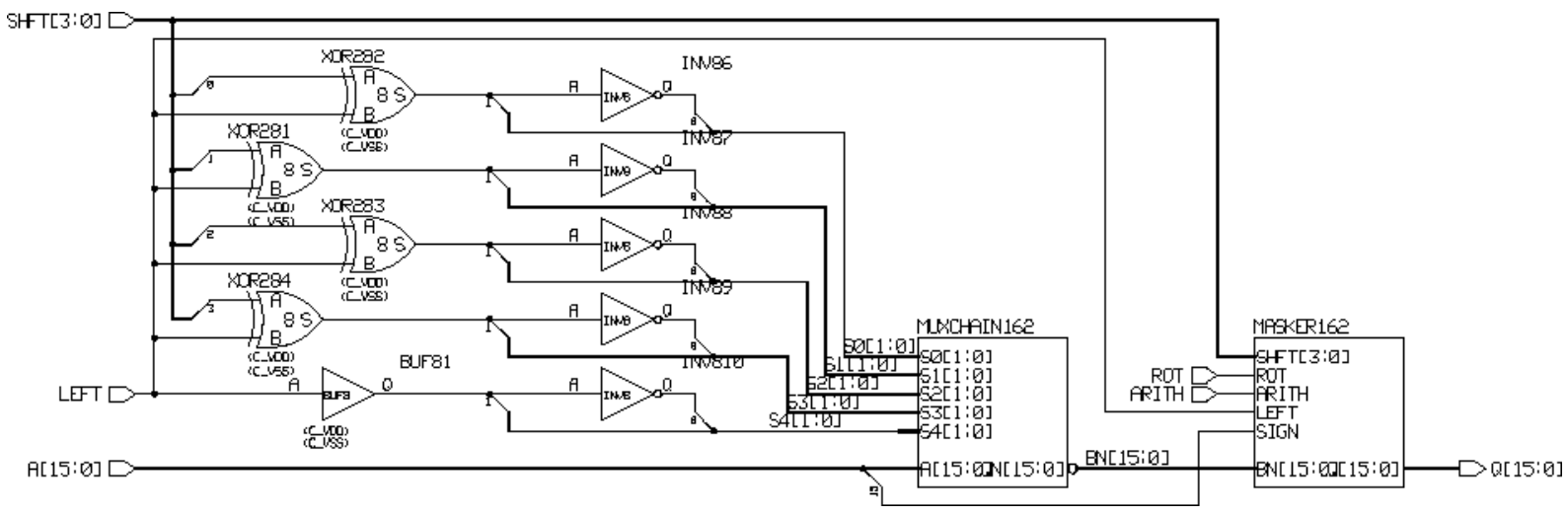

Figura C.6: Esquemático da célula barrel16: barrel shifter. 


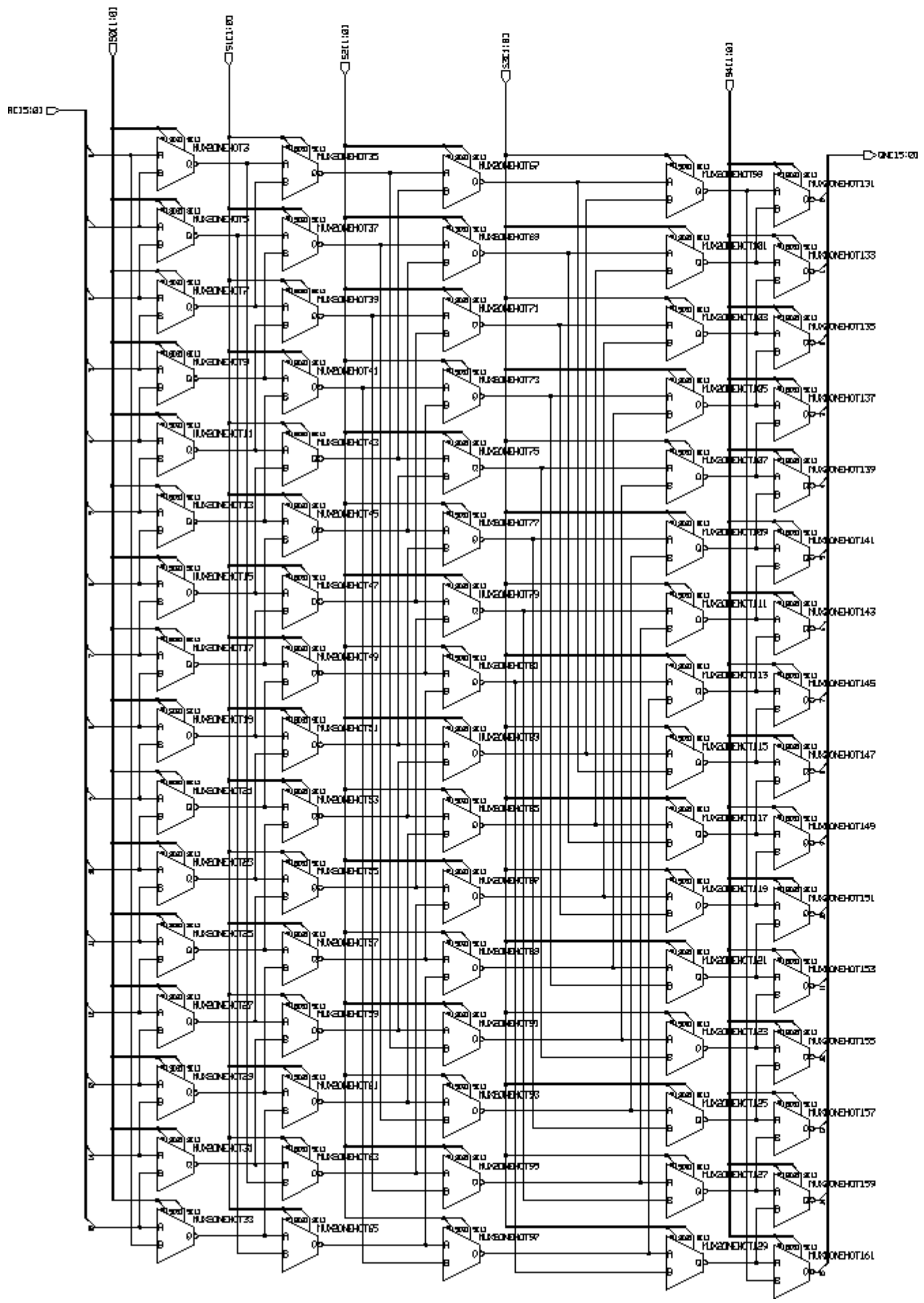

Figura C.7: Esquemático da célula muxchain16: cadeia de multiplexadores do barrel shifter. 


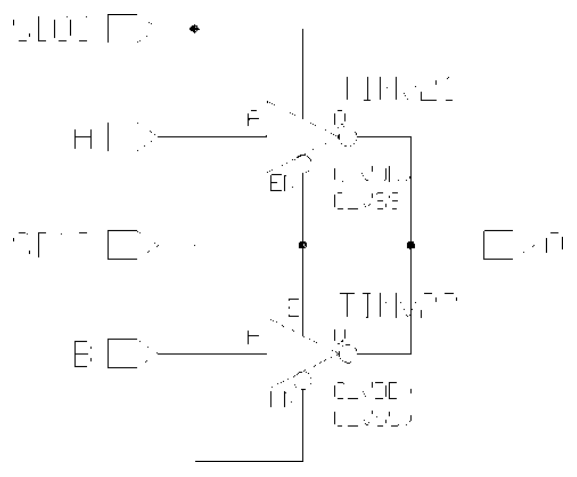

Figura C.8: Esquemático da célula mux2: multiplexador de duas entradas usado no barrel shifter.

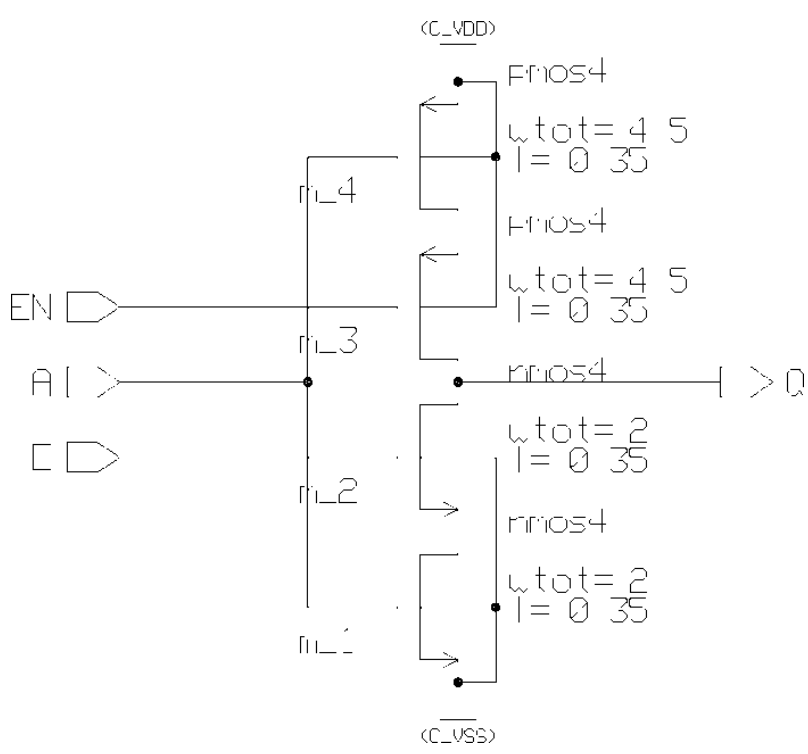

Figura C.9: Esquemático da célula tinv2: inversor utilizado na construção do multiplexador.

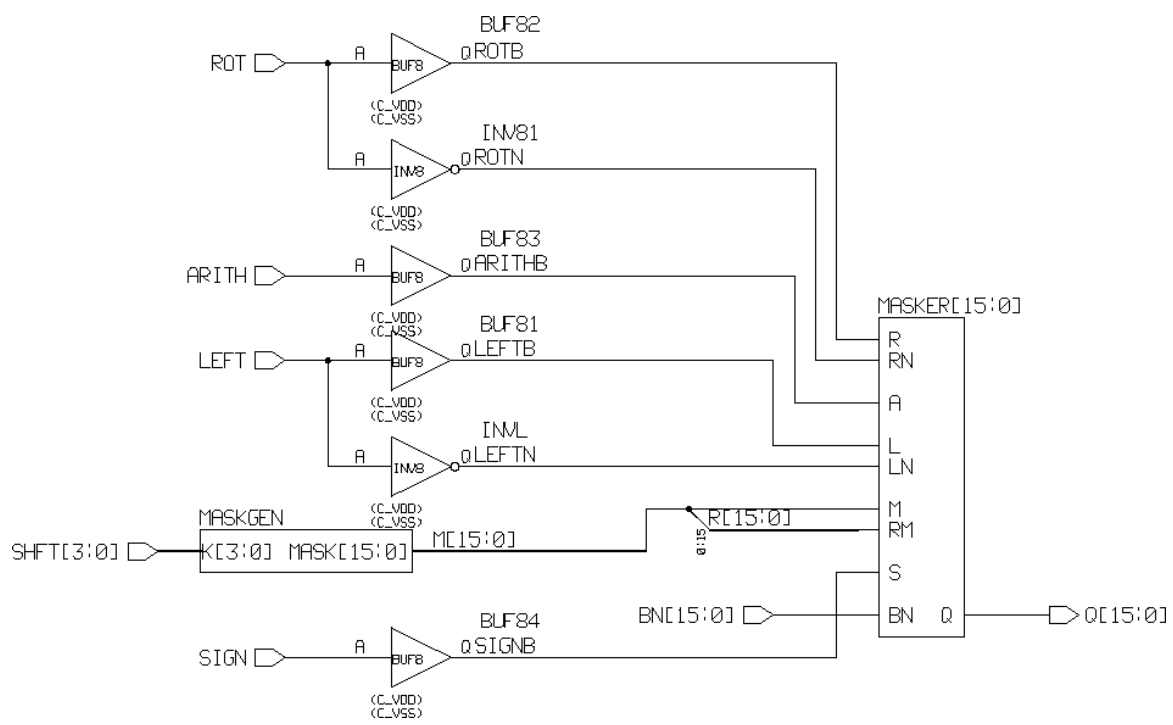

Figura C.10: Esquemático da célula masker16: geração da máscara e mascarador do barrel shifter. 


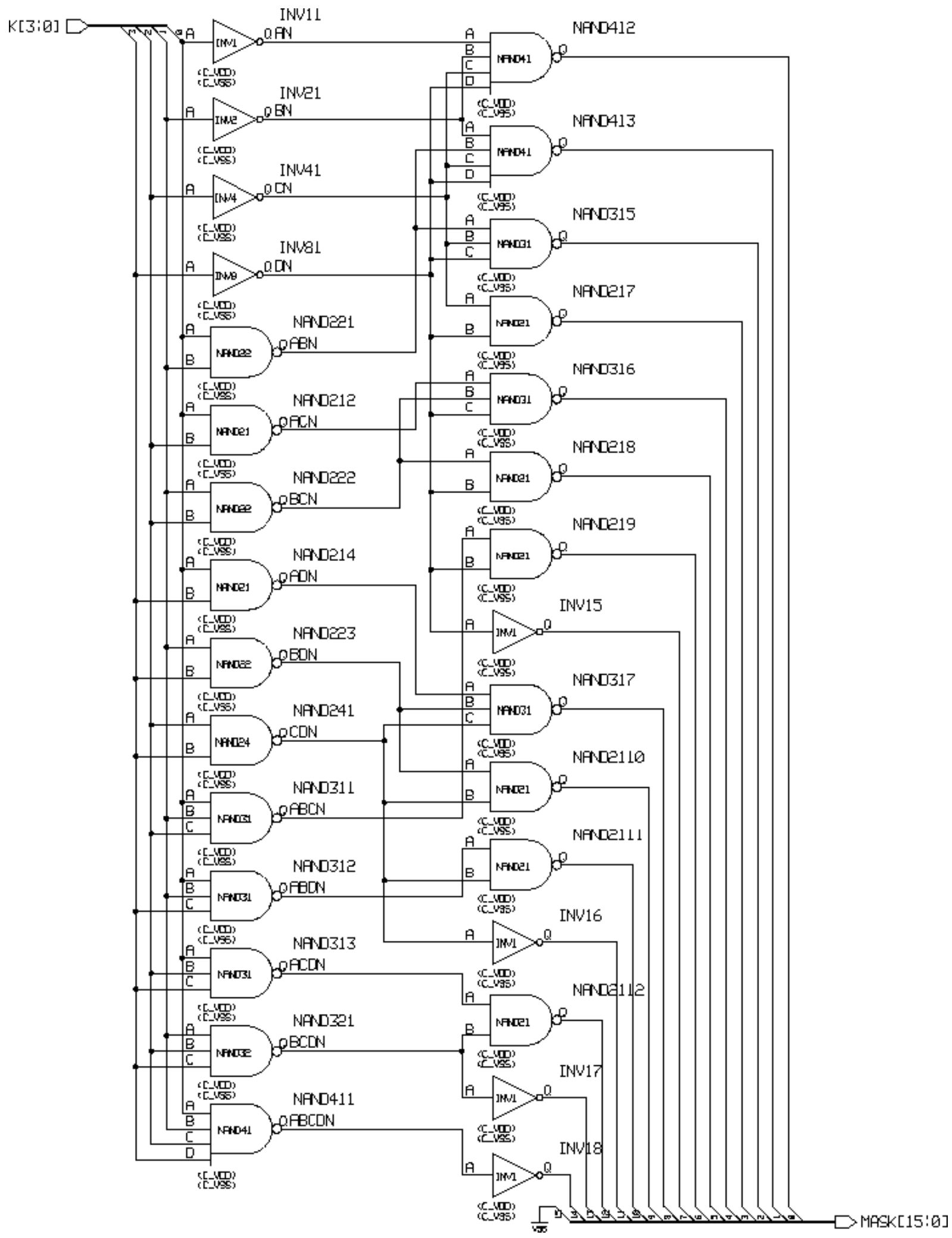

Figura C.11: Esquemático da célula maskgen16: gerador da máscara do barrel shifter. 


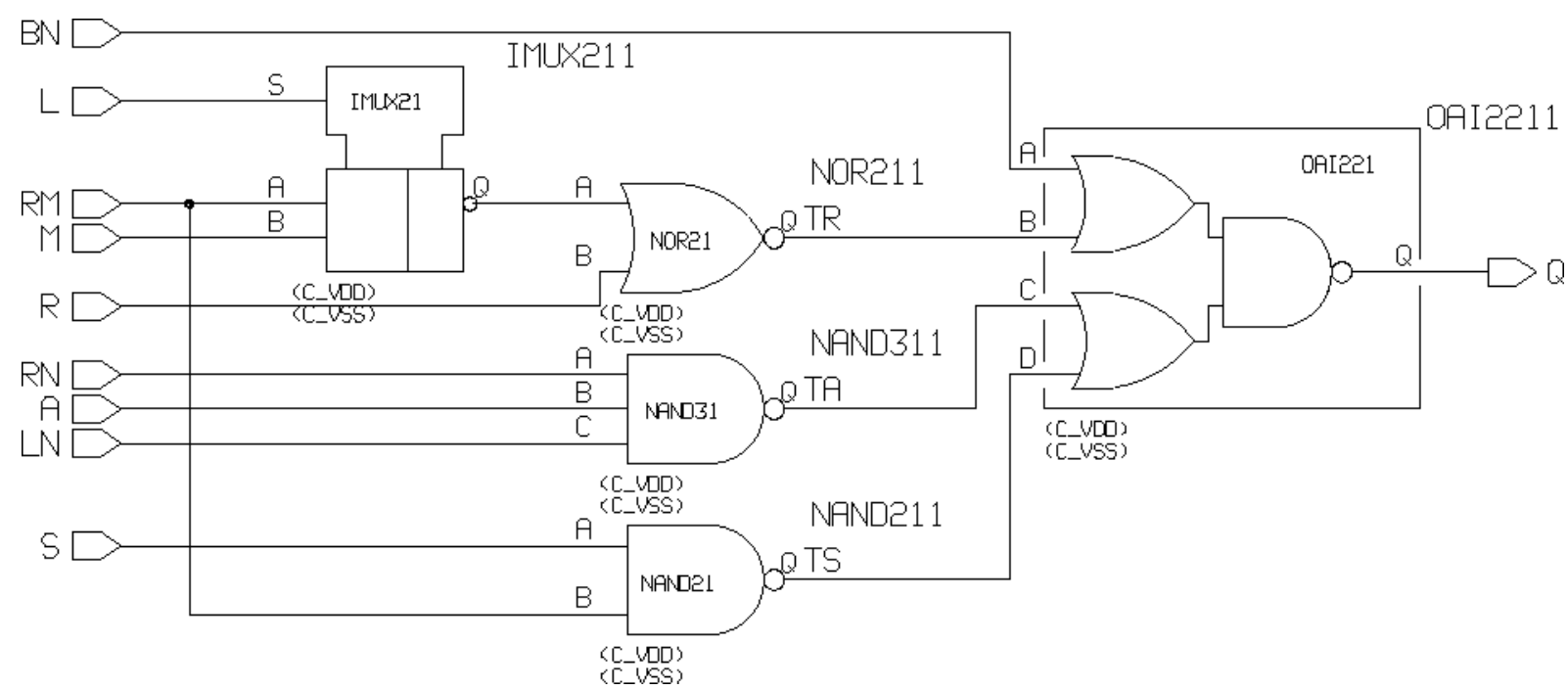

Figura C.12: Esquemático da célula masker1: mascarador de um bit do barrel shifter.

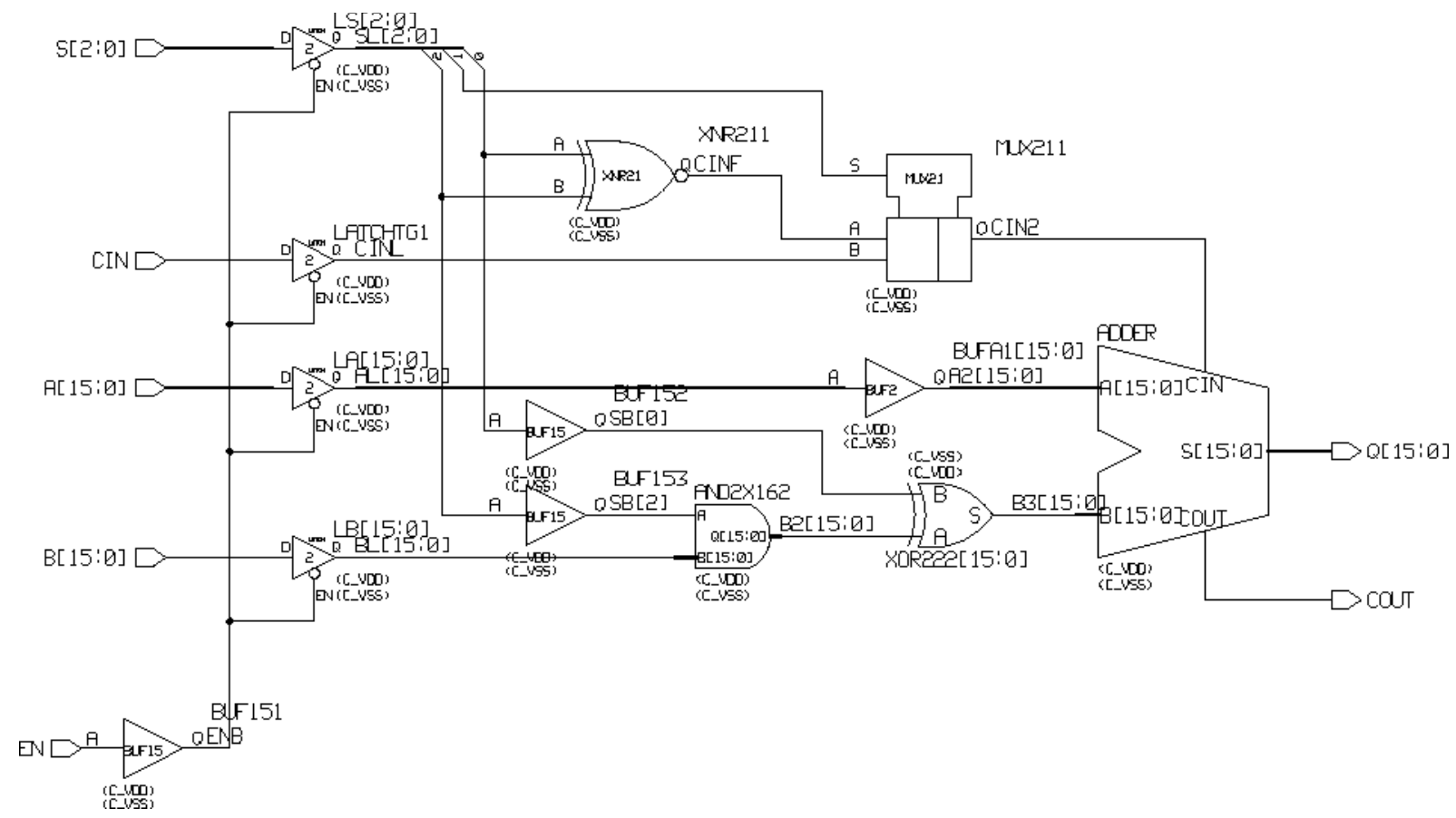

Figura C.13: Esquemático da célula addsub16: bloco de operações aritméticas. 


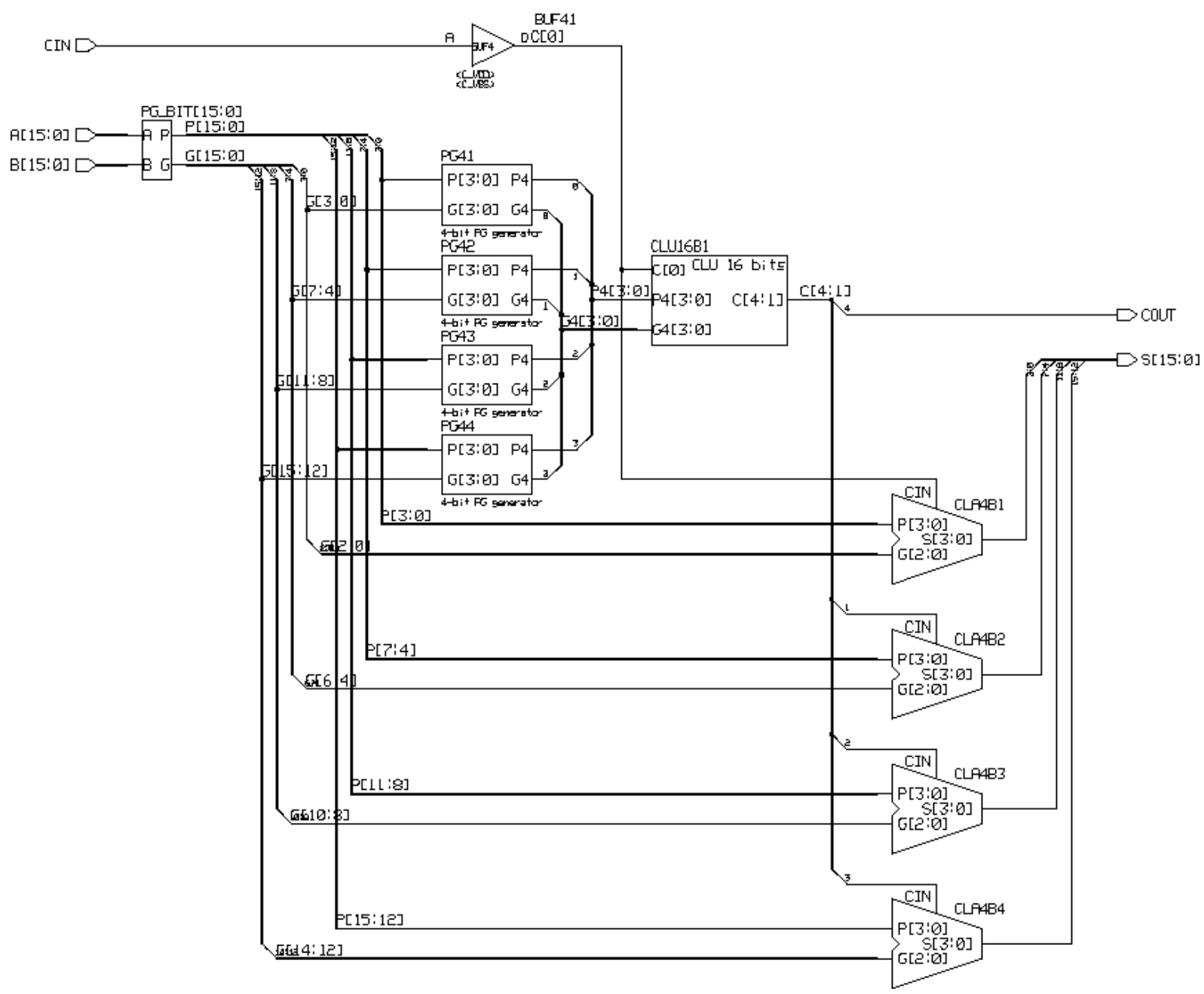

Figura C.14: Esquemático da célula cla16: somador do tipo CLA de 16 bits.

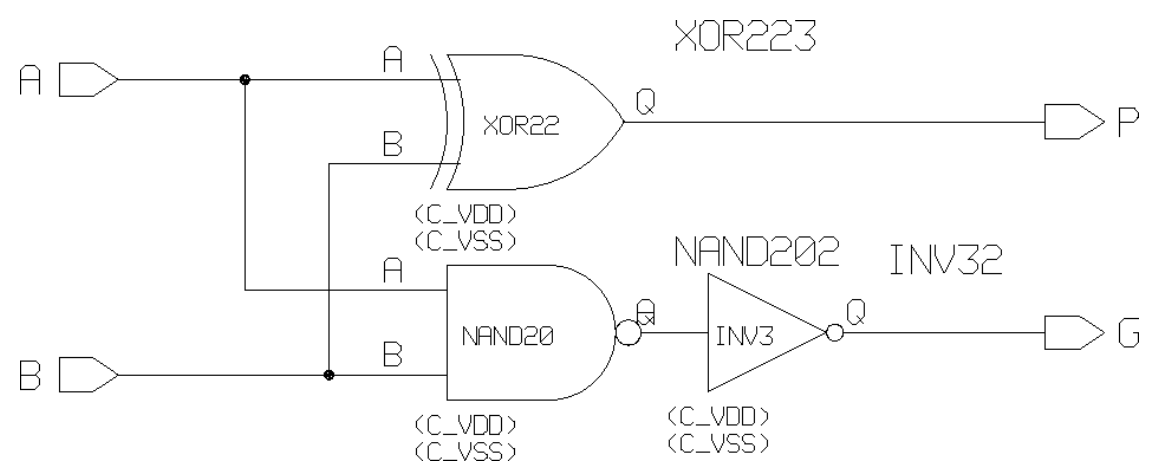

Figura C.15: Esquemático da célula pg1: geração dos sinais $p$ e $g$ para somador CLA. 


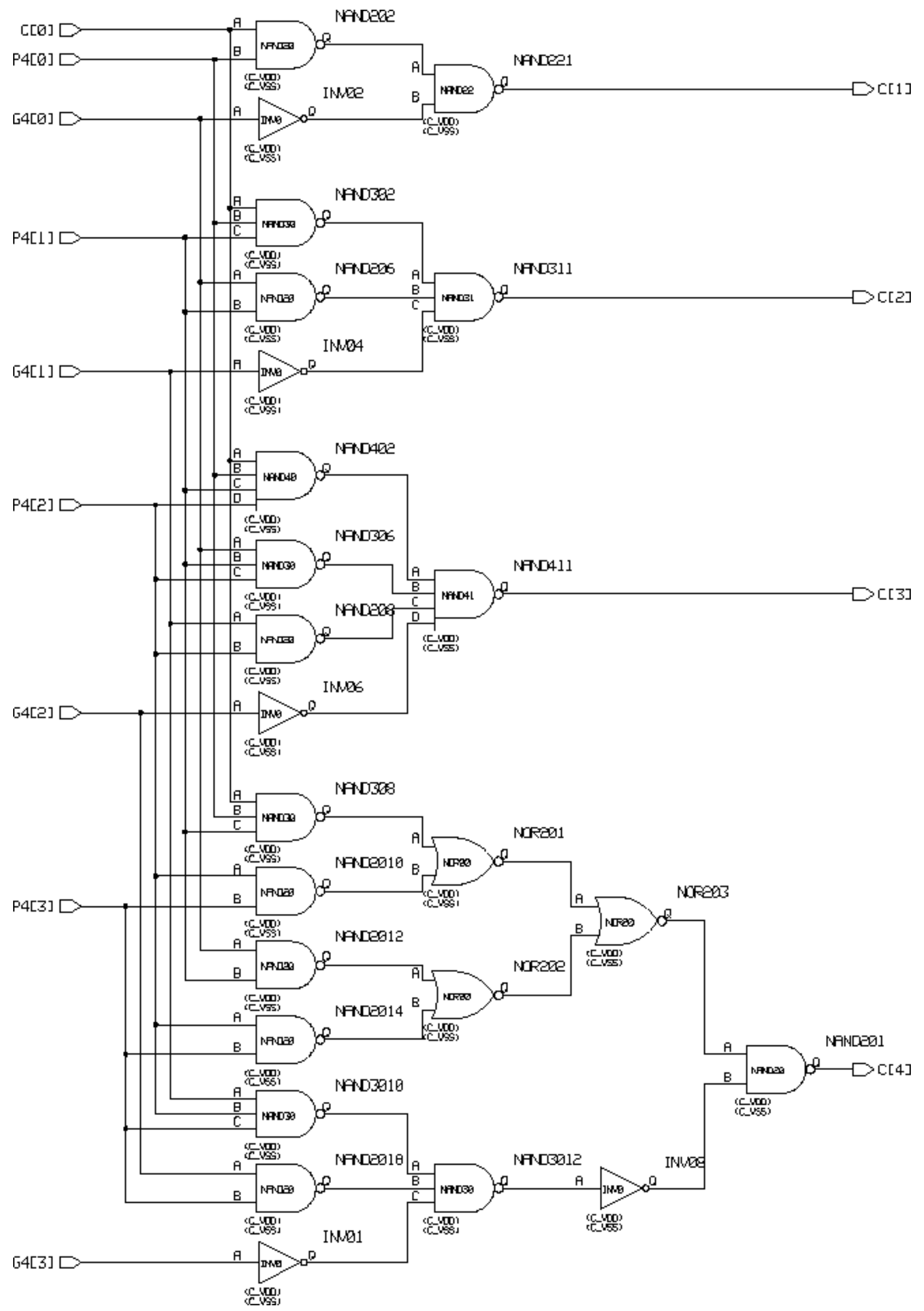

Figura C.16: Esquemático da célula clu16: carry-lookahead unit para CLA de 16 bits. 


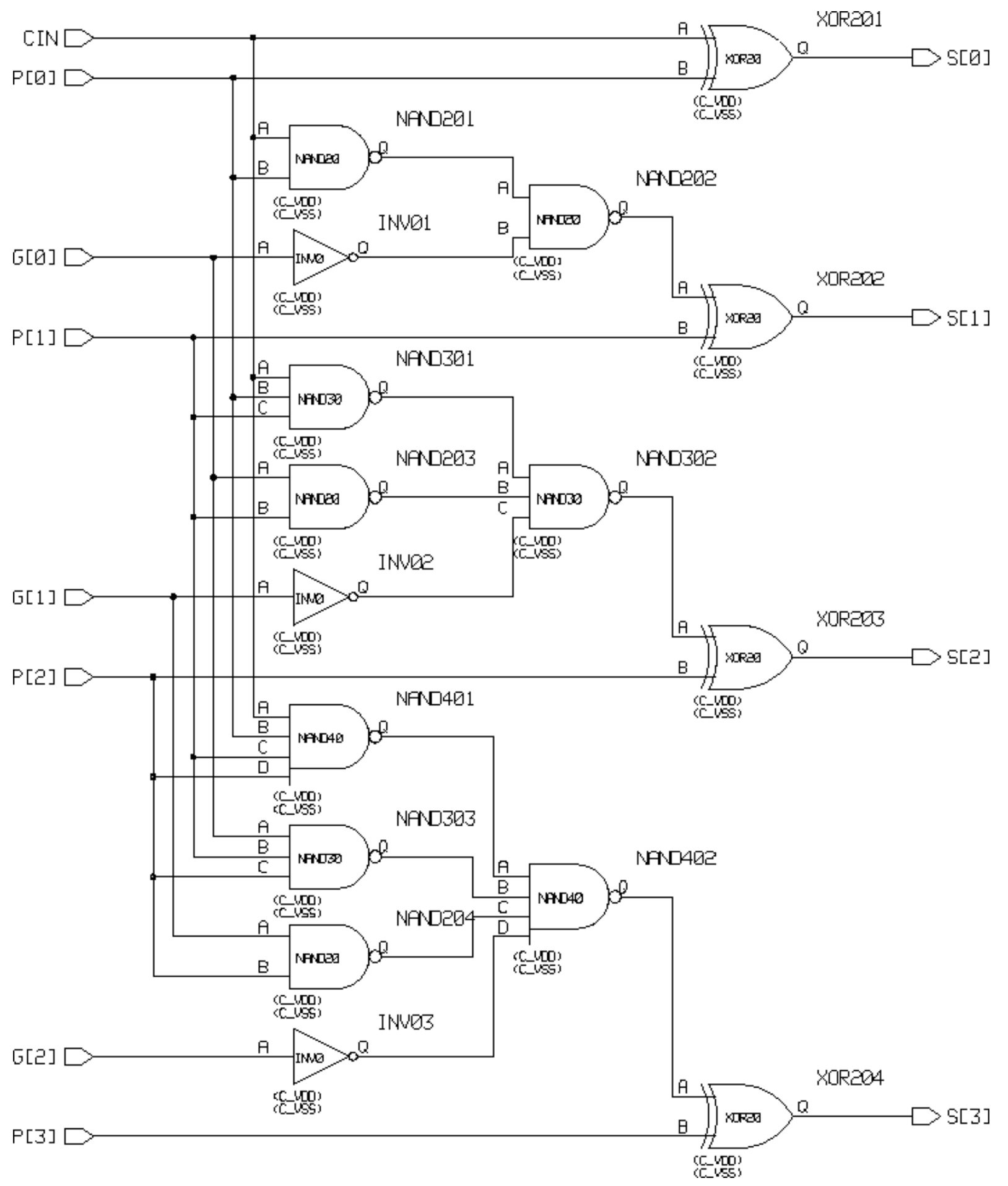

Figura C.17: Esquemático da célula cla4: somador do tipo CLA de 4 bits sem carry-out. 


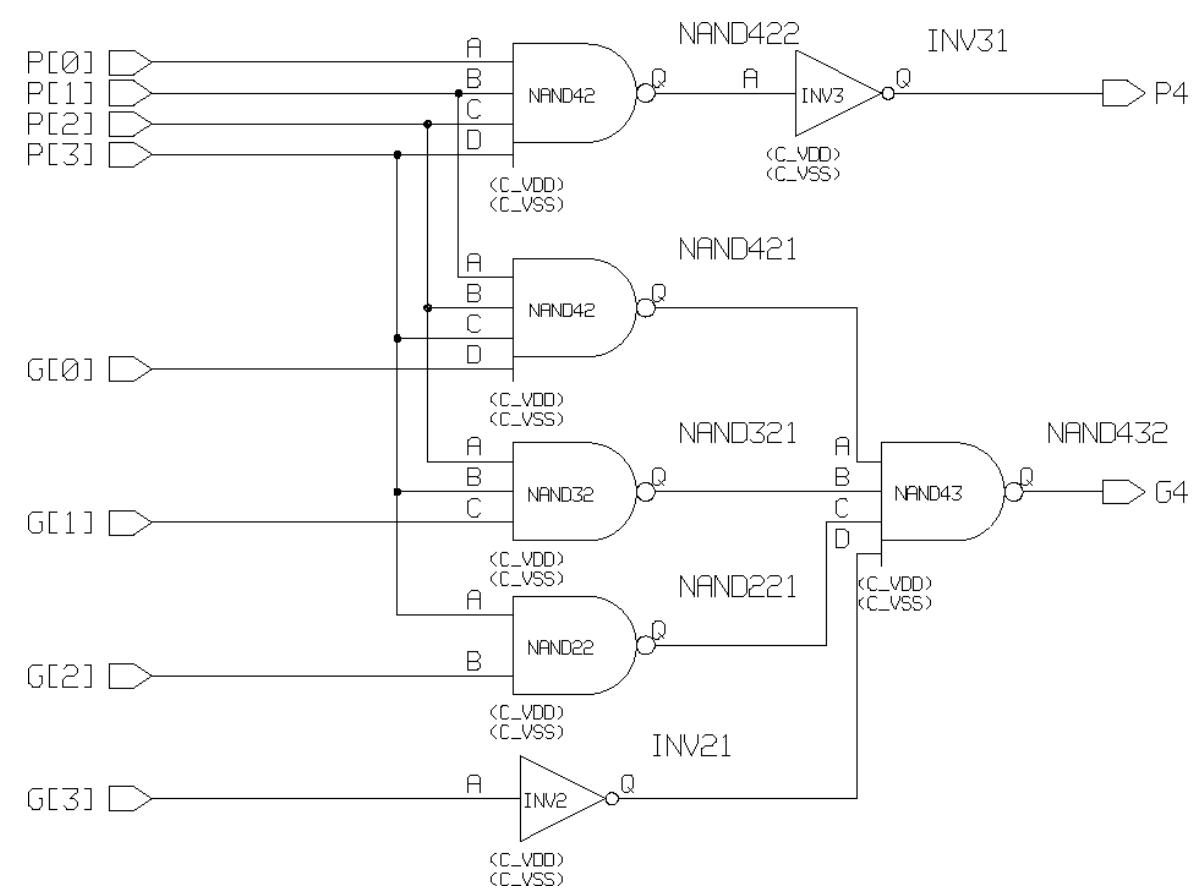

Figura C.18: Esquemático da célula pg4: geração dos sinais $p_{G}$ e $g_{G}$ para somador CLA.

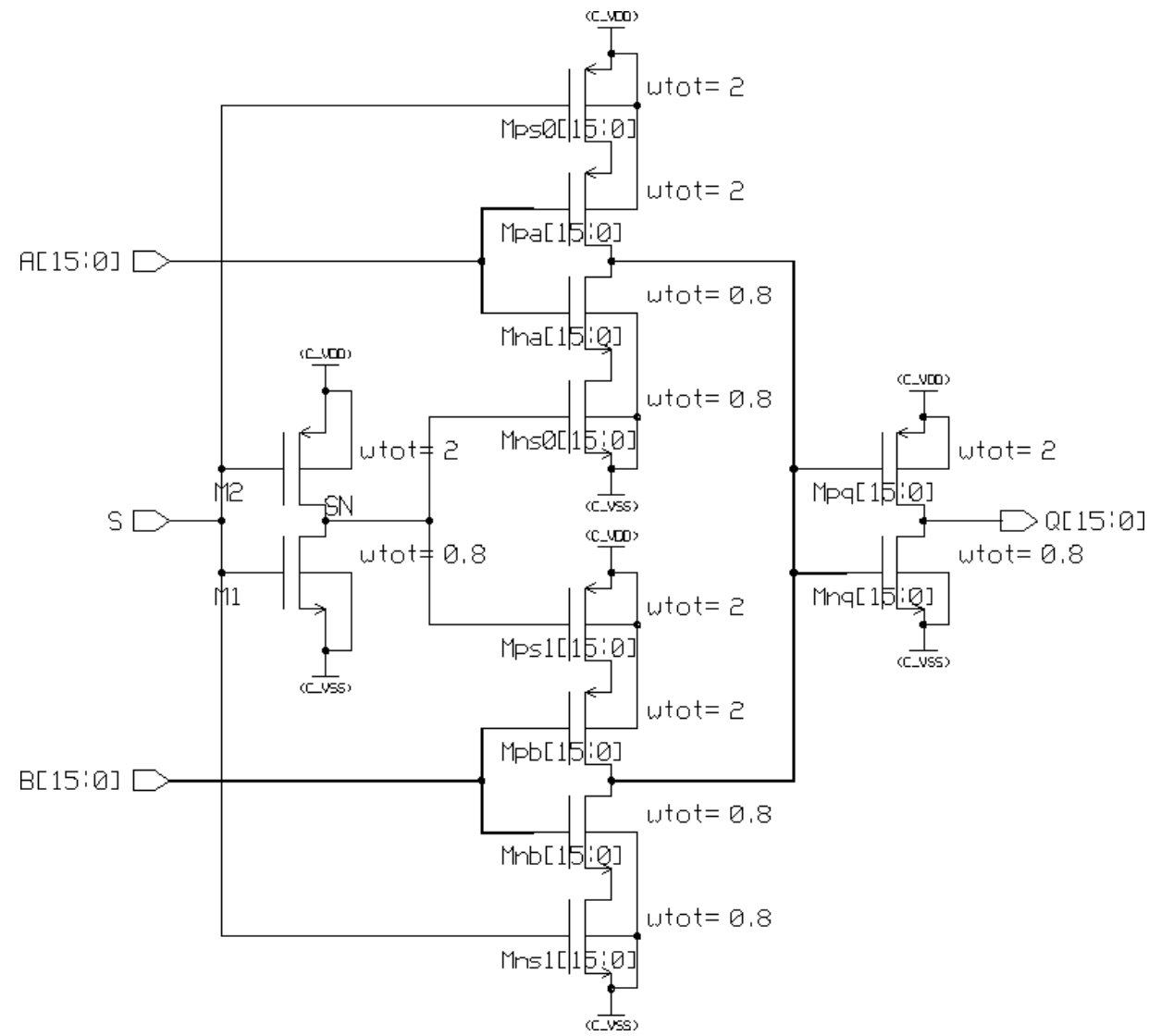

Figura C.19: Esquemático da célula mux16: multiplexador de duas entradas de 16 bits. 



\section{APÊNDICE D - Layouts da ULA projetada}

Abaixo, estão todos os layouts desenhados no projeto da ULA, conforme visualizados na ferramenta utilizada. Não estão apresentados os layouts das célulaspadrão da biblioteca fornecida pela AMS. As dimensões apresentadas de cada layout consideram a região da célula efetivamente ocupada, isto é, não considera a área ocupada por camadas que não impedem o posicionamento de outras células.

As cores utilizadas nas Figuras D.2 a D.18 para as principais camadas de projeto estão relacionadas na legenda a seguir:

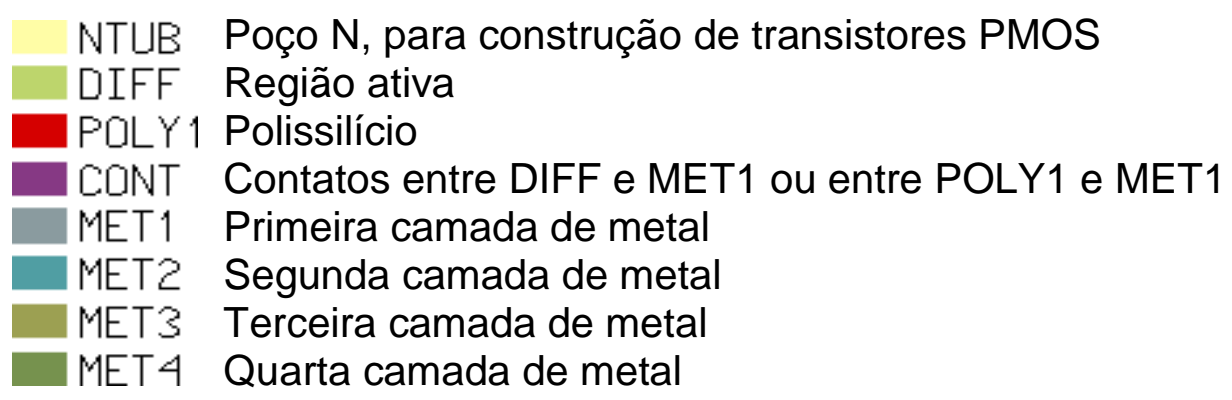

Figura D.1: Legenda das principais camadas apresentadas nos layouts deste apêndice. 


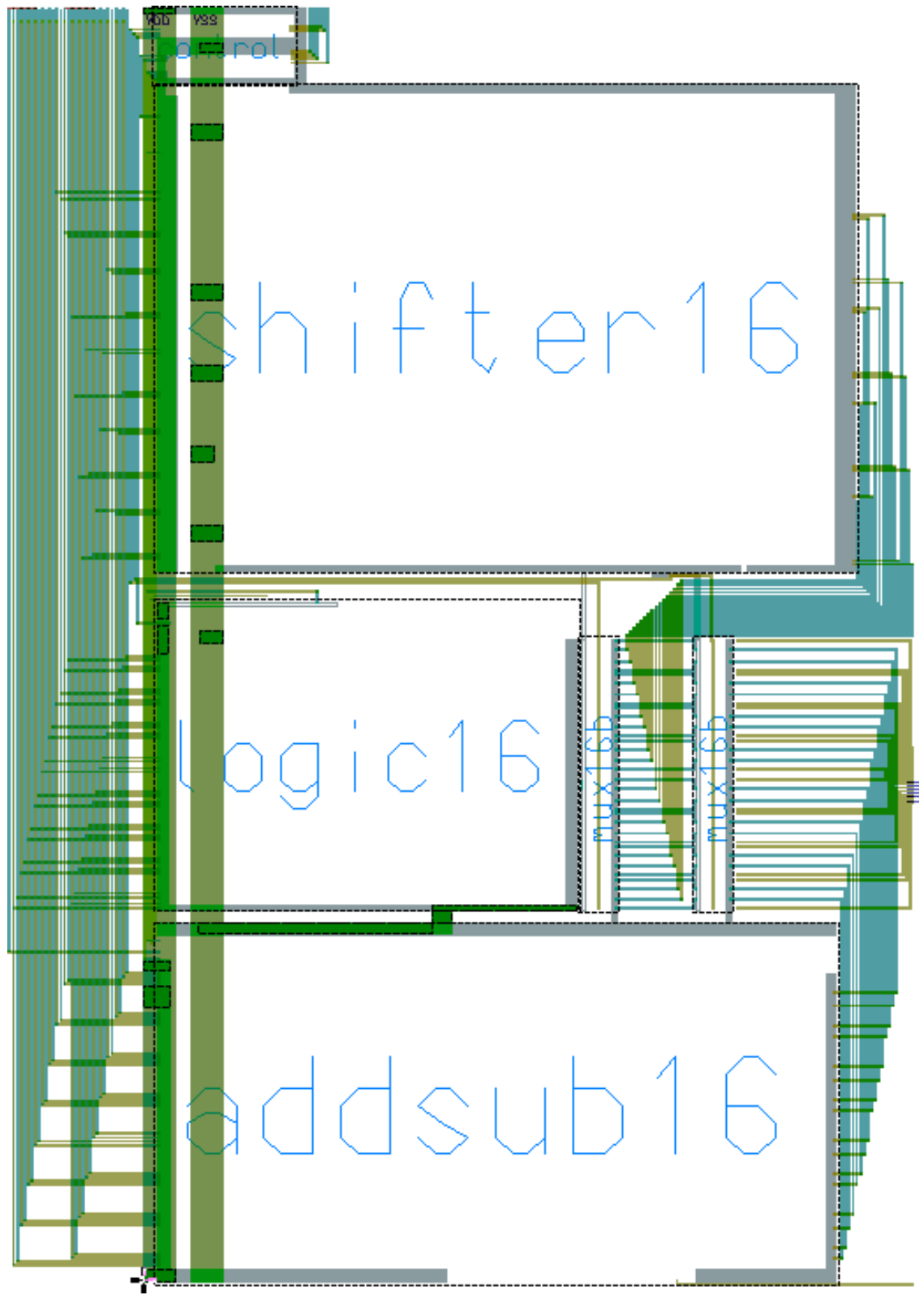

Figura D.2: Layout da célula alu16. Dimensões: 348,7 $\mu \mathrm{m}$ x 488,7 $\mu \mathrm{m}$.

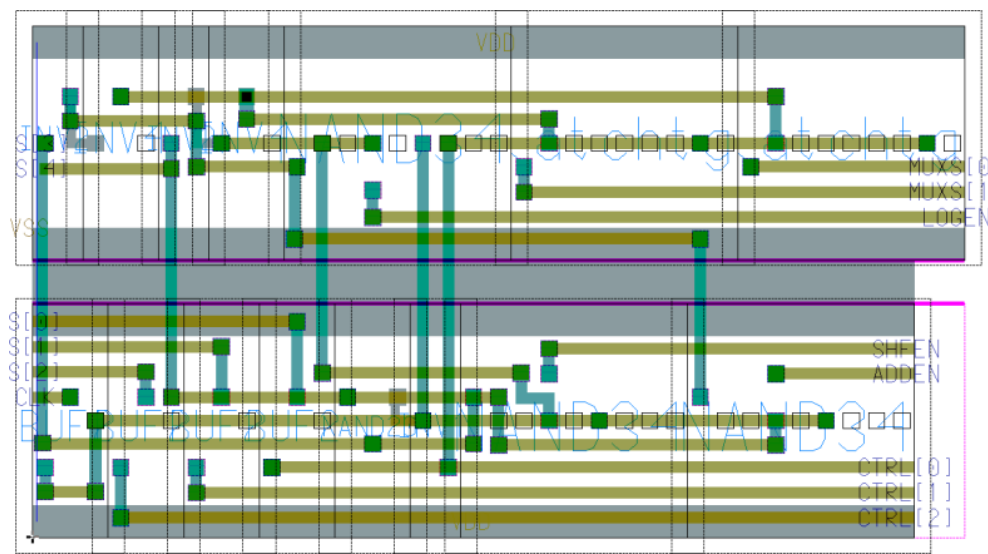

Figura D.3: Layout da célula control. Dimensões: 51,8 $\mu \mathrm{m} \times 28,4 \mu \mathrm{m}$. 


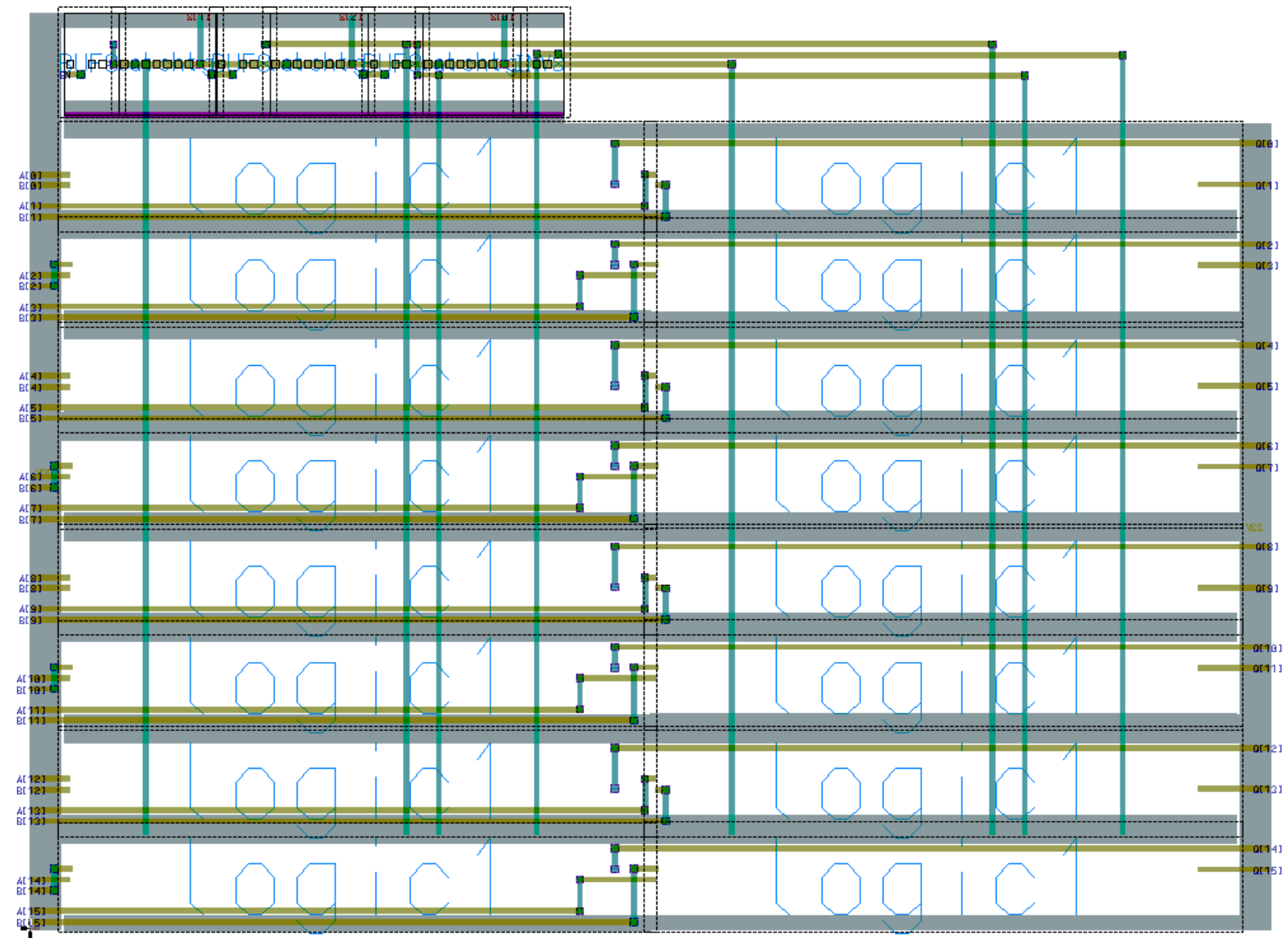

Figura D.4: Layout da célula logic16. Dimensões: 160,2 $\mu \mathrm{m}$ x 118,2 $\mu \mathrm{m}$.

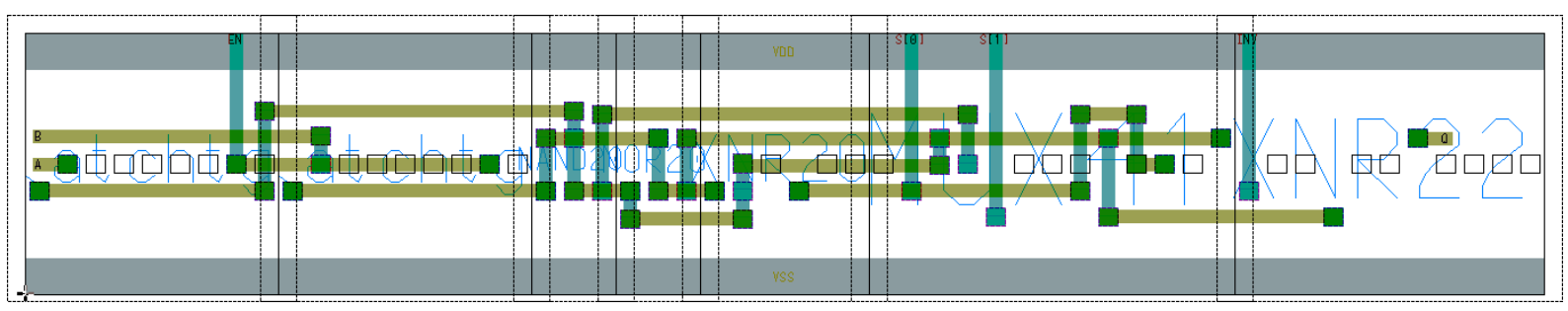

Figura D.5: Layout da célula logic1. Dimensões: 75,6 $\mu \mathrm{m} \times 13,0 \mu \mathrm{m}$.

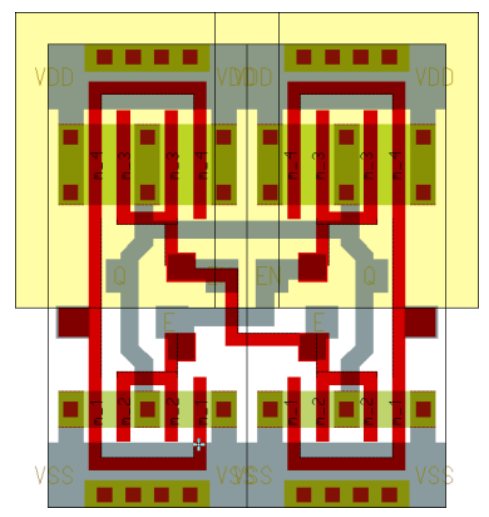

Figura D.6: Layout da célula mux2. Dimensões: 11,2 $\mu \mathrm{m} \times 13,0 \mu \mathrm{m}$. 


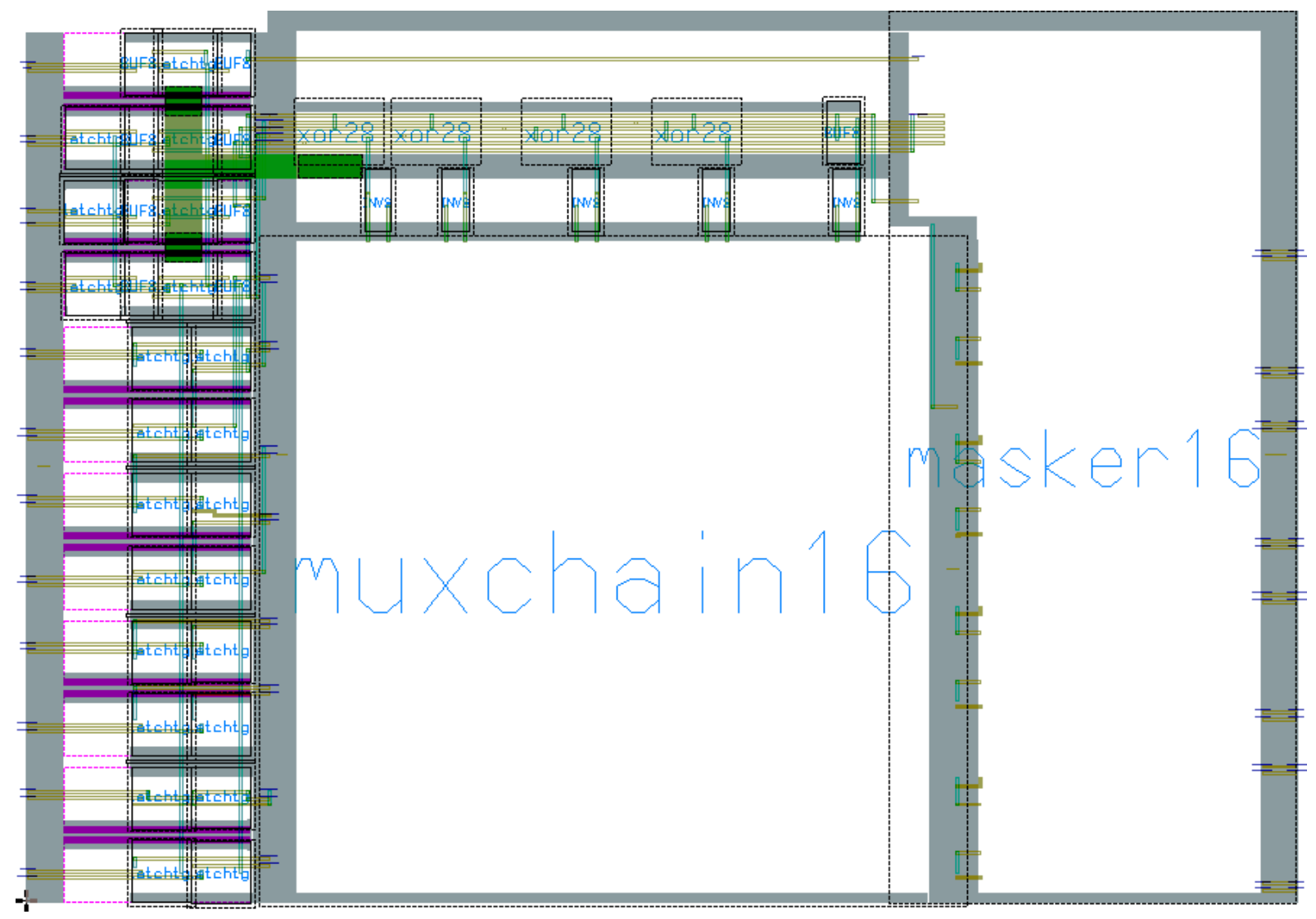

Figura D.7: Layout das células shifter16 e barrel16. Dimensões: $267,0 \mu \mathrm{m} \times 187,1 \mu \mathrm{m}$. 


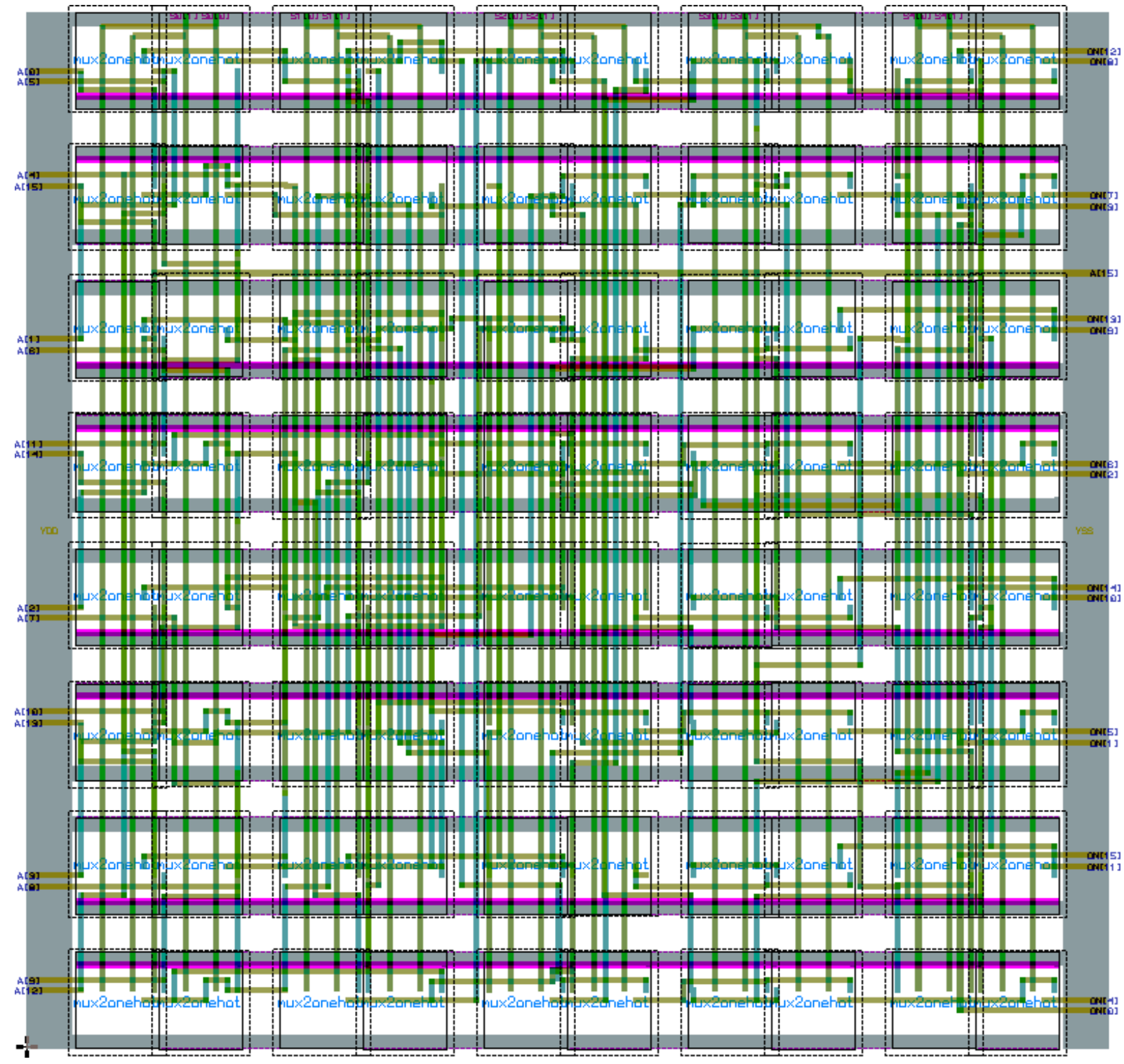

Figura D.8: Layout da célula muxchain16. Dimensões: 145,0 $\mu \mathrm{m}$ x 139,0 $\mu \mathrm{m}$. 


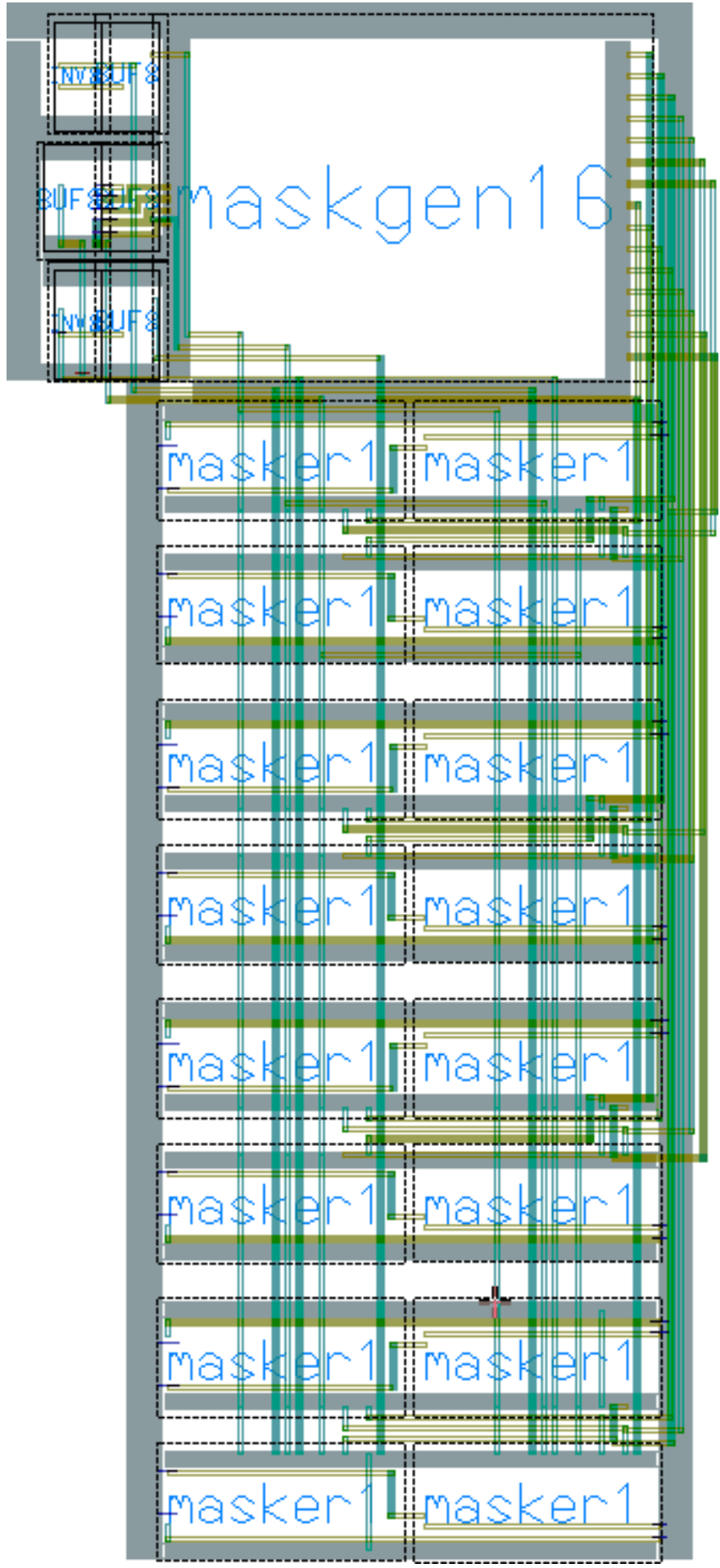

Figura D.9: Layout da célula masker16. Dimensões: $187,1 \mu \mathrm{m} \times 85,3 \mu \mathrm{m}$. 


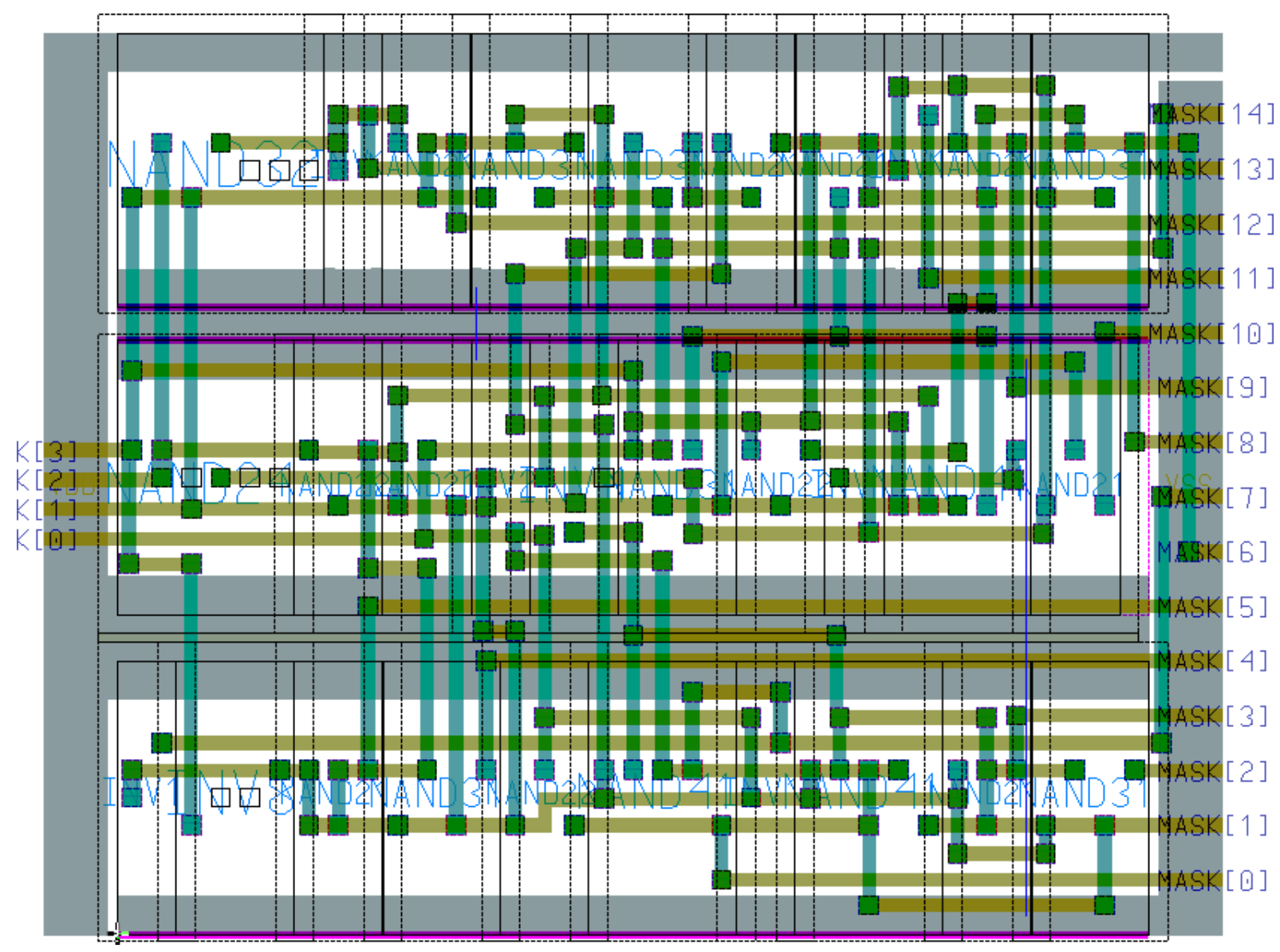

Figura D.10: Layout da célula maskgen16. Dimensões: $56,0 \mu \mathrm{m} \times 42,8 \mu \mathrm{m}$.

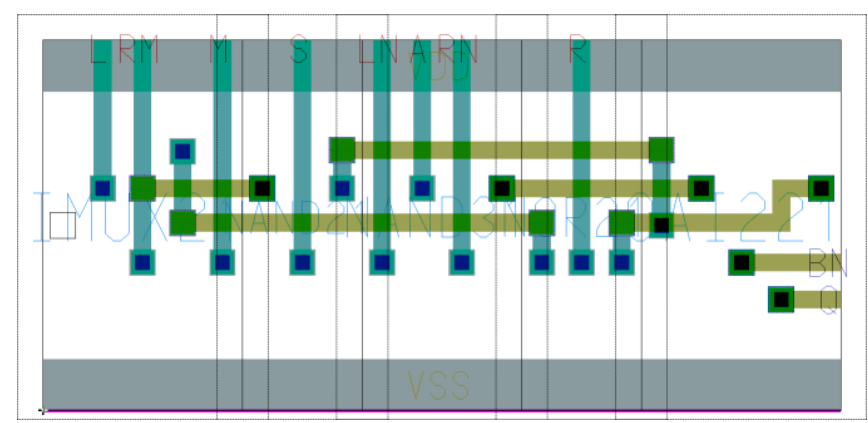

Figura D.11: Layout da célula masker1. Dimensões: 28,0 $\mu \mathrm{m} \times 13,0 \mu \mathrm{m}$. 


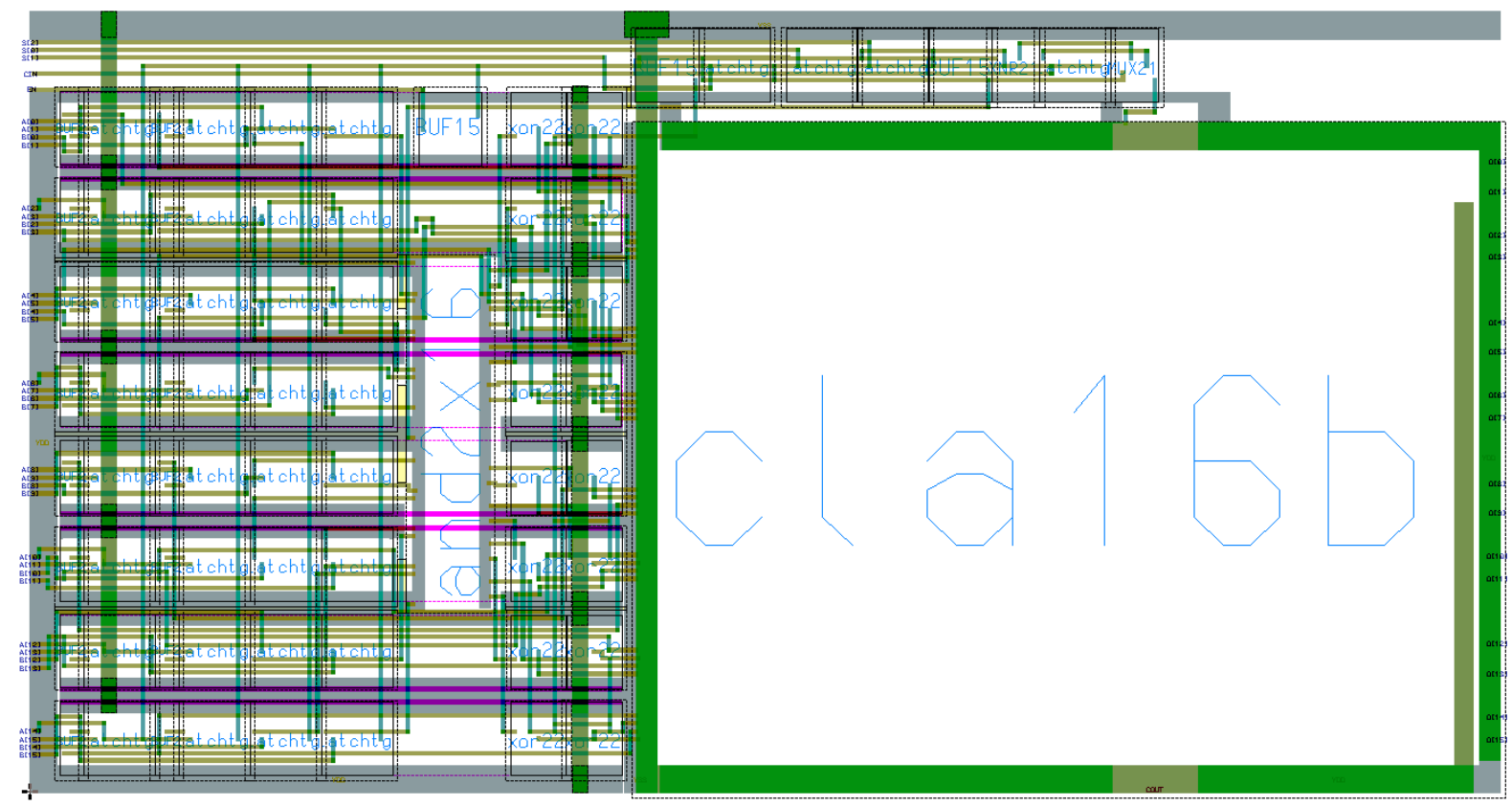

Figura D.12: Layout da célula addsub16. Dimensões: 259,8 $\mu \mathrm{m}$ x 138,0 $\mu \mathrm{m}$.

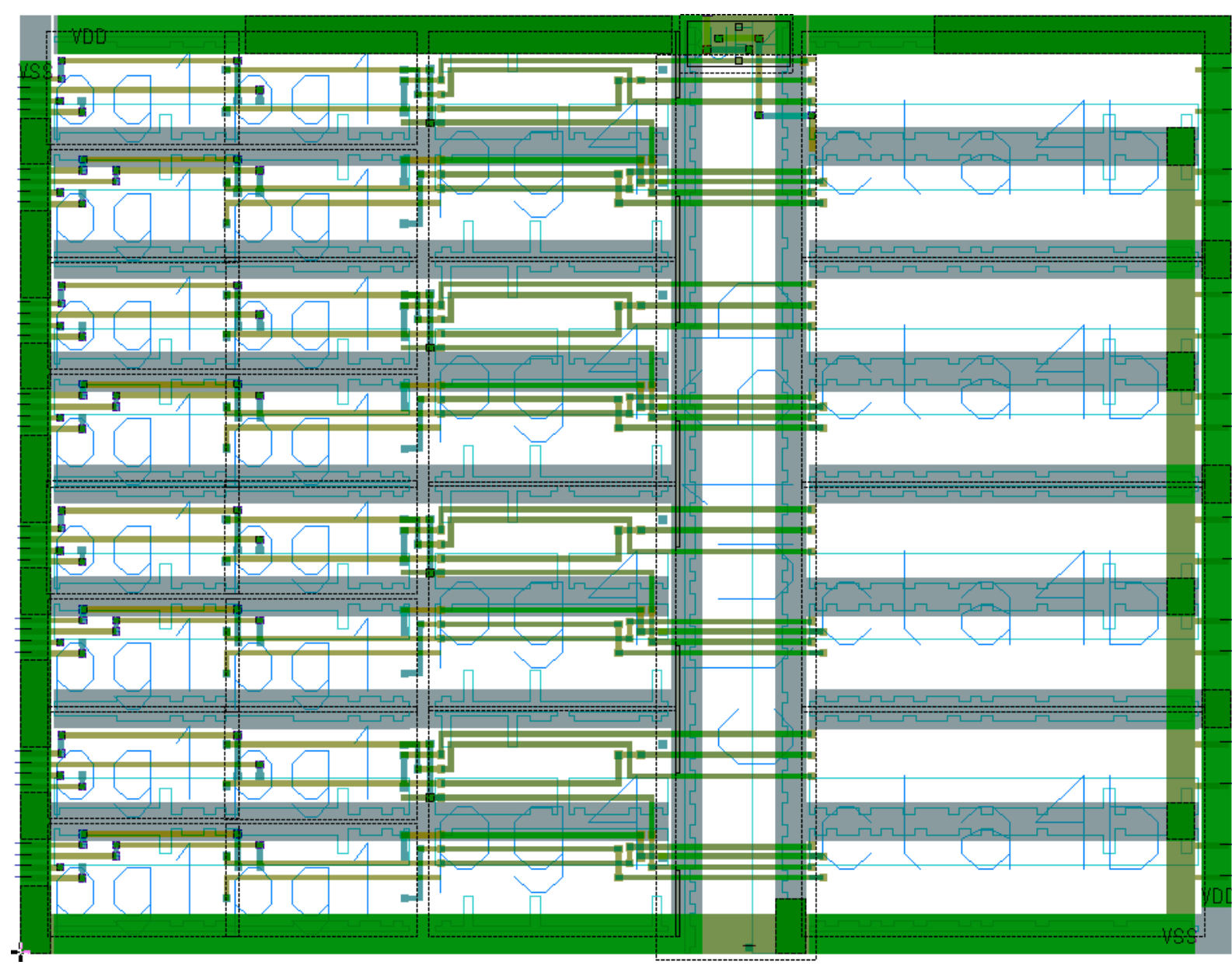

Figura D.13: Layout da célula cla16. Dimensões: 152,7 $\mu \mathrm{m}$ x 118,4 $\mu \mathrm{m}$. 


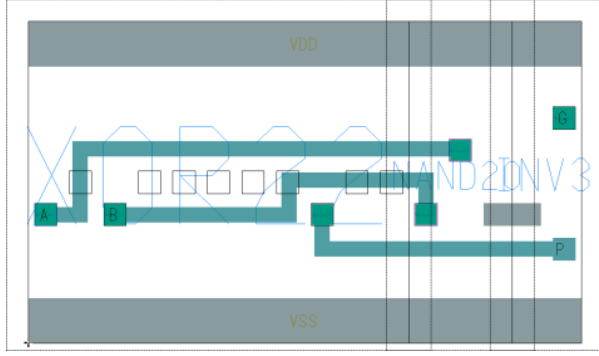

Figura D.14: Layout da célula pg1. Dimensões: 22,4 $\mu \mathrm{m}$ x 13,0 $\mu \mathrm{m}$.

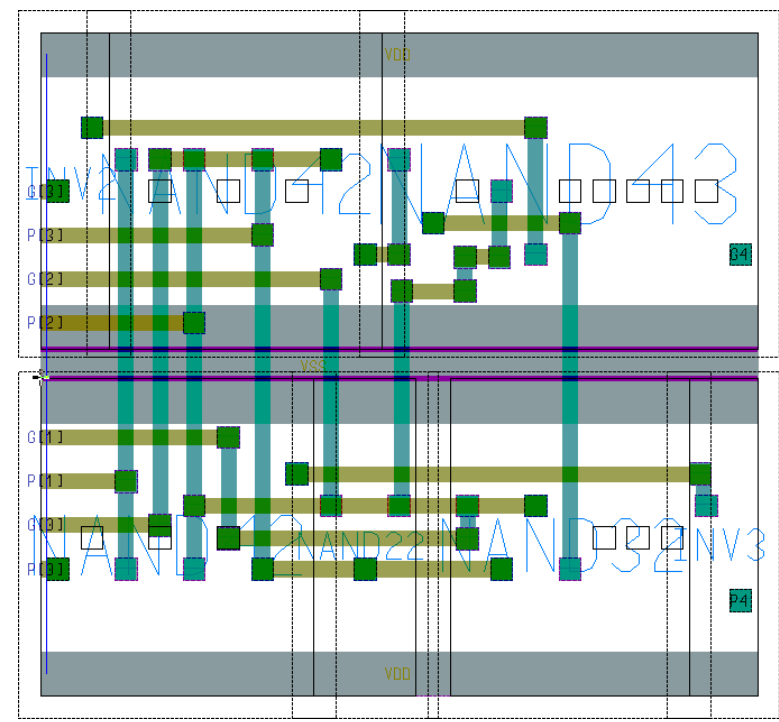

Figura D.15: Layout da célula pg4. Dimensões: 29,4 $\mu \mathrm{m}$ x 27,2 $\mu \mathrm{m}$.

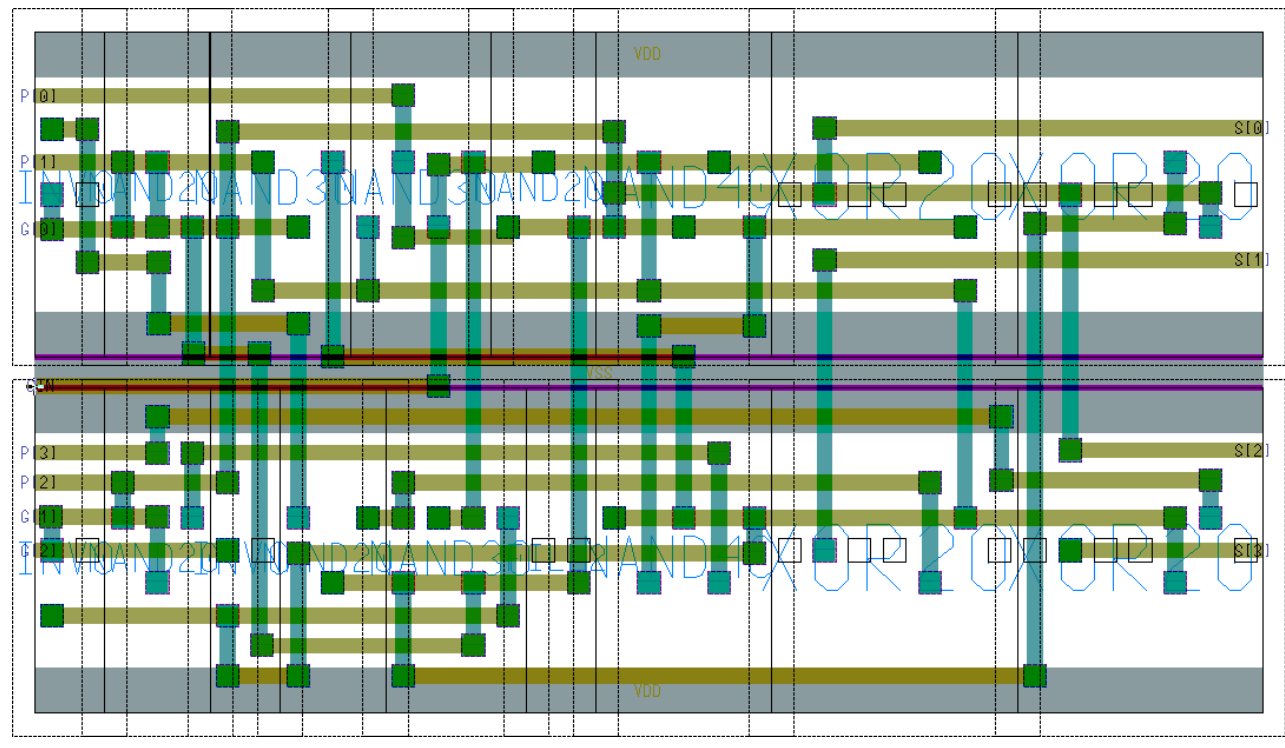

Figura D.16: Layout da célula cla4. Dimensões: 49,0 $\mu \mathrm{m}$ x 27,2 $\mu \mathrm{m}$. 

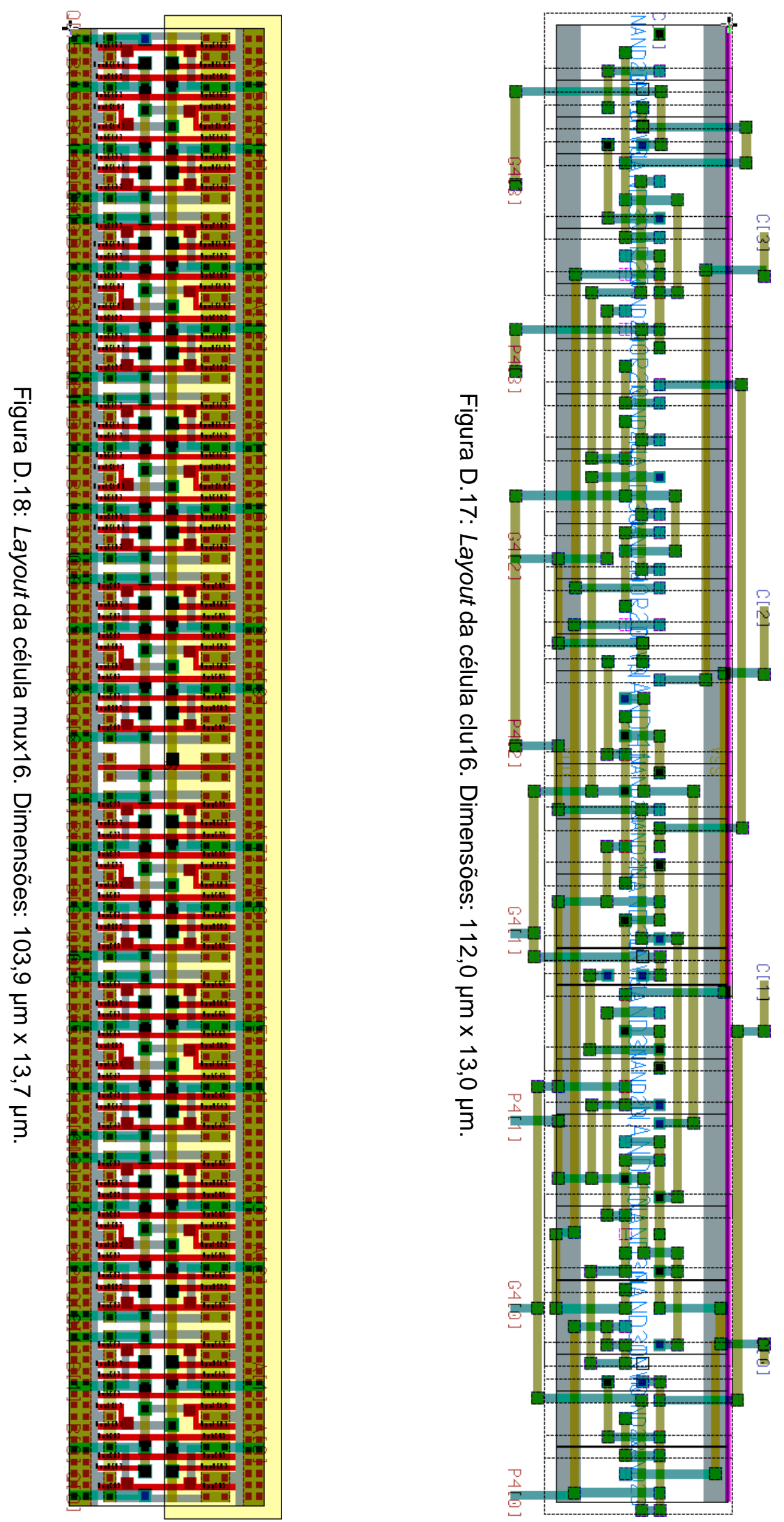


\section{APÊNDICE E - Programa para gerar vetores de entrada}

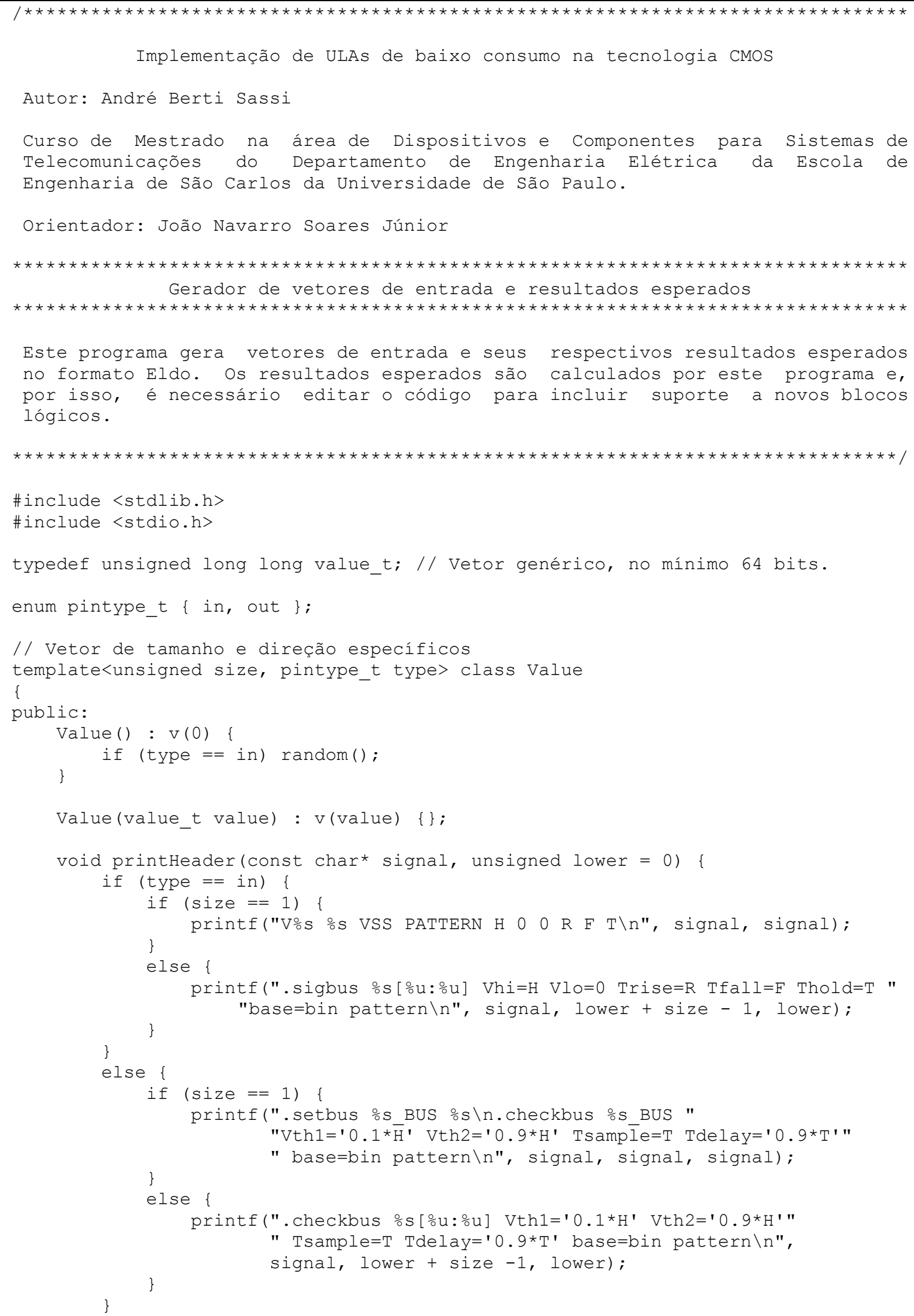




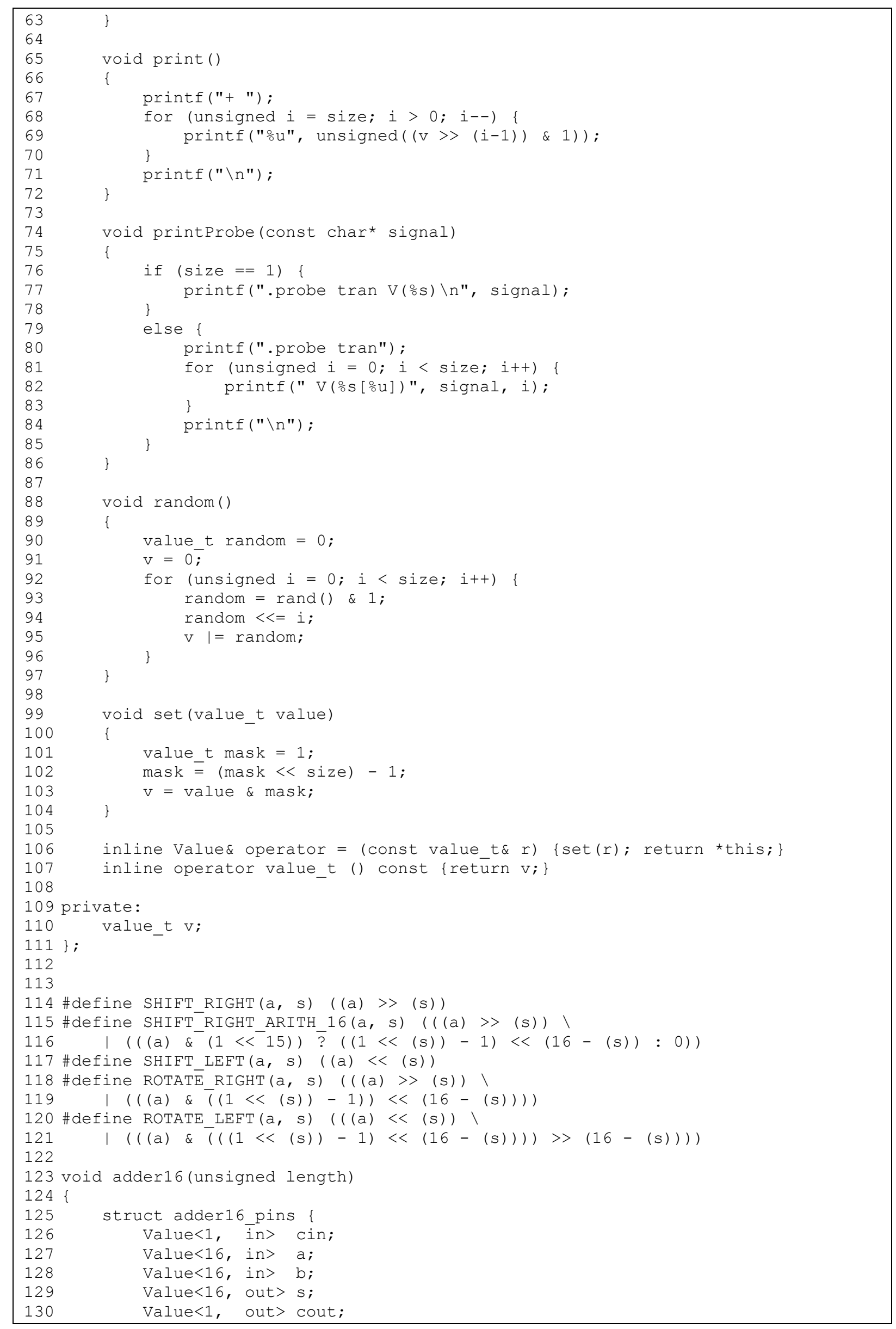




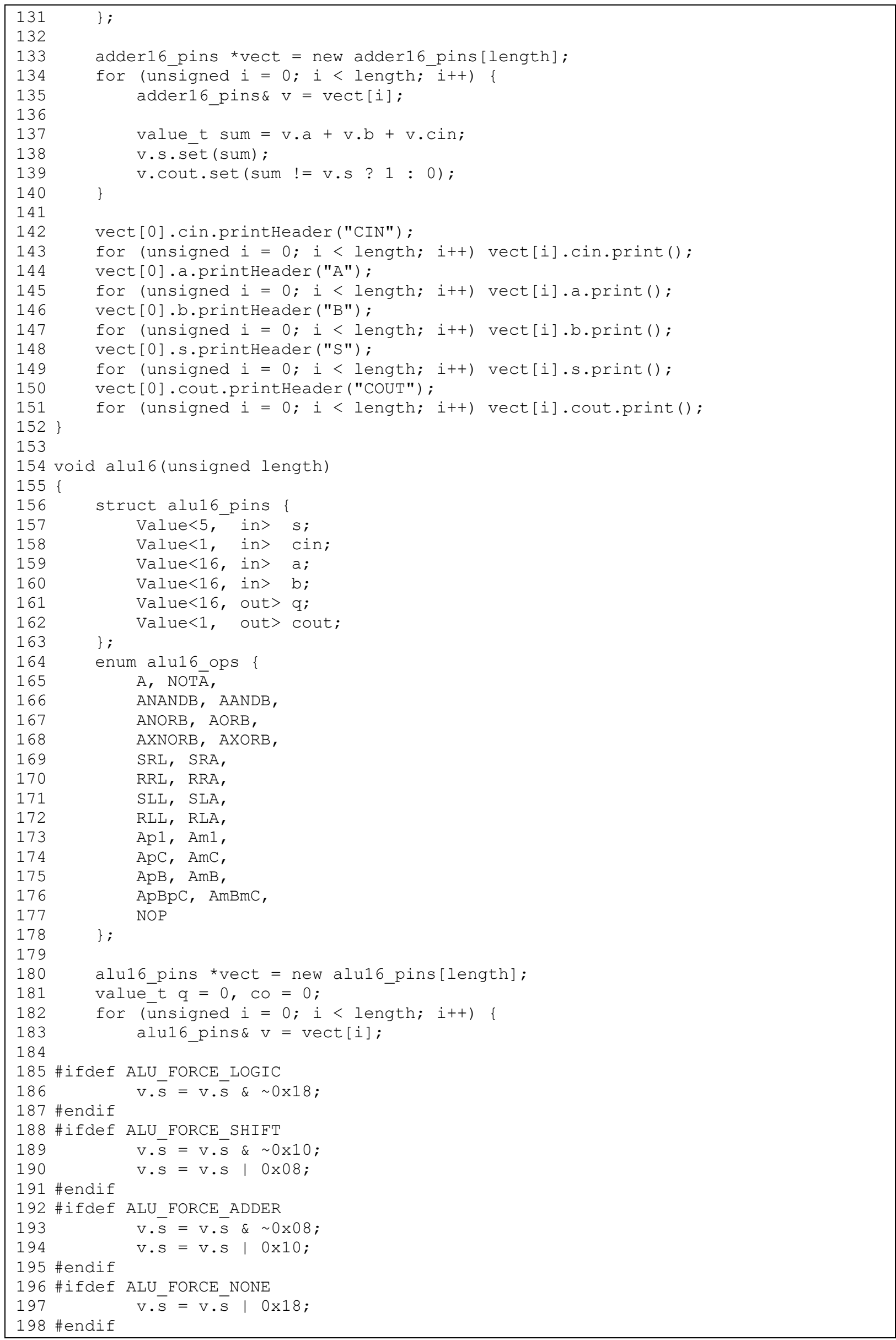




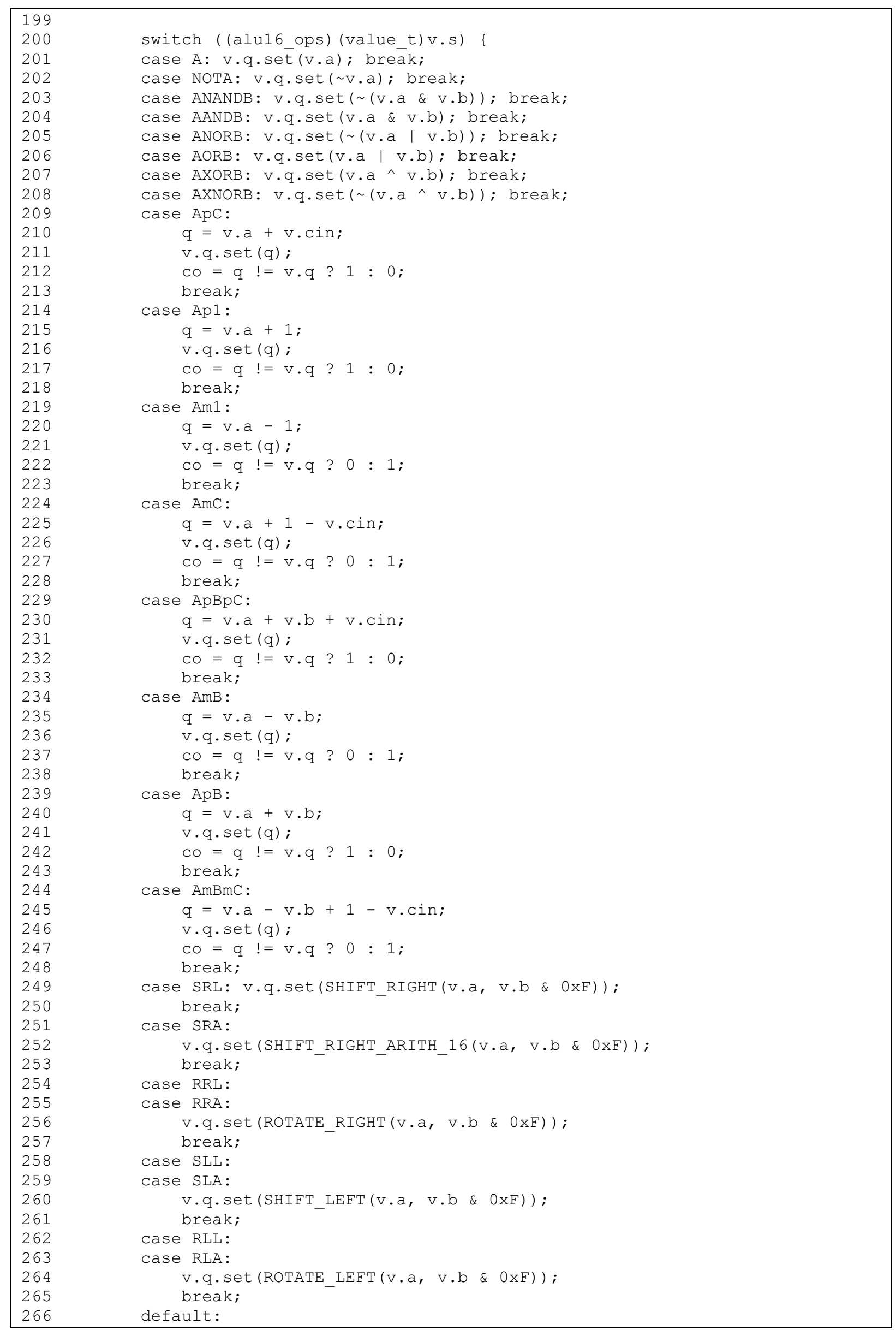




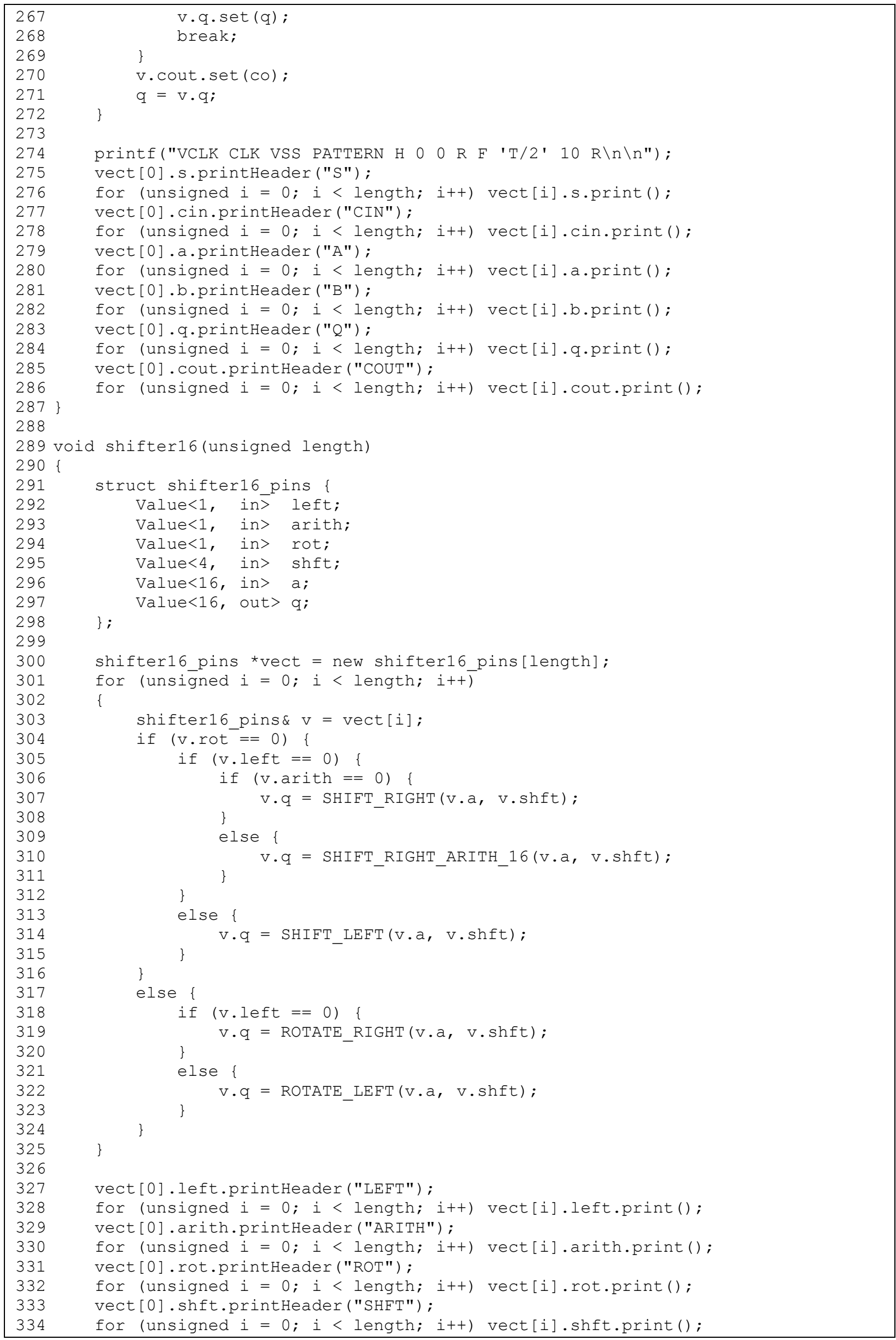




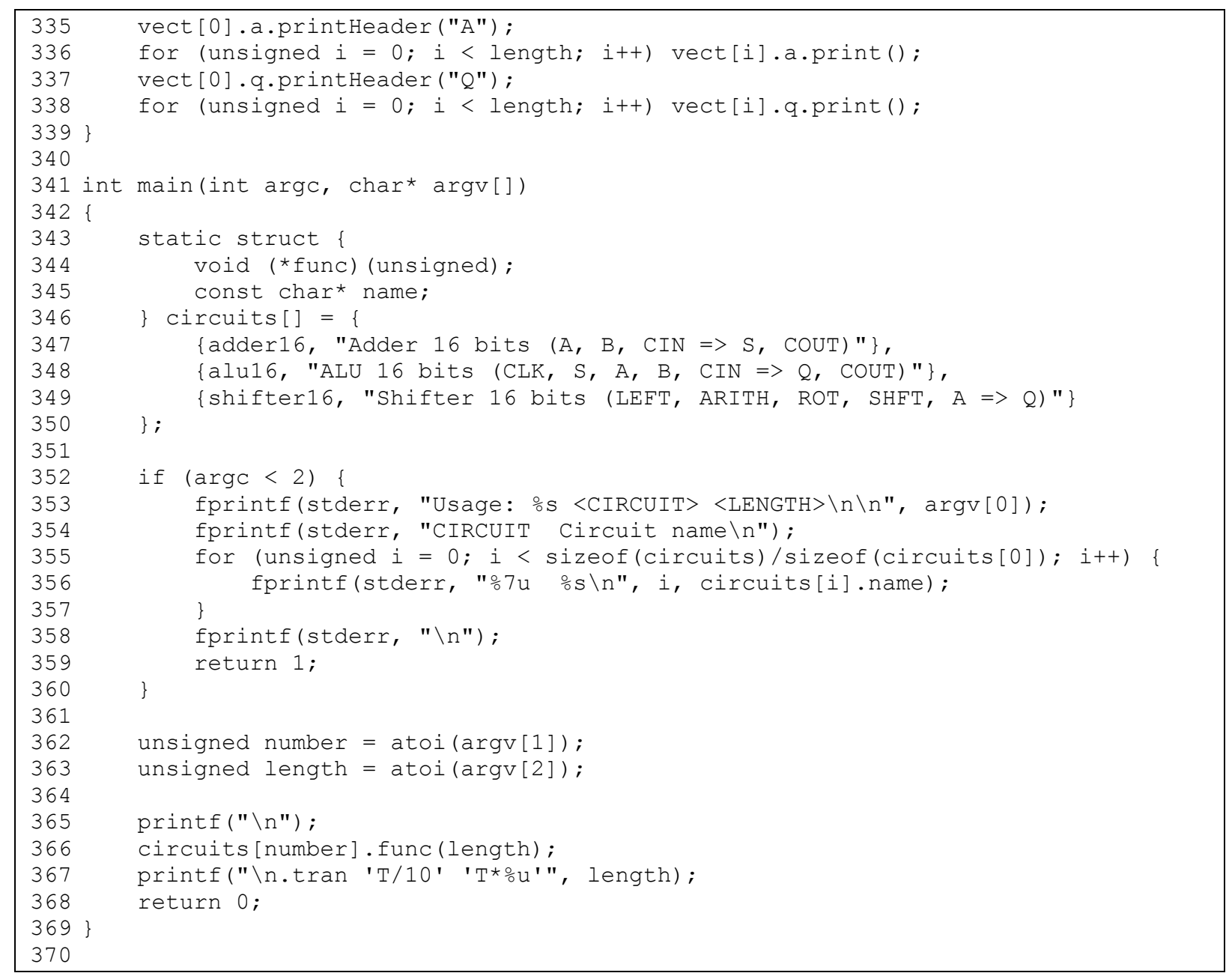




\section{APÊNDICE F - Programa para calcular atraso máximo}

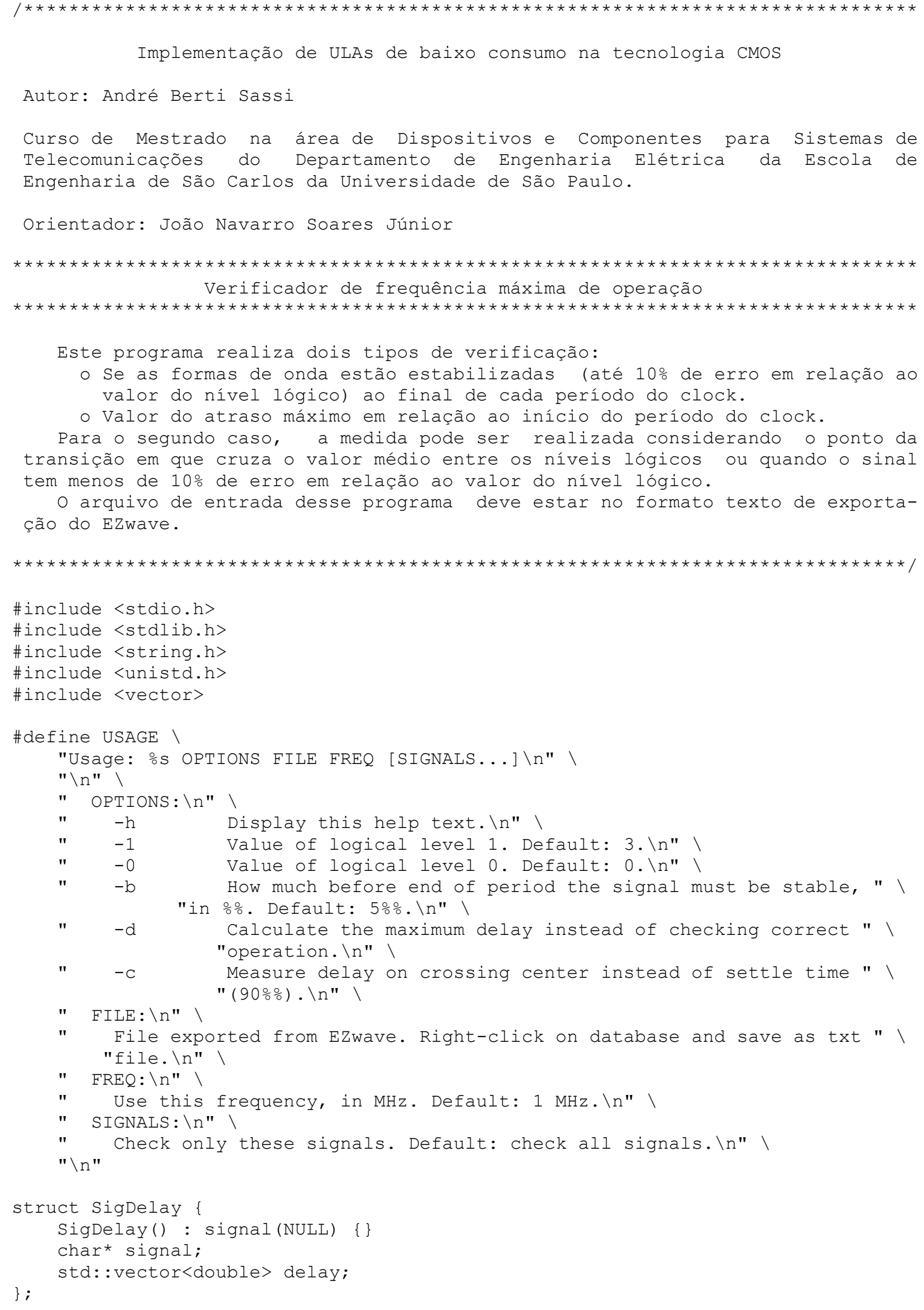




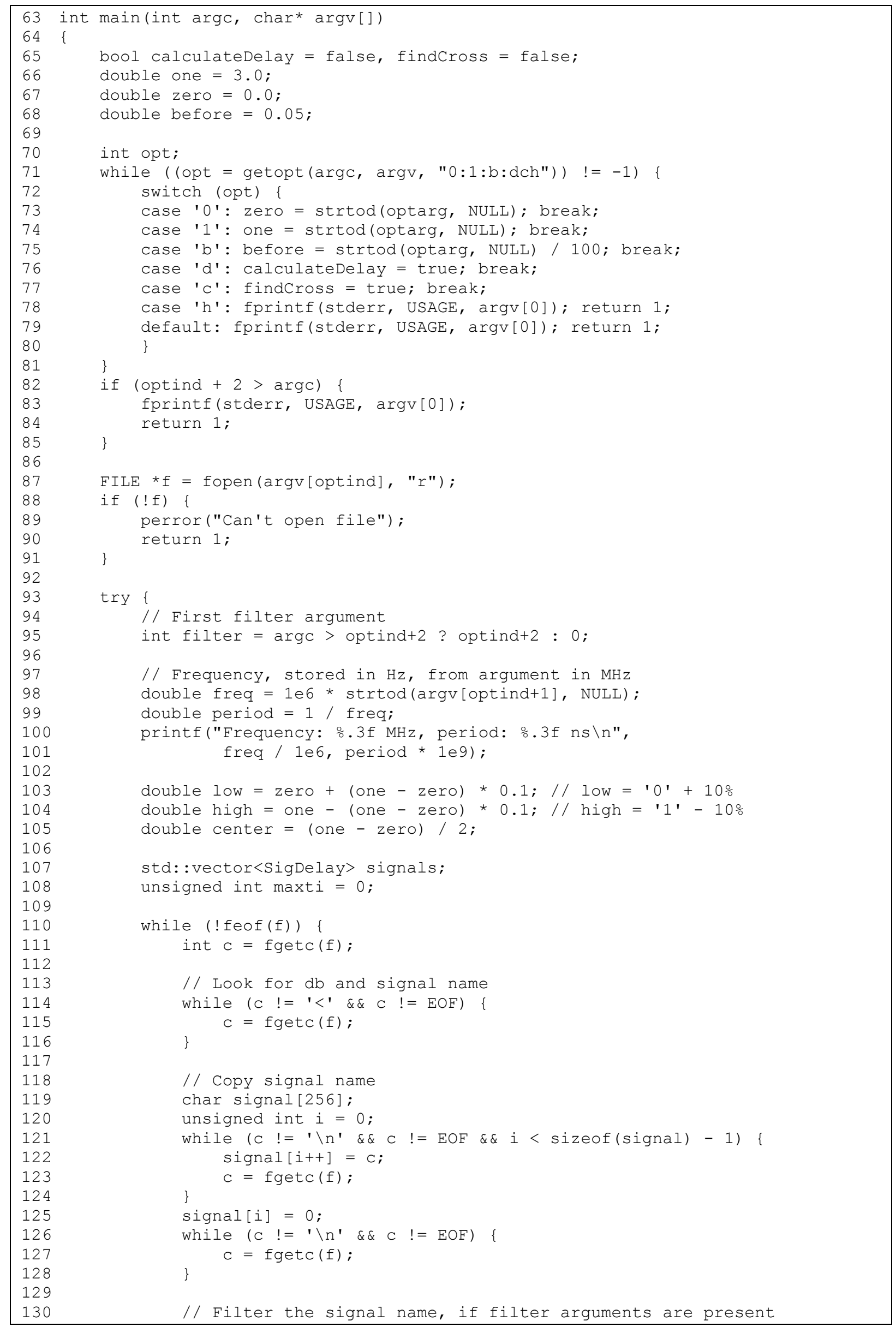




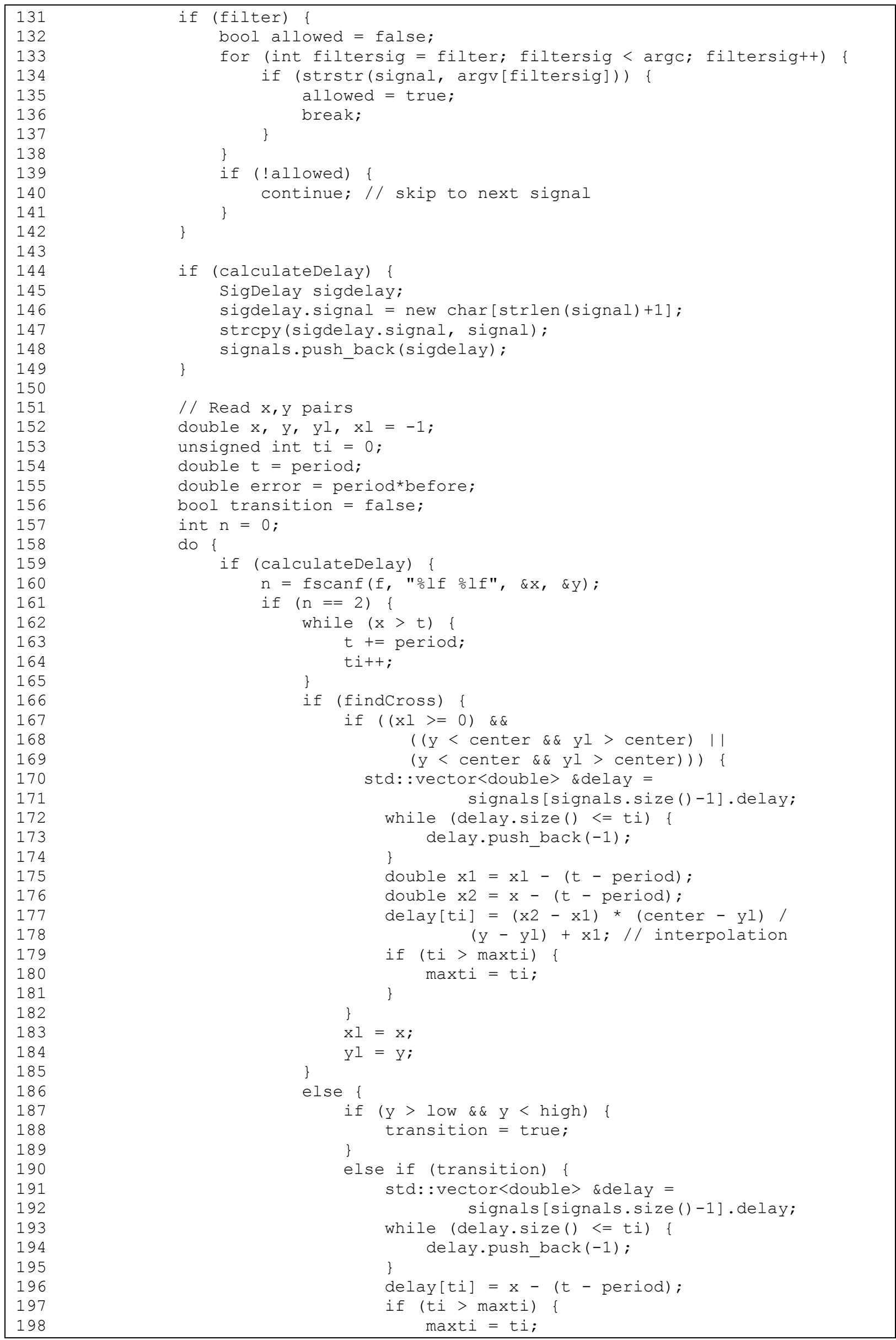




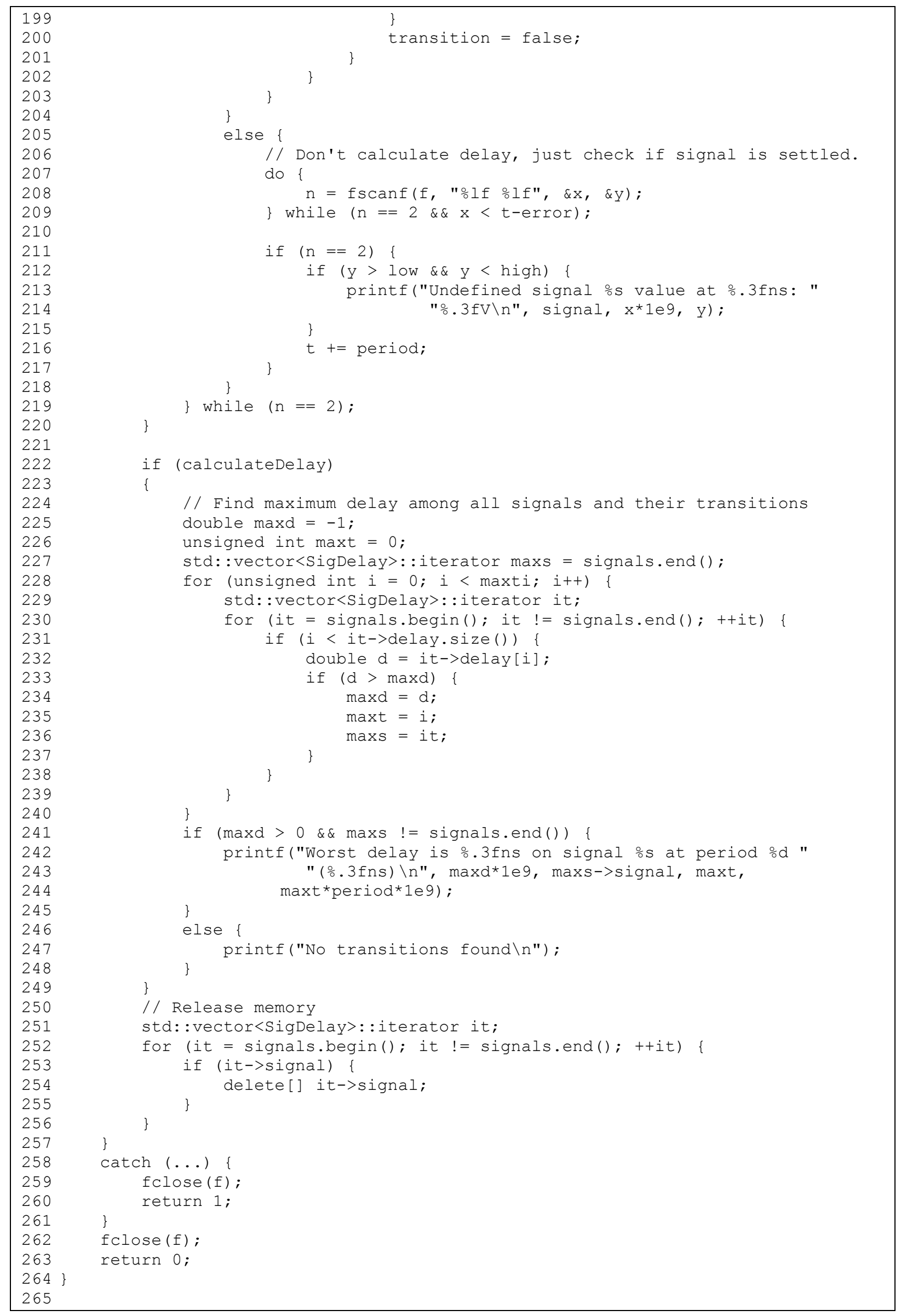

